$8 x$

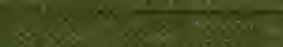





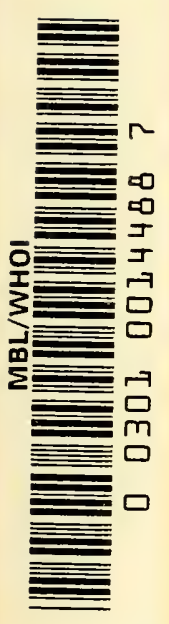



KOSTYCHEV'S

\section{PLANT RESPIRATION}

TRANSLATED AND EDITED BY

CHARLES J. LYON 



\title{
KOSTYCHEV'S \\ PLANT RESPIRATION
}

\author{
AUTHORIZED EDITION IN ENGLISH \\ WITH EDITORIAL NOTES
}

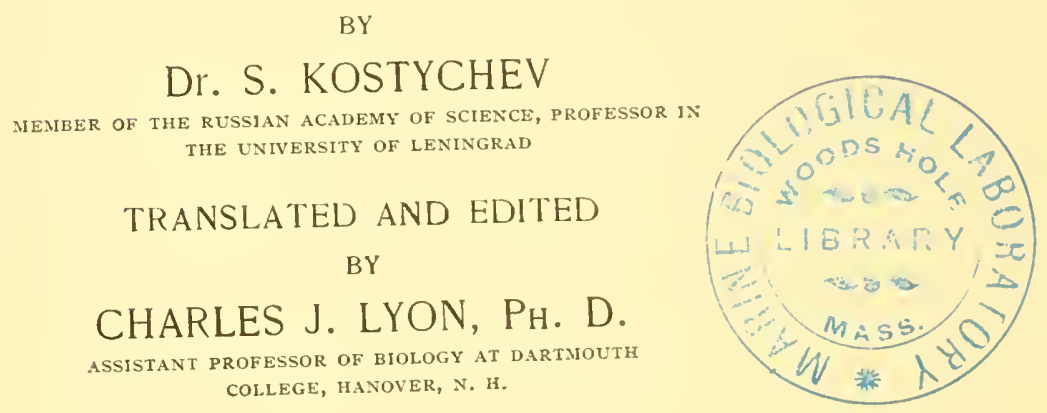

WITH ILLUSTRATIONS

PHILADELPHIA

P. BLAKISTON'S SON \& CO.

1012 WALNUT STREET 
Copyright, I927, By P. Blakiston's Son \& Co.

PRINTED IN U. S. A. BY THE MAPLE PRESS COMPANY, YORK, PA. 


\section{AUTHOR'S PREFACE}

A new period in the investigation of plant respiration began with the opening of the twentieth century. The discovery of cell free alcoholic fermentation, a process not accomplished by purely chemical means, suggested that material transformations which underlie normal plant respiration could possibly be detached from the living substance. Soon after in fact, W. Palladin and his coworkers as well as the author of this book succeeded in proving for killed plants an enzymatic metabolism completely analogous to oxygen respiration. ${ }^{1}$ This condition meant, inasmuch as it was later established beyond doubt, that the respiratory metabolism is not to be conceived as a resultant of heterogenous reactions which take place in the protoplasm, but as a chemical process which actually consists of intermediate steps and which is always uniform. It is only in this light that a chemical investigation of the material transformations which take place in respiration appears possible and practical. For example, how could one raise even the first basic questions of the respiratory material if respiration were not an independent process?

Even before the discovery of "cell free respiration" the author of this book developed a new theory of the genetic connection of oxygen respiration with alcoholic fermentation, a theory which is in accord with modern conceptions and which could serve as a working hypothesis in investigations of the chemical nature of plant respiration.

The above mentioned favorable instances have ushered in a comprehensive biochemical study of plant respiration. Previously the chief consideration had been only the biological side of respiration and the influence of external factors. This came about only because, as was previously noted, no proof

\footnotetext{
1 The first publication on the cell free oxygen respiration of aerobic plants was: Kostytschew, S. Über Atmungsenzyme der Schimmelpilze. Ber, d. bot. Ges, 22: 207. I904; also Maximow, N. Ibid., p. 325.
} 
had been produced of the uniform chemical nature of respiration. Neither were methods sufficiently developed, and on that account the biochemical study of plant respiration was rendered extremely difficult. However, as soon as the way was made fairly smooth, most investigators devoted their attention particularly to the chemical nature of the respiratory processes, and during the past two decades there appeared numerous accounts of research in this field, in which experimental work on the biological side of respiration and on the influence of external factors was left in the background. This is thoroughly comprehensible. The aim of physiology consists in reducing all living phenomena to physical and chemical processes and, whenever possible, in explaining them by the laws of these two basic sciences.

This book seeks to do what has not yet been done, so far as my knowledge of the literature goes, namely, to portray the modern, outstanding features of the science of plant respiration, and to consider carefully the whole biochemical side of the problem from a uniform standpoint. In addition I have endeavored to describe the methods in such a way that this book may serve as a guide to experimental studies of plant respiration. This appears to me to be fundamentally desirable because the competent treatment by Palladin and Kostychev in Abderhalden's "Handbuch der biochemischen Arbeitsmethoden" appeared 14 years ago and so is not wholly up-to-date on some points.

S. Kostychev.

Peterhof, U.S.S.R. July, I924. 


\section{EDITOR'S NOTE}

There is no student of plant respiration better qualified to write on this subject than the Russian physiologist, Kostycher. Trained in part by Palladin and long an active worker in the field of chemical problems associated with fermentation and respiration, he is in a position to present a balanced, authoritative discussion of all phases of the subject in which Russian workers have long been interested. It was with this in mind that an English edition of his monograph in German was undertaken.

Although there are many English-speaking physiologists who would easily read this work in German they are far outnumbered by the less experienced students and biologists in general. These readers would be compelled to spend hours to obtain the same information as could be grasped in minutes from an English text. In many cases they would feel it necessary to use a less dependable source in their own language.

In order to preserve the spirit and the fine distinctions in the author's statements, the general attempt has been made to present a close translation of the German text. Many sentences have been shortened and minor changes made in phrases which would otherwise be awkward but no extensive alterations or additions have been made except those given as editorial notes or in brackets. The greater part of these notes involve experimental results reported after the preparation of the German edition.

Kostychev's treatment of the methods of measuring normal respiration may be found more or less unsatisfactory by many readers. Only a few methods are described fully and it has seemed best to add but brief references to other and newer methods at the end of that section. There are so many methods which are or have been used that the consideration of them all would require a book of itself. Figure ro, showing Osterhout's 
apparatus, has been added as representative of the important new methods. Still it is well for the student to review the older methods, particularly the description of the use of the Pettenkoffer tubes which are by no means antiquated.

The emphasis which the author has placed on his "theory of connection" is apparently justified by the central position occupied by the problem of chemical relationships between the two phases of respiration. It is in this field of the chemical aspects of the subject that Kostychev is particularly well qualified to write, and that the most work needs to be done.

A difficult problem in all translation of material involving the Russian workers is the matter of transliteration of proper names. It has seemed best in this case to take the spelling as given in the German text, except for the name of the author of this book wherever it occurs in the text, the form Kostytschew being kept in the citations. This decision is based largely on the difficulty of determining the exact form of all the Russian names as used in the original works, while for citations it is customary to copy the author of papers in French or German as given in such papers. The pronunciation can usually be determined from the form of the word used in the German text, the greatest difficulty being with the letter $w$ which is equivalent to $v$ in English.

The form of citation is a condensation of that used by the author. It uses a Roman numeral in parentheses (followed by a period) for a series number, a bold-face Arabic numeral (followed by a colon) for the volume number, an Arabic numeral in ordinary type (followed by a period) for the first page of the article cited, and an ordinary Arabic numeral for the year of publication. When an article or series of articles occurs at several points in the same volume, the first-page numbers are separated by commas. In the case of the editorial notes and matter in brackets, both the first and last page of the citation are usually given, separated by a dash. This might have been done for most of the author's citations but it was felt that the additional information was not important enough to warrant the extra effort and space. 
The authors' names are given in bold-face type in the citations in order to facilitate reference to original papers. Idem denotes a repetition of the author's name while Ibid.indicates a repetition of the name of the serial next preceding. Mlost of the abbreviations of serial names are those in general use. Biochem. Z. is used for Biochem. Zeitschr. for the sake of brevity, in view of the large number of citations from this journal. In the case of the names of monographs in Russian, the titles are left in the German version, followed by the word "Russian."

The index has been enlarged over the original by the insertion of more detailed subject entries and by the compilation of an index to the authors which is merged with the subject index. Authors' names are placed in bold-face type as are the pages on which such names appear in a complete citation.

Dr. Kostychev took advantage of the opportunity to correct certain errors in the German edition and these changes have been incorporated without comment. A few new paragraphs have been inserted by him, notably those dealing with Warburg's theory of respiration (pages II3-II6). This edition is therefore brought up-to-date by the editorial notes and by all changes and additions made in the author's private copy which was kindly loaned to me for the purpose.

The entire manuscript has been carefully read by my colleague, Mr. George M. Robertson, who has contributed valuable advice and criticism, for which I am grateful. I also tender my thanks to Prof. C. E. Bolser and Prof. R. IV. Jones, of Dartmouth College, and to others who have assisted in the determination of certain troublesome points. I gladly acknowledge the material assistance rendered me by the Sigma Xi society which advanced the cost of the translation rights through its Committee on Award of Sigma Xi Aid to Research.

Charles J. Lyox.

Dartmouth College, August, 1927. 



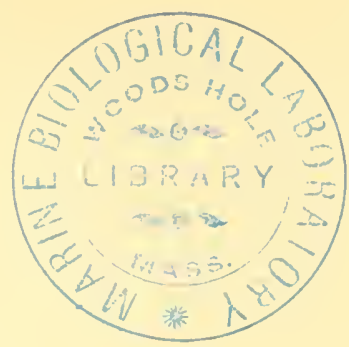

\section{TABLE OF CONTENTS}

PAGE

Author's Preface.................. . . v

EdtToR's Note. . . . . . . . . . . . . . . . vii vi

Chapter

I. Oxygen Respiration. . . . . . . . . . . . . . . . . . . . . . I I

I. The general conception of oxygen respiration . . . . . . . . I

2. The gas exchange of respiration . . . . . . . . . . . 3

3. Production of radiant energy in plant respiration. . . . . . . I 2

4. The influence of various external factors on oxygen respiration . . I $_{5}$

5. Analytical methods for the determination of oxygen respiration . . 25

II. Anaerobic Respiration . . . . . . . . . . . . . . . . 52

I. The general conception of anaerobic respiration . . . . . . 52

2. The products of anaerobic respiration. . . . . . . . . . . 59

3. Anaerobic respiration under natural conditions. . . . . . . 63

4. Analytical methods for the determination of anaerobic respiration . . . . . . . . . . . . . . 65

III. The Connection of Oxygen Respiration with Anaerobic RespiraTION . . . . . . . . . . . 79

r. Review of the older literature . . . . . . . . . . . 79

2. Review of the recent literature. . . . . . . . . . . 86

3. The latest objections to the theory of the connection of anaerobic with normal respiration. . . . . . . . . . . . . . 92

IV. The Chemical Processes in Plant Respiration . . . . . . . 97

I. The anaerobic material transformations and the participating enzymes . . . . . . . . . . . . . . . . 97

2. The nature of the oxidation processes in plant cells. . . . . . 102

3. The respiratory material . . . . . . . . . . . . . . II9

4. The nature of the connection between the anaerobic cleavage processes and the subsequent oxidation of the cleavage products. . . I 24

5. Hypotheses as to the nature of the oxidisable products of fermentation ........ . 130

6. The supposed formation of organic acids in the respiratory process. . I 35

7. The coördination of the various processes in plant respiration . . I I43

V. Respiration at the Expense of Mrneral Stbstaxces . . . . . I50

I. Nitrifying bacteria. . . . . . . . . . . . . . I50

2. Sulphur bacteria, iron bacteria, hydrogen bacteria, etc.. . . . . . I5I

INDEX ................... 155 



\section{PLANT RESPIRATION}

\section{OXYGEN RESPIRATION}

\section{THE GENERAL CONCEPTION OF OXYGEN RESPIRATION}

The most important vital processes are bound up with an expenditure of energy. Thus most syntheses of organic substances, such as the synthesis of proteins, represent endothermic reactions. In the same way the various types of architectural processes of tissue differentiation require a supply of energy. Accordingly there are found in all organisms specific material transformations, the sole aim of which is to develop free energy. Certain chemical reactions which are attended by the formation of heat serve as energy-producing processes. Such of these processes as proceed in the absence of oxygen are called fermentations. They are peculiar to a limited group of microörganisms. Vital oxidation processes are more widely distributed, result in a considerable development of energy, and are generally designated as oxygen respiration ${ }^{a}$ or simply respiration.

Lavoisier has already pointed out that the respiration of animals is to be interpreted as a slow combustion, in which oxygen is consumed and carbon dioxide is liberated. The classic investigations of Th. de Saussure ${ }^{1}$ showed that plant respiration is essentially identical with the respiration of animals, since the absorption of oxygen and the formation of $\mathrm{CO}_{2}$ are likewise

\footnotetext{
${ }^{1}$ de Saussure, Th. Ann. de chim. 24: 135, 227. 1797; Recherches chimiques sur la végétation. P. 8 and 60 . 1804 .

"Kostychev's use of the term "Sauerstoffatmung" rather than "aerobe Atmung" is quite in line with the present tendency to avoid the implications involved in the use of the contrasting terms-aerobic and anaerobic respiration. The best criticism of the older usage is to be found in an article by W. M. Clark (Jour. Wash. Acad. Science 14: I 23-138. I924). The term "oxygen respiration" may seem strange but it has the merit of emphasizing the oxidative features of this phase of respiration. There seems to be no way of avoiding a literal translation of the phrase "anaerobe Atmung" as "anacrobic respiration." $-E d$.
} 
found in plant respiration. Saussure also considered the formation of water in plant respiration and explained in an excellent manner the vital significance of the entire process. This investigator is really to be regarded as the founder of the science of plant respiration.

Respiration continues without interruption during the life of the plant and accordingly involves a considerable consumption of the organic working materials (Betriebsmaterials). Full grown green plants make up this loss by the process of photosynthesis, while the chlorophyll-free lower plants replace this material by means of nutrients absorbed from their environment. However, in germinating seeds, which respire at the expense of the reserve food materials, there is a considerable material loss through respiration. Thus Boussingault ${ }^{1}$ proved that ungerminated seeds always have a greater dry weight than seedling plants grown from them, the seedlings not having developed a photosynthetic activity. For example:

\begin{tabular}{|c|c|c|c|}
\hline Material & $\begin{array}{l}\text { Dry wt. } \\
\text { of seeds }\end{array}$ & $\begin{array}{c}\text { Dry wt. } \\
\text { of seedlings }\end{array}$ & $\begin{array}{l}\text { Wt. lost in } \\
\text { grermination }\end{array}$ \\
\hline $\begin{array}{l}46 \text { wheat seeds . . . . . . . . } \\
\text { I kernel of corn "géant". . . } \\
\text { Io pea seeds............ }\end{array}$ & $\begin{array}{l}\mathrm{x} .665 \mathrm{~g} . \\
0.5292 \mathrm{~g} . \\
2.237 \mathrm{~g} .\end{array}$ & $\begin{array}{l}0.712 \mathrm{~g} . \\
0.290 \mathrm{~g} . \\
\mathrm{I} .076 \mathrm{~g} .\end{array}$ & $\begin{array}{l}0.953 \mathrm{~g} .=57 \% \\
0.2392 \mathrm{~g} .=45 \% \\
\text { I. IOI g. }=52 \%\end{array}$ \\
\hline
\end{tabular}

The analyses carried out by Boussingault established without doubt that the loss in weight applies only to the carbon, hydrogen and oxygen. It is now known that certain sugars form the normal respiratory material. The entire respiratory process can then be expressed by the equation:

$$
\mathrm{C}_{6} \mathrm{H}_{12} \mathrm{O}_{6}+6 \mathrm{O}_{2}=6 \mathrm{CO}_{2}+6 \mathrm{H}_{2} \mathrm{O}+674 \mathrm{Cal}^{b}
$$

Therefore oxygen respiration is a process antagonistic to the photosynthetic building of carbohydrate. The production of sugar by chloroplasts in the presence of light is expressed by the equation:

$$
6 \mathrm{CO}_{2}+6 \mathrm{H}_{2} \mathrm{O}+674 \mathrm{Cal} .=\mathrm{C}_{6} \mathrm{H}_{12} \mathrm{O}_{6}+6 \mathrm{O}_{2} \text {. }
$$

${ }^{1}$ Boussingault, J. B. Agronomie, chimie agricole et physiologie 4:245. I868.

${ }^{b}$ This is $674 \mathrm{~kg}$.-calories or 674,000 gram-calories. For the data in the case of starch cf. Palladin's Plant Physiology (trans. by Livingston), 3rd ed., p. 223. $-E d$. 
Hence it is apparent that through respiration green plants release again, in the form of chemical energy and heat, and use for various vital requirements the radiant energy which was stored up by the sunlight. Plants without chlorophyll are likewise nourished by substances formed in green plants at the expense of solar energy. Thus in this case also the solar energy stored up by the chloroplasts is released.

The above equation of oxygen respiration is of course only important as a general scheme indicative of a complete vital combustion of sugar to carbon dioxide and water. If we regard, with Lavoisier, respiration as a slow combustion, it must be borne in mind that respiration is not analogous to a pile of wood burning in the middle of a field but is more like a combustion of fuel in a steam engine. In the latter case alone is the heat of combustion not completely dispersed but, by means of ingeniously designed apparatus, transformed to a large extent into mechanical energy. Vital combustion in a plant cell also effects various transformations of energy and causes the mysterious apparatus of the living protoplasm to function. ${ }^{c} \mathrm{IVe}$ therefore regard respiration as a characteristic criterion of life. Respiration becomes more energetic with increased activity. On the contrary if the spark of life burns feebly, the respiratory metabolism gradually fades out.

\section{THE GAS EXCHANGE OF RESPIRATION}

Although the respiratory energy amounts to but a small fraction of the amount of photosynthetic energy of the green plants, ${ }^{1}$ it is a matter of importance that the respiratory gas exchange continues day and night. On this account the consumption of respiratory material, calculated per unit of living substance, is very important. The respiratory energy is largely dependent upon the stage of development and the amount of living substance. In plant organs which are growing rapidly and which are rich in protoplasm, the respira tory metabolism is scarcely less than that of animal organisms.

${ }^{1}$ Cf. e.g. Willstätter, R. und A. Stoll. Untersuchungen über Assimilation der Kohlensäure, I9I 8; Kostytschew, S. Ber. d. bot. Ges. 39:319. 1921.

c It is quite certain that the solar energy acts directly no further than the synthesis of a hexose sugar (possibly as far as sucrose). All other energy available for the life and growth of the cell must come from respiration.-Ed. 
The amount of $\mathrm{CO}_{2}$ given off from a unit of living substance per unit of time serves as a measure of the respiratory energy. Ordinarily one is content with a calculation of the $\mathrm{CO}_{2}$-production per gram of dry weight. Still it is evident that no great accuracy is possible with this kind of calculation. The percentage of protoplasm is not uniform in the various plants and parts of plants, the respiratory gas exchange of which depends entirely upon the activity of the living substance. Only the cells of embryonic tissues are filled with protoplasm while in the cells of differentiated tissues the plasma at the most forms merely an inner lining of the wall. There are some tissues such as wood and cork, consisting for the most part of dead cells, which do not respire at all. On this account some investigators have attempted to develop more exact methods for the determination of the respiratory energy.

Palladin ${ }^{1}$ attempted to explain the dependence of respiration on the amount of living substance through the determination, for the research materials, of the amount of $\mathrm{N}$ in the proteins which are undigested by gastric juice. He regarded this nitrogen as the nitrogen of nuclein which forms the chief part of the protoplasmic structure. The quantity $\mathrm{CO}_{2} / \mathrm{N}$, i.e. the amount of $\mathrm{CO}_{2}$ given off from the research material divided by the nitrogen of the undigested protein, is, according to Palladin, the correct measure of respiratory energy, i.e. of the $\mathrm{CO}_{2}$ produced by the unit weight of protoplasm.

Nevertheless this kind of calculation is also linked with unavoidable sources of error. Gastric juice leaves undigested not only nucleins but also some reserve proteins such as prolamine. But in every case Palladin's method, in spite of objections on the part of various investigators, is more exact than the simple calculation of the carbon dioxide per unit of fresh or dry weight of the research material.

A still more accurate calculation might be possible, to be sure. For this purpose one should refer the respiratory carbon dioxide to the phosphorus of nuclein or to the purine nitrogen; but such determinations would never be carried out. They are so tech-

1 Palladin, W. Rev. gén. de bot. 8: 225. I896; 1 I : 81. 1899; 13: 18. I90 I; Hettlinger, A. Ibid. 13:2.48. I901; Burlakoff. Arb. d. Naturf.-Ges. in Charkow Vul. 31. 1897; and others. 
nically bothersome that they do not well merit consideration for numerous quantitative experiments. On the other hand, the simple calculation by total weight is permissible in cases in which one deals with materials which contain no considerable number of dead cells and exhibit no very great cellulose content. Useful comparative material yields such results in the case of investigation of lower organisms or embryonic organs of seed-plants. The respiratory energy of various plants and plant parts is illustrated by the following table, compiled from the experimental results of several investigators. The quantity of the carbon dioxide liberated or of the oxygen absorbed is computed throughout for I gram dry weight.

PLANT MATER1AL

Entire young wheat roots ${ }^{1}$.

Older wheat roots ${ }^{1}$...

Entire young rice roots ${ }^{1} \ldots$

Older rice roots ${ }^{1}$

Roots of Mentha aquatica ${ }^{1}$.

Roots of Caltha palustris ${ }^{1}$.

Leaves of Plleum pratense

Leaves of Lolium italicum ${ }^{1}$.

Leaves of Phragmites communis ${ }^{1}$

Leaves of Vcronica Beccabunga

Leaf buds of Syringa vulgaris ${ }^{2}$

Leaf buds of Ribes nigrum ${ }^{2}$.

Leaf buds of Tilia europe $a^{2}$.

Sphagnum cuspidatum (moss) ${ }^{3}$.

Hypnum cupressiforme (moss) ${ }^{3}$

Germ. seeds of Sinapis nigra ${ }^{2}$

Germ. seeds of Lactuca sativa ${ }^{2}$.

Germ. seeds of Papaver somniferum.

Azotobacter chroococcum 4 ....

Aspergillus niger 4 day cultures on quinic acid ${ }^{5}$ Aspergillus niger 3 day cultures on quinic acid ${ }^{5}$ Aspergillus niger 2 day cultures on quinic acid ${ }^{5}$ Aspergillus niger 2 day cultures on quinie acid ${ }^{5}$ Aspergillus niger 2 day cultures on quinic acid ${ }^{5}$ Bacillus mesentericus vulgatus ${ }^{\circ} . . \ldots \ldots \ldots \ldots$.
Roots of Lamium album ${ }^{1}$.

RESPIRATORI ENERGY IN 24 HOURS

$15^{-1} 8^{\circ} 67.9 \mathrm{cc} . \mathrm{O}_{2}$ absorbed I $5^{-1} 8^{\circ} \quad 82.8 \mathrm{cc}, \mathrm{O}_{2}$ absorbed $14^{-1} 7^{\circ} \quad 44.4 \mathrm{cc}$. $\mathrm{O}_{2}$ absorbed $14^{-1} 7^{\circ} 55.1$ cc. O. absorbed I $8-10^{\circ} 62.5 \mathrm{cc}$. $\mathrm{O}_{2}$ absorbed I $8-\mathrm{Ig}^{\circ} \quad 37.2 \mathrm{cc} . \mathrm{O}_{2}$ absorbed I 8-19 $9^{\circ}$ I9. I cc. $\mathrm{O}_{2}$ absorbed $20-2 \mathrm{I}^{\circ} \quad 27.2 \mathrm{cc}$. $\mathrm{O}_{2}$ absorbed I9-20 $24.8 \mathrm{cc}$. $\mathrm{O}_{2}$ absorbed I $9-20^{\circ} \quad 12.8 \mathrm{cc}$. O. absorbed I $6-17^{\circ} 24.8$ cc. O 2 absorbed $\mathrm{I}^{\circ} \quad 35$. cc. $\mathrm{CO}_{2}$ liberated ${ }_{1} 5^{\circ} 48$. cc. $\mathrm{CO}_{2}$ liberated 66. cc. $\mathrm{CO}_{2}$ liberated 32.9 cc. $\mathrm{CO}_{2}$ liberated I 7.2 cc. $\mathrm{CO}_{2}$ liberated ${ }_{1} 6^{\circ} \quad 58$. o cc. $\mathrm{CO}_{2}$ liberated ${ }_{1} 6^{\circ} \quad 82.5 \mathrm{cc}$. $\mathrm{CO}_{2}$ liberated I $6^{\circ}$ I $22.0 \mathrm{cc} . \mathrm{CO}_{2}$ liberated $709.5 \mathrm{cc}$. $\mathrm{CO}_{2}$ liberated 276 . I cc. $\mathrm{CO}_{2}$ liberated $6 \mathrm{~S}_{2}$. o cc. $\mathrm{CO}_{2}$ liberated I75I. cc. $\mathrm{CO}_{2}$ liberated I 800 . cc. $\mathrm{CO}_{2}$ liberated I 874 . cc. $\mathrm{CO}_{2}$ liberated I 64.3 cc. $\mathrm{O}_{2}$ absorbed

1 Freyberg. Landwirtschaftl. Versuchs-Stationen 23: 463. 1879.

2 Garreau. Ann. des sci, nat. (III) I5:I. 1851 .

${ }^{3}$ Jönsson, B. Compt, rend. I19: 4.40. 1894.

4 Stoklasa, J. Ber. d. bot. Ges. 24: 22. 1906; Zentralbl. f. Bakt., Parasitenk. u. Infektionskrankh. (II) $21: \Delta 84$. I 908 .

${ }^{5}$ Kostytschew, S. Jahrb. f. wiss. Bot. 40:563. 1904.

${ }^{6}$ Vignol, M. Contribution a l'êtude des Bactériacées. I 889 . 
From this table it is apparent that in some cases the energy of plant respiration is not less than that of animal respiration. The respiration of microörganisms is particularly intensive during the period of a rapid development. The mold Aspergillus niger is noted for its fabulous speed of growth. In 2 to 3 days rank, matted layers of mold develop on suitable nutrient solutions. The rate of respiration of Aspergillus niger is correspondingly extraordinary among the lower organisms.

In the case of seed-plants the rate of respiration is also dependent to a marked degree upon the rate of growth. ${ }^{d}$ To be sure, resting seeds show a decline in weight which is traceable in part to loss of water and in part to respiration, yet it is evident from the direct quantitative determinations of Kolkwitz, ${ }^{1}$ that the respiration of resting seeds is utterly unimportant. The respiratory energy of $\mathrm{I} \mathrm{kg}$. of seeds is I cc. of $\mathrm{CO}_{2}$ [for 24 hours] with a water content of IO-II \%. It is worthy of note that an increase of the water content of seeds to $33 \%$ increases the $\mathrm{CO}_{2}$-formation to $\mathrm{I} 200 \mathrm{cc}$. per kilogram. Of course it remains undecided whether this process is to be regarded as true respiration or merely as a spontaneous autoxidation of various labile substances contained in the seed coats. ${ }^{2}$ Completely soaked seeds liberate very considerable amounts of $\mathrm{CO}_{2}$.

In the course of the germination of the seed the rate of growth increases during the first days, then gradually becomes smaller. The graphic representation of the process gives the so-called grand curve of growth. If one follows the course of respiration during the grand period of growth, one obtains the so-called grand curve of respiration of germinating seeds. ${ }^{3}$ It is similar

\footnotetext{
${ }_{1}$ Kolkwitz, R. Ber. d. bot. Ges. 19: 285. 1901; see also Muntz. Compt. rend. 92: 97 , 137. 1881 .

2 Becquerel, R. Compt. rend. 138: 1347. 1904; 143: 974, 1177. I906; Ann. sci. nat. Bot. (IX) 5: 193. 1907.

3 Mayer, A. Landwirtschaft1. Versuchs-Stationen I8: 245-270. I875; Rischawi. Ibid. 19: $321-340.1876$. The first determination of respiration of germinating seeds we owe to de Saussure. Mém. soc. phys. de Genève 6:557. I833.

$d$ 'The respiration of plants older than seedlings has been followed by Kidd, West and Briggs (Proc. Roy. Soc. London. 13. 92:368. 1921) in the case of Helianthus anmuss. Their respiratory index declines steadily with increasing age of the plant. Hover and Gustafson (J. Gen. Physiol. 10: 33-39. 1926-27) obserwed a decrease followed by a gradual increase after middle age, using leaves of cereal plants. $-E d$.
} 
throughout to that of the grand period of growth.e During the first days of germination the respiratory energy gradually increases, finally reaches a maximum and then decreases again at the end of germination. This connection between the curves is easily understood. The mechanical energy required for the formative processes of growth is developed in the respiratory processes. An increase of energy consumption requires a corresponding increase of energy production. Careful experiments showed that embryonic, growing organs respire more vigorously than endosperm. ${ }^{1}$

In the ripening of seeds the energy of their respiration gradually becomes weaker and reaches a minimum value at the time of the complete dessication of the mature seeds.?

There is an intensive respiration in flowers which in general develop quickly and last but a short time. ${ }^{3}$ According to the data of de Saussure, ${ }^{4}$ sexual organs respire more vigorously than involucral leaves. After pollination the respiration of the fruiting growth becomes very vigorous, a condition which is obviously connected with the formative processes in the organization of the embryo.

The analyses of de Saussure show that the respiratory energy of flowers reaches a value of $2-4 \frac{1}{2}$ times that of foliage leaves. ${ }^{5}$ According to the most recent data, leaves which are rich in anthocyanins exhibit especially vigorous respiration. With these the oxygen absorption is said to be very great. ${ }^{6}$ The chlorophyll free, parasitic phanerogams respire fairly intensively according to the older researches of various writers.

${ }^{1}$ Burlakoff. Arb. d. Naturf.-Ges. Charkow. Suppl. I to vol. 3 I. I897.

2 Appleman and Arthur. Amer. Jour. Bot. 5: 207. I918; Jour. Agr. Res. Vol. 17, no. 4. I9I9.

${ }^{3}$ de Saussure. Rech. chim. sur la végétation. I So4; Ann. de chim. et de physique. (II) $21: 279$. 1822 .

- de Saussure. loc. cit.; Cahours. Compt. rend. 51 : 496. I864; Maige, A. Ibid. 142 : 104. 1906; Rev. gén. de bot. 19: 9. 1907; Maige, G. Ibill. 21: 32.1909.

o de Saussure. loc, cil.

- Nicolas, G. Compt. rend. I65: 130. I918.

' This is the well-known sigmoid curve of autocatalysis. It is only recently, however, that the conception of growth as an autocatalytic process has been correctly applied in deriving the exact equation for a given growth curve. Crozier (J. Gen. Physiol. I0: 53-73. 1926-27) has shown how precisely the growth of an animal (the rat) and a plant (sunflower) follows the correct equation for autocatalysis. The grand curves of both plant respiration and plant growth should be further tested by the same method.- - Ed. 
The ratio of the expelled carbon dioxide to the absorbed oxygen is called the respiratory quotient and is written $\frac{\mathrm{CO}_{2}}{\mathrm{O}_{2}}$. The value of $\frac{\mathrm{CO}_{2}}{\mathrm{O}_{2}}$ is subject to various fluctuations which can not be traced to the antagonistic incidents of the $\mathrm{CO}_{2}$-assimilation of photosynthesis in green leaves. The equation of aerobic respiration

$$
\mathrm{C}_{6} \mathrm{H}_{12} \mathrm{O}_{5}+6 \mathrm{O}_{2}=6 \mathrm{CO}_{2}+6 \mathrm{H}_{2} \mathrm{O}
$$

states, of course, on the basis of the law of Avogadro that the volumes of $\mathrm{CO}_{2}$ and $\mathrm{O}_{2}$ in the gas exchange should be equal. This holds in many cases, but various kinds of deviations from this regularity are possible. This can come from the following reasons.

I. Simultaneously with the oxygen respiration there also takes place an independent absorption of oxygen for other purposes. The extra oxygen is used in the formation of organic carboxylic acids and other compounds rich in oxygen. In all such cases $\frac{\mathrm{CO}_{2}}{\mathrm{O}_{2}}$ is less than I. As a common example of this type there are those respiratory processes which occur in seed germination ${ }^{1}$ just as in general in vigorous growth and vegetative development. ${ }^{2}$ Also the storage of organic acids in ripening fleshy fruits and in succulents effects a depression of the value of $\frac{\mathrm{CO}_{2}}{\mathrm{O}_{2}}$.

II. In other cases, on the contrary, a surplus of $\mathrm{CO}_{2}$ is formed by processes which proceed without an absorption of oxygen. Very common is the case in which oxygen respiration and alcoholic fermentation take place simultaneously. With this condition $\frac{\mathrm{CO}_{2}}{\mathrm{O}_{2}}$ is greater than $\mathrm{I}$. In the early stages of germination of some seeds whose compact seed coat is scarcely permeable to oxygen, alcoholic fermentation stands out as the normal process of germination, so long as the seed coat is not

1 Bonnier, G. et Mangin. Ann. des. sci. nat. (VI) 18: 364 . I $\$ 86$.

2 Palladin, W. Ber. d. bot. Ges. 4:322. 1886; Constamm. Rev. gén. de bot. Vol. 25 as far as p. 539. I9r. 
pierced by the radicle. ${ }^{1}$ Analogous phenomena are to be found in the respiration of yeast ${ }^{2}$ and some of the Iucoraceac. $^{3}$ Here there is oxygen respiration as well as alcoholic fermentation and $\frac{\mathrm{CO}_{2}}{\mathrm{O}_{2}}$ is greater than $\mathrm{I}$.

III. Various fluctuations in the value of $\frac{\mathrm{CO}_{2}}{\mathrm{O}_{2}}$ can originate as a result of the given respiratory material having a percentage composition different from that of sugar. This is the most common basis of "abnormal" size of $\frac{\mathrm{CO}_{2}}{\mathrm{O}_{2}}$. For example, after the complete consumption of the sugars and by way of a satisfactory substitution, the plants begin to burn the protein material of their protoplasmic framework, and in consequence $\frac{\mathrm{CO}_{2}}{\mathrm{O}_{2}}$ falls to $0.70-0.80$ : that is to say, protein is poorer in oxygen than sugar and so uses up. for complete combustion to $\mathrm{CO}_{2}, \mathrm{H}_{2} \mathrm{O}$ and $\mathrm{N}$, a greater quantity of atmospheric oxygen per unit weight. In other cases there is consumed the ethyl alcohol which is split off under unfavorable conditions of aeration (see above). The total combustion of alcohol involves a lower value of $\frac{\mathrm{CO}_{2}}{\mathrm{O}_{2}}$ :

$$
\begin{gathered}
\mathrm{CH}_{3}-\mathrm{CH}_{2} \mathrm{OH}+{ }_{3} \mathrm{O}_{2}={ }_{2} \mathrm{CO}_{2}+{ }_{3} \mathrm{H}_{2} \mathrm{O} . \\
\mathrm{CO}_{2}=\frac{2}{3}=0.66 .
\end{gathered}
$$

This process stands out as the normal phenomenon in the germination of pea seeds up to the time that the compact seed coats burst. The alcohol which is split off in the first stages of germination (see above) is burned with a considerable oxygen

${ }_{1}$ Polowzow, V. Untersuch. über Pflanzenatmung. IgoI [Russian]; Kostytschew, S. Biochem. Z. 15: 164. 1908; Physiol.-Chem. Untersuch. uber Pfanzenatmung. I9Io. [Russian.]

2 Buchrer, E., H. Buchner und M. Hahn. Die Zymasegärung. P. 350. I903; Kostytschew, S. und P. Eliasberg. Z. f. physiol. Chem. III: I4I. I9zo. [Meyerhof, O. Biochem. Z. $168: 43$. 1925.]

${ }^{3}$ Kostytschew, S. Zentralbl. f. Bakt., Parasitenk. U. Infektionskrankh (II). 13: 4 (90. 1904.

Another cause for marked fluctuations is the amount of water contained in the tissues, according to Mayer, A. et L. Plantefol. Compt. rend. I8I: I3 I- $^{-}$ I32. I925. In general the respiratory quotient varies inversely with the total amount of water imbibed.- $E d$. 
consumption. ${ }^{1}$ In this case the respiratory quotient is very small.

In other cases, however, materials rich in oxygen, such as organic acids, might proceed to a complete combustion, which would bring about an appreciable increase in the value of $\frac{\mathrm{CO}_{2}}{\mathrm{O}_{2}}$. For example, the respiratory quotient for the complete oxidation of oxalic acid is theoretically 4 :

$$
\begin{gathered}
{ }_{2} \mathrm{COOH}-\mathrm{COOH}+\mathrm{O}_{2}={ }_{4} \mathrm{CO}_{2}+{ }_{2} \mathrm{H}_{2} \mathrm{O} . \\
\frac{\mathrm{CO}_{2}}{\mathrm{O}_{2}}={ }_{\mathrm{I}}^{4}=4 .
\end{gathered}
$$

In the case of this oxidation the heat production is really insignificant. In the oxidation of tartaric acid $\frac{\mathrm{CO}_{2}}{\mathrm{O}_{2}}$ equals I.6: ${ }_{2} \mathrm{COOH}-\mathrm{CHOH}-\mathrm{CHOH}-\mathrm{COOH}+{ }_{5} \mathrm{O}_{2}=8 \mathrm{CO}_{2}+6 \mathrm{H}_{2} \mathrm{O}$.

$$
\frac{\mathrm{CO}_{2}}{\mathrm{O}_{2}}=\frac{8}{5}=\text { I.6. }
$$

Further on the evidence will be brought out that all reserve. nitrogen free substances consumed by respiratory processes are burned by way of the intermediate stage of sugar. By this means the theoretical value of the respiratory quotients of the above materials will naturally not be influenced. It is enlightening that in the case of the transformation of a non-carbohydrate into sugar exactly the same amount of oxygen is separated or consumed which, with a direct combustion, brings about the "abnormal" value of the respiratory quotient. Hence in the respiration of oily seeds, low values of $\mathrm{CO}_{2}$ would be observed. ${ }^{2}$ a condition which is connected with the fact that fats change over into sugars. ${ }^{3}$ If fatty seeds are nourished with prepared sugar, $\mathrm{CO}_{2}$ reaches the normal value, I, since under these conditions a direct combustion of sugar ensues and the respiration of fat is discontinued. ${ }^{*}$ In the case of the ripening of oily seeds, on the contrary, the quotient is greater than I

Kostytschew, S. Physiol.-chem. Untersuch. über Pflanzenatmung. 1910. Russian.

2 Godlewski, E. Jahrb. f. wiss. Bot. 13: 49 r. I882.

${ }^{3}$ Liaskowski, N. Chemische Untersuch. uber die Keimung von Kurbissamen. I874. Russian.

'Polowzow, V. Untersuch. uber dic Pflanzenatmung. I901. Russian. 
because carbohydrate is changed into fat, whereat a certain amount of oxygen is set free. Accordingly the absorption of atmospheric oxygen for respiration must decrease, since a part of the carbon compounds are oxidised to $\mathrm{CO}_{2}$ by the oxygen left from the fat formation. ${ }^{1}$

For experimental studies of $\frac{\mathrm{CO}_{2}}{\mathrm{O}_{2}}$, the rapidly growing and energetically respiring molds are very suitable. Studies carried out with them have proven that the respiratory quotient is not exactly the same for various sources of carbon. ${ }^{2}$ With the very abundant respiration of Aspergillus niger, the expected theoretical values of $\mathrm{CO}_{2}$ for various organic nutrients can be established analytically. ${ }^{3}$

On the basis of this evidence we may conclude that the heat production of respiration may not always be traced to a direct combustion of sugar. This is permissible only when $\frac{\mathrm{CO}_{2}}{\mathrm{O}_{2}}$ is equal to $\mathrm{I}$, while $\mathrm{CO}_{2}>\mathrm{I}$ indicates a lower heating effect. As to what a value less than $\mathrm{I}$ indicates, no definite conclusion is possible since the low value of the respiratory quotient can depend upon various conditions. If complete combustion of an oxygen poor respiratory material (such as fat) takes place the heating effect is, of course, very great but if only an oxygentying action. which does not result in complete combustion. is in volved, the heating effect in such cases remains small.

Unfortunately the formation of water in plant respiration has been insufficiently studied. This is all the more to be regretted since the amount of water formation in many cases can serve as a criterion of a complete combustion of respiratory material. Direct analytical determinations of the water formed in respiratory processes are to be found in the older work of $\mathrm{N}$. Liaskowski, ${ }^{4}$ yet the question of water formation in

1 Godlewski, E. loc. cil.

2 Diakonow, N. Ber. d. bot. Ges. 5: II5. I887; Puriewitsch, K. Jahrb. f. wiss. Bot. $35: 573.1900$.

${ }^{8}$ Kostytschew, S. Jahrb, f. wiss. Bot. 40:563. I904.

4 Liaskowski, N. loc. cit.; of. also Landwirtschaft. Versuchs-Stationen 17: 210. I874. [For a brief description of the experiments of Liaskowski see Palladin's Plant Physiology (trans. by livingston) 3rd ed., p. 220-221.l 
respiration is not settled by them since the continual hydrolytic processes evoke appreciable but unexplored fluctuations of water formation. ${ }^{g}$ Experimental studies of water formation are rendered difficult by reason of the complicated methods and manifold sources of error; in spite of this there is an urgent need to remedy such a serious omission.

\section{PRODUCTION OF RADIANT ENERGY IN PLANT RESPIRATION}

Plant respiration, like all slow combustions, involves a production of heat. The amount of heat depends upon the given respiratory material. Since in plant respiration carbohydrate serves for the most part as direct material for combustion, we may select as the point of departure for theoretical considerations the heat of combustion of I molecule of grape sugar. This amounts to 674 Calories. ${ }^{1}$ It was pointed out above that we may assume a direct oxidation of sugar only when $\frac{\mathrm{CO}_{2}}{\mathrm{O}_{2}}$ is exactly I as shown by the gas analysis.

Plants provide no thermo-regulatory contrivances. For that reason the temperature of the plant body is for the most part hardly different from that of the surrounding medium. Thus, at first sight, it appears that plant respiration produces no heat. In some cases in which moderately large plant organs evince a considerable respiratory process, a direct increase in temperature is at once perceptible. ${ }^{2}$ Thus a direct measurement of temperature shows that in the Cereus flowers between the filaments there is a temperature rise of $1.2^{\circ} .^{3}$ In the flowers of Victoria regia a temperature increase of $12.5^{\circ}$ was observed. ${ }^{*}$ in flower spadices of Arum italicum-a rise of $36^{\circ}$. The tem-

\footnotetext{
'Stohmann, F. Jour. f. prakt. Chem. 19: 115. 1879; 31:273. 1885; Zeitschr. f. Biol. I3: 364. I894. [See also the editorial note on page 2.]

2 de Saussure. Ann. sci. nat. $21: 285$. I822; Ann. de chim. et de physique (II) 21 : 279. 1822; Dutrochet. Compt. rend. 8: 741. 1839; 9:613. I839; Ann. sci. nat. (II) I3: I. I 840 ; and others.

${ }^{3}$ Leick, E. Ber. d. bot. Ges. 33:518. 1915; 34:14. 19i6.

'Knoch, E. Untersuch. uber die Morphologie und Biol. der Blüte von lictoria regia. P. 38 . 1897 .

- A strong proof of the existence of such hydrolytic processes resulted from Bonnier's studies of heat production during seed germination (Bonnier, G. Ann. sci. nat. de Bot. (VII) $18: 1-35$. 1893). - Ed.
} 
perature of the spadices then reaches $5 \mathrm{I}^{\circ}$ in an air temperature of $15^{\circ}$. The heat production of $A r u m$ can be further increased by wounding. ${ }^{2}$ Also in the blossoms of Ceralostmia and some palms a considerable amount of heat is freed. ${ }^{3}$ Indeed it is easy to demonstrate a considerable production of heat by many other kinds of plants if the measurement of temperature is carried out in a Dewar flask or a similar method used to prevent dispersion of the heat. In this way it is possible, for example, to obtain a temperature of $50^{\circ}$ with foliage leaves. ${ }^{4}$ Similar temperatures have been shown by the respiration of seeds of various cereals. The heating of hay, which reaches a very high point, is evoked by various bacteria which produce an enormous amount of heat. ${ }^{5}$ In the case of some plants respiration is accompanied by the formation of not only heat but also light. The great British physicist Boyle has already noted that rotting wood does not glow in an air free medium. Phosphorescence of plants is actually a result of oxygen respiration. Included among the phosphorescent plants are some fungi such as certain species of Agaricus, Polyporus, Auricularia and others ${ }^{6}$ not to mention some algae and specific bacteria (Photobacterium and others). ${ }^{7}$ The phosphorescent bacteria soon perish on the usual nutrient media; the phosphorescence revives in cultures on fish bouillon. Not until recently was this phosphorescence observed on artificial substrates of known composition. ${ }^{8}$ It takes place only within fixed temperature limits. It is worthy of note that phosphorescent bacteria often belong

1 Kraus, G. Abh. d. Naturf.-Ges. Halle. Vol. 16. I882; Ann. Jard. bot. Buitenzorg. 13: 217 . I 896 .

${ }^{2}$ Sanders, C. B. Report Brit. Assoc. York. P. 739. I906. [Experiments with the so-called wound stimulus are of little value because they provide such radical changes in the inter-relations of the several parts and components of the tissue affecter. The increase in the exposed surface and the interference with the normal conditions of permeability are but two of the changed factors which could only be expected to increase the respiratory processes.]

${ }^{3}$ Kraus, G. loc. cil.

4 Molisch, H. Bot. Zeitg. 66: 2II. 1908; Zeitschr. f. Bot. 6:305. 1914.

${ }^{5}$ Literature references of Miehe, $\mathbf{H}$. Die Selbsterhitzung des Heues. Iga7; $c f$. als $)$ Gorini, C. Atti d. Reale. Accad. dei Lincei, rendiconto (V) Vol. 23, pt. I, p. 984. I9I4; Burri, R. Landwirtschaftl. Jahrb. 33:23. I919; and others.

6 Smith, W. G. Gardeners' Chronicle 7: 83. I877; Crié, L. Compt. rend. 93: 853. I 884; Kutscher, F. Z. f. physiol. Chem. 23: 109. I897; Atkinson. Bot. Gaz. 14: 19. I 889; and others.

7 Beijerinck. Medd. Akad. Ansterdam. I890. No. II. p. 7; Mo:isch, H. Leuchtende Pfianzen. 2nd ed. I9I2.

${ }_{8}$ Chodat, R. et de Coulon. Arch. sci. phys, et nat. Genève (IV) 4 I : 237. I9r6. 
to the group of decay fungi which grow well on proteins alone (i.e. in the absence of carbohydrates). The intensity of the bacterial light is sufficient to evoke the formation of chlorophyll in etiolated plants. ${ }^{1}$

The nature of the phosphorescence consists in this-that in the respiration of the phosphorescent plants there are formed certain materials which glow after death and are designated as luciferins. Their chemical nature is not yet established but it is very probable that they are to be classed in the group of protein compounds ${ }^{2}$ and are formed under the influence of specific enzymes. ${ }^{3}$ Moreover, it is well-known that a few organic compounds glow with slow oxidation.

Various workers have endeavored to determine quantitatively the respiratory energy used up by plants. It is enlightening that the fraction of the total energy of respiration which is not dispersed in the form of radiant energy but is used in the protoplasm for various vital needs, may, under some conditions, be moderately small. We know how insignificant is the economic quotient [efficiency] of our steam engines and other heat apparatus. The first calorimetric determinations were carried out with resting organs $;{ }^{4}$ no wonder that in this case the radiant energy produced by the respiration was practically equal to the total heat of combustion of sugar. The following table of Rodewald shows what quantity of heat corresponds to the production of $\mathrm{I}$ cc. of $\mathrm{CO}_{2}$ or the absorption of I cc. of oxygen.

\begin{tabular}{c|c|c|c|c|c}
\hline $\begin{array}{c}\mathrm{CO}_{2} \\
\text { given off }\end{array}$ & $\begin{array}{c}\mathrm{O}_{2} \\
\text { absorbed }\end{array}$ & $\begin{array}{c}\mathrm{CO}_{2} \\
\mathrm{O}_{2}\end{array}$ & $\begin{array}{c}\text { Heat produced } \\
\text { in Calories }\end{array}$ & $\begin{array}{c}\mathrm{Heat} \text { in } \begin{array}{c}\mathrm{Cal} . \mathrm{Heat} \text { in Cal. } \\
\text { per cc. } \mathrm{CO}_{2}\end{array} \\
\text { per cc. } \mathrm{O}_{2}\end{array}$ \\
\hline 6.175 & 5.842 & 1.06 & 30.3 & 4.91 & 5.19 \\
4.883 & 4.354 & $\mathrm{I} .12$ & 19.7 & 4.03 & 4.53 \\
4.625 & 4.507 & 1.03 & 19.6 & 4.24 & 4.35 \\
\hline
\end{tabular}

${ }^{1}$ Isatschenko, B. Abh. d. bot. Gartens in St. Petersburg I I : 3 I, 4.. 19 II.

${ }^{2}$ Dubois, R. Compt. rend. II I : 363. I 890; I23:653. I 896; I 53:690. I9II; I65: 33. I917; 166:578. I9I8; Compt. rend. des sèances de la soc. de biol. 81: 317. I9IS; $82: 840$. I9I9.

- Dubois, R. loc. cil.; Harvey, E. N. Amer. Jour. Physiol. 44: 449. I916; 45: 318,342, 349. I917; J. Ger. Physiol. 5: 275. I92 2-23.

- Rodewald. Jahrb. f. wiss. Bot. I8:263. I88 7 ; 19:22I. I888; 20:26I. I889. 
The determinations of Bonnier ${ }^{1}$ showed an even greater heat production as it corresponds to the total oxidation of sugar (respiration is, as we know, not the only source of energy of living cells). The more recent exact studies of L. C. Doyer ${ }^{2}$ yielded still other results. It was shown that, during the periods in which intense growth and formative processes are taking place, as is the case for example during the early days of seed germination, the greater part of the respiratory energy is used for vital needs and only a little energy vanishes in the form of heat. E.g.,

Wheat Seedlings

\begin{tabular}{c|c|c}
\hline $\begin{array}{c}\text { Day of } \\
\text { germination }\end{array}$ & $\begin{array}{c}\text { Respiratory energy per } \\
\mathrm{kg} \text {. at } 25^{\circ} \text { (accord. to } \\
\text { CO2-production) in Cal. }\end{array}$ & $\begin{array}{c}\text { Energy directly measure- } \\
\text { able as heat per kg. at } \\
25^{\circ} \text { in Calories. }\end{array}$ \\
\hline 2 & $2 \mathrm{I} 35$ & 363 \\
3 & 3502 & 540 \\
4 & 6277 & 2938 \\
5 & 6886 & 3216 \\
6 & 5837 & $434 \mathrm{I}$ \\
\hline
\end{tabular}

It is evident that on the second day of germination only i $2 \%$ of the total energy is released as heat. The greater part of the chemical energy is used in the formative processes. Even on the sixth day only half of the total energy could be measured as heat.

According to the latest determinations, molds liberate the greater part of the respiratory energy as heat. ${ }^{3}$ In this case old fungus mats were employed for the experiments. Probably young, vigorously growing fungus mats would yield entirely different results.

\section{THE INFLUENCE OF VARIOUS EXTERNAL FACTORS ON OXYGEN RESPIRATION}

It was mentioned above that respiration as a constant feature of life is a criterion of the living condition of the cells. The modification of the respiratory process under the influence of external factors might often serve as a direct measure of the

I Bonnier, G. Ann. sci. nat. (VII) I8: I. I893.

2 Doyer, L. C. Medd. Akad. Wet. Amsterdam 17:62, I914; Recuil des trav. bot. néerland 12: 372 . 1915 .

${ }^{3}$ Molliard, M. Compt. rend. des séances de la soc. de biol. 87:219. 1922. 
reaction of the living protoplasm to various stimuli. Hence various kinds of studies of the action of external stimuli on respiration have been carried out by many investigators. We shall consider them briefly. The chief aim of modern investigation is the solution of the problem of the real nature of respiration; these questions are treated under the following topics. ${ }^{h}$

The Influence of Temperature on Respiration.-Many plants still respire at temperatures which are far below $0^{\circ} .1$ Thus the respiration of the leaves of conifers and Viscum continues at $-20^{\circ},{ }^{2}$ although at a very slow rate. An increase in temperature always effects an increase of the respiratory energy in connection with which for the most part ${ }^{i}$ the law of van't $\mathrm{Hoff}^{3}$ prevails, that the temperature coefficient ${ }^{i}$ is $2-3$

'Kreusler, U. Landwirtschaftl. Jahrb. 17: 16r. I888.

${ }^{2}$ Maximow, N. Bot. Jour. d. Naturf.-Ges. in Petersburg. 1908. P. 23.

3van't Hoff. Vorlesungen. Vol. I, p. 229; Arrhenius, S. Z. f. physikal. Chem. 4: 226. I 889; Matthaei, G. L. C. Phil. trans. roy. soc. B. I97: 47. I90.4; Blackman, F. F. and Matthaei. Proc. Roy. Soc. London. B. 76: 402. I905; Smith, A. M. Proc. Camb. Phil. Soc. 14: 296. 1907; and others.

${ }^{h} \mathrm{~A}$ direct relationship between the rate of respiration and the percentage content of water in the moss, Hypnum triquetrum, has been reported by Mayer et Plantefol. Ann. Physiol. et Physicochim. Biol. I : 239-280. 1925.-Ed.

iThe agreement is closer for temperatures below $25^{\circ} \mathrm{C}$.; $c f$. also Kuijper. Extr. Trav. Bot. Néerland, 7: 130. 1910.-Ed.

iThe term "temperature characteristic" has been proposed by Crozier (J. Gen. Physiol. 7: I 23. 1924-25 and other papers) as a name for the quantity $\mu$, or $E$, in the Arrhenius-MFarcelin-J. Rice equation for velocity of a chemical reaction as controlled by temperature, this being of greater theoretical significance than the $Q_{10}$ ratio. From the results of numerous experimental studies and the analyses of existing records, Crozier has calculited $\mu$ (the critical thermal increment) of the Arrhenius equation

$$
\frac{K_{2}}{K_{1}}=e^{\frac{\mu}{2}}\left(\frac{\mathrm{I}}{T_{1}}-\frac{\mathrm{I}}{T_{2}}\right)
$$

for a number of vital processes including respiration. It appears that there are two, probably three, well-defined "temperature characteristics" for respiration, II ,500, 16,200, and 8,000 (Crozier, W. J. J. Gen. Physiol. 7: I89-216. $1924^{-25}$ ). Each of these may be understood as a measure of the heat of activation for one molecule of the substance used in the respiratory process, or of the respiratory catalyst. There is reason to think that the value II,500 indicates the cxistence of hydroxyl ion catalysis as the "slow reaction" in such a catenary series as $A \rightarrow B \rightarrow C$, while 16,200 marks a slower acrobic respiration (possibly catalysed by $\mathrm{Fe}$ ). Hence the precise study of the influence of temperature on respiration may lead to a more detailed knowledge of the chemical reactions involved. $-E d$. 
as for all reactions of organic materials. Contrary to the opinion of various older workers, at present it can be considered as proven that for plant respiration there is no optimum temperature. The amount of the carbon dioxide given off increases regularly with the gradual increase in temperature, finally reaches a maximum value and remains at the same level until the death of the plant from the high temperature ${ }^{1}$ (at about $50^{\circ}$ ). Marked temperature fluctuations effect an increase in the respiratory energy. ${ }^{2}$ It can hardly be doubted that we have to do here with a complicated irritation effect (Reisirirkung). The same explanation also holds for the influence of warm baths on respiration. ${ }^{3}$ The warm bath is a strong irritation effect which in horticultural practice is used to shorten the latent period of winter.

If a complete combustion of respiratory material takes place in respiration, $\frac{\mathrm{CO}_{2}}{\mathrm{O}_{2}}$ remains perfectly constant for various temperatures. ${ }^{4}$ It does not remain so in the case of succulents, which with lower temperatures effect an incomplete oxidation of sugar and take in a surplus of oxygen which serves for the formation of organic acids. With higher temperatures the sugar is burned without a residue and the respiratory quotient is equal to $\mathrm{r}^{5}$

The Influence of Light on Respiration.--The stimulatory effect of light on the respiration of plant parts containing chlorophy $1 l^{6}$ is undoubtedly due to the fact that particularly in the light there are formed carbohydrates which then serve as respiratory material. The respiration of chlorophyll free plants and plant parts is practically unaffected by light ${ }^{\top}$ or is somewha retarded. ${ }^{8}$ It must be noticed, however, that all inves-

\footnotetext{
${ }_{1}^{1}$ Bonnier, G. et Mangin. Ann. sci. nat. Bot. (VI) 17: 210. I884; I9:217. I884.

2 Palladin, W. Rev. gén. de bot. I I : 24I. I899.

${ }^{3}$ Iraklionoff. Jahrb. f. wiss. Bot. 51 : 5 I 5. I9r 2; Arb. d. Petersb. Naturf.-Ges. 42: 241 . IgII.

SPuriewitsch, K. Ann. sci. nat. bot. (VIII) I: I. I905.

${ }^{5}$ Aubert, E. Rev. gén. de bot. 4:203. I892.

${ }^{6}$ Borodin, J. Physiol. Untersuch. über die Atmung der Laubsprosse. 1876. Russian.

7 Maximow, N. Zentralbl. f. Bakt., Parasitenk. u. Infektions-krankh. (II) 9: 193. I902.

8 Bonnier et Mangin. Compt. rend. 96: I075. I883; 99: I60. I88; 102: I 23. I 886 ; Ann. sci. nat. bot. (VI) I 7: 2 IO. I884; 18:293. 1884; 19:21\%. I884; Elfving. Studien über die Einwirkung des Lichtes auf die Pflanze. I 890 ; Löwschin, A. Beih. z. bot. Centralbl. $23: 54$. 1907 .
} 
tigations of the influence of light on plant respiration have been carried out in the absence of materials sensitive to light. It would be most interesting to perform experiments with intensive illumination, on the action of catalysts sensitive to light on the respiratory changes. Likewise in the study of the effect of light, the influence of the heating of the material by the ray's of light has not always been taken into consideration. ${ }^{k} \mathrm{~A}$. Mayer and Deleano ${ }^{1}$ noted a daily periodicity in the intensity of respiration under natural conditions. Spoehr ${ }^{2}$ has made the interesting assumption that during the day the respiration of plants is increased by reason of the fact that under the influence of the sun's rays an ionization of the atmospheric oxygen takes place and in consequence thereof autoxidation is instigated in the protoplasm.

\section{The Influence of the Concentration of Oxygen on Respira-} tion.- - Saussure ${ }^{3}$ has already pointed out that a reduction of oxygen content in the surrounding atmosphere to half the normal concentration has no effect on plant respiration. Wilson $^{4}$ subsequently proved that plants respire normally in an artificial mixture of 0.2 parts atmospheric air and 0.8 parts hydrogen, and indeed exhibited the same rate of respiration as in ordinary air. Even with an oxygen content of $\mathrm{I}_{0}$ no checking of plant respiration could be noted. Likewise the ratio $\mathrm{CO}_{2}$ grew larger only with a very low content of oxygen $(\mathrm{I}-2 \%){ }^{5}$

1 Mayer, A. und Deleano. Zeitschr. f. Bot. 3: 65\%. 1911.

2 Spoehr, H. A. Bot. Gaz. 59:366. I9I5. [This hypothesis has been tested recently by students of Blackman who have increased the ionization of air by exposure to polonium. Middleton (Ann. of Bot. 4I:343-356. 1927) used barley seedlings and Whimster (Ibid. 41:357-374. 1927) worked with leaves of Pelargon 4 m zonale. Undercarefuly controlled conditions, both workers found that the rate of $\mathrm{CO}_{2}$-production is appreciably increased by the presence of a high concentration of ions in the air, the effect being greater with the green leaves.]

a de Saussure, Th. Mém. de la soc. phys. de Genève 6: 552 . I 833 .

4 Wilson. Untersuch. aus d. bot. Inst. Tübingen I: 685 . I 885 .

Johannsen, W. Untersuch, aus d. bot. Inst. Tubingen I: 7I6. Is35; Stich, C. Flora. 74: 1. I891.

$k$ Neither has the strength of the illumination been properly measured. Is illustrations of the results obtained by the use of the katharometer in studying both respiration and photosynthesis, Waller (New Phyt. 25: 109-IIS. I020) gives a few measurements which do recognize the several factors that must be measured.- Ed. 
In pure oxygen plants respire more vigorously but are soon killed by it. ${ }^{1}$

The question has also been raised whether a deficiency of oxygen does not exist naturally in the interior of large plant parts because of the insufficient aeration. Older workers" expressed their opinion that the systematic arrangement of plant organs precludes a deficiency, yet it subsequently appeared that this question is complicated. It was shown that living wood parenchyma cells, ${ }^{3}$ roots, ${ }^{4}$ and germinating seeds with compact, swollen coats ${ }^{5}$ have an oxygen deficiency under natural conditions. In large fruits the composition of the gas mixture in the internal hollow spaces is not the same as that of the atmospheric air. An analysis of the gas contained in the hollow of a large pumpkin gave the following result: $\mathrm{CO}_{2}=$ $2.52 \%, \mathrm{O}_{2}=18.29 \%{ }^{6}$ In this case of course there can be no question of an oxygen deficiency. ${ }^{7}$ The assumption is not precluded that some plants store quite large amounts of looselybound oxygen. This oxygen is set free in an active condition when needed and is used in the oxidation of the respiratory material.

The Influence of $\mathrm{CO}_{2}$-concentration on Respiration.- Green plants can tolerate high concentrations of $\mathrm{CO}_{2}$ in the light without injury. However, according to de Saussure, a $4 \%$ content of carbon dioxide injures plants. With a high content of $\mathrm{CO}_{2}$ seed germination is entirely checked, ${ }^{8}$ but is again started upon restoration of the normal composition of the sur-

\footnotetext{
${ }^{1}$ Borodin, J. Bot. Zeitg. 39: I 27. I $88 \mathrm{I}$; Déhérain et Landrin. Compt. rend. 78 : I488. I 874 .

${ }^{2}$ Pfeffer, W. Abh. Math-physik. Klasse Sächs. Ges. d. Wiss. 15: 449. I889; Celakowski. Flora. 76: 194. I892.

${ }^{3}$ Devaux. Compt. rend. I28: I3.76. I 899; Mém. de la soc. sciences pliys. et natur. Bordeaux. June I5, I 899 .

4 Stoklasa, J. und A. Ernest. Jahrb. f. wiss. Bot. 46:55. 1909.

${ }^{5}$ Kostytschew, S. Biochem. Z. 15: I64. I908; Physiol.-chem. Untersuch, uber die Pflanzenatmung. I9I0. Russian.

${ }^{6}$ Devaux, H. Ann. sci. nat. bot. (VII) 14:297. I 89I; Rev. gén. de bot. 3: 49. I.89 I. [Langdon and Gailey (Langdon. Jour. Amer. Chem. Soc. 39: 149. 1917; Langdon and Gailey. Bot. Gaz. 70:230. I920) report carbon monoxide as a respiratory product in the hollow pneumatocysts of Nereocystis Luetkeana. The bladders contain nitrogen, oxygen ( 5 to $25 \%$ ), carbon monoxide (I to I $2 \%$ ) and no carbon dioxide.]

7 Gerber. (Ann. sci. nat. bot. (V11I) 4: 1. I 896) attempted to prove that a considerable oxygen deficiency of ten prevails in the interior of fleshy fruits on account of which alcoholic fermentation is introduced as a normal process in fruits.
}

${ }^{8}$ Bernard, Ci. Leçons sur les effets des subst. toxiques. I 883. P. 200 , 
rounding atmosphere. ${ }^{1}$ Protoplasmic streaming is also stopped by $\mathrm{CO}_{2} .=$ It is worthy of note that the respiratory quotient is not altered in the presence of $40 \% \mathrm{CO}_{2}{ }^{3}$

The Influence of Nutrient Materials on Respiration.-Borodin ${ }^{4}$ first showed that carbohydrates, which are formed in the light in green parts of plants, increase the rate of respiration. Subsequently the important significance of the sugars for respiration was established beyond doubt by several investigators. Particularly instructive in this connection are the experiments of Palladin ${ }^{5}$ who nourished green and etiolated young leaves of various plants with solutions of sugars and other organic nutrient materials and then measured the respiratory intensity of the plants. It appeared that leaves which contain a very small supply of carbohydrates in general respire feebly. The application of sugar to such leaves always effected a very appreciable increase in the rate of respiration. The fluctuations of the respiratory quotient as influenced by the percentage composition of the organic nutrients were described above.

The Influence of Concentrations of Various Solutions on Respiration.-For molds and other lower plants growing on solutions of various organic materials the concentration of the solution is of salient importance. On concentrated sugar solutions the respiration is generally weaker than on dilute solutions. ${ }^{6}$ The same rule was confirmed for young leaves of seed-plants when they are artificially nourished with sugar.' The checking action of high concentrations of sugar is apparently due to osmotic action. Solutions of mineral salts also produce the same effect. ${ }^{8}$ In other respects the action of mineral substances on oxygen respiration of plants is quite a complicated process. ${ }^{9}$ Antagonism of the metallic ions [cations] plays an

${ }^{1}$ Kidd, F. Proc. Roy. Soc. London. B. 87:609. 19it; 89: 136, 612. 1915.

${ }^{2}$ Lopriore. Jahrb. f. wiss. Bot. 28: 57 I. 1895.

${ }^{3}$ Déhérain et Maquenne. Ann. de la science agronom. franç. et étrangere. Tol. I2. I 886.

Borodin, J. Physiol. Untersuch, über die Atmung der Laubsprosse. 1876. Russian.

${ }^{5}$ Palladin, W. Rev. gén. de bot. 5: 449 . I893; 6: 201. I894; 13: 18. I90I; Maige, A. et G. Nicolas. Compt. rend, 147: 139. I908; Rev. gén. de bot. 22: 409. I9Io.

${ }^{6}$ Kosinski. Jahrb. f. wiss. Bot. 34: 137. 1902.

'Palladin, W. et Komleff. Rev. gén. de bot. 14:497. 1902.

6 Inman, O. L. J. Gen. Physiol. 3:533. 1920-21.

Krzemieniewski, S. Bull. acad. Cracovie 1902; Zaleski, W. und Reinhard. Biochem. 2.123: 193. I909. [For a thorough study of the effect of various concentrations of salts of the heary metals see Cook, S. F. J. Gen. Physiol. 8: 575-60I. 1925-26.] 
important rôle. Protoplasmic poisoning by unbalanced solutions is at once revealed by a reduction in the rate of respiration. Balanced solutions, on the contrary, produce no injurious effect and the rate of respiration remains normal. ${ }^{1}$

The Influence of Chemical and Mechanical Stimulating Effects on Respiration.-It is known that the reaction of living protoplasm to various stimulating effects is subject to definite laws. ${ }^{m}$ Weak stimulations effect an increased protoplasmic activity which often exceeds that of untreated protoplasm. A somewhat stronger stimulation evokes the same effect. After a certain time, however, there follows a condition of protoplasmic fatigue and the activity then follows that of the normal state. Very strong stimulations result at once in an appreciable decrease in activity. ${ }^{n}$

The results of stimulation of the living cell may be due to the alterations of the respiratory process. For example, wounding evokes an increased protoplasmic activity for the purpose of healing the wound. ${ }^{\circ}$ In this case there is a considerable increase in the rate of respiration ${ }^{2}$ and in the heat liberated. Since in this case vigorous growth and formative process take place, the value of $\frac{\mathrm{CO}_{2}}{\mathrm{O}_{2}}$ is lowered.

1. Gustafson, F. G. J. Gen. Physiol, 2: I7. I919-20; Brooks, M. M. Ibid. 3: 337. I $920-2$ I.

${ }^{2}$ Böhm. Bot. Zeitg. 45: 67I. I887; Stich, C. Flora. 74: I. I89I; Smirnoff. Rev. gén. de bot. 15: 26. 1903; Tscherniaeff. Ber. d. bot. Ges. 23: 207. I905; Richards. Ann. of Bot. Io: 53I. I896; I I : 29. I897; Zaleski, W. Ber. d. bot. Ges, 19:33I. I90I; Dorof eieff. Ibid. 20:396. I902; Krasnoselsky, T. Ibid. 24: 134. I906; and others.

$m$ Another law than that referred to here appeared in the work of Lyon (The rôle of phosphate in plant respiration. Thesis. Harvard. 1926; J. Gen. Physiol. Io: 599-6r5. 1926-27) when solutions of orthophosphate were applied to Elodea canadensis. The resulting increase in production of $\mathrm{CO}_{2}$ was found to be related to the concentration of $\mathrm{PO}_{4}{ }^{\prime \prime \prime}$ ion according to the equation

$$
\left(\mathrm{CO}_{2}-62.475\right)\left(\mathrm{pPO}_{4}-2 . \mathrm{I}_{3}\right)={ }_{\mathrm{I}} 4.43 \text {. }
$$

$\mathrm{CO}_{2}$ was stated in per cent and $\mathrm{PPO}_{4}$ indicated the concentration of $\mathrm{PO}_{4}{ }^{\prime \prime}$ ion in the same way that $\mathrm{pH}$ is used to denote the concentration of hydrogen ions.Ed.

$n$ These rules for chemical stimulation are illustrated by the action of ether or chloroform on respiration as measured by the production of $\mathrm{CO}_{2}$. Representative studies of this type are those of Brooks, M. M. J. Gen. Physiol. I : 193201. I918-19; Thomas, H. S. Ibid. I:203-207. I9IS-19; Ray, G. B. Ibid. 5: 469-477. I922-23; Gustafson, F. G. Ibid. I : ISI-I9x. I9IS-I9.-Ed.

$o$ Both the conclusion and this teleological form of statement are open to question. See also note 2 on page I $3 .-E d$. 
Chemical stimulation is best eroked by weak poisoning. The strength of the stimulant in this case can be altered as desired by the administration of various amounts of the poison. The effects of toxic substances on the oxygen respiration of plants have not yielded the same results in the experiments of various investigators. ${ }^{1}$ In fairly weak narcosis the rate of respiration increases and remains a long time in the stimulated condition, after which it finally returns to the normal condition. ${ }^{2}$ With stronger poisoning the increase in respiration is accompanied by a subsequent decrease. ${ }^{3}$ Strong poisons applied in sufficiently large quantities effect an immediate marked decrease in respiration. ${ }^{*}$ Under the influence of hydrogen cyanicle the output of $\mathrm{CO}_{2}$ in some cases is entirely suspended without death ensuing. The absorption of oxygen continues to a small extent and after some time returns to normal if the poison is removed. ${ }^{5}$ After a prolonged stay in an oxygen free medium, the mold Aspergillus niger is so badly poisoned by the products of anaerobic metabolism that the gas exchange becomes nil although the fungus is not yet killed. ${ }^{6}$

The following table, taken from the extensive monograph by Morkowin, ${ }^{7}$ illustrates the strongest increases in respiratory energy induced by toxic substances.

\section{Plant Material}

Etiol. leaves of Lupinus

Etiol. leaves of Vicia Faba

Etiol. leaves of Vicia Faba

Etiol. leaves of I'icia Faba

Etiol. leaves of I icia Faba

Etiol. leaves of Vicia Faba

Etiol. leaves of Vicia Faba
Not Stimulated Stimelated

$\mathrm{CO}_{2}$ IN MG, $\mathrm{CO}_{2}$ IN MG. StMulant

$\begin{array}{rrl}\text { I 24.9 } & 242.6 & \text { Paraldehyde } \\ \text { I60.4 } & 296.3 & \text { Ether } \\ \text { I } 89.9 & 229.5 & \text { Pyridine } \\ 82.5 & \text { I } 78.2 & \text { Cocaine } \\ 49.3 & 89.3 & \text { Morphine } \\ 39.7 & 105.6 & \text { Quinine } \\ 45.6 & 97.8 & \text { Solanin }\end{array}$

1 Elfving. Ofvers. af Finska Vet. Soc. Vol. 28. 1886; Johannsen. Bot. Zentralbl. 68 : 337. 1896; Morkowin, N. Der Einfluss von anästhetischen und giftigen Stoffen auf die Pflanzenatmung. I90I. Russian; Jacobi, B. Flora. 86: 289. I 899.

2Irving, A. Ann. of Bot. 25: 1077. 1911; Thoday, D. Ibid. 27:697. 1913; Haas, A. R. C. Bot. Gaz. 67:377. 1919.

${ }^{3}$ Zaleski, W. Zur Frage der Einwirkung von Reizstoffen auf die Pflanzenatmung. $190 \%$. Russian. [This behavior is also reported in the papers mentioned in the editorial note on the preceding page.]

4 Warburg, O. Z. f. physiol. Chem, 79:421. I9I2.

Schroeder, H. Jahrb. f, wiss, Bot. 44:409. I907.

- Kostytschew, S. Untersuch. über die anaerobe Atmung der Pflanzen. 1907. Russian.

7 Morkowin, N. Der Einfluss von anâsthetischen und giftigen Stoffen auf die Pflanzenatmung. 1901. Russian. 
Of the usual explanations of toxic action the following are worthy of note.

Palladin ${ }^{1}$ assumed that under the influence of poisons there was a large production of respiratory enzymes within the poisoned cells. According to Palladin this is a common effect from weak poisoning. It is established that enzymatic oxidation and fermentation processes cannot be increased by alkaloids and other stimulants outside of cells. At present the formation of an enzyme outside of living protoplasm is also unknown.

Warburg has expressed his belief ${ }^{2}$ that boundary surface phenomena play an important rôle in the respiratory process. Many poisons are strongly surface active and for that reason interfere violently in the respiratory process. Both theories are really valuable as working hypotheses.

It will be demonstrated later on that most of the processes which take place in respiration also persist outside of living cells, if the protoplasm is killed in such a way that most of its enzymes of fermentation and oxidation are not destroyed. It happens that many poisons which act injuriously on the living protoplasm (toluol, ether and others), only slightly influence the activity of the enzymes. Such substances are called protoplasmic poisons. ${ }^{3}$ Other poisons are about as toxic to the protoplasm as to the enzymes isolated therefrom. These are the so-called enzyme poisons. They include corrosive sublimate, sodium fluoride and similar poisons. Above all it is certainly very important to clarify the mechanism of enzyme poisons. ${ }^{p}$

Chemically indifferent substances can also produce noticeable stimulating effects under certain conditions. Thus Zaleski ${ }^{4}$ has shown that the respiratory intensity of bulbs of Gladiolus

\footnotetext{
1 Palladin, W. Jahrb. f. wiss. Bot. 47: 431. 1910.

2 Warburg, O. Zeitschr. f. Elektrochem. 28: 70. I922. [Idem. Science 61:575-582, 1925; Biochem. Z. I19: I34. I92I.]

${ }^{3}$ Palladin, W. loc. cit.; Euler, H. v. und af Ugglas. Z. f. physiol. Chem. 70: 279. igr I.

${ }^{4}$ Zaleski, W. Zur Frage der Einwirkung von Reizstoffen auf die Pflanzenatmung. I907. Russian.

${ }^{p}$ From discussions which follow it will be evident that the toxic effect of $\mathrm{KCN}$ is probably due to its relation to the iron content of both enzymes and living cells.-Ed.
} 
increases considerably after a short stay in pure water. ${ }^{q}$ Possibly the temporary withdrawal of oxygen is here to be considered as the cause. Later, attention will be called to the striking increase in respiration after temporary anaerobiosis, the explanation of which agrees with the modern theories of respiration. According to the data of Kostychev, a slightly alkaline reaction of the surrounding solution has a stimulating influence on the respiratory process. ${ }^{1}$ This agrees with the consideration that the enzymatic, biochemical, oxidation processes require a slightly alkaline reaction. ${ }^{r}$

The Influence of Yeast Extracts and of Sugar Solutions Fermented by Yeast, on the Respiration of Plants.-According to the statements of Kostychev and his coworkers ${ }^{2}$ the oxygen respiration of plants is very strikingly increased by yeast extracts and particularly by sugar solutions fermented by yeast. This condition will engage our attention later in connection with the discussion of the chemical nature of normal plant respiration. Since alcoholic fermentation may be regarded as one of the first steps in the physiological oxidation of sugar, a violent oxidation of the oxidisable intermediate products of sugar respiration, formed by yeast, could occur in the abore cases. $^{3}$ On the other hand, it is also plausible that the vitamines

${ }_{1}$ Kostytschew, S. und A. Scheloumow. Jahrb. f. wiss. Bot. 50: I57. I9II; cf. also Loeb, J. und H. Wasteneys. Biochem. Z. 37: 410 . 1911; Jour. Biol. Chem. 14: 335, 459. 469, 517. I913; 21: 153. 1915. [For the influence of hydrogen ion concentration on respiration see Gustafson, F. G. J. Gen. Physiol. 2: 617-626. I919-20, and Bode, H. R. Jahrb. f. wiss. Bot. 65:352-387. 1926. The latter deals only with Spirogyra and chiefly on the acid side of neutrality.]

${ }^{2}$ Kostytschew, S. Biochem. Z. 15: 164. I908; 23: 137. I909; Physiol.-chem. Untersuch. über Pflanzenatmung. I9I0. Russian; Kostytschew, S. und Scheloumow. loc. cil.; Ber. d. bot. Ges. 31 : 422. I913; Kostytschew, S., Brilliant, W. und A. Scheloumow. Ibid. 31 : 432. I9I3.

3 Yeast effects a vigorous alcoholic fermentation but an insignificant oxidation. With restricted access to oxygen it is also unable to oxidise alone all the fermentation products which are formed.

"Water can hardly be termed "chemically indifferent" for it is very generally accepted that its presence is essential for all, or nearly all, chemical (and hence physiological) reactions. $-E d$.

${ }^{\tau}$ It is difficult to reconcile this suggestion with the increasing evidence that the reaction of those parts of the protoplasm which may be tested is found to be on the acid rather than the alkaline side of neutrality ( $c f$. Crozier, W. J. Proc. Soc. Exptl. Biol. Med. 21 : 58. 1923). On the other hand the influence of an alkaline reaction may be regarded as more favorable to the catalytic action of iron (Warburg, O. Science 61 : 575-582. I925; Meyerhof und Matsuoka. Biochem. Z. I50:I-II. I924) or to the third ionization of phosphates which are reported to increase the rate of respiration (see editorial note $k$, page I 26). $-E d$. 
and similar stimulating substances in the yeast extracts induce a powerful stimulation of respiration.

In any case it is important that the increase in rate of respiration under the influence of fermented sugar solutions is entirely unique. Such an increase is not even approximately reached by the provision of nutrients or even by the action of poisons. The above table of Morkowin shows that the rate of respiration of plants stimulated by poisons rearhes at the most $266 \%$ of the normal rate (the quinine effect). From fermented solutions there results $\mathrm{CO}_{2}$-productions which exceed $400-600 \%$ of the normal rate for the material used. In examining the following table it is to be taken into consideration that the respiratory intensity of control portions (in $5 \%$ sugar solution) amounts to $150 \%$ of the normal of the wheat embryos (without sugar). The table is an extract taken from S. Kostychev and A. Scheloumow.

$\mathrm{CO}_{2}$-Production of Soaked Wheat Embryos in Mg.

\begin{tabular}{c|c|c}
\hline $\begin{array}{c}\text { A. In 5\% } \\
\text { sugar sol. }\end{array}$ & $\begin{array}{r}\text { B. In yeast extracts plus } \\
5 \% \text { sugar sol. }\end{array}$ & $\begin{array}{c}\text { C. In a fermented } \\
5 \% \text { sugar solution }\end{array}$ \\
\hline 37.4 & I 20.8 & I 38.4 \\
63.0 & I32.0 & 93.8 \\
22.2 & 80.6 & 92.4 \\
26.4 & 80.2 & 96.4 \\
\hline
\end{tabular}

This table shows that fermented sugar solutions always effect a larger increase of respiratory energy than sugar-containing yeast extracts. From the following data ${ }^{1}$ it is apparent that the addition of sugar alone increases the $\mathrm{CO}_{2}$-production of wheat embryos.

$\mathrm{CO}_{2}$-production of Soaked Wheat Embryos.
A. In water.
B. In a $5 \%$ sugar solution. $86.4 \mathrm{mg}$. r $33.9 \mathrm{mg}$.

\section{ANALYTICAL METHODS FOR THE DETERMINATION OF OXYGEN RESPIRATION}

If one wishes to make sure that plants liberate $\mathrm{CO}_{2}$ the material to be studied is placed in a special container (see below) and $\mathrm{CO}_{2}$-free air is passed through it. The current of air is

\footnotetext{
${ }^{1}$ Kostytschew, S. Biochem. Z. 15: I64. 1908.
} 
then directed into a container with clear baryta water. The separation of barium carbonate, if necessary with subsequent analysis of the precipitate, serves to identify the carbon dioxide. Still, only quantitative determinations of plant respiration have real physiological significance. These quantitative determinations either measure the amount of the carbon dioxide liberated (determination of the respiratory intensity) or give the value of $\mathrm{CO}_{2}$ $\frac{\mathrm{O}_{2}}{\mathrm{O}_{2}}$ (determination of the respiratory quotient).

For the determination of the carbon dioxide formed by plants, various types of apparatus are used. The research material is enclosed in a container with an entry and an exit tube ( $Z_{u-u n d}$ Ableitungsrohr) and left for a time in a stream of air free from $\mathrm{CO}_{2}$. The carbon dioxide which is formed is intercepted in a special absorption apparatus.

In order to free completely the incoming air of atmospheric $\mathrm{CO}_{2}$, the current of air is first passed through a drying tower filled with soda lime. ${ }^{1}$ The containers for the research material are of various forms and sizes according to the nature of the object of study. One must make sure that the container is nearly filled with plants, for the use of large ones and small quantities of plants will introduce experimental errors. For considerable amounts of research material, glass bell jars are used. The upper openings of the jars are closed with close fitting rubber stoppers, each with an entry and an exit tube. The former must extend nearer to the bottom. The bell jars are sealed to ground glass plates by means of vacuum stop cock grease (of course the lower rim of the bell jar must be evenly ground or an air-tight seal is impossible).

For experiments with smaller quantities of plants, U-tubes or thick-walled flasks may be used to advantage. ${ }^{\text {. For his }}$ studies of the respiration of molds, Puriewitsch ${ }^{2}$ arranged

\footnotetext{
${ }^{1}$ Soda lime must be renewed frequently and contains so much water that the heating of a small quantity in a test tube frees some water vapor which condenses on the walls of the upper part of the tube. The use of too dry soda lime prevents a complete absorption of $\mathrm{CO}_{2}$.

2 Puriewitsch, K. Ber. d. bot. Ges. 16: 290. 1898; Jahrb. f. wiss. Bot. 35: 573.1900.

"The study of the respiration of bacteria is a special problem. While it may be followed as regards its $\mathrm{CO}_{2}$-production by means of certain indicator methods. the complete study requires such apparatus and technique as that described by Novy, Roehm and Soule (Jour. Infect. Diseases. 36:109-167. 1925).-Ed.
} 
Erlenmeyer flasks as follows (Fig. I). Through the tube $c$ a certain quantity of nutrient solution inoculated with fungus spores would be run in until a height of only $\mathrm{I}-\mathrm{I} .5 \mathrm{~cm}$. was left between the surface of the solution $(e-e)$ and the bottom of the flask. The fungus mat then developed at the surface of the liquid. By opening the pinch cock $d$ the nutrient solution can be let out whenever necessary and be replaced by another nutrient solution after rinsing off the lower surface of the fungus mat. When the liquid runs out no change occurs in the position of the compact fungus mat. Its center merely sags somewhat. For the determination of the carbon dioxide formed by large amounts of the expressed juice of Psalliota campestris [= Agaricus campestris], Kostychev made use of large, and like-wise inverted, cylindrical-conical flasks (Fig. 2). For work with

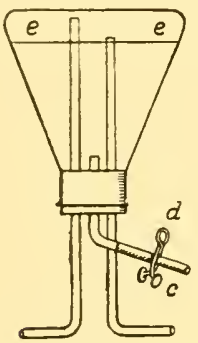

FIG. 1.-Flask for experiinents with molds.

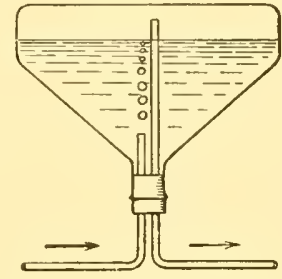

FIG. 2.-Flask for studying $\mathrm{CO}_{2}$-formation by plant juices.

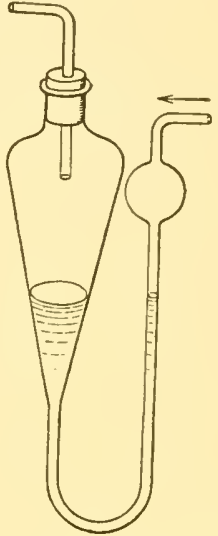

FIG. 3.-Chudiakow's vessel.

small volumes of liquids, the use of Chudiakow's apparatus (Fig. 3) is to be recommended. The arrow indicates the direction of the current of gas.

For his studies of the respiration of the lower plants, Palladin ${ }^{1}$ set up roll cultures on gelatine. A narrow-mouthed glass bottle was very well suited to this purpose, the mouth being fitted with a two-hole rubber stopper and an entry and an exit tube inserted in the holes. Palladin used large cylinders of $35^{\circ}-65^{\circ}$ cc. capacity or test tubes of about 600 cc. capacity. The walls of the sterilized cylinder were coated with a thin layer of hot,

I Palladin, W. Zentralbl. f. Bakt., Parasitenk. u. Infektions krankh. (II) II : I46. I903. 
sterilized, nutrient solution plus $12 \%$ gelatine. After the substrate had set, a pure culture was poured in and by rotation [of the cylinder] distributed evenly over the walls of the vessel (Fig. 4).

The above examples suffice to show how varied the containers can be. In all types the inner openings of the entry and the exit tubes are as far removed from one another as possible.

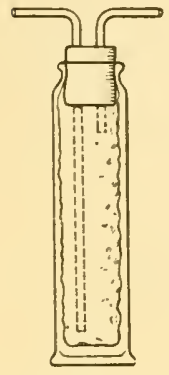

FIg. 4.-Roll culture.

This is always a necessary precaution to prevent an accumulation of $\mathrm{CO}_{2}$ in the container.

As for the absorption apparatus, it can likewise be varied. If a more common type of absorption ressel is not required, but the amount of $\mathrm{CO}_{2}$ dereloped considerable, the Geissler potash tubes or soda lime tubes may be used to adrantage. The bulbs of the potash tubes are about twothirds filled with $40-45 \%$ caustic potash. The use of concentrated potash solution is not to be recommended, for a stoppage of the tubes often results from the precipitation of crystalline potassium hydroxide. ${ }^{t}$ The calcium chloride tube of the Geissler apparatus is filled with solid calcium hydrate, or still better, with asbestos soaked in concentrated sulphuric acid, to prevent a loss of water. Both ends of the tube are plugged with glass wool.

The potash apparatus thus prepared provides for a complete absorption of $\mathrm{CO}_{2}$ even if a rapid stream of pure carbon dioxide is passed through it. In this case one can easily make sure that the stream of gas passes through the second bulb only in single small bubbles but that it does not pass the third bulb. The gas which passes the potash apparatus must be entirely dry however. To provide for this a wash bottle filled with concentrated sulphuric acid is interposed before the apparatus. This precaution is entirely sufficient while the use of calcium chloride introduces experimental errors, since potassium hydrate absorbs water vapor as does calcium chloride. The difference is really unimportant with short exposures but can be quite marked in experiments of an hour's duration.

'There is nothing to prevent the use of sodium hydroxide in place of the potash solution.-Ed. 
A light wash bottle filled with concentrated sulphuric acid must be inserted behind the potash apparatus if the gas stream passes through sulphuric acid in front of the potash apparatus. Only thus is it possible to preserve a constant weight of water in the absorption apparatus. A second potash apparatus filled with concentrated sulphuric acid will serve as a weighable wash bottle. It is still simpler to place some asbestos soaked in conc. sulphuric acid in the calcium chloride tube of the potash apparatus. In this case the calcium chloride tube must be freshly filled for every experiment. Behind all the above absorption vessels there must be inserted a wash bottle with sulphuric acid in order to aroid a direct connection between the moist air of the air pump and the absorption ressels.

The results of $\mathrm{CO}_{2}$-determinations in the Geissler potash apparatus filled in this manner are very accurate. With care it is possible to determine fractions of a milligram with a fair degree of certainty. Weighed soda lime tubes are no less reliable and are perhaps still simpler to use. Small U-tubes with ground glass stoppers are the best to use and are prepared with not too dry soda lime (see previous note). Two U-tubes are inserted one after another. The second tube must show no, or only a very small, increase in weight. To dry the gas stream, conc. sulphuric acid is used here also. As to the general handling and weighing of the potash apparatus and soda lime tubes, handbooks of analytical chemistry must be consulted. During each experiment all apparatus and wash bottles are connected by rubber tubing. Before and behind the potash apparatus or soda lime tube a screw pinchcock is applied. The current of gas is regulated by means of the pinchcock opening behind the potash apparatus. The other pinchcock is left open except to interchange the potash apparatus when both are closed, the potash apparatus removed and replaced by another which is prepared with fresh $\mathrm{KOH}$ and weighed.

If one is to follow the progress of respiration more accurately by means of rapid, successive $\mathrm{CO}_{2}$-determinations, and eventually to plot them, a continual interchange and weighing of potash apparatus or soda lime tubes proves to consume considerable time. For such experiments one uses for the most 
part the so-called Pettenkoffer tubes, ${ }^{1}$ which are made in various forms. In the laboratory of plant physiology at the University of St. Petersburg the thick-walled tubes, bent once at an angle of $130^{\circ}$, are used. The shorter arm is $10 \mathrm{~cm}$. long and the longer one is $\mathrm{I} 20 \mathrm{~cm}$. The diameter of the tubes is $14 \mathrm{~mm}$. The second bend with a spherical enlargement first described by Pfeffer ${ }^{2}$ is unnecessary. If the tubes are long enough no baryta water flows out of the tube with as rapid a gas current as desired. The singly-bent tube is much more easily cleaned. To clean the tubes there is needed a thin wooden rod the end of which is wrapped in Joseph paper or cotton. The fore end of the Pettenkoffer tube is connected with the plant container by means of a I-hole rubber stopper and entry tube. The end of the entry tube must be drawn out in order that the gas may pass through the Pettenkoffer tube in the form of the smallest possible bubbles. The Pettenkoffer tubes are mounted on a wooden frame which consists of two vertical strips of unequal height, fastened together. Both strips are provided with grooves which are lined with cloth. The tubes are laid in these grooves and fastened with wooden screw clamps. The rear end of each Pettenkoffer tube is connected with one of the sidetubes of a wide collecting tube, which itself communicates with an ordinary aspirator. Each Pettenkoffer tube is provided with roo cc. of baryta water. First, the fore end of the Pettenkoffer tube is closed with the rubber stopper and entry tube. The latter is furnished with a rubber tube which remains hermetically closed by a screw pinchcock. The tube is now filled with baryta water and closed at once with a second rubber stopper with an exit tube. The Pettenkoffer tube is now ready for use.

The baryta water is all prepared at once in large quantities in ressels of $10-I_{5}$ liters capacity. Usually $7 \mathrm{~g}$. of cryst. barium hydroxide are dissolved in each liter of distilled water. For determinations of exceptionally large amounts of $\mathrm{CO}_{2}$ two or three times this concentration of barium hydroxide is used.

\footnotetext{
1 Pettenkoffer, M. Abdh. math.-physik. Klasse. Bayr. Akad. d. Wiss. (II) 9: 23 I. I862. [See also the several types of more recentiy devised apparatus described at the end of this section.]

${ }^{2}$ Pfeffer, W. Untersuch. aus d. bot. Inst. Tubingen $1: 636.188 \mathrm{I}-\mathrm{I} 885$.
} 
To every liter is added I gram of barium chloride. ${ }^{1}$ The large vessel of baryta water is closed with a stopper fitted with a soda lime tube, so that no carbon dioxide from the air can enter the ressel. Through another hole in the stopper the ressel is provided with an accurate burette. After any possible precipitate has settled the baryta water always remains clear. The titration of the baryta water is best done with hydrochloric acid for the standardization of which pure cryst. oxalic acid is used to advantage. ${ }^{u}$

With the tubes filled with baryta water and fastened to the frame, one tube is connected with the plant container and

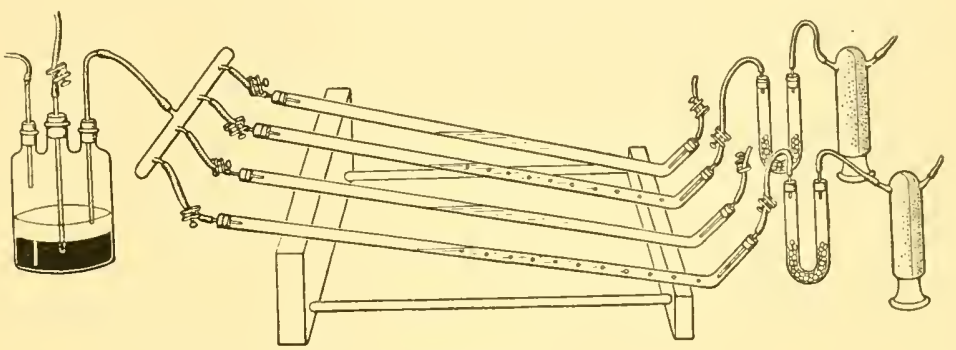

Fig. 5.-Pettenkoffer tubes.

the experiment starts as follows. One starts the air pump, completely opens the pinchcock at the rear end of the tube which is connected with the plant container, and then gradually unscrews the pinchcock at the fore end. With the aid of this pinchcock the stream of gas is arlmitted at the desired rate. The gas bubbles must rise in the Pettenkoffer tube at a uniform rate and must not fuse but pass singly through the whole tube. After the lapse of a certain time, that tube is cut out and the plant container at once joined to another fresh Pettenkoffer tube. In cutting out the tube, first the rear and then the fore pinchcock is closed and the rubber tubing communicating with the plant container is removed from the entry tube. In this

1 Clausen, H. Landwirtschaft1. Jahrb. 19:898. 1890.

$u$ As an alternative to the use of baryta water, Nishi (Jour. Biochen. Tokyo 4:473-480. 1925) describes the use of $\mathrm{N} / 50 \mathrm{NaOH}$ which is titrated in the presence of the $\mathrm{NaHCO}_{3}$. Since thymolphthalein becomes blue at the pH of a dilute solution of $\mathrm{NaHCO}_{3}$ its use permits the titration of the $\mathrm{NaOH}$ to completion without a bicarbonate error.-Ed. 
manner one can easily work. by continual interchange of tubes, as long as one pleases without interruption. Fig. 5 represents a complete Pettenkoffer apparatus in action. The Pettenkoffer tubes which have been cut out are emptied by shaking into dry r 50 cc. glass bottles with ground and greased glass stoppers. The bottles are allowed to stand quietly until the next day in order that the precipitate may settle completely. Then $25 \mathrm{cc}$. of clear baryta solution are measured out with a pipette from each bottle, for titration.

Ordinary aspirators are used for the production of the air current. It is very practical not to join the aspirator directly to the water supply but to a ressel of large capacity placed as high as possible, filled from the tap and fitted with a siphon. The latter arrangement prevents an overflow of the vessel. In this way there is always a weak but constant water pressure. A considerable pressure is unnecessary to draw the air through the absorption vessels. The possible uncertainty of the water pressure in the water supply could also be entirely aroided by using Palladin's mercury regulator. This simple device should be used for all work in which a continual current of gas is desired and a constant supervision is not always possible. The regulator is set up in the following manner. A layer of mercury about $2 \mathrm{~cm}$. deep is poured into a triple-necked bottle and on it poured a layer of water of the same depth. The entry tube is fitted into one opening and the open end immersed $\mathrm{I} \mathrm{cm}$. in the water. The exit tube passes out through the other opening but in the middle one is an upright glass tube whose lower end dips in the mercury by I cm. (Fig. 5). The regulator is inserted in the air current between the absorption vessels and the air pump. By the use of this regulator the rarefaction of the air in the apparatus can reach at the most $\mathrm{I} \mathrm{cm}$. of mercury pressure, since the air breaks in to the pump through the middle tube of the regulator in case the passage of gas is obstructed or entirely blocked. In this way the interchange of absorption apparatus may be accomplished without stopping the action of the air pump.

The series of various vessels for the passage of air is then as follows: I. Vessel with soda lime to absorb the atmospheric 
carbon dioxide; 2. Wash bottle with water, or with moist scraps of paper, which serves to moisten the air which was dried by the soda lime (this is necessary to prevent the drying up of the research material); 3. Container with plant material; 4 . Absorption vessel which is either (a) wash bottle of sulphuric acid, (b) potash apparatus, (c) small weighed wash bottle of sulphuric acid, and (d) control bottle of sulphuric acid, or (a) Pettenkoffer tubes and (b) collecting tube; 5. Mercury regulator; 6. Air pump.

By the methods just described, the respiratory intensity can be measured for various conditions. A control experiment is also made possible by using two or more lots of plant material and two or more series of absorption apparatus simultaneously for each experiment. However, if it is also necessary to measure the absorption of oxygen, wholly different apparatus is required. It must be pointed out at once that a determination of the oxygen absorption without a simultaneous measurement of the quantity of carbon dioxide given out, in the case of experiments in plant respiration, may lead to incorrect results since the oxygen is not uncommonly used for incomplete oxidation processes which are not attended by the formation of $\mathrm{CO}_{2}$. This assimilation of oxygen, which is often connected with an unimportant release of heat, must not be confused with true respiration.

From this it is apparent that the determination of the absorption of oxygen must always take place simultaneously with the determination of the liberated $\mathrm{CO}_{2}$ and so serves to measure the value of $\frac{\mathrm{CO}_{2}}{\mathrm{O}_{2}}$. These determinations are best carried out by gas analysis. The plant material is inclosed in a suitable container with pure air. After the passage of a given interval of time. ${ }^{v}$ samples of gas are removed from the container and

$v$ The dynamics of any physiological process are best studied by observations of the time required to do a certain amount of work, rather than by measurements of work done in equal times ( $f$. Osterhout, W. J. V. Science. 48: $172-174$. I9r8). This is an inherent fault in methods which require a titration or a measurement of absolute changes in gaseous content. It has been aroided in some of the new methods, notably in the colorimetric methods as used in the Osterhout apparatus described at the end of the section.-Ed. 
analyzed by the usual methods which need not be fully described here. For the general technique of manipulation of gases and the description of long-established, accurate methods of gas analysis, consult the complete manuals. ${ }^{1}$ Only two pieces of apparatus, which have proven to be particularly suitable for plant physiology experiments and which are not described in manuals of gas analysis, will be mentioned here. ${ }^{2}$

For exact work in biochemical gas analysis, the PolowzowRichter apparatus ${ }^{3}$ is particularly worthy of recommendation, for it yields very accurate results and can be used for very small quantities of gas. The most important part of the apparatus (Fig. 6) is the measuring tube $\mathrm{AA}^{\prime} \mathrm{A}^{\prime \prime} \mathrm{A}^{\prime \prime \prime}$. The part of the tube which is furnished and calibrated with millimeter divisions is contained in a glass cylinder B filled with water, the outer end $\mathrm{A}^{\prime \prime \prime}$, in the cylindrical mercury bath $\mathrm{C}$. The ends of the glass pipettes $\mathrm{D}$ and $\mathrm{E}$ are also placed in the same bath. The left end $\mathrm{A}$ of the measuring tube is connected with the glass bulbs $\mathrm{H}$ by means of a thick-walled rubber tube $\mathrm{P}$, which is filled with purest mercury. By the aid of this pear-shaped bulb and the glass stopcock $a$, the level of the mercury in the measuring tube can be set at any height. The steel screw $e$ which is set in mercury in a side tube is used for delicate adjustments of the level of mercury. The left side of the measuring tube marked in millimeters is a thick-walled capillary tube of about $2 \mathrm{~mm}$. bore. From the line $o$ on, the hollow of the tube

${ }_{1}$ Bunsen, R. Gasometric Methoden, 1877; Hempe'. Gasanalytische Methoden. 1913; Berthelot, M. Traité pratique de l'analyse des gas. I906; The method of Doyère (Ann. de chim. et de physique. (III) $28: 5$. I850) is very commendable. [Reliable manuals in English include: Haldane, J. S. Methods of Arr Analysis. London. Igr 2; Hempel, W. Methods of Gas Analysis. Trans, by L. M. Dennis. London. 1892.]

2 Barcroft's method, which is much used in animal physiology, together with its later modifications (measurement of changes in pressure of the gas in sma!l experimental flasks with the aid of sensitive manometers), has recently been used by some plant physiologists. It will not be described here, however, since it is not very suitable for plant material and is less reliable than the following gasometric method. The change in pressure of the oxygen plays an important rôle in the Barcroft method. Various plants absorb considerable amounts of oxygen not for combustion of the respiratory material but for other purposes (formation of acids, amino acıds, etc.). Likewise the marked variations in $\mathrm{pH}$ which occur in the case of many plants and especially with microörganisms, might give rise to considerable errors, since the solubility of $\mathrm{CO}_{2}$ and other gases is thereby altered. Such sudden fluctuations in $\mathrm{pH}$ are made impossible in the blood of animals and are not taken into consideration by Barcroft's method which was designed especially for blood experinents.

Hence in studies of plant respiration, only chemical methods of gas a nalysis are absolutely reliable [for absolute measurements].

${ }^{3}$ Polowzow, V. Untersuch. Uber Pfanzcnatmung. 190I. Russian; Richter, A. Arb. d. Naturf.-Ges. in Petersburg. 33:311. 1902. 
is considerably narrower. The line $\mathrm{O}$ is cut only on the right side of the measuring tube and level with the line $l m$ on the mercury bath $\mathrm{C}$.

The mercury bath $\mathrm{C}$ and the two gas pipettes $\mathrm{D}$ and $\mathrm{E}$ are joined, by thick-walled rubber tubes and a T-tube, with the large pear-shaped bulb $\mathrm{G}$, the volume of which is approxi-

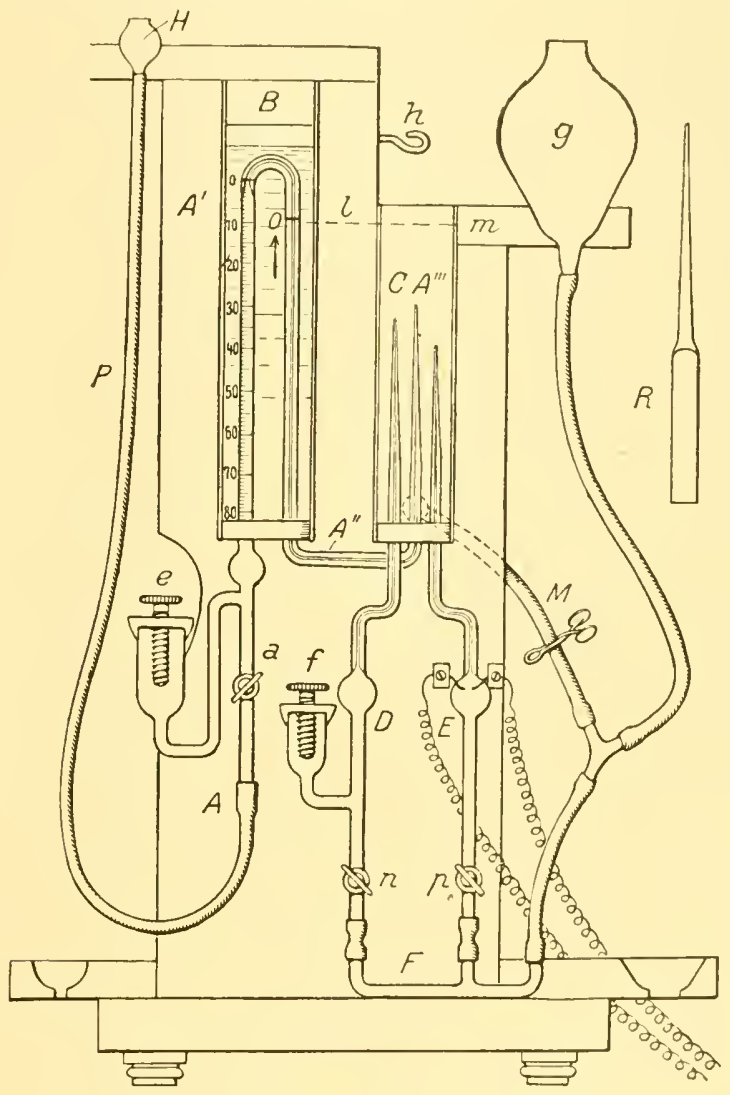

FIG. 6.-The Polowzow-Richter apparatus.

mately the same as that of the bath. If the two glass stopcocks $n$ and 2 are closed, it is possible either to empty or to fill the bath $\mathrm{C}$ with mercury by means of the opened pinchcock $\mathrm{M}$, according to the position of the pear-shaped bulb. With the pinchcock $M$ closed, one is able, by means of the bulb $G$ and the two glass stopcocks $n$ and $p$, to cause mercury to flow 
through each pipette in any desired direction (according to the position of the bulb). The steel screw $f$, which is entirely analogous to the screw $\varepsilon$, serves the pipette D for delicate adjustments of the mercury column in the tube above. The pipette $\mathrm{D}$ is an absorption pipette but the pipette $\mathrm{E}$ is an explosion pipette. In the upper part of the bulb are fused platinum. wires, the ends of which are $I^{-2} \mathrm{~mm}$. apart. Outside the bulb the platinum wires are joined to the poles of a Rumkorf spark coil. The latter is itself joined to a zinc-carbon element. The element is filled with a chromic acid solution which is prepared from 92 grams of potassium dichromate, $93.5 \mathrm{cc}$. of conc. sulphuric acid, and $900 \mathrm{cc}$. of water. For taking readings on the measuring tube there is used a horizontal reading microscope which is placed on set screws and moved by a slide and gearing at a height of $4^{\circ}-50 \mathrm{~cm} .^{1}$ The exact fixation on the object is done with a rack and pinion. The instrument is so focused that each millimeter division of the measuring tube is divided into 20 parts by the ocular micrometer of the microscope. Small analysis tubes. closed above and with fused supports (R), are needed in addition to carry out the analyses. The length of each tube is about $6-7 \mathrm{~cm}$. (without supports).

The measuring tube, the two gas pipettes D and $\mathrm{E}$, and the bath $\mathrm{C}$ are filled with pure, dry mercury by the use of the two bulbs $\mathrm{G}$ and $\mathrm{H}$. After filling the gas pipettes and the bath. only 2-3 cc. of mercury should remain in the pear-shaped bulb G. The glass cylinder B is filled with distilled water and covered with a glass plate to protect the water from dust. From time to time water which has become somewhat turbid is replaced by fresh. The bulb of the pipette D is filled to a third with about $30 \%$ potash [or $\mathrm{NaOH}$ ]. To accomplish this an analysis tube is prepared with $3-4 \mathrm{cc}$. of potash and the lye sealed off with mercury. The analysis tube is carried to the mercury bath $\mathrm{C}$ with the aid of an iron ladle ( $c f$. manuals of gas analysis methods) and placed under the mercury on the upper tube of the absorption pipette so far that the end of the pipette dips into the potash. The bulb $\mathrm{G}$ is now lowered, the stopcock $n$

1 Nodel of Leitz. Since the side of the measuring tube that is divided into millimeters is only about $20 \mathrm{~cm}$. long, the adjustable cathetometer, which can be set to read lower, could also be used. 
opened, and in this way a suitable quantity of potash is sucked into the pipette, after which the end of the pipette is let into the mercury by raising the analysis tube, and mercury is drawn into the pipette for a time in order to remove the lye that adheres to the walls of the capillary tube. After filling the pipette, the potash solution contained within the bulb is thus sealed by the mercury in the capillary tube above it.

The determination of oxygen in the apparatus of PolowzowRichter is done by combustion with hydrogen. Hence, hydrogen and oxy-hydrogen gas are required for the analysis. These gases are prepared by electrolysis according to the detailed directions of Bunsen ${ }^{1}$ and stored in thick-walled test tubes which are sealed with mercury.

The apparatus must be carefully calibrated before use. The accuracy of the analysis depends above all on the accuracy of the calibration. The absolute volume of the bore of the measuring tube is unknown and for measuring the percentage composition of the gases to be analysed is unimportant. But it is very important to rectify by suitable corrections the inequality of the volumes contained between millimeter markings, due to the inaccurately cylindrical form of the measuring tube. This is done as follows. One incloses with mercury in an analysis tube a couple of cubic centimeters of air, transfers the analysis tube to the bath $\mathrm{C}$, places it under mercury on the end of the measuring tube, lowers the pear-shaped bulb $\mathrm{H}$ and sucks into the measuring tube, by opening the stopcock $a$, first some air, then a small quantity of mercury, and finally some more air. This procedure is analogous to filling the absorption pipette with potash solution as described above. The volume of the mercury introduced must be scarcely larger than or at best exactly as large as the space between $\mathrm{O}$ and $o$. If too much mercury has been drawn in the surplus is removed with the aid of the screw $e$. The introduced mercury column is so suspended that the top of the meniscus in the right side coincides with the line $\mathrm{O}$, and by the use of the reading microscope the position of the highest point of the other meniscus in the left-hand, wide side of the tube is then noted. The column of mercury is next

\footnotetext{
1 Bunsen, R. Gasomethrischen Methoden, 2nd. ed. Pp. 76 and 80.1877.
} 
shifted so that the rear meniscus takes the exact position of the forward one and the new position of the forward meniscus is noted. By continuing in this manner the whole measuring tube is measured with the same column of mercury. Since the volume of the mercury does not change (care must be taken that the temperature of the water in the cylinder $\mathrm{B}$ remains constant) the apparent inequality of the lengths of the column in various parts of the tube is due to the unequal widths of the inner space of the measuring tube. Thus a table of corrections can be drawn up, which are to be taken into consideration for each analysis. The calculations of the corrections are carried out according to the exact directions of Bunsen. ${ }^{1}$ To all data obtained there is to be added the number ascertained for the space between $\mathrm{O}$ and $o$ which is not divided into millimeters, since this space is to be included in the similar analysis of gas.

The gas analysis is carried out in the following manner. The gas to be analyzed must be sealed in an analysis tube with mercury (see below). The analysis tube is transferred to the bath $C$, placed under mercury on the end of the measuring tube, a suitable amount of gas drawn into the measuring tube by lowering the pear-shaped bulb $\mathrm{H}$ and opening the stopcock $a$, and sealed with mercury by raising the analysis tube. The analysis tube with the surplus of gas is then removed from the bath and replaced by another full of pure, dry mercury. This analysis tube is allowed to float in the bath with the lower end dipped in mercury while the glass support rests against the hook $h$. The level of mercury in the bath $\mathrm{C}$ is now adjusted exactly to the line $l m$. The mercury meniscus in the righthand, narrow side of the measuring tube is set at the line $\mathrm{O}$ with the aid of the screw $e$ and a microscope; then the position of the mercury meniscus in the left side of the measuring tube is noted with the aid of the reading microscope and the relative, corrected volume of gas is calculated according to the table of corrections. $^{2}$ It is recommended that the accurate setting on the line $\mathrm{O}$ be clone twice in succession with subsequent readings

\footnotetext{
1 Bunsen, R. Gasometrischen Methoden. 2nd. ed. Pp. 34-35. 1877.

2 If one wishes to know the absolute volume of the measuring tube, the column of mercury used for the calibration of the measuring tube must be carefully weighed. $C f$. Bunsen. loc. cil. This can be done only in cases of exceptional importance.
} 
at the microscope, and that the volume be recorded only if the two readings coincide, since accidental adherence of the mercury to the walls of the tube will lead to fluctuations in the volume of the gas. This is an indication of the insufficient purity or dryness of the tube or the mercury.

The gas is now passed from the measuring tube into the analysis tube filled with mercury, by raising the pear-shaped bulb $\mathrm{H}$ and opening the stopcock $a$, which tube has been placed so far under mercury on the end of the measuring tube that the end of the measuring tube touches the bend of the analysis tube. The latter, with the gas contained within it, is then conveyed under mercury to the end of the absorption pipette $\mathrm{D}$ and the gas is drawn into the pipette by lowering the bulb Gr and opening the stopcock $n$. The gas is left about ro minutes in contact with the potash. During this time the bulb $\mathrm{G}$ is left lowered and the stopcock $n$ opened so wide that mercury drops continuously out of the bath into the pipette. After the lapse of ro minutes the gas is forced back out of the pipette into the analysis tube as follows: without changing the position of the stopcock, the bulb G is raised and the greater part of the gas is thereby quickly crowded out of the pipette into the analysis tube. Then the stopcock is closed and the rest of the gas is removed with the aid of the screw $f$, after which the level of mercury in the bath $\mathrm{C}$ has been so lowered that the orifice of the pipette with the analysis tube resting on it is visible. In forcing gas out of the absorption pipette, care must be taken that no trace of potash enters the analysis tube. If it does the gas is replaced in the pipette and the analysis tube with the impurities is replaced by another tube filled with pure, dry mercury. If this precaution is not observed the lye might easily enter the measuring tube and produce serious errors in subsequent analyses. In order to prevent a gushing of the $\mathrm{KOH}$ from the end of the pipette into the analysis tube, the analysis tube must not be lifted before the last trace of gas is forced from the pipette. In addition, the level of mercury in the bath must be so adjusted that the capillary tube of the absorption pipette juts out only about $\frac{1}{2} \mathrm{~cm}$. after the displacement of the gas. 
After the absorption of the $\mathrm{CO}_{2}$ the gas is passed into the measuring tube and again measured. The difference between the two readings gives the volume of carbon dioxide. After this measurement the gas is forced back into the analysis tube. An analysis tube filled with pure hydrogen is transferred to the bath, placed on the end of the measuring tube and the necessary amount of hydrogen drawn into the measuring tube, the amount of hydrogen being computed approximately according to the probable oxygen content of the gas to be analysed. If the quantity of carbon dioxide be less than $8 \%$, the amount of hydrogen used for analysis must amount to about ${ }^{2} 5$ of the original volume of the gas to be analysed. The exact rolume of hydrogen is measured with the aid of the reading microscope and the hydrogen is mixed in the analysis tube with the gas to be analysed. The contents of the analysis tube is now transferred to the explosion pipette. The explosion is fired off by setting the zinc-carbon element for a spark. With this the bulb $\mathrm{G}$ is lowered as far as possible and the stopcock $p$ is opened at the same time, whereby a stream of mercury is produced from the bath $\mathrm{C}$ into the explosion pipette. After the explosion the gas is at once forced back into the analysis tube by raising the bulb $\mathrm{G}$. Then the analysis tube is transferred to the end of the measuring tube, the gas drawn into the measuring tube and its volume accurately measured. If $a$ were the volume of the gas after the absorption of $\mathrm{CO}_{2}, b$, the volume of hydrogen, and $c$, the volume of the gas mixture after the explosion, the volume of the oxygen is $\frac{a+b-c}{3}$. If the data obtained for $\mathrm{CO}_{2}$ and oxygen is then expressed in percentages, the nitrogen is computed according to the difference. If the oxygen content of the gas to be analyzed is very small, it can easily happen that no explosion takes place when the spark is passed. In this case some illuminating gas is added and the explosion repeated. The volume of the illuminating gas must be about $1 / 3$ that of the gas to be analysed. With the use of an excess of illuminating gas, part of the nitrogen may be oxidised as a result of too violent an explosion. Of course this introduces a considerable error in the analysis. 
An analysis of a gas mixture of carbon dioxide, oxygen and nitrogen has just been described. Determinations of hydrogen, carbon monoxide, methane, ethylene and other gases could also be carried out in the apparatus of Polowzow-Richter. The analysis of a gas mixture of carbon dioxide, oxygen, hydrogen and nitrogen is performed as follows. First the carbon dioxide is measured, then the gas is conveyed to the explosion pipette where it is exploded with the addition of illuminating gas. If a decrease in total volume has taken place after the explosion, a quantity of $\mathrm{CO}_{2}$-free air, accurately measured in the measuring tube, is added to the gas and again exploded with illuminating gas. If the total volume remains unchanged after the second explosion or if all the oxygen introduced with the air is not used up by the explosion, the volume of hydrogen is computed as follows: if $a$ were the volume of the gas to be analysed, after the $\mathrm{CO}_{2}$-absorption, and $b$, after the explosion, the volume of the hydrogen equals $2 \frac{3}{3}(a-b)$, in case no change in volume occurred aiter the second explosion. ${ }^{1}$ If the gas which was combustible with oxygen were pure hydrogen, no trace of $\mathrm{CO}_{2}$ would be produced by the explosion. This is tested by treatment of the gas mixture with caustic potash after the explosion. It is best to use another sample of gas for the determination of oxygen, and in the admission of hydrogen the amount of hydrogen already in the gas mixture to be analysed is taken into account. Consideration of the procedure of analysis of carbon monoxide, methane and ethylene must be referred to the manuals of gas analysis, particularly to Bunsen's "Gasometrische Methoden." 2

It must also be taken into consideration that the apparatus can be made to fit various other types of analyses as required. It is quite possible to use a larger mercury bath on the apparatus and to use more absorption pipettes filled with various solutions.

The accuracy of gas analysis in the apparatus of PolowzowRichter is scarcely less than that of the approved methods of Bunsen and Doyère. With care the determinations of $\mathrm{CO}_{2}$ reach an accuracy of $0.15 \%$, the oxygen determinations down

1 If further decrease in volume took place after the second explosion, $3 / 3$ of the second decrease in volume is still to be added to the above number.

${ }^{2}$ Bunsen, R. loc. cil. Pp. 24,127 and 130. 
to o.I $\%{ }^{1}$ The following points are important for the reliability of analysis: I. Exact calibration of the measuring tube and II. Absolute cleanliness of the measuring tube and of the mercury. ${ }^{2}$ The column of mercury must move freely in the measuring tube and not adhere to the walls of the tube. As soon as it is noticed that the movement of mercury in the measuring tube is not uniform, steps must be taken at once to clean the tube. For this purpose an analysis tube filled with $15 \%$ nitric acid is placed under the mercury on the end of the measuring tube and the liquid drawn into the measuring tube. After repeated to-andfro movement, the acid is forced back into the analysis tube and the measuring tube is rinsed with distilled water several times by means of the procedure just described. Then the measuring tube, the rubber tubing $\mathrm{P}$ and the pear-shaped bulb $\mathrm{H}$ are emptied and dried by blasts of hot air. ${ }^{3}$

In carrying out the analyses, the adjustment of the column of mercury at the line $\mathrm{O}$ in the measuring tube must always be made by a movement in the direction of the arrow (Fig. 6 near O). Readings on the measuring tube are also to be carried out at a constant temperature. The fluctuations in temperature which may possibly take place in the course of each analysis are controlled with the aid of a thermometer dipped in the water in the cylinder B and at once equalized by the addition of warm or cold water. Any appreciable change in barometric pressure can hardly take place with the short duration of the analysis. In regard to the $\mathrm{CO}_{2}$-determination in particular, its accuracy can be increased by placing the gas for a short time in the explosion pipette before its measurement after the absorption of the $\mathrm{CO}_{2}$. The gas is deprived of a part of its water vapor by the $30 \%$ potash and is again moistened ${ }^{4}$ in the explosion pipette, for the latter always contains some water from the previous determinations of oxygen. ${ }^{5}$

\footnotetext{
1 The analysis figures of S. Kostytschew in Ber. d. bot. Ges. 39:319. I92 illustrate the accuracy which may be reached with this apparatus.

2For the purification of mercury see Hempei. Gasanalytische Methoden. 4th ed. P. 79. 1913 lor other standard texts].

${ }_{3}$ The use of alcohol and ether to dry the tube is expressly to be avoided.

4 A gas taken from the plant container is always moist.

s If drops of water visible to the naked eye have gathered in the absorption [= explosion] pipette, they are driven out with mercury.
} 
Some experiences show that it is possible to carry out a series of exact analyses in a short time in the apparatus of PolowzowRichter, since each analysis requires but 20-30 minutes and the apparatus can at once be used again after completing an analysis. ${ }^{1}$ For the physiologist it is of great importance that the apparatus makes possible the analysis of very small amounts of gas. Other merits of the apparatus are: simplicity of construction, inexpensiveness, and the small quantity of mercury required for the analyses.

In the original model of Polowzow, oxygen was determined by absorption with an alkaline solution of pyrogallol. The essential modification introduced by Richter consisted in the determination of oxygen by explosion with hydrogen. The use of the explosion pipette makes possible a more rapid and, at the same time, a more accurate determination of oxygen. Moreover, the modified apparatus is useful for determinations of hydrogen, carbon monoxide and other gases.

The manipulation of the apparatus of Bonnier and Mangin ${ }^{2}$ is simpler. However, it yields less accurate results. In this apparatus the determinations of $\mathrm{CO}_{2}$ are reliable up to $0.3 \%$, the oxygen determinations, to $0.5 \%$. This accuracy is entirely satisfactory in many cases; moreover the apparatus is so constructed that it is conveniently portable and can thus be used on trips and excursions. Fig. 7 represents the small model of the apparatus, which is mounted on a wooden base, and, packed in a specially fitted wooden box, is particularly suitable for carrving about.

The horizontal portion of the measuring tube $\mathrm{R}$ is divided into millimeters. The twice-bent end of the measuring tube is immersed in mercury in the bath $W$. The piston $S$ with handle, moved by means of a screw thread in a metal shell filled with mercury, serves for the introduction and expulsion of gases and reagents.

The analyses of gas are carried out in this apparatus as follows. The analysis tube with gas contained therein is placed

1 After closing a series of analyses the mercury bath $\mathrm{C}$ must be emptied at once and the level of mercury somewhat lowered in the capillary tube of the absorption pipette.

2 Aubert. Rev. gén. de bot. 3:97. I891. [Thoday (Ann. of Bot. 27: 565-573. 1913) gives the detailed procedure, and mentions important precautions to be observed, when using this apparatus.] 
on the end of the measuring tube under mercury, the gas drawn into the measuring tube by unscrewing the piston $\mathrm{S}$, and sealed with mercury by raising the analysis tube. Now the analysis tube is removed from the bath and the length of the gas column in the calibrated part of the tube is measured by the use of a microscope. The condition is somewhat troublesome that the tube, as will be seen from subsequent statements, always remains moist from previous analyses. Drying the tube after each analysis is not only time-consuming but directly disturbing, since the next readings must be carried out in the wet tube and the measurements obtained are thus not comparable with an original length of the gas column as read in the dry tube.

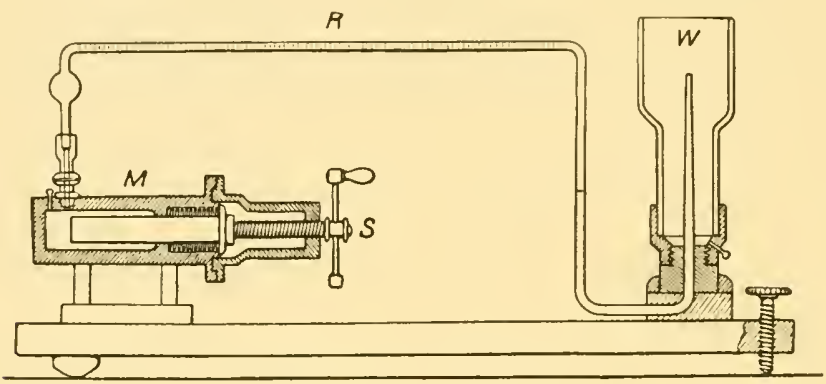

FIG. 7.-The apparatus of Bonnier and Mangin.

After reading the original relative volume of gas, the gas is treated with caustic potash solution. To do this an analysis tube filled with a concentrated solution of caustic potash is set on the end of the measuring tube under mercury and the potash is introduced into the measuring tube by the suitable turning of the piston S. The gas collects in the spherical distension of the tube (above the socket joint). The potash is at once driven back into the analysis tube. The gas column thereby occupies its original position in the measuring tube and $\mathrm{CO}_{2}$ is absorbed by the potash which adheres to the walls of the tube. The length of the gas column is now read. The difference in the two readings shows the relative quantity of carbon dioxide. In exactly the same manner the amount of oxygen is determined by the introduction of an alkaline solution of pyrogallol which absorbs the oxygen. The observed data are expressed in percentages. After each analysis the measuring tube is rinsed with 
dilute nitric acid and then three times with distilled water. If a still smaller degree of accuracy is needed for the purpose of the study, one may desist from the use of the various apparatus for gas analysis and make use of simpler devices. There is, for example, the respiratory apparatus of Godlewski ${ }^{1}$ which is constructed as follows: a thick-walled, calibrated flask provided with a manometer tube serves as a container. A small vessel containing a measured amount of concentrated caustic potash is suspended within the flask, which is tightly sealed. As soon as the plants begin to take up oxygen and to give off $\mathrm{CO}_{2}$, the latter is absorbed by the potash. Consequently the air pressure in the apparatus is diminished and the mercury begins to rise in the manometer tube. The lowering of the pressure at the same time yields, by simple calculation, the volume of oxygen absorbed. The carbon dioxide which is given off is determined at the close of the experiment. The solution of potash is diluted with a large volume of water and the $\mathrm{CO}_{2}$ determined in the form of $\mathrm{BaCO}_{3}$. For the various corrections which are essential with this method the original communication of Godlewski must be consulted.

In the simultaneous determination of the absorbed oxygen and the carbon dioxide given off, of course there must be used containers into which plants can be sealed air-tight and which provide for the removal of test portions for analysis. Kostychev used to advantage conical flasks which are also useful for cultures of lower organisms on liquid or solid media (Fig. 8). The capacity of each flask is $200-500 \mathrm{cc}$. and each is closed by a two-hole rubber stopper fitted with an entrance and an exit tube. ${ }^{2}$ The distension $\mathrm{C}$ in the neck of the flask above the stopper is filled with mercury and a completely air-tight seal is thereby obtained. The outer, vertical side of the exit tube $b$ is calibrated and serves as a manometer. The flask containing the plant material is closed as above, the manometer tube inserted in mercury and the entrance tube $a$ connected by means of a thick-walled rubber tube with the gas pipette (see below)

1 Godlewski, E. Jarhb. f. wiss. Bot, 13: 49 I. 1882.

2 For cultures of lower organisms it is practical to place close to the bottom of the flask a side tube closed by rubber tubing and a pinchcock. A change of nutrient solution can easily be effected through it, as is often necessary. 
designed to remove test portions of gas. A pinchcock is fitted to the rubber tubing. To withdraw a suitable amount of gas the level of mercury in the manometer tube is adjusted at any level and the outer, vertical side of the entrance tube is then filled with mercury. If the pinchcock is now closed the internal atmosphere of the flask is left entirely separated from the external air by glass and mercury, as is shown in Fig. 8. The stopper is also faultlessly air-tight. The gas pipette of Kostychev (Fig. 9) serves to draw the test portions of gas from the container. By the aid of the three-way stopcock $r$, the bulb $l$ can be connected with either the tube $g$ or the tube $h$. The single

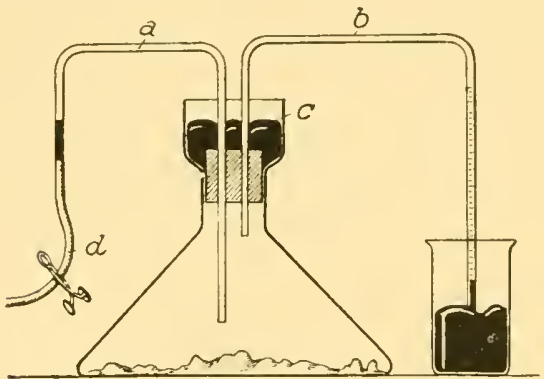

Fig. 8.-Kostychev's flask.

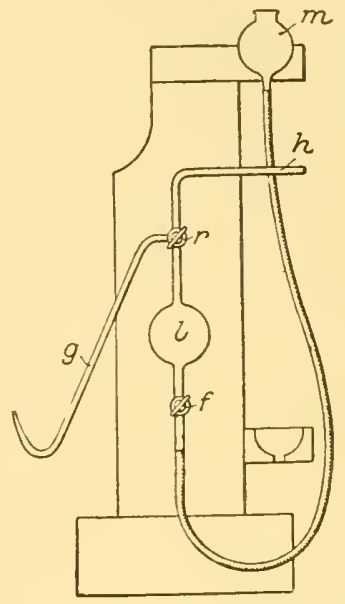

FIG. 9.-Kostycher's gas pipette.

stopcock $f$ connects the bulb $l$ with the pear-shaped bulb $m$. The pipette is screwed to a stable wooden frame.

With the aid of the pear-shaped bulb $m$, the bulb $l$ and both tubes $g$ and $h$ are filled with mercury. For this purpose the pear-shaped bulb is elevated, the bulb $l$ connected with the tube $g$ and the stopcock $f$ opened. As soon as the bulb and the whole tube are filled to the further aperture with mercury and a drop of mercury projects out, the stopcock $r$ is so turned as to connect the tube $h$ with the bulb and to fill this tube with mercury, after which the single stopcock $f$ is closed. The curved end of the tube $g$ is then dipped in a thick-walled vessel of mercury and the tube $h$ is connected with the rubber tubing $d$ of the Kostycher flask just fitted out for the experiment. A certain amount of mercury is drawn through it by lowering the pear-shaped 
bulb $m$ and opening the glass stopcock $f$. As a result the mercury in the manometer tube $b$ of the flask rises to a certain level. The stopcock $f$ is now closed, the bulb $l$ is connected with the tube $g$ by a suitable turn of the three-way stopcock $r$, the pearshaped bulb $m$ is elevated, the stopcock $f$ is opened, and the last trace of gas is driven out of the bulb and the tube. After closing the stopcock $f$, the bulb $l$ is again connected with the tube $h$ and this tube and the attached vertical arm $a$ of the flask tube are filled with mercury. The necessary manipulations are intelligible from the explanation above: the pear-shaped bulb $m$ is raised and the stopcock $f$ is opened. The experimental flask is now perfectly sealed as shown in the figure. The barometer reading and the level of mercury in the manometer tube are noted and the experiment begins therewith. This sealing of the flask is really very simple. After a little practice it is easily and safely performed in less time than when it is necessary to follow the above explanation.

The experiment proper consists in withdrawing, from time to time, test portions of gas from the experimental flask as described above, and in passing them through the tube $g$ into the analysis tubes completely filled with mercury. This procedure is entirely analogous to the original closing of the flask except that in the latter case the gas sample is not kept for analysis.

The gas analysis yields the percentage content but not the absolute amounts of the single components of the gas mixture which is being studied. These are needed, however, for the determination of the magnitude of $\frac{\mathrm{CO}_{2}}{\mathrm{O}_{2}}$. The calculation of $\mathrm{CO}_{2}$ is based on the fact that in respiration there is neither an absorption nor a liberation of nitrogen. We assume that $a$ is the percentage of $\mathrm{CO}_{2}, b$ is the percentage of oxygen, and $c$ is that of nitrogen and other inert gases in the gas mixture just analyzed. Let it be further known that at the beginning of the experiment the air inclosed in the container had a normal composition $\left(\mathrm{O}_{2}=20.9 \% ; \mathrm{N}_{2}=79 . \mathrm{I} \%\right)$. If $c$ is not exactly 79. I the total volume of the gas mixture (reduced to normal 
pressure) has changed. If $c$ is less than 79. I there has been an increase in the total volume. If $c$ is greater than 79. I the total volume at the end of the experiment is less than at the start. The increase in total volume signifies that there has taken place a production of $\mathrm{CO}_{2}$ without the corresponding absorption of oxygen. In the opposite case one is justified in supposing that there has been an excess absorption of oxygen. In both cases the value obtained for the oxygen absorbed requires a correction in order that it be directly comparable with the percentage of $\mathrm{CO}_{2}$ found. The original content of oxygen corresponding to the nitrogen content $c$ would be equal to $20.9 \cdot \frac{c}{79 . \text { I }}$. Accordingly the amount of oxygen absorbed is equal to $\frac{20.9 \cdot c}{79 \cdot I}-b$ and $\frac{\mathrm{CO}_{2}}{\mathrm{O}_{2}}=\frac{a}{\frac{20.9}{79 . \mathrm{I}} c-b}$, or if we represent $\frac{20.9}{79 . \mathrm{I}}$ by $q$, the following equation results :

$$
\frac{\mathrm{CO}_{2}}{\mathrm{O}_{2}}=\frac{a}{c q-b} .
$$

The oxygen content of the surrounding air, which varies between $20.80 \%$ and $20.96 \%$. is determined by a series of analyses and value of $q$ is calculated accordingly.

In some experiments one may not be content with the determination of $\frac{\mathrm{CO}_{2}}{\mathrm{O}_{2}}$, but must also know the absolute amounts of the oxygen absorbed and the $\mathrm{CO}_{2}$ liberated. For this purpose it is necessary to determine the total volume of the gas mixture in the container as well as the percentages of the single constituents. Since a direct calibration of the research vessel together with the experimental material contained therein is in most cases not feasible, the volume of the inclosed space is determined as follows. Before the experiment is started a gas sample $v$. measured at atmospheric pressure $\mathrm{H}$ in a calibrated eudiometer, is drawn from the flask. 'The lowering of the pressure in the flask which results from the removal of the test portion of gas is then noted with the aid of the manometer tube. Let $h$ be the gas pressure in the flask before, and $h^{\prime}$ the pressure after 
the removal of the portion $x$. The desired total volume $x$ of gas in the flask is calculated from these data on the basis of the law of Boyle-Mariotte:

$$
\mathrm{x}=\frac{\mathrm{vH}}{\mathrm{h}-\mathrm{h}^{\prime}}
$$

Then

$$
\mathrm{xh}=\mathrm{xh}+\mathrm{vH} \text {. }
$$

If the volumes of the oxygen absorbed and the carbon dioxide liberated are known, the amounts by weight of both gases are obtained by simple calculation.

If very large amounts of plants are being used for investigation. or if it is impossible to introduce the research material into the neck of the flask without damaging it, the flask is replaced by a bell jar, the upper opening of which is closed with a two-hole rubber stopper. Into the holes of the stopper are introduced the same tubes as were referred to in the preceding description of the Kostycher flasks. The lower rim of the bell jar must be fitted to a ground glass plate by means of vacuum grease. For accurate experiments the bell jar together with the glass plate is placed in a crystallising dish of mercury in order to obtain an entirely faultless seal. The rubber stopper at the upper opening of the bell jar is also immersed in mercury. In this way the manipulation of the bell jar is entirely analogous to that of the flask. The research material is placed in a dish on the glass plate and then covered with the bell jar.

Ordinary eudiometer tubes may be used to advantage for very small amounts of research material. The material is introduced into the upper part of the eudiometer and held in position with glass wool. The lower end of the eudiometer is then immersed in mercury and the operation proceeds according to the general principles of gas analysis methods. ${ }^{w}$

w The reader must realize that many of the most important methods for the study of respiration have not been mentioned by Kostycher. The present tendency appears to be toward the use of physical rather than chemical methods of following the changes in concentrations of the oxygen, carbon dioxide or both. The following are representative and most easily adapted to a variety of material and the various types of problems which arise.

B. D. Bolas has recently presented the details and results of a comparative study of three "methods for the study of assimilation and respiration in closed systems" (New Phyt, 25: I27-144. 1926). The Haldane gasometric method 
(which is very accurate) and the electrical conductivity method were found to be less satisfactory than a form of the indicator method which uses colored glass slips for standards and bromcresol purple for the indicator.

One of the most satisfactory and adaptable forms of the indicator methods is that originally described by Osterhout (J. Gen. Physiol. I : I7-22. I9I8-19) for measurement of the rate of $\mathrm{CO}_{2}$-production (or consumption) and used in different forms by his students and associates. The diagram shown in Fig. Io is that of a useful form of this system, showing in some detail the practical modifications (but not the correct proportions by rolume) of the several elements of the system. The total volume should be no larger than is necessary for convenience in manipulation of the parts and for adjustment of the amount of living material (or chemical mixtures) required to effect a rapid change in the color of the indicator.

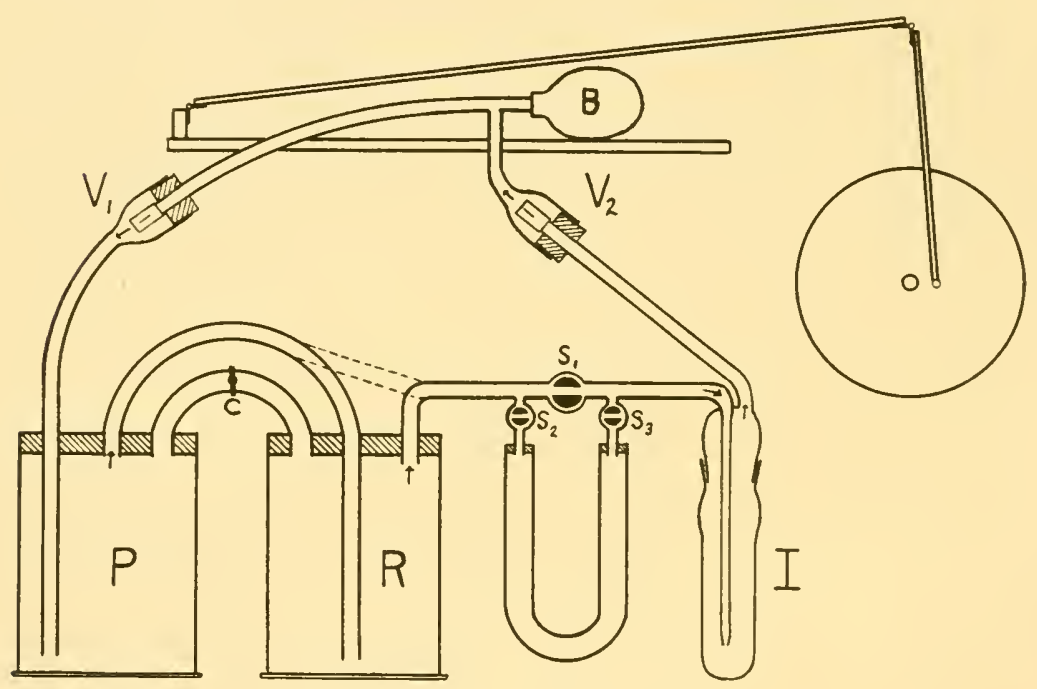

FIG. I0.-The Osterhout apparatus.

The diagram shows two chambers, $\mathrm{P}$ and $\mathrm{R}$, one of which may be eliminated as indicated by the dotted lines. The second one, R, may be used to guard against a possible buffer effect of a reagent which may be emptied into the plant chamber by way of the flexible tube $\mathrm{C}$ without stopping the current of air. This current is caused to flow as indicated by the arrows by the regular compression and expansion of the rubber bulb $B$, and by the action of the two Bunsen valves, $V_{1}$ and $V_{2}$. The $\mathrm{CO}_{2}$ is thereby passed from the chamber $\mathrm{P}$ to the indicator tube $I$ unless the stopcock $S_{1}$ is closed and $S_{2}$ and $S_{3}$ are open, in which case the $\mathrm{CO}_{2}$ is removed by passing over solid $\mathrm{NaOH}$ in the U-tube. Under the latter conditions $\mathrm{CO}_{2}$ is removed from the indicator solution (preferably phenol red).

The relative rate of $\mathrm{CO}_{2}$ release in (or withdrawal from) the system is the reciprocal of the time required for the color of indicator solution to change from an exact match with the color of one standard to that of another. The indicator 
tube shown in the diagram has a ground glass joint and is the most satisfactory type designed for the purpose. The system may be used only when all joints are so closed that the color of the indicator remains constant at some point in its working range for a period of an hour or more.

For further details of the use and modification of this apparatus see various papers in the Jour. General Physiology, I9I8 to date, particularly those by Parker $(4: 689$. 1921-22; 7: 641. 1924-25; and others) who calibrated his system and brought out the extreme delicacy of this method. Measurements of rates may be made a few minutes apart and a continuous record kept for hours.

A few workers have successfully modified the Katharometer ( $c f$. Daynes, H. A. Proc. Roy. Soc. London. A. 97:273-286. 1920) for use in plant and animal respiration. The fluctuations in the readings of a galvanometer record the changes in thermal conductivity of a gas mixture, which conductivity is lowered by an increase in $\mathrm{CO}_{2}$ content. A good account of such a method and its results is given by Waller, J. C. (New Phyt. 25: 109-118. I926) while Noyons (Arch. Néerland d. Physiol d. l'Homme et d. Anim. 7: 488-495. I922) and Weaver E. R. and others (Jour. Indus, and Eng. Chem. 12:359-366. 1920) also explain the modifications necessary to the use of the method for detecting minute changes in concentration of carbon dioxide.

Two other important methods which can only be mentioned here are those of O. Warburg (Biochem. Z. 152: $5 \mathrm{I}-63$. I 924) and Barcroft (Jour. of Physiol. $37: \mathrm{r} 2$. I908). The general technique of using the latter in its various modifications has already been mentioned briefly (p. 34). The details are well stated by Straub in Abderhalden's Handbuch der biologischen Arbeitsmethoden. Abt. IV, Teil 1o, Heft I where other methods for biological gas analysis are also described in detail. Both of these types of apparatus have been utilized in the production of valuable work in respiration. Only small quantities of material are needed but both methods are somewhat restricted as to the type of problem for which they are best suited, that of Barcroft having been developed for studies of blood, as was Van Slyke's rolumetric method (Jour. Biol. Chem. 61: $5^{23}$. I924). $-E d$. 


\section{ANAEROBIC RESPIRATION}

\section{THE GENERAL CONCEPTION OF ANAEROBIC RESPIRATION}

Since we consider oxygen respiration of plants as a slow combustion of sugars and other organic substances, the question arises, how can such combustion of sugar take place in living cells at low temperatures? We know that sugar solutions themselves show no alteration after standing a year at room temperature under sterile conditions, and sugar especially is not at all oxidised with complete access to air. The sugar content of the solution remains constant by the year. Various facts described below, among which the process of so-called anaerobic respiration really occupies first place, furnish the key to the solution of this most highly interesting and important puzzle. This noteworthy rital phenomenon must now be described exhaustively.

In the course of his epoch-making studies of fermentation, L. Pasteur made the notable observation that various plants and parts of plants liberate $\mathrm{CO}_{2}$ even in an oxygen free atmosphere. At the same time ethyl alcohol is formed in the tissues. The formation of alcohol by seed-plants was established beyond question by Pasteur ${ }^{1}$ himself as well as by his students, Lechartier and Bellamy." This discovery was not accidental. It is rather a consequence of Pasteur's theory of fermentation, which Pasteur first expressed in relation to yeast and supported by ingenious experiments. This theory says: "Fermentation is life without oxygen." According to Pasteur's view, the energy requirement of yeast plants is satisfied by ordinary oxygen respiration with complete access to oxygen. When oxygen is excluded alcoholic fermentation commences as the substitute source of energy. Continued life and even increase

\footnotetext{
1 Pasteur, L. Compt. rend. 75:784. 1872; Êtudes sur la bière. 1876.

${ }^{2}$ Lechartier et Bellamy. Compt. rend. 69:356, 466. 1869; 75: 1203. 1872; 79: 1006. 1874 .
} 
in the number of yeast cells is thereby made possible with a deficiency of oxygen. Now Pasteur assumed that analogous phenomena also proceed in other plants with a deficiency of oxygen, although less markedly. The experimental proof of this assumption showed in fact that the primary products of alcoholic fermentation, ${ }^{x}$ i.e. ethyl alcohol and carbon dioxide. are also formed in seed-plants under anaerobic conditions.

It is easy to understand why the systematic investigations of Pasteur and his students were the first to receive attention, although the liberation of $\mathrm{CO}_{2}$ in the absence of oxygen had already been established for various plant organs by numerous investigators, as e.g. by Rollo, ${ }^{1}$ de Saussure, ${ }^{2}$ Dumont. ${ }^{3}$ Bérard, ${ }^{4}$ and Döbereiner. ${ }^{5}$ However, it was left uncertain whether the formation of $\mathrm{CO}_{2}$ should be regarded at all as a vital phenomenon. Especially since Pasteur was the first to speak of an alcoholic fermentation of seed-plants and thus labelled the anaerobic formation of $\mathrm{CO}_{2}$ as a strictly vital process, he is really to be called the founder of the doctrine of the anaerobic respiration of plants. Pasteur also studied various molds with a deficiency of oxygen and established the important fact that there are various transition stages between yeast and strictly aerobic fungi (e.g. Penicillium glaucum). Thus mucors in part represent strictly aerobic molds but in part are organisms of fermentation. According to Pasteur's statements, even strictly aerobic molds form small quantities of $\mathrm{CO}_{2}$ and alcohol in the absence of oxygen.

The investigations of Pasteur were not known to $\mathrm{Böhm}{ }^{6}$ when he rediscovered anaerobic production of $\mathrm{CO}_{2}$ by green parts of plants, but he drew no theoretical conclusions therefrom. The iormation of alcohol also escaped his notice. The later

Rollo. Ann. de chim. 25: 42. I 798.

2 de Saussure. Rech. chim. sur la vêgétation. I 804.

${ }^{3}$ Dumont. Neues Jour. f. Pharmaz. 3: 568 . I819.

4 Bérard. Ann. de chim. et de physique. Vol. I6. I821.

${ }^{3}$ Döbereiner. Ann. d. Physik. 72:430. I822.

${ }^{6}$ Böhm. Sitzungsber. d. Akad. d. Wiss. Wien (I) 67:210. 1873 .

$x$ For a concise statement of the nature of alcoholic fermentation see Palladin's Plant Physiology. 3rd. Eng. ed., pp. 204-2I I. where references to the original papers are also given. For recent theory see Warden, C. C. Imer. Jour. Phýsiol. 57:454-469. 192I. F. F. Nord (Chem. Rev. 3:4I-79. I926) has recently summarized our knowledge of the chemical processes in all fermentations.-Ed. 
investigations of Muntz, ${ }^{1}$ Brefeld, ${ }^{2}$ and de Luca ${ }^{3}$ brought to light the wide distribution of "anaerobic respiration" in the plant kingdom. Muntz carried out his studies with higher plants and established the regular formation of $\mathrm{CO}_{2}$ and alcohol. The extensive researches of Brefeld showed that various molds as well as seeds, fleshy fruits, foliage leaves, flowers, and the wood of various seed-plants produce alcohol when oxygen is excluded. De Luca came to the same conclusions with the foliage leaves and fruits of various plants. More recently Matruchot and Molliard ${ }^{4}$ have repeated these older investigations with the aid of modern methods under aseptic conditions and have confirmed them in general. Muntz $z^{5}$ had already left entire potted plants in an atmosphere of pure nitrogen in order to meet the objection that severed parts of plants quickly die in the absence of oxyger and cause a production of alcohol as a pathological phenomenon. In these experiments also a production of alcohol regularly occurred but the plants remained healthy and Muntz demonstrated a further, unhindered development of them after the restoration of normal aeration. These refined experiments were much too little considered by later investigators. They prove unequivocally that the formation of alcohol is not a phenomenon which is merely incidental to the death of the plants, as many writers claimed even after the publication of this work of Muntz.

As for the intensity of anaerobic respiration, it is generally less, often considerably less, than that of oxygen respiration. The first careful studies of the magnitude of $\mathrm{I} / \mathrm{N}$, i.e. the ratio of the intensity of the so-called intramolecular (anaerobic ${ }^{6}$ ) respiration to that of the normal were made by Wilson. ${ }^{7}$ The results of these determinations are summarized in the following table.

1 Muntz. Ann. de chim. et de physique (V) 8:56. 1876.

2 Brefeld. Landwirtschaftl. Jahrb. 5: 281 , 1876.

${ }^{3}$ de Luca. Ann. sci. nat. bot. (VI) 6:286. 1876 .

- Matruchot et Molliard. Rev. gén. de bot. 15: 193. 1903.

5 Muntz. Ann, de. chim, et de physique. (V). 13:543. I878.

"The term "anaerobic respiration" was first introduced by S. Kostychev in I902. Cf. Kostytschew, S. Ber. d. bot. Ges. 20:327. 1902; also Jahrb. f. wiss. Bot. 40: 563. 1904.

7 Wilson. Flora. 65: 93. I882; $f f$. also Pfeffer. Untersuch. aus d. bot. Inst. Tübingen I : I05. $188 \mathrm{I}-1885$. 
Plant Material

Germinating seeds of Vicia Faba....................... 0.99

Germinating seeds of Vicia Faba...................... 1.09

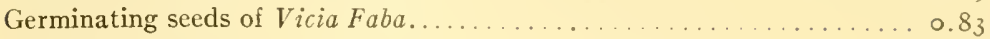

Germinating seeds of Vicia Faba......................... I.20

Seedlings of Triiicum vulgare ........................... . . 49

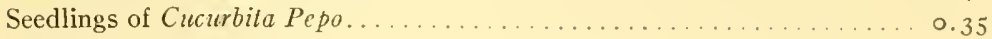

Seedlings of Sinapis alba .......................... I 8

Seedlings of Sinapis alba.......................... o.18

Seedlings of Brassica Napus........................... . . . . 25

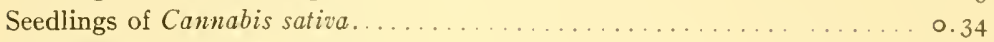

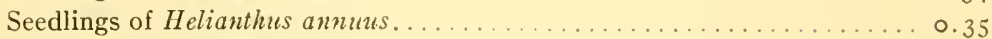

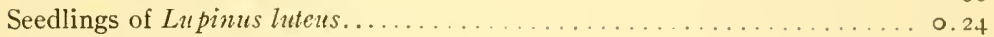

Unripe fruits of Heracleum giganteum.................... 0.42

Leafy twigs of Abies excelsa.............................. 0.08

Stem of Orobanche ramosa ..... . . . . . . . . . . . . . . . . . . . . 0.32

Spike of Arum maculatum............................ 0.62

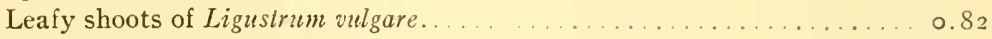

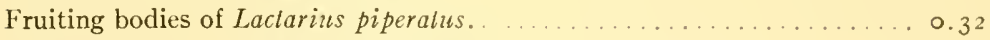

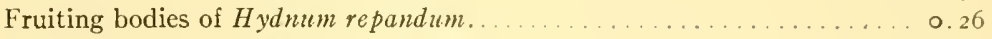

Fruiting bodies of Cantharellus cibarius................... 67

Yeast on a solution of lactose.....................

From the above table it is evident that the value of $\mathrm{I} / \mathrm{N}$ does not remain constant for different plants.

Moeller ${ }^{1}$ also carried out determinations of $\mathrm{I} / \mathrm{N}$ with various seedlings and obtained equally fluctuating results. Whether any theoretical meaning can be attributed to determinations of $\mathrm{I} / \mathrm{N}$ is questionable, since the rate of anaerobic respiration generally decreases from hour to hour. This is particularly true of such plants as are found to have a small value of $I / \mathrm{N}$. On account of a lack of working energy and because of the poisoning by toxic products of the anaerobic metabolism, the plant becomes paralyzed and gradually dies. Under such conditions the value of $I / N$ depends in the first place upon how long the plant remained under anaerobic conditions. For this reason divergent results are often obtained with the same research material. More recently Boysen-Jensen² has again carried out determinations of $I^{\prime} N$. His results are given in the following table.

\footnotetext{
1 Moeller. Ber. d. bot. Ges. 2: 306. I884.

${ }^{2}$ Boysen-Jensen, P. Det kgl. danske videnskabernes selskab. biol. meddelelser. 4: I. 192.3 .
} 
Plant Material

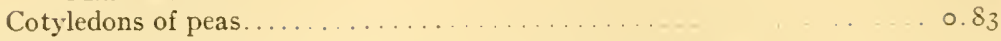

Cotyledons of peas............................. . . . 79

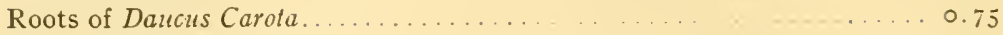

Roots of Dancus Carota.......................... . . . . I. IO

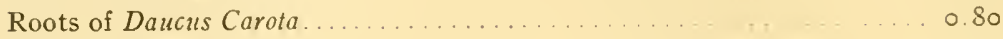

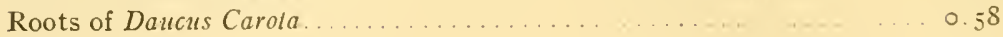

Green grapes........................... . . . . I.3

Green grapes . . . . . . . . . . . . . . . . .

Blue grapes. . . . . . . . . . . . . . . . . . . . . . 2

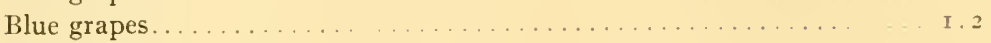

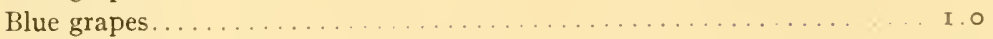

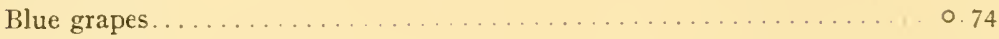

Potato tubers. . . . . . . . . . . . . . . . . 73

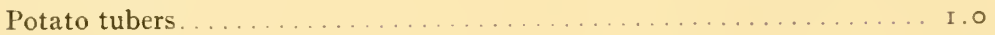

Potato tubers. . . . . . . . . . . . . . . 44

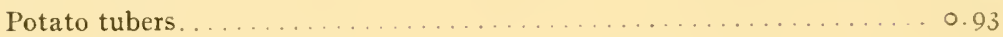

Potato tubers......................... I

Leaves of Tropacolum majus......................... 0.55

Leaves of Tropacolum majus. . . . . . . . . . . . . . . . . . . . . . . . 56

Leaves of Tropaeolum majus........................... o. 56

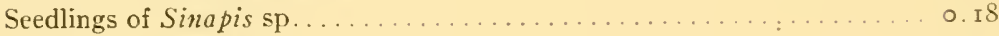

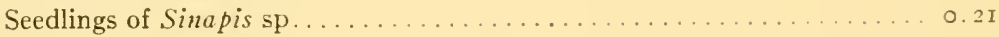

It is clear that such a weak alcoholic fermentation as takes place in the above quoted plants with oxygen excluded does not even approximately suffice for the normal living processes of the plants. Theoretical calculations as well as direct calorimetric determinations show that the best production of heat in the fermentation of $\mathrm{I}$ mol of grape sugar is equal to $24^{-2} \mathrm{~S}$ Calories, while the combustion of I mol of grape sugar in respiratory processes yields $6{ }_{74}$ Calories. Consequently about 25 mols of sugar must be fermented in order to produce the amount of energy which is formed by the combustion of I mol of sugar in respiration. In fact such an increased consumption of sugar takes place in the alcoholic fermentation by yeast plants but not in the anaerobic respiration of seed-plants where the production of energy is often 50 to roo times less than under normal living conditions. On account of the lack of working energy the plants finally go to ruin if the temporary anaerobic condition continues too long. Even after a short period of deprivation of oxygen a poisoning of the research material is sometimes noted. After the restoration of normal aeration the plants gradually recover, since the substances produced in the absence of oxygen are consumed in the processes of oxidation. 
Direct calorimetric measurements carried out by Eriksson ${ }^{1}$ showed that the production of heat by anaerobic respiration is utterly trifling and, in complete agreement with theoretical calculation, amounts to but a small fraction of that of normal respiration.

Yet it is worthy of note that the influence of various circumstances on the normal and the anaerobic respiration is identical. Thus $\mathrm{Amm}^{2}$ made the interesting observation that in the yellow lupine the value of $I / N$ remains constant at various stages of germination, if the anaerobiosis does not continue too long. Since the intensity of the normal respiration in the course of the period of germination is expressed (see page 6) by the so-called grand curve of respiration, it may be concluded that with increased vital activity not only normal respiration becomes more energetic but also the anaerobic respiration in corresponding measure. ${ }^{y}$ This is a new proof of the fact that the anaerobic respiration represents not a pathological phenomenon but a process connected with the normal respiratory metabolism. We could easily draw the same conclusion from the experimental results of Chudiakow ${ }^{3}$ and Palladin. ${ }^{4}$ Chudiakow has shown that the value of $\mathrm{I} / \mathrm{N}$ remains constant at various temperatures, since the rate of anaerobic respiration is influenced by changes in temperature in the same degree as that of normal respiration. ${ }^{z}$ Also, no optimum temperature can be stated for the anaerobic any more than for normal respiration, according to Chudiakow's results. Still more interesting is the following fact which appears through the recalculation of Chudiakow's figures:-5 as long as the rate of anaerobic respira-

1 Friksson. Untersuch. aus d, bot. Inst. Tübingen I: 636 . I 88 I-I 885 .

2 Amm. Jahrb. f. wiss. Bot. 25: I. I 893.

3 Chudiakow, N. Landwirtschaftl. Jahrb. 23:333. I894.

4 Palladin, W. Rev. gén. de bot. 6: 201. I 894.

${ }_{5}^{5}$ For this point $c f$. S. Kostytschew. Untersuch. uber die anaerobe Atmung der Pflanzen. 1907. P. 23. Russian.

${ }^{y}$ Two other items of proof for this point are contained in recent papers. Lyon (J. Gen. Physiol. 6: 299-306. 1923-24) found the two phases of respiration of wheat seedlings to be equally accelerated by phosphate while Miss A. Karlsen (Am. Jour. Bot. I2: 619-624. I925) obtained similar results for the action of anesthetics on wheat seedlings. $-E d$.

z Compare, however, the recent studies by Crozier on the influence of temperature, as mentioned in editorial note $j$ above. $-E d$. 
tion remains constant (hence the plant material is not poisoned), on the whole, various seedlings liberate equal amounts of $\mathrm{CO}_{2}$ at various temperatures. Since the rate of anaerobic respiration is increased by raising the temperature, it is clear that the paralysis of vital activity commences more quickly with high temperatures than with low. This is illustrated by the following data:

\begin{tabular}{|c|c|}
\hline $\begin{array}{l}\text { Exp. } \\
\text { No. }\end{array}$ & SEEDLINGS OF \\
\hline la & Vicia Faba.... \\
\hline $\mathrm{lb}$ & Vicia Faba. \\
\hline $2 a$ & Pisum sativum. \\
\hline $2 \mathrm{~b}$ & Pisum sativum. \\
\hline $2 \mathrm{C}$ & Pisum sativum. \\
\hline $3 a$ & Pisum sativum. \\
\hline h & Pisum sativum. \\
\hline
\end{tabular}

\begin{tabular}{|c|c|c|}
\hline T. & $\begin{array}{l}\text { SUDDEY FALL } \\
\text { IN CO C-FOR- } \\
\text { MATION (WITH } \\
\text { OXYGEN EX- } \\
\text { CLUDED)AFTER }\end{array}$ & $\begin{array}{c}\text { TOTAL } \\
\text { CO } \\
\text { FORMED }\end{array}$ \\
\hline $20^{\circ}$ & 9 hours & $218 \mathrm{cc}^{\mathrm{I}}$ \\
\hline $35^{\circ}$ & 6 hours & $223 \mathrm{cc}^{\mathrm{I}}$ \\
\hline & 9 hours & I $54 \mathrm{ccc}^{2}$ \\
\hline $30^{\circ}$ & 6 hours & I59 cc. ${ }^{2}$ \\
\hline $40^{\circ}$ & 5 hours & I $59 \mathrm{cc} .{ }^{2}$ \\
\hline 20 & 7 hours & $35^{8} \mathrm{cc}^{1}$ \\
\hline $35^{\circ}$ & 4 hours & $366 \mathrm{cc}^{1}$ \\
\hline
\end{tabular}

It must be taken into consideration that an increase of temperature stimulates various material transformations in the living cell. These more intensive vital operations require a greater expenditure of energy. Since anaerobic respiration is unable to produce a corresponding amount of energy, the cell can prolong its life a longer time at a lower temperature than at a higher one, for in the latter case the poisoning asserts itself more rapidly through products of the imperfect metabolism.

Palladin ${ }^{3}$ has shown that etiolated bean leaves increase the formation of $\mathrm{CO}_{2}$ after an application of sugar not only in the presence but also in the absence of oxygen, and indeed in exactly the same ratio. Consequently the value of $I / N$ is not altered by the application of sugar. This result cannot be regarded as a chance agreement of the experimental data. No less noteworthy are the results of Morkowin ${ }^{4}$ who found that even such a temporary stimulation of respiration as is brought about by toxic action does not alter the ratio $\mathrm{I} / \mathrm{N}$. The normal respiration is thus increased by chemical stimulation effects in exactly the same relative degree as the anaerobic respiration.

1 Chudiakow, N. loc. cil. p. 381 .

2 Idem. loc. cit. p. 384.

Palladin, W. Rev. gén. de bot. 6: 201. I 894.

- Morkowin, N. Ber. d. bot. Ges. 21: 72.1903. 
Not all piants change from normal to anaerobic respiration with the same facility. Observations on fungi are especially instructive in this respect. Very active yeasts and Mucoraceae develop a normal alcoholic fermentation even if the aeration is appreciably checked (immersion in a thin film of nutrient solution) and the oxidation processes in their cells are thereby depressed. ${ }^{1}$ Such a small inducement thus suffices to replace normal respiration by anaerobic cleavage processes in these organisms. The so-called strongly aerobic molds behave quite differently. On the basis of the writer's experience, ${ }^{2}$ Aspergillus niger does not produce a trace of alcohol even if the fungus mat is entirely submerged in nutrient solution containing sugar, but if the atmosphere above the solution is left with its oxygen. The quantity of oxygen dissolved in the water alone suffices to exclude completely the anaerobic processes. Only with the exclusion of oxygen (not with a deficiency of oxygen) is alcoholic fermentation set going by strongly aerobic molds. The investigations of Wilson, ${ }^{3}$ Stich,${ }^{4}$ and Johannsen ${ }^{5}$ show that seed-plants are sensitive to a checking of aeration but not to an equal degree. According to Stich, a considerable increase in the value of the respiratory quotient generally results with an oxygen content of $\mathrm{I}^{-4} \%$. This excess production of $\mathrm{CO}_{2}$ is to be traced to the participation of anaerobic processes in the metabolism.

\section{THE PRODUCTS OF ANAEROBIC RESPIRATION}

Pasteur's first studies of the anaerobic respiration of plants suggest that $\mathrm{CO}_{2}$ and alcohol are formed in this process just as in fermentation by yeast. However, the question of an identity of anaerobic respiration with alcoholic fermentation could not be raised before the ratio $\mathrm{CO}_{2}$ : alcohol was obtained through quantitative measurements with various plants. In alcoholic fermentation, equi-molecular amounts of $\mathrm{CO}_{2}$ and alcohol

\footnotetext{
${ }^{1}$ Kostytschew, S. Zentralbl. f. Bakt., Parasitenk. u. Infektions-krankh. (II) 13: 490. 1904; Kostytschew, S. und P. Ełiasberg. Z. f. physiol. Chem. III: I4I. 1920. [Cf. also Meyerhof citation in note 2, page 9.]

2 Kostytschew, S. und M. Afanassjewa. Jahrb. f. wiss. Bot. 60:628. I92I.

${ }^{3}$ Wilson. Untersuch. aus d. bot. Inst. Tubingen. I: $685 . \quad 188 \mathrm{r}-1885$.

4 Stich, C. Flora. 74: I. I 89 I.

${ }^{5}$ Johannsen, W. Untersuch. aus d. bot. Inst. Tübingen. I: 716 . I88I-I $88_{5}$.
} 
are formed according to the equation $\mathrm{C}_{6} \mathrm{H}_{12} \mathrm{O}_{6}={ }_{2} \mathrm{CO}_{2}+$ ${ }_{2} \mathrm{C}_{2} \mathrm{H}_{5} \mathrm{OH}$ or, according to Pasteur's accurate analyses, roo parts by weight of $\mathrm{CO}_{2}$ to 100-I05 parts by weight of ethyl alcohol. This ratio was first obtained for the anaerobic respiration of seed-plants by Godlewski and Polzeniusz. ${ }^{1}$ These investigators found that in the case of germinating pea seeds which develop an energetic anaerobic respiration, the ratio $\mathrm{CO}_{2}$ :$\mathrm{C}_{2} \mathrm{H}_{5} \mathrm{OH}$ corresponds fairly exactly to the theoretical value for alcoholic fermentation. Godlewski and Polzeniusz identified the anaerobic respiration of seed-plants with alcoholic fermentation on the basis of these results.

Numerous later analyses by Kostychev and his collaborators have shown, however, that the value of $\mathrm{CO}_{2}: \mathrm{C}_{2} \mathrm{H}_{5} \mathrm{OH}$ often does not agree with the equation of alcoholic fermentation. In some cases the deviation from the theoretical value is so considerable that there can be no question of a similarity of the anaerobic respiration with alcoholic fermentation. The following table will illustrate the point:

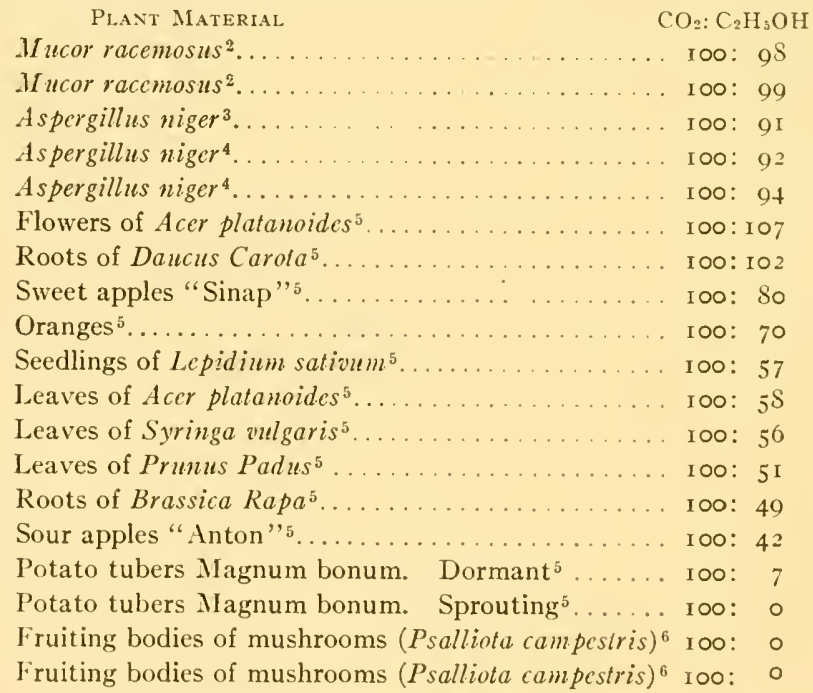

\footnotetext{
${ }^{1}$ Godlewski, E. und Poizeniusz. Anz. d. Akad. d. Wiss. Cracau. 1897, p. 267; 1901, p. 227.

${ }^{2}$ Kostytschew, S. und P. Eliasberg. Z. f. physiol. Chem. III: IfI. I920.

${ }^{3}$ Kostytschew, S. Ber. d. bot. Ges. 25: 44.1907.

4 Kostytschew, S. und M. Afanassjewa. Jahrb. f. wiss. Bot. 60:628. 1921 .

${ }^{3}$ Kostytschew, S. Ber. d. bot. Ges. 31 : 125. I9I3.

${ }^{6}$ Kostytschew, S. Ibid. 25: 188. 1907.
} 
From this table it is evident that for molds the ratio $\mathrm{CO}_{2}: \mathrm{C}_{2} \mathrm{H}_{3} \mathrm{OH}$ corresponds approximately to the equation of alcoholic fermentation. With seed-plants on the other hand, the theoretically correct ratio of alcoholic fermentation is an exception and an excess of carbon dioxide is always produced. An abundant formation of $\mathrm{CO}_{2}$ occurs in some cases without the slightest production of alcohol. Potato tubers and the fruiting bodies of Psalliota campestris behave thus. In the above experiments of Kostychev the fruiting bodies of Psalliota gave off I 563.5 or I $_{3} 64.4 \mathrm{mg}$. of $\mathrm{CO}_{2}$ but formed no trace of ethyl alcohol. These extreme cases admit of two explanations. Either a different type of anaerobic respiration is here exhibited, which has nothing to do with alcoholic fermentation and exists without the participation of enzymes of fermentation, or the alcohol or its forerunner (acetaldehyde! etc.) which perhaps is formed, is consumed immediately after its formation and there is no accumulation of alcohol. This point will be treated in detail in the next section. Here it suffices to refer to the fact that peptone cultures of Aspergillus niger, which likewise exhibit no production of alcohol in the absence of oxygen, are found to contain no zymase, according to the results of Kostycher and M. Afanassjewa. ${ }^{1}$ They are unable to ferment any added sugar. However, after some time such cultures also produce enzymes of fermentation if they are left on sugar solutions with complcte access to air. They then attain the capacity to produce large amounts of alcohol in the absence of air. From these results it may be concluded that the anaerobic respiration of peptone cultures of Aspergillus niger is in fact a process sui generis which has nothing in common with alcoholic fermentation. In the following table of Boysen-Jensen² we again find very different values for $\mathrm{CO}_{2}: \mathrm{C}_{2} \mathrm{H}_{5} \mathrm{OH}$. These latest studies have supported the most important results of Kostychev.

Plant MATERIAL

Cotyledons of peas.

Cotyledons of peas.

Roots of Daucus Carola

Roots of Daucus Carota.

$\mathrm{CO}_{2}: \mathrm{C}_{2} \mathrm{H}_{5} \mathrm{OH}$
$\ldots \quad 100: 65$
$\ldots \quad 100: 8 \mathrm{I}$
$\ldots \quad 100: 9 \mathrm{I}$
$\ldots \quad 100: 86$

1 Kostytschew, S. und M. Afanassjewa. Jahrb. f. wiss. Bot. 60:628. 1921.

${ }_{2}$ Boysen-Jensen. P. Det. kgl. danske videnskab. selskab. biol. meddel. 4: I. I923. 


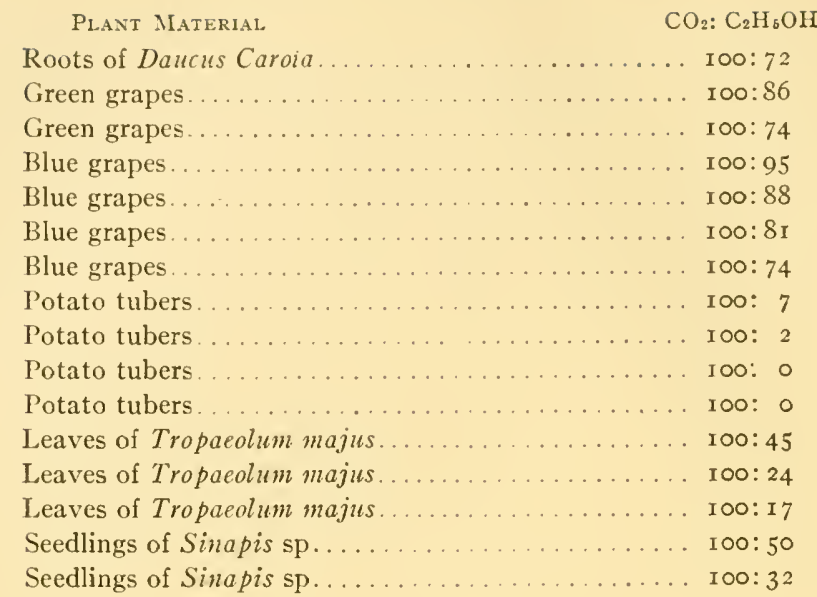

The noteworthy behavior of potatoes also appears in these experiments. It is very likely that in the case of dormant potatoes there is a deficiency of the enzymes of fermentation. Kostychev ${ }^{1}$ succeeded by wound stimulation in increasing the ratio $\mathrm{CO}_{2}: \mathrm{C}_{2} \mathrm{H}_{5} \mathrm{OH}$ in potatoes to $100: 35$ or $100: 28$, thus inducing a noticeable production of alcohol. Still a very considerable excess of $\mathrm{CO}_{2}$ is formed even after wound stimulation. Hence the anaerobic respiration of potato tubers is not wholly identical with the typical alcoholic fermentation. Whether other products than alcohol and $\mathrm{CO}_{2}$ appear in anaerobic respiration remains undecided. In all cases in which a considerable excess of $\mathrm{CO}_{2}$ appears with the formation of alcohol, a formation of other substances is certainly very likely, ${ }^{a}$ for it would be scarcely conceivable that organic substances from which the excess of $\mathrm{CO}_{2}$ is liberated should, in the absence of oxygen, entirely decompose into $\mathrm{CO}_{2}$ and $\mathrm{H}_{2} \mathrm{O}$ without forming other products. Older investigators reported that molecular

\footnotetext{
${ }^{1}$ Kostytschew, S. Ber. d. bot. Ges. 31 : 125. I9I3. [Stoklasa (Ibid. Vol. 4t, p. 250. 1926) reports that such low proportions of alcohol were never found in his experiments with potatoes. I

${ }^{a}$ Under anaerobic conditions, the ground tissues of germinating peas and beans were found by Neuberg und Gottschalk (Biochem. Z. 160: 256 . I925) to produce traces of acetaldehyde. Kostychev himself notes later that this substance may be formed in quantities sufficient to interfere with the determination of alcohol.-Ed.
} 
hydrogen $^{1}$ is formed by the anaerobic respiration of plants containing mannite, since mannite undergoes hydrolytic cleavage into sugar:

$$
\begin{aligned}
\mathrm{CH}_{2} \mathrm{OH}-(\mathrm{CHOH})_{4}-\mathrm{CH}_{2} \mathrm{OH} \rightarrow \mathrm{CH}_{2} \mathrm{OH}- & (\mathrm{CHOH})_{3} \\
& -\mathrm{CO}-\mathrm{CH}_{2} \mathrm{OH}+\mathrm{H}_{2}
\end{aligned}
$$

Kostychev 2 proved by detailed experiments that hydrogen is never formed in anaerobic respiration. Hydrogen is actually formed by the fermentation of mannite only with a bacterial infection. This process has nothing to do with the physiological transformations in plants containing mannite.

\section{ANAEROBIC RESPIRATION UNDER NATURAL CONDITIONS}

Only a few plants exhibit anaerobic respiration under natural living conditions. Some inhabitants of marshes and plants which grow on annually submerged lands, some seeds at certain stages of germination, some fruits, and living wood parenchyma cells are probably to be included in this group. V. Polowzow ${ }^{3}$ alluded to the fact that at certain stages of germination, maize and pea seeds exhibit a considerable magnitude of $\frac{\mathrm{CO}_{2}}{\mathrm{O}_{2}}$ and form alcohol, and that the anaerobic phase exists along with the normal respiration. This investigator thought he could show that, with slow growth and an excess of sugar, alcoholic fermentation generally appears as a normal phenomenon in seed-plants with free access to oxygen. This concept is by no means entirely correct. It shows that with the given seeds a deficiency of oxygen appears during the germination. ${ }^{4}$ This deficiency is due to the presence of firm seed coats which are but slightly permeable to oxygen. As soon as these coats are removed a strong absorption of oxygen follows, and the alcohol which accumulated in the living cells is quickly consumed.

1 Humboldt. Flora friburgensis. I793; Marcet. Ann. de chim. et de physique. (II.) 40: 218; Muntz. Ibid. (V.) 8:67. I876; de Luca. Ann. sci. nat. bot. (VI) 6: 286. I 878 .

2 Kostytschew, S. Ber. d. bot. Ges. 24: 436. 1906; 25: 178. 1907; Physiol.-chem. Untersuch. über Pflanzenatmung. I910. Russian.

3 Polowzow, V. Untersuch. über die Pflanzenatumng. Igor. Russian.

${ }_{4}$ Kostytschew, S. Biochem. Z. 15: 164. 1908; Physiol.-chem. Untersuch. über die Pflanzenatmung. igıo. Russian. 
Thus it is evident that in pea seeds alcoholic fermentation appears as a normal germination process which is induced by a temporarily anaerobic mode of life. Devaux ${ }^{1}$ has shown that a deficiency of oxygen often exists in the interior of the woody cylinder of trees and anaerobic respiration then sets in. This investigator proved that in wood parenchyma an accumulation of alcohol takes place under some circumstances. Gerber ${ }^{2}$ claims that alcoholic fermentation never fails to appear during the ripening of various fleshy fruits and that the process is related to the formation of various esters which are to be regarded as normal constituents of the given fruits. In fact it is not unlikely that a deficiency of oxygen makes itself felt in the ripening of various fruits. The results of Boysen-Jensen ${ }^{3}$ allow it to be supposed that for grapes the absorption of oxygen is only slight. This is also easily understood, since the skin of the grape is but slightly permeable to oxygen.

On the other hand we are justified in claiming that various plants and plant organs, such as the foliage leaves of most trees, never experience a lack of oxygen, since they live continually under conditions of excellent aeration. The situation is the more noticeable that these parts are also qualified to respire anaerobically and to form alcohol in the absence of oxygen. In their review of the physiological significance of anaerobic respiration, various investigators have assumed that this process represents a biological adaptation. The immediate death of the plant is thought to be prevented by means of anaerobic respiration in the case of an occasional deprivation of oxygen. This conception must be rejected as insufficient and too weak to hold. Apart from the consideration that biological-teleological ways of thinking are in general insufficient for biochemical questions, the supposition is in itself scarcely plausible that a physiological process could appear only incidentally as a precautionary measure. Indeed we know that anaerobic respiration is universally widespread. So far there has not been found a single plant which is unable to form $\mathrm{CO}_{2}$ in the absence of

${ }^{1}$ Devaux. Compt. rend. 128: 13ł6. 1899.

2 Gerber. Ann, sci, nat. bot. 4: 1. I 896.

3 Boysen-Jensen, P. Det. kgl. danske videnskab. selskab. biol. meddel. 4: 1. 1923. 
oxygen. ${ }^{b}$ On the other hand, anaerobic respiration occurs very seldom under natural living conditions, as is evident from the preceding statements. In what manner could a rarely occurring process attain the standing of a widesprearl phenomenon of adaptation? Finally, it is to be taken into consideration that plants do not die instantly without forming $\mathrm{CO}_{2}$. The energy value of anaerobic respiration often appears to be so insignificant that no biological usefulness can be granted to it. It is questionable whether the scanty gain of energy supplied by anaerobic respiration can delay the death of the plant even for a short time.

On the basis of this analysis it may be concluded that the conception of anaerobic respiration as an adaptive phenomenon merits no consideration at present. Even at the start this assumption was a downright abstraction. It relied on no experimental evidence and contradicted some of the best-known facts.

\section{ANALYTICAL METHODS FOR THE DETERMINATION OF ANAEROBIC RESPIRATION}

The determination of the carbon dioxide liberated in the course of anaerobic respiration is carried out by the use of the same methods which were described for the determination of oxygen respiration. The plants might be either left in the current of an inert gas or confined in appropriate, air-tight containers with the oxygen excluded. Absorption ressels for $\mathrm{CO}_{2}$ which have already been described are used in the first case. Care has to be taken that the absorption tubes for weighing. such as potash tubes, absorb no alcohol vapor whereby considerable errors could appear in the analyses. ${ }^{1}$ The devices required for this purpose will be discussed in the description of the determination of alcohol. If closed vessels are used as plant containers, the $\mathrm{CO}_{2}$ is determined by analysis of test portions of the gas. This method is to be recommended particularly for experiments in which, besides the determination of

\footnotetext{
${ }^{1} 1 \mathrm{t}$ is also essential to replace the inert gas in the potash tubes and soda lime tubes with air before weighing.

b An apparent exception is that of Elodea according to a few experiments by Lyon (J. Gen. Physiol. 6: 299-306. 1923-24).-Ed. 
anaerobic respiration, the value of the respiratory quotient in the normal respiration must also be obtained.

There remains to be described here first, the methods of removal of oxygen and secondly, the methods of determination of alcohol. In general, if no quantitative determinations are to be carried out it suffices to confine the plants in a suitable container and then to absorb the oxygen with alkaline pyrogallol solution. Ordinary exsiccators are very well suited to this purpose. A concentrated solution of caustic potash is poured into the lower part of the exsiccator and an easily overturned dish of concentrated pyrogallol solution is placed in the lye. The plant material is then placed in position. the exsiccator well sealed, and the little dish of pyrogallol solution is upset. The oxygen is absorbed and the plants are left under anaerobic conditions. Assertions are found in the literature to the effect that some carbon monoxide is formed at times when oxygen is absorbed by alkaline solutions of pyrogallol. This situation can be disregarded since carbon monoxide represents an inert gas for plants. ${ }^{\circ}$

The atmospheric air must be replaced by an inert gas for quantitative determinations of the products of anaerobic respiration. If the work is done in a current of gas it is usually preferable to use hydrogen, because this gas is easy to admit in large quantities and sufficiently pure. The apparatus of Bardeleben (Fig. II) is more commendable than the ordinary Kipp generator for the continual passage of hydrogen, since the latter cannot be filled with fresh acid without interrupting the gas current and requires a larger amount of acid for the production of the same quantity of gas than does the Bardeleben apparatus. The latter consists of a large glass cylinder which is filled with the purest dilute sulphuric acid. Concentrated sulphuric acid is diluted with three times its volume of water and enough copper sulphate is added to color the solution bright blue. In the acid is set a glass bell jar which is closed above with a one-hole rubber stopper. In the hole of the stopper is inserted an exit tube with a glass stopcock. Under the

- The concentration of carbon monoxide produced by this action must be very low and hence is quite negligible.- Ed. 
bell jar rests a dish, the proper form of which may be learned from the figure. This dish is filled with small sticks of the purest metallic zinc. The purity of the metal is controlled as follows. After immersing the sticks in pure dilute sulphuric acid without copper sulphate only a very insignificant generation of gas should occur. This becomes vigorous only after the addition of copper sulphate. Only such sticks of metal should be used for accurate experiments; otherwise the research material may be poisoned. This has actually occurred in the experiments of various investigators.

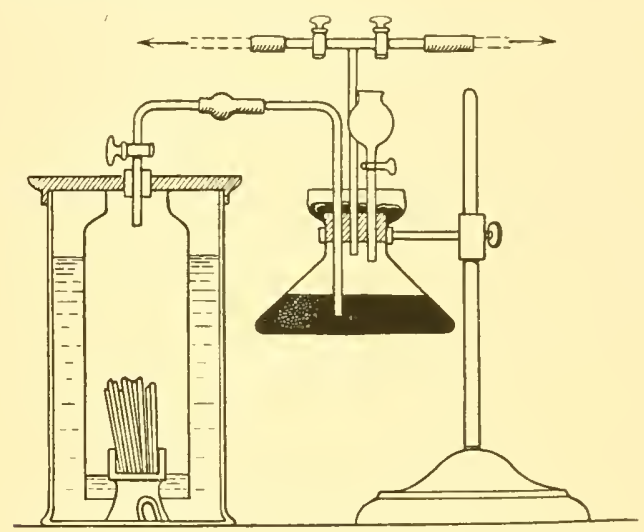

Fig. I I. - The Bardeleben apparatus.

The gas needs only to be passed through an alkaline solution of pyrogallol if the reagents are sufficiently pure. The wash bottle shown in Fig. I is closed with a three-hole rubber stopper. The right-angled entrance tube passes through one hole and is connected with the exit tube of the Bardeleben apparatus. Into another hole is placed the T-tube fitted with two glass stopcochs by means of which the gas current may be passed through at least two plant containers and two series of absorption tubes. A funnel with a glass stopcock goes in the third hole. The expansion of the neck of the flask above the stopper is filled with mercury. The flask is next supplied with concentrated caustic potash, and hydrogen is passed through for a time until all the oxygen is driven from the flask. Then a concentrated solution of pyrogallol is run in through the funnel. A little of it is left in the funnel above the stopcock in order to isolate more securely 
the contents of the flask from the external air. The solution which has been thus introduced has only a pale brownish color after months of work.

To insure a uniform generation of hydrogen, attention must be paid to make sure that the acid does not become too dilute through the formation of zinc sulphate. As soon as the acid begins to rise in the bell jar so that the sticks of zinc are partly immersed in the solution, the lower layer of liquid, consisting of heavier zinc sulphate solution, must be removed and fresh sulphuric acid added. This can be easily accomplished while the current of gas continues to flow without interrupting the experiment. In the case of accurate and refined experiments the acid must touch only the lower ends of the zinc sticks even for a vigorous stream of hydrogen. An apparatus fitted with sufficient zinc can be used a long time in this manner and yield very large amounts of hydrogen. If there are traces of arsenic in the zinc or in the acid the gas is passed first through a solution of iodine, then through concentrated potassium iodide solution, and finally through an alkaline solution of pyrogallol.

The gas can also be drawn from a cylinder (Bombe). 'The compressed hydrogen is generally prepared by electrolysis and is therefore entirely free from the trihydride of arsenic, though it often contains some oxygen. In the use of compressed hydrogen the stream of gas must be passed through at least two wash bottles of alkaline pyrogallol solution and of course in the form of separate bubbles. A considerable velocity of the gas current is therefore prohibited in this case.

Although most of the investigations of anaerobic respiration have been carried out by the use of hydrogen, it appears questionable whether hydrogen actually represents an entirely inert gas. We now know that most of the oxidations and reductions in plants are to be traced to the splitting-off or the adding-on of hydrogen. Of course molecular hydrogen is nearly inactive, but it is a fact that for plants it constitutes an absolutely unusual gas medium. Hence the use of nitrogen is always more commendable and refined.

For a continual passage of gas it is best to use compressed nitrogen which is drawn from a cylinder with a reducing valve. 
The gas is passed through two wash bottles of concentrated alkaline solution of pyrogallol in order to remove the small amounts of the admixture of oxygen and carbon dioxide. The presence of the noble gases is of course unimportant. If no compressed nitrogen is available, this gas may be prepared as follows. In a round-bottomed flask are mixed I part of sodium nitrite, 2 parts of ammonium sulphate, I part of $\mathrm{K}_{2} \mathrm{CrO}_{4}$, and about $7 \mathrm{cc}$. of water. The flask is closed with a rubber stopper and an exit tube, and cautiously heated with a small flame. The reaction proceeds according to the equation:

$$
\begin{aligned}
\left(\mathrm{NH}_{4}\right)_{2} \mathrm{SO}_{4}+2 \mathrm{NaNO}_{3}= & \mathrm{Na}_{2} \mathrm{SO}_{4}+2 \mathrm{NH}_{4} \mathrm{NO}_{2} \\
\mathrm{NH}_{4} \mathrm{NO}_{2}= & \mathrm{N}_{2}+2 \mathrm{H}_{2} \mathrm{O} .
\end{aligned}
$$

The following reaction also takes place in traces:

$$
{ }_{3} \mathrm{HNO}_{2}=\mathrm{HNO}_{3}+2 \mathrm{NO}+\mathrm{H}_{2} \mathrm{O} \text {. }
$$

The escaping gas passes through a vessel containing soda lime or pieces of $\mathrm{KOH}$ the size of peas, then either through a wash bottle filled with chromic acid mixture ( 5 vol. of a saturated potassium bichromate solution to $\mathrm{I}$ vol. of conc. sulphuric acid) or through a short combustion tube with a spiral of reduced copper (IO-I $5 \mathrm{~cm}$. long), such as is used in analyses for the elements. The copper spiral is kept red-hot by heating with a suitable burner. This purification of the gas is for the purpose of destroying the nitric oxide.

This method of preparation of nitrogen is rather simple, and the gas is obtained in a pure state. It is also possible, by suitable warming or cooling of the flask, to regulate the velocity of the current of gas. For an easier regulation the exit tube is fitted with a side tube which dips into mercury and functions as a safety valve. With the help of this valve and a glass stopcock or screw pinchcock it is possible to govern perfectly the velocity of the current of gas. Still, the apparatus requires constant oversight and so is not commendable for a continuous experiment with a current of gas. It is best to drive the air out of the plant containers with nitrogen, to seal the containers air-tight, and then to work by the use of gasometric methods. If the Kostychev flasks (Fig. 8) are used the procedure is as 
follows. The thick-walled rubber tubing $d$ of the flask is connected with the tube $h$ of the gas pipette (Fig. 9) and the tube $h$ is connected with the tube $g$ by a suitable turn of the three-way stopcock $r$. At the same time the bulb $l$ must be filled with mercury up to the stopcock $r$. The bent end of the tube $g$ is connected by thick-walled rubber tubing with the apparatus for the production of nitrogen and the air in the tubes $g$ and $h$ and the research flask is replaced with pure nitrogen. The stopcock $r$ is then so turned that the bulb $l$ communicates with the tube $g$, and the tube $h$ together with the research flask is separated. The rubber tube is now taken from the end of the tube $g$. this tube is filled with mercury from the bulb $l$, the end of the tube is immersed in mercury, and then the bulb $l$ is connected with the tube $h$ and the research flask. A test portion of gas is withdrawn from the flask in the same manner as was described for the experiments on oxygen respiration. This gas is passed into an analysis tube, the upper part being prepared with the oxygen excluded ${ }^{1}$ and containing almost colorless alkaline pyrogallol solution. If the solution remains colorless, the displacement of oxygen is complete. If the solution turns brown or dark-brown, more nitrogen must be passed through the flask. If the internal atmosphere of the experiment flask is free of oxygen the flask can be closed and the experiment begun. Through the removal of the control portion the gas pressure in the flask has already been lowered and the mercury has risen in the manometer. The bulb $l$ is now connected with the tube $h$, and the rubber tubing $d$ and the outer side of the entrance tube $a$ on the experiment flask are filled with mercury. If the screw pinchcock on the rubber tubing $d$ is then closed, the flask is left filled with pure nitrogen and sealed air-tight. Fig. $\delta$ shows that the inner atmosphere of the flask is entirely separated from the air by glass and mercury.

Of course the flask can be filled as above not only with nitrogen but also with hydrogen or another gas. Either nitrogen or hydrogen may be used as an inert gas. Moeller ${ }^{2}$ has been

\footnotetext{
1 This is accomplished as follows. Into an analysis tube full of mercury are introduced under the mercury with the aid of two pipettes with bent outlet tubes, first a couple of cubic centimeters of concentrated caustic potash, then some pyrogallol solution.

${ }^{2}$ Moeller. Ber, d. bot. Ges. 2 : 306. I 884.
} 
the only one to use nitrous oxide. More detailed accounts of these experiments are to be found in Moeller's original paper.

Carbon dioxide has even been used in some cases to provide an atmosphere free from oxygen. Carbon dioxide is not an inert gas and may be used only for special problems. Such is the case, for example, if the liberation by anaerobic respiration of gases other than $\mathrm{CO}_{2}$ is being tested. ${ }^{1}$ Such experiments must be of short duration or the material is injured by the carbon dioxide. ${ }^{d}$ It is best to pass a current of carbon dioxide through the plant container until the air is completely displaced. and then to close off the container. After closing the experiment, the gases are displaced from the container by a current of carbon dioxide in to a eudiometer filled with concentrated caustic potash solution, where the $\mathrm{CO}_{2}$ is absorbed and any other gases remain in high concentration. The residue not absorbed by lye can now be analysed. It is evident that only strictly. pure carbon dioxide can be used for these experiments. It can best be produced by heating chemically pure sodium bicarbonate in a combustion tube. Very pure carbon dioxide is obtainerl by the action of a dilute solution of sodium bisulphate on a coarsely pulverized fusion of sodium carbonate and potassium carbonate. $^{2}$ It is scarcely possible to obtain carbon dioxide free of air by the use of marble and hydrochloric or sulphuric acid. The following method of procedure reduces this contamination with air to a minimum. Well-boiled marble in small pieces the size of peas is used in the solution of hydrochloric acid, which is made up with distilled water. The middle bulb of a small Kipp generator is entirely filled with such pieces of marble and the air is displaced from the apparatus in the following manner. By opening the stopcock the middle bulb is rapidly filled with the acid and then the stopcock is suddenly closed. The liquid is thereby forced in to the upper bulb by the carbon dioxide. This operation is repeated three or four times.

${ }_{1}$ Kostytschew, S. Ber. d. bot. Ges. 24:436. 1906; $25: 178 . \quad 1907$.

${ }^{2}$ Bornträger, H. Z. f. analyt. Chem, 29: 1 40. I890.

$d$ A very marked exception to this rule is the increased growth of anaerobic bacteria, such as Bacillus welchii, B. telani or B. Bolulinus, when exposed in tube cultures to increased tensions of $\mathrm{CO}_{2}$. This behaviour is reported by Rockwell, G. E. Jour. Infect. Diseases 35:58I-586. I924.-Ed. 
Each time care is taken that the middle bulb is entirely filled with acid. Then the experiment is begun. The gas now includes so little air that after the absorption of $100 \mathrm{cc}$. of carbon dioxide with caustic potash [in a eudiometer] there remains a small bubble of air scarcely visible to the naked eye. For most investigations such an insignificant amount of air is of no account.

A vacuum has seldom been used to provide anaerobic conditions of life. Nabokich ${ }^{1}$ placed the research material in a racuum flask and exhausted the flask with a strong air pump to a mercury pressure of $0.25 \mathrm{~mm}$. It must be pointed out that with this method the material is placed under an extraordinary physical condition which cannot possibly fail to affect the experimental results.

It would be entirely inadmissible to be content with immersion of the experimental material in water or various dilute solutions. It has already been pointed out [p. 59] that strongly aerobic plants provided with powerful oxidising enzymes respire normally even under water and there obtain oxygen in sufficient quantity. It is also absolutely insufficient for accurate experiments to immerse the material in water or dilute solutions and to cover the surface of the water with a fluid in which oxygen is insoluble. It is impossible by this method to isolate entirely the experimental material from the atmospheric oxygen. On the other hand, it is satisfactory to dip in water or certain nutrient solutions plants which are rapidly killed by anaerobic conditions, and then to replace the air in the container with an inert gas. This measure tones down the poisoning of the experimental material, since the toxic products of the anaerobic metabolism diffuse out into the solution.

It has already been pointed out that it is often of interest to carry out quantitative determinations of alcohol in the case of studies of anaerobic respiration. A qualitative demonstration of ethyl alcohol is also often of great importance. To prevent a loss of the alcohol in experiments with a gas current, a wash bottle set in melting ice and filled with distilled water is inter-

\footnotetext{
1 Nabokich, A. Ber. d. bot. Ges. 19: 222. I901; 21: 398, 467. 1903; Beih. z. bot. Centralbl. I3: 272. I903.
} 
posed between the container and the apparatus for the absorption of carbon dioxide. Wash bottles with the exit tube wound in a coil are very practical. Direct determinations show that by the use of these flasks even a minimum loss of alcohol is prevented. ${ }^{1}$ At the close of each experiment, the experimental material and the contents of the wash bottle are placed in a large distilling flask, the container and the wash bottle are rinsed with water, considerably more water is added, and the whole is distilled until about half of the liquid has passed over into the receiver. If the distillate is acid it is neutralized by the addition of $\mathrm{CaCO}_{3}$. If, on the contrary, the first distillate is alkaline (which happens only in exceptional cases), it is rectified by the addition of phosphoric or tartaric acid. If a cloudy distillate is obtained the flask is placed at a slope for the next distillation, as for steam distillations. The use of distillation heads such as are used in Kjeldahl determinations of nitrogen, also give good service. The volume of the alcohol solution is reduced to about $50 \mathrm{cc}$. by further distillations. This solution must be perfectly clear and neutral in reaction.

If a qualitative demonstration of alcohol is desired, the solution is concentrated as far as possible by repeated distillations. The following are recommended as qualitative tests:

1. The appearance of oily streaks in the upper part of the condenser at the beginning of the distillation. After some practice the presence of ethyl alcohol may be recognized with certainty by the appearance of these oily streaks. ${ }^{2}$ This test is not very sensitive. Traces of alcohol are not detected by it.

2. The iodoform reaction of A. Muntz. ${ }^{3}$ Io $\mathrm{cc}$. of the clear distillate are mixed with $2 \mathrm{~g}$. sodium carbonate and O.I g. sublimed iodine and the mixture is warmed on the water bath at $60^{\circ}$ until the iodine is dissolved. After cooling there separate out the characteristic crystals of iodoform, which may be easily recognized under the microscope. The iodoform test is really very sensitive but not entirely reliable. It also gives a positive reaction with various other substances, among which

\footnotetext{
1 Kostytschew, S. und P. Eliasberg. Z. f. physiol. Chem. III: I 1 I. 1920.

2 Pasteur, L. Compt. rend. 52: I260. I86 I; cf. also Hansen, A. Meddel. frá Carlsherg ab. I : I 75. I $88 \mathrm{I}$.

${ }^{3}$ Muntz, A. Ann. de chim. et de physique (V) 13:543. I878.
} 
lactic acid, acetaldehyde, and acetone deserve particular mention, since they occur in plants and also pass over into the distillate with water vapor.

3. The test of M. Berthelot ${ }^{1}$ which depends on the formation of the ethyl ester of benzoic acid is more reliable. The alcoholic solution must be concentrated as much as possible by repeated distillations. This solution is shaken with two drops of benzoyl chloride and an excess of caustic potash solution. The characteristic odor of the ethyl ester of benzoic acid is evolved in the presence of alcohol. The surplus of benzoyl chloride must be completely destroyed by continued shaking with caustic potash.

4. By cautious oxidation the ethyl alcohol is changed to acetaldehyde with which various characteristic tests can then be made. ${ }^{2}$ For example, a cherry-red color is obtained with fuchsin-sulphurous acid. A deep blue color appears with sodium nitroprusside and diethylamine or pyridine. The characteristic precipitate of acetaldehyde-p-nitrophenyl-hydrazone (melting point $125^{\circ} \mathrm{C}$.) is formed with an acetic acid solution of p-nitrophenylhydrazine.

Certainly the most reliable tests are those in which ethyl alcohol changes to characteristic derivatives which can then be conveniently analysed. Hence the following methods of identification of ethyl alcohol are to be recommended. It must be pointed out in this connection that all these reactions are best carried out with isolated alcohol dehydrated with potassium carbonate. If the quantity of alcohol is insufficient for isolation the solution must at least be concentrated as much as possible.

I. Formation of Ethylene. ${ }^{3}$ - Ethyl alcohol is converted into ethylene by cautious heating with concentrated sulphuric acid in an atmosphere of $\mathrm{CO}_{2}$. The ethylene is driven over into an analysis tube filled with concentrated caustic potash by means of a stream of $\mathrm{CO}_{2}$, and the $\mathrm{C}$ content of the gas is then ascertained by gas analysis. The apparatus of PolowzowRichter (see above) with its explosion pipette is especially suitable for this purpose.

${ }^{1}$ Berthelot, M. Compt. rend. 73: 496. I87I.

${ }^{2}$ Denigès, G. Bull. de la soc. de chim.-biol. (IV). 7: 95 I. I910.

s Berthelot, M. Compt. rend. I 28 : 1366. I 899. 
II. Formation of the Ethyl Ester of p-Nitro-benzoic Acid. The alcohol is shaken with p-nitro-benzoyl chloride in alkaline solution and the resultant ester is recrystallized first from gasoline and then from benzene. The melting point is $57^{\circ}$. The nitrogen in the resulting pure product is determined according to Dumas.

III. Formation of Acetaldehyde-p-nitrophenyl-hydrazone.The alcohol is oxidised to acetaldehyde ${ }^{2}$ and the latter precipitated in the cold with an acetic acid solution of p-nitrophenylhydrazine. The yellow precipitate is recrystallized from $50 \%$ alcohol and the nitrogen content of the resulting product is determined according to Dumas. Since acetaldehyde is formed by oxidation not only from ethyl alcohol but also from some other substances, both of the above described methods (I and II) of identification are always preferable.

The following methods of quantitative determination of alcohol are recommended for studies of anaerobic respiration:

\section{PHYSICAL METHODS}

I. Pycnometric Determination.-The last distillate is collected in a small weighed flask and the weight of the entire solution of alcohol is obtained by a second weighing. Then the specific gravity of the distillate is determined and the percentage content of ethyl alcohol is calculated according to tables at hand. The amount of absolute alcohol may also be obtained by a simple recalculation.

2. Cryoscopic Determination. ${ }^{3}$ - This is more reliable and less detailed than the pycnometric determination. The freezing point of the alcoholic solution is ascertained, from which the alcohol content results by a simple calculation. For the details consult the original paper by Gaunt. The noted Beckmann apparatus for the determination of molecular weights is useful for determining the freezing point depression.

3. Stalagmometric Determination.-This method is also supposed to be very practical. It is based on the fact that

\footnotetext{
${ }^{1}$ Buchner, E. und J. Meisenheimer. Ber. d. chem. Ges. 38:624. 1905.

2 Denigès, G. loc. cit.

${ }^{3}$ Gaunt, R. Z f. analyt. Chem. 44: 106.1905.
} 
alcohol lowers the surface tension of water. The method is being worked out by the writer and the pertinent investigations are not yet concluded.

\section{CHEMICAL METHODS}

I. Oxidation with Bichromate and Sulphuric Acid According to Nicloux's Method. ${ }^{1}$ - This method is especially well-suited to the determination of small amounts of alcohol, hence to be recommended particularly for studies of anaerobic respiration. The oxidation of the alcohol proceeds according to the equation:

$$
\begin{array}{r}
{ }_{2} \mathrm{~K}_{2} \mathrm{Cr}_{2} \mathrm{O}_{7}+8 \mathrm{H}_{2} \mathrm{SO}_{4}+{ }_{3} \mathrm{CH}_{3}-\mathrm{CH}_{2} \mathrm{OH}={ }_{2} \mathrm{~K}_{2} \mathrm{SO}_{4}+{ }_{2} \mathrm{Cr}\left(\mathrm{SO}_{4}\right)_{3} \\
+{ }_{3} \mathrm{CH}_{3}-\mathrm{COOH}+\mathrm{II} \mathrm{H}_{2} \mathrm{O} .
\end{array}
$$

Ethyl alcohol is thus oxidised to acetic acid. The amount of alcohol is computed from the amount of oxygen used.

Five cc. of the solution to be tested are placed in a test tube of Jena glass. This solution may contain not more than $2 \%$ alcohol, the necessary dilution of the distillate being found from preliminary experiments if necessary. To it are added from a burette 2 drops of potassium bichromate $(9.5 \mathrm{~g}$. in a liter) and then $5^{-6} \mathrm{cc}$. of conc. sulphuric acid. If there is alcohol in the liquid it turns blue-green in color as a result of the formation of chromium sulphate. The solution of bichromate is now allowed to run in from the burette, while the liquid is shaken and heated to feeble boiling, until the color changes from blue-green to yellow-green. The number of cubic centimeters of bichromate used is then noted. The change in the color depends on the fact that potassium bichromate is not decomposed on account of the exhaustion of alcohol and the solution is colored yellow. The titration is easier if a pair of comparison tubes are prepared and the coloration of the liquid to be investigated is compared with the color tone of these tubes after the change to yellowgreen. The alcohol content in per cent corresponds to half the number of cubic centimeters of potassium bichromate used and the whole analysis requires but a few minutes. Thus if $n$ is the number of cubic centimeters of bichromate used, the alcohol is $0.05 n$ cubic centimeters per $100 \mathrm{cc}$. of solution. The

\footnotetext{
${ }^{1}$ Nicioux, M. Bull. de la soc. de chim.-biol. (III). 35: 330. 1906.
} 
percentage by weight is calculated on the basis of the specific gravity of alcohol.

2. Oxidation with Permanganate in Alkaline Solution. ${ }^{1-}$ This determination of alcohol is based on the following reaction: $\begin{aligned} \mathrm{I}_{2} \mathrm{KMnO}_{4}+\mathrm{I}_{2} \mathrm{KOH}+\mathrm{CH}_{3}-\mathrm{CH}_{2} \mathrm{OH}= & { }_{2} \mathrm{~K}_{2} \mathrm{MnO}_{4}+ \\ & { }_{9} \mathrm{H}_{2} \mathrm{O}+{ }_{2} \mathrm{CO}_{2} .\end{aligned}$ Alcohol is thereby burned to carbon dioxide and water. The following solutions are prepared:

(a) A solution of $39 \mathrm{~g}$. $\mathrm{KMnO}_{4}$ in 4 liters of water.

(b) A solution of $80 \mathrm{~g}$. oxalic acid in 4 liters of water.

(c) A solution of $150 \mathrm{~g}$. $\mathrm{NaOH}$ in I liter of water.

(d) A solution of 2 vols. conc. $\mathrm{H}_{2} \mathrm{SO}_{4}$ in 5 vols. dist. water.

(e) A solution of 3.1 82 g. purest $\mathrm{KMnO}_{4}$ (Kahlbaum preparation "Zur Analyse mit Garantieschein," or ordinary preparations twice recrystallized) in I liter of water. I cc. of this solution yields $0.8 \mathrm{mg}$. of oxygen.

The alcoholic content of the solution to be tested must not exceed $0.2 \%$. The determination is carried out as follows. I00 cc. of solution $a$ and $40 \mathrm{cc}$. of solution $c$ are placed in a 700 cc. flask. The mixture is heated to boiling and then exactly $5 \mathrm{cc}$. of the alcohol solution are poured in. The whole is boiled I minute and then roo cc. of solution $b$ and $40 \mathrm{cc}$. of solution $d$ are added to the hot liquid. This causes an immediate coloration of the liquid. The mixture is titrated with solution $e$ and the amount $\mathrm{A}$ of cubic centimeters of permanganate solution used is noted.

The whole operation is now repeated with a $0.4 \%$ sugar solution substituted for the solution of alcohol. $5 \mathrm{cc}$. of this solution should theoretically use up $28.05 \mathrm{cc}$. of solution $e$. In practice a larger quantity of permanganate is used on account of its decomposition in boiling with sodium hydroxide. The oxidation of the sugar is for the purpose of determining the correction $\mathrm{B}-28.05$ which must also be considered in the determination of the alcohol. The desired amount of alcohol is A $(B-28.05) \cdot 0.384 \mathrm{mg}$. It is obvious that the control analysis needs to be carried out only once for a given solution.

The chemical as well as the physical methods of determination of alcohol depend upon the assumption that only pure ethyl alcohol is contained in the distillate. Actually the basic, as

\footnotetext{
${ }_{1}$ Barendrecht, H. P. Z. f. analyt. Chem. 52: 167. I9I3.
} 
well as acid, volatile plant compounds, which could pass over into the first distillate, are removed by the distillation from acid or alkaline solutions. In addition acetaldehyde, which is probably to be regarded as a forerunner (Vorstufe) of alcohol, is sometimes formed in anaerobic respiration. ${ }^{1}$ 'To be sure, the amounts of aldehyde are trifling at the most, but inaccuracies often beyond the limits of error of the analytical mathods are introduced by the presence of acetaldehyde.

Kostychev has found that the removal of acetaldehyde is absolutely necessary if the aldehyde content rises to at least 0.05 the alcohol content. The removal of acetaldehyde is accomplished as follows according to Kostychev. ${ }^{2} \quad 50 \mathrm{cc}$. of a diluted solution of alcohol (as used for quantitative determinations according to Nicloux or Barendrecht) are allowed to stand is to 20 minutes with the addition of about $10 \mathrm{cc}$. of a concentrated solution on $\mathrm{NaHSO}_{3}$. Then the mixture is distilled on the water bath at 30 to $35^{\circ}$ with about ${ }_{5} \mathrm{~mm}$. pressure. In doing this, as long a condenser as possible is used and the receiver is cooled with ice. The adapter of the condenser must be placed within the cooled part of the receiver. If this precaution is not observed small losses of alcohol are not always prevented. To protect the rubber tubing, the receiver is first treated with a small quantity of caustic soda solution, because some $\mathrm{SO}_{2}$ escapes during the distillation. The distillation can be discontinued after about $20 \mathrm{cc}$. of distillate has passed over into the receiver. The distillate is treated with about $40 \mathrm{cc}$. of distilled water. It is made certain that the liquid is alkaline in reaction (if not, caustic soda is added), and the mixture is rectified at the usual pressure, for which a measuring flask of 5o cc. capacity is used as a receiver, the flask being filled to the mark with distilled water after stopping the distillation. Numerous control analyses showed that no alcohol is lost in the purification just described and the aldehyde is entirely removed. The last distillate can be used directly for the determination of alcohol according to Nicloux.

${ }^{1}$ Cf. e.g. Kostytschew, S., Hubbenet, E. und A. Scheloumow. Z. f. physiol. Chem. 83 : 105. I913. [cf. also editorial note on page 62.]

2 Kostytschew, S. Bull. de lacad. des sciences de Petersbourg. rgr5:327; Biochem. Z. $64: 237 . \quad 1914$. 


\section{THE CONNECTION OF OXIGEN RESPIRATION WITH ANAEROBIC RESPIRATION}

\section{REVIEW OF THE OLDER LITERATURE}

A discussion of the chemical processes in plant respiration must precede an analysis of the aerobic and anaerobic material transformations of respiration. All coherent theories of plant respiration start with the assumption that anaerobic respiration constitutes a preliminary step to oxygen respiration. This theory, at present established by numerous facts, has passed through an instructive evolution.

Pasteur, ${ }^{1}$ the founder of the science of anaerobic respiration. was satisfied with proof of the fact that an alcoholic fermentation is peculiar to various lower fungi and seed-plants. He occupied himself with questions of fermentation and dealt with anaerobic respiration only from the standpoint of his theory of fermentation. The normal oxygen respiration did not interest him.

Soon after, however, Pflüger ${ }^{2}$ proved that in the case of some animals the liberation of $\mathrm{CO}_{2}$ continues after oxygen is excluded. Pflüger characterised this formation of $\mathrm{CO}_{2}$ as intramolecular respiration. According to Pflüger's view, intramolecular respiration is not an abnormal or pathological phenomenon. On the contrary it constitutes an essential preliminary step to normal oxygen respiration. According to Pfluger, the latter consists of two series of reactions. In the first, easily oxidised substances are formed from the reserve respiratory material and $\mathrm{CO}_{2}$ is liberated in the process. According to Pflüger, all these processes take place without the intervention of atmospheric oxygen and so continue in a medium free of oxygen. The second phase of respiration, according to Pflüger, consists of

${ }_{1}^{1}$ Pasteur, L. Compt. rend. 75: 784. I872; Êtudes sur la bière. 1876.

2 Pfluger. Arch. ges. Physiol, 10: 25I. 1875 . 
the complete oxidation to $\mathrm{CO}_{2}$ and water, by atmospheric oxygen, of the labile substances formed intramolecularly.

This conception is the basis of all modern theories of the connection of anaerobic with normal respiration. Yet it is worthy of note that the facts experimentally established by Pflüger could serve just as little to confirm his theory as could the balance of the alcoholic fermentation of yeast confirm Lavoisier's law of the conservation of matter (as is known, Lavoisier and others used the fermentation of sugar by yeast as a particularly good illustration of his law). The "anaerobic respiration" of animals is to all appearances analogous not to alcoholic but to lactic acid fermentation. The first phase of oxygen respiration in animal bodies proceeds in the absence of oxygen without forming $\mathrm{CO}_{2}$. The production of $\mathrm{CO}_{2}$ observed by Pfluger is actually not a general, widespread phenomenon and has nothing to do with the first phase of respiration. On the other hand, Pflüger did not know of Pasteur's investigations when he published his communication, else he would have perhaps withdrawn his assumption of the formation of hypothetical "labile" substances, because ethyl alcohol is less labile and less capable of oxidation than is the sugar from which it is produced. Contrary to the assumption of Pfluger, the oxidation of sugar is not expedited through the formation of alcohol. Still Pflüger's idea was most prolific, and the strange part is that he was apparently correct in the main. This is a novel illustration of the rôle of chance in scientific discoveries.

It is evident that neither Pasteur nor Pflüger conceived of anaerobic respiration as an abnormal, pathological phenomenon. Nägeli, ${ }^{1}$ Brefeld, ${ }^{2}$ and Sachs ${ }^{3}$ took a different attitude. In his book "Theorie der Gärung" (Theory of fermentation) which was so quickly discredited, Nägeli expressed his opinion of Pasteur's discovery of anaerobic respiration in the following manner: "Here, howerer, it is actually an abnormal phenomenon, since it is wanting in cells which are in a healthy and vigorous condition and first appears whenever they are deprived

${ }^{1}$ Nägeli C. Theorie der Gărung. 1879. P. II.7.

2 Brefeld, O. Landwirtschaftl. Jahrb. 5: 28 I. I876.

3 Sachs, J. Vorlesungen uber Pflanzenphysiologie. I882. Pp. $486-487$. 
of nutrient substances (?!), especially oxygen."1 Brefeld and Sachs concurred in this opinion. Thus, for example, Sachs makes the following unequivocal statement: "I draw the conclusion, which Nägeli and Borodin have already reached in another way, that the formation of alcohol in the absence of oxygen is an absolutely abnormal process which has nothing to do with ordinary respiration." The investigations of Muntz which have already been mentioned [p. 54] refute all these ideas. The experiments of Amm, Chudiakow, Palladin and Morkowin, which are cited in section II, prove beyond doubt that there can no longer be the question of anaerobic respiration in the sense of an abnormal phenomenon preceding death.

The credit for having carried over Pflüger's theory of the connection of anaerobic with normal respiration into the sphere of plant physiology belongs to Pfeffer. ${ }^{2}$ Because he was acquainted with the work of Pasteur, Lechartier and Bellamy, Muntz, de Luca, and Brefeld, he was compelled to take into consideration the fact that alcohol is formed in the anaerobic respiration of plants. Pfeffer believed the connection of anaerobic with normal respiration to be capable of definition in the following simple manner. In alcoholic fermentation only a third of the carbon contained in the sugar molecule is liberated in the form of carbon dioxide, as appears from the equation

$$
\mathrm{C}_{6} \mathrm{H}_{12} \mathrm{O}_{6}={ }_{2} \mathrm{CO}_{2}+{ }_{2} \mathrm{CH}_{3}-\mathrm{CH}_{2} \mathrm{OH} \text {. }
$$

On the basis of this calculation Pfeffer assumed that one-third of the carbon dioxide formed in the process of oxygen respiration is to be traced to anaerobic transformations of material i.e. to alcoholic fermentation. The remaining two-thirds of the total amount of carbon dioxide is formed by the oxidation of alcohol. In this communication of Pfeffer only theoretical considerations, not experimental results, are set forth. At that time it was not known whether anaerobic respiration is actually

\footnotetext{
1 Nägeli believed that the admission of oxygen only promotes fermentation. How Nägel resisted every acknowledgment of anaerobiosis is evident from the following words with which he stated his attitude toward the discovery of butyric acid fermentation. In the opinion of Nägeli this discovery of Pasteur depends "auf unrichtiger Beurteilung mangelhafter Beobachtungen" (on false judgment of faulty observations). Cf. Theorie der Gärung. I879. P. 71 .
}

${ }_{2}$ Pfeffer, w. Landwirtschaftl. Jahrb. $7: 805$. I878. 
identical with alcoholic fermentation and whether the ratio $\mathrm{I} / \mathrm{N}$ has the value $1 / 3$ as required by Pfeffer's theory.

When Wortmann ${ }^{1}$ determined the ratio I $\mathrm{N}$ for the germinating seeds of Vicia Faba in the Torricellian vacuum he found that with this material $\mathrm{I} / \mathrm{N}$ is equal to $\mathrm{I} .^{2}$ On the basis of this observation Wortmann assumed that all the carbon dioxide from oxygen respiration is produced through the process of alcoholic fermentation. In Wortmann's opinion, the absorption of oxygen only serves to change the resultant alcohol to sugar through the action of synthetic processes. According to Wortmann the whole process of oxygen respiration consists of the following phases:

(I) ${ }_{3} \mathrm{C}_{6} \mathrm{H}_{12} \mathrm{O}_{6}=6 \mathrm{C}_{2} \mathrm{H}_{5} \mathrm{OH}+6 \mathrm{CO}_{2}$ (Liberation of $\mathrm{CO}_{2}$ )

(II) $6 \mathrm{C}_{2} \mathrm{H}_{5} \mathrm{OH}+6 \mathrm{O}_{2}={ }_{2} \mathrm{C}_{6} \mathrm{H}_{12} \mathrm{O}_{6}+6 \mathrm{H}_{2} \mathrm{O}$ (Absorption of $\mathrm{O}_{2}$ )

The addition of the two processes gives the following equation which represents the respiratory process in toto.

(III) $\mathrm{C}_{6} \mathrm{H}_{12} \mathrm{O}_{6}=6 \mathrm{CO}_{2}+6 \mathrm{H}_{2} \mathrm{O}$.

It is evident that Wortmann as well as Pfeffer regarded ethyl alcohol as an intermediate product of oxygen respiration.

As soon as the schematic representations of Pfeffer and Wortmann were published the experimental proof of them was attempted. The work done in Pfeffer's laboratory by Wilson ${ }^{3}$ which has been referred to already, showed that the value of $\mathrm{I} / \mathrm{N}$, contrary to the supposition of Pfeffer and Wortmann, fluctuates within wide limits in the case of various plants. Wilson's results were confirmed by Moeller ${ }^{4}$ and the lastnamed investigator concluded from his experiments that there is no connection between anaerobic and normal respiration.

Borodin $^{5}$ sought to prove the connection of anaerobic with normal respiration in the following manner. If we assume with Pflüger that labile, easily-oxidised substances are formed in the absence of oxygen. then after a temporary anaerobiosis an

1 Wortmann, J. Arb. d. dtsch. bot. Inst. Wurzburg. 2 : 500. I 880.

2 Wortmann's experimental method really allowed only the comparison of the amount of $\mathrm{CO}_{2}$ liberated in the absence of oxygen with the amount of oxygen absorbed with access to oxygen.

Wilson. Flora. 65:93. I882.

4 Moeller. Ber. d. bot. Ges. 2 : 306. I884.

Sorodin, J. Bot. Zeitg. 1881: 127 . 
increase in the production of $\mathrm{CO}_{2}$ is to be expected when oxygen is admitted, since the intermediate products formed in considerable quantity in the absence of oxygen should burn vigorously with renewed access to oxygen. The author carried out only one experiment with an elder branch and observed no increased production of $\mathrm{CO}_{2}$ after leaving it for a time in a chamber free of oxygen. That this kind of increase in the respiratory energy does in fact often take place will be clear from later descriptions.

Godlewski ${ }^{1}$ expressed his opinion that the absorption of oxygen and the release of $\mathrm{CO}_{2}$ in oxygen respiration constitute a uniform process and require no preliminary step to true respiration. Reinke ${ }^{2}$ follows this view entirely and assumes that the respiratory material is burned directly to $\mathrm{CO}_{2}$ and $\mathrm{H}_{2} \mathrm{O}$ by the activity of powerful catalysts which activate the atmospheric oxygen.

It is evident that the theory of the connection of anaerobic with normal respiration met with little approval in plant physiology. Only Pfeffer and Wortmann declared themselves in favor of it but their schematic representations proved to be unsound. When Diakonow next came forward with his refined experimental studies the fate of the "Theory of Connection" was decided for a considerable time. Diakonow's results are incompatible with the assumption of a connection of anaerobic with normal respiration for the following reason. If anaerobic respiration is a preliminary step to the normal process, it must meet all the conditions of nutrition under which normal respiration continues unhindered. If this is not the case it must be concluded that normal respiration can take place without the participation of material transformations which are only possible in the absence of oxygen under certain conditions. Diakonow really sought to prove that normal oxygen respiration continues under conditions which preclude anaerobic respiration.

The interesting experiments of Diakonow ${ }^{3}$ were carried out with pure cultures of the molds, Penicillium glaucum, A spergillus niger and Rhizopus nigricans. The experimental method con-

1 Godlewski, E. Jahrb. f. wiss. Bot. 13:524. I882.

2 Reinke, J. Bot. Zeitg. 1883: 65.

3 Drakonow, N. Arch. slaves de biol. I: 531. 1886;4:31, I21. I887; Ber. d. bot. Ges. 4: 1. 1886. 
sisted in growing the molds on various organic substances as sources of carbon. After fungus mats had formed a quantitative determination was made of the respiration of these mats, first in an air current, then in a current of hydrogen and finally in the air current again. This result followed with great precision: the fungi formed $\mathrm{CO}_{2}$ in a current of hydrogen only with saccharine nutrients; on other substances not a trace of $\mathrm{CO}_{2}$ was liberated and the fungus mats died after a few hours of anaerobiosis. On the basis of these results this author concluded that anaerobic respiration of molds is nothing but alcoholic fermentation which can take place only in the presence of sugar. Since normal oxygen respiration proceeds vigorously in the absence of sugar Diakonow assumed that anaerobic respiration is an entirely independent process which has no connection with oxygen respiration, and is to be regarded as a biological adaptation. According to Diakonow the rôle of anaerobic respiration is to supply the organism with a small amount of energy which just suffices to sustain its life for a short time in case of eventual anaerobiosis. It has already been pointed out that the latter explanation is positively to be refused. There can be no question of a biological adaptation in such cases.

In another piece of work ${ }^{1}$ Diakonow sought to obtain the same results with seed-plants. He found that seeds of Vicia Faba and Pisum sativum, which contain a considerable amount of reserve carbohydrate, form $\mathrm{CO}_{2}$ in the presence of oxygen while the seeds of Ricinus communis, which are provided with only small amounts of carbohydrate, exhibit a very weak anaerobic respiration. Moreover, Diakonow pointed out that the seeds of Vicia Faba form more $\mathrm{CO}_{2}$ when oxygen is excluded than when it is admitted. In Diakonow's opinion, this result is a direct contradiction of the Pflüger-Pfeffer theory.

Diakonow's results with seed-plants have been confirmed by Palladin ${ }^{2}$ with great precision. Palladin was able to nourish etiolated and green leaves of various plants with solutions of organic substances. Sugar-poor, etiolated bean leaves in

\footnotetext{
Diakonow, N. Arch. slaves de biol. 3:6. I887; Ber. ๔. bot. Ges. 4: 4 II. I886.

${ }^{2}$ Palladin, W. Rev. gén, de bot. 6: 201. 1894.
} 
Palladin's experiments formed only very small quantities of $\mathrm{CO}_{2}$ in the absence of oxygen. After feeding them sugar the rate of the anaerobic respiration of these leaves increased considerably. On the basis of these results Palladin adopted the view of Diakonow, so much the more because the former had earlier established without doubt ${ }^{1}$ the other facts brought out by Diakonow to the effect that in the case of some plants I/N is greater than I. At the time Palladin noticed that another result of his experiments did not fit in the theory. The feeding of sugar increased not only the anaerobic but also the normal respiration of leaves to the same degree. The value of $I / N$ remained constant under all conditions.

These results of Diakonow were decisive. Even Pfeffer changed his views after the appearance of Diakonow's results. In his second communication ${ }^{2}$ on the subject of anaerobic respiration he takes into consideration Diakonow's results which, though not yet published, were already known to him because the work was done in his laboratory. Pfeffer had by this time given up his earlier views and speaks very vaguely and ambiguously of the connection of anaerobic with normal respiration. He states his new standpoint in the following words: "These primary causes, which in normal respiration bring about the oxidising action of oxygen, in the absence of free oxygen show to advantage the prominent oxygen affinities and hereby effect reactions (Umlagcrungen) which presiously did nol take place wholly or in part, reactions out of which arise carbonic acid as well as other products of intramolecular respiration." This is really a mild way of entirely giving up the theory of connection. In fact it may be noted that Pfeffer's position was very difficult. There had just been carried out in his laboratory the investigations of Wilson and Diakonow which contradicted his theory. In the second edition of his textbook Pfeffer treats the whole question of anaerobic respiration according to the results and conclusions of Diakonow. ${ }^{3}$

\footnotetext{
${ }_{1}^{1}$ Palladin, W. Bull. de la soc. des nat. de Moscou. 62: 44. I886. Russian.

${ }_{2}$ Pfeffer, W. Untersuch. aus d. bot. Inst. Tübingen I : I05. I885.

${ }^{3}$ Pfeffer, W. Lehrb. d. Pflanzenphysiol, 2nd. ed. Vol, I, I897.
} 


\section{REVIEW OF THE RECENT LITERATURE}

It is evident that at the close of the Igth century the theory of the connection of anaerobic with normal respiration was considered too weak to hold. The views of the opponents of this theory, especially of Diakonow, Godlewski and Palladin, were accepted at this time. Thus Chudiakow ${ }^{1}$ sought to prove that not only molds but also yeast produces $\mathrm{CO}_{2}$ from sugar solutions only in the absence of oxygen. Polowzow ${ }^{2}$ likewise accepts Diakonow's views and assumes that anaerobic respiration represents an independent process which has no genetic connection with oxygen respiration, yet it is not to be regarded as an abnormal phenomenon because it takes place simultaneously with normal respiration with unrestricted access to oxygen, and indeed stands out in the case of retarded growth. At the time at which Polowzow advanced this hypothesisimportant facts in favor of the connection of anaerobic with normal respiration had been disclosed. The Polowzow hypothesis is to be regarded as an "after-effect" of Diakonow's work and serves to illustrate the strong influence of that work upon his younger colleagues. In the same way Maquenne ${ }^{3}$ observed the marked increase of normal respiration after four hours of anaerobiosis, a fact missed by Borodin (loc. cit.), but in spite of this he retained the old theory and recognized no connection between anaerobic and normal respiration. However, Pflüger's theory supposes that there are formed in anaerobic respiration easily oxidisable materials which are then burned to $\mathrm{CO}_{2}$ and $\mathrm{H}_{2} \mathrm{O}$ through the agency of oxidising catalysts. Maquenne's experiments could thus be interpreted as directly in favor of the Pflüger theory.

The adherents to Diakonow's views passed over a later work of Diakonow ${ }^{4}$ without due consideration. Indeed this particular piece of work was published in Russian yet it was left almost unconsidered by Russian investigators. In this work Diakonow declares that his earlier results were not wholly reliable and repeats his experiments with molds under other

\footnotetext{
1 Chudiakow, J. Landwirtschaftl. Jahrb. 23: 486. 1894.

${ }^{2}$ Polowzow, V. Untersuch. uber die Pflanzenatmung. I90I. Russian.

${ }^{3}$ Maquenne. Compt. rend. Ir9: 100, 697. I 894.

- Diakonow, N. Arb. d. Naturf.-Ges, in Petersburg 23: I. 1893.
} 
conditions and likewise with very young fungus mats. The new results were startling. It appeared that strongly aerobic molds do not give off a trace of $\mathrm{CO}_{2}$ in the absence of oxygen, even when supplied with fermentable sugars, and they die after ${ }_{1-I^{1}}^{1} \frac{2}{2}$ hours. Diakonow believes they are to be defined as typical aerobic representatives of the Lebenssubstrate (basis of life) which in general effect no material transformations in the absence of oxygen and grow only with a free access to oxygen. Indeed this view found adherents, for in an article published in the year 1903. Dude ${ }^{1}$ sought to show that Aspergillus niger dies in hydrogen after 40-I 20 minutes (in each case after the preparation of the nutrient solution). It will be clear from what follows that this conclusion was entirely unwarranted.

It seemed very probable that this last work of Diakonow2 led to incorrect results. The test carried out by Kostychev in the year $1899^{3}$ showed in fact that Penicillium glaucum liberates $\mathrm{CO}_{2}$ regularly on sugar solutions with oxygen excluded. This suggested that the earlier experiments of Diakonow as well had not been correctly carried out or interpreted. In the course of time various kinds of studies appeared, the results of which were really in favor of the theory of connection. To these belong, among others, all those studies which prove that $\mathrm{I} / \mathrm{N}$ is constant under various conditions, particularly the results of Chudiakow, Amm, Palladin and Morkowin ${ }^{t}$ already cited. It is evident that from Diakonow's standpoint all these regularities were nothing but chance agreements; a very improbable explanation! On the other hand, the following interpretation of these facts is clearly more significant in the light of Pflüger's theory. Influences which act on the first phases of the respiratory process must sway the whole process in the same direction.

The discovery of zymase by $\mathrm{E}$. and $\mathrm{H}$. Buchner ${ }^{j}$ furnished another important support to the theory of connection.

Dude. Flora. 92 : 205. I903.

2 Diakonow, N. loc. cit.

${ }^{3}$ Kostytschew, S. Arb. d. Naturf.-Ges, in Petersburg 30: I $20 . \quad$ I 899.

4 Chudiakow, N. Landwirtschaftl. Jahrb. 23: 333. I894; Amm. Jahrb. f. wiss. Bot. 25: I. I893; Palladin, W. Rev. gén. de bot. 6: 201. I894; Morkowin, N. Ber. d. bot. Ges. $21: 72.1903$.

3 Buchner, E. Ber. d. chem. Ges. 30: I17, I100. 1897; Buchner, E., H. Buchner und M. Hahn. Die Zymasegärung. 1903. 
Detailed studies by these workers have established the fact that the zymase of yeast is indifferent to atmospheric oxygen. Its action is the same with access to oxygen as with the exclusion of oxygen. Now the question is: why do seed-plants and other aerobic organisms produce no alcohol under normal living conditions, and why does the action of zymase become conspicuous in them only when oxygen is excluded? Either the zymase of seed-plants is not wholly identical with that of yeasts or the products of the action of zymase disappear when exposed to air as a result of the action of oxidation processes. The latter assumption forms the most important basis of the theory of the connection of anaerobic with normal respiration.

Actually only the results of Diakonow's experiments could be lined up against all the points which favor the theory of connection, but it must be kept in mind that Diakonow himself in a later paper declared that his earlier results were not wholly reliable. For that reason it was necessary to repeat Diakonow's work.

This repetition was carried out by Kostychev ${ }^{1}$ and yielded a disproof and clarification of the most important results of Diakonow. The experiments were performed first in nitrogen in order to rule out the eventually injurious effect of hydrogen or its impurities. Pure cultures of the molds Aspergillus niger and Rhizopus nigricans were grown on solutions of grape sugar, quinic acid, peptone and tartaric acid. Cultures fed with either sugars or non-sugars gave off $\mathrm{CO}_{2}$ in the absence of oxygen. Later it was found that lactic acid, glycerine and mannite cultures of Aspergillus niger elicit anaerobic formation of $\mathrm{CO}_{2}$. On the strength of these results, as well as his numerous later experiments with various seed-plants, Kostycher was justified in concluding that the so-called anaerobic respiration is peculiar to all aerobic plants. Thus Diakonow's thesis was changed. Diakonow's results may be traced to a poisoning of the aerobic molds in the absence of oxygen by products of imperfect metabolism. Kostychev ${ }^{2}$ showed, among other points, that Aspergillus niger produces considerable quantities of $\mathrm{CO}_{2}$ and

${ }_{1}^{1}$ Kostytschew, S. Jahrb. f. wiss. Bot. 40:563. I904.

${ }^{2}$ Kostytschew, S. Ber. d. bot. Ges. 25: 44. 1907; Untersuch. über anaerobe Atmung. 1907. Russian. 
alcohol in the absence of oxygen if the fungus mat is immersed in a sugar solution and is not left in a gaseous medium. Under these conditions part of the products of metabolism diffuse into the surrounding solution, whereby the poisoning of the fungus is diminished. The more recent investigations of Kostycher and Afanassjewa ${ }^{1}$ have weakened the question of the poisoning of aerobic fungi. It has turned out that Aspergillus niger and Penicillium glaucum, which under normal living conditions tolerate very considerable concentrations of acid and grow luxuriantly on a 5 per cent solution of free tartaric acid for example, are severely poisoned by minimal amounts of acid in the absence of oxygen. For example, a tartaric acid culture of Aspergillus niger formed no ethyl alcohol on the same solution which served very well for its previous development. After the restoration of a weak alkaline reaction it was able to evoke a considerable formation of alcohol by Aspergillus and Penicillium. On sugar solutions Aspergillus niger was alone able to produce alcohol under anaerobic conditions and with an acid reaction. Penicillium glaucum was unable to form more than traces of ethyl alcohol under these conditions. This result was the more surprising because both fungi produce alcohol by the gram with a slightly alkaline reaction (in the presence of $\mathrm{CaCO}_{3}$ and with oxygen excluded). The alcoholic fermentation of these so-called "strongly aerobic" fungi was so considerable in the experiments of Kostychev and Afanassjewa that the progress of $\mathrm{CO}_{2}$-formation could be followed with the naked eye by the development of bubbles. In Diakonow's experiments as well as in those of Kostychev and Afanassjewa, Penicillium, for example, on the surface of a slightly acid solution did not produce a trace of alcohol, while the fungus mats which were immersed in large quantities of sugar solution with neutral reaction effected a normal alcoholic fermentation.

Kostychev and Afanassjewa have also put an end to the idea of a supposed distinction between feeding with sugar and with non-sugars, so strongly emphasized by Diakonow. It was found that various organic, nitrogen free nutrients, such as glycerine, mannite, tartaric acid, quinic acid, and lactic acid

\footnotetext{
${ }^{1}$ Kostytschew, S. und M. Afanassjewa. Jahrb. f. Wiss. Bot. 60:628. I92I.
} 
are changed to sugar by fungi. The sugar is then fermented to $\mathrm{CO}_{2}$ and ethyl alcohol. ${ }^{1}$

By means of all these results, not only the work of Diakonow but the older investigations of Wilson and Moeller were overhauled. ${ }^{2}$ The theory of the genetic connection of anaerobic with normal respiration has again been re-established and can now be expanded further.

Influenced by the discovery of zymase and by the various later experimental results, the opponents of the theory of connection, Godlewski and Palladin, have also modified their views. After Godlewski and Polzeniusz proved the identity of anaerobic respiration of pea seeds with alcoholic fermentation, Godlewski ${ }^{3}$ accepted the theory of connection and believed that he could take for granted that the Wortmann hypothesis is in the main correct. Wortmann made the unproven assumption that $\mathrm{I} / \mathrm{N}$ equals $I$, and in his scheme it is upon this value that the representation of the decomposition of sugar depends. Yet Godlewski alludes to the fact that this scheme can hold in principle for other values of $\mathrm{I} / \mathrm{N}$. For example, if $\mathrm{I} \mathrm{N}=0.5$, the following reactions are possible, according to Godlewski:

(I) ${ }_{3} \mathrm{C}_{6} \mathrm{H}_{12} \mathrm{O}_{6}=6 \mathrm{CH}_{3}-\mathrm{CH}_{2} \mathrm{OH}+6 \mathrm{CO}_{2}$

(II) $6 \mathrm{CH}_{3}-\mathrm{CH}_{2} \mathrm{OH}+\mathrm{I}_{2} \mathrm{O}_{2}=\mathrm{C}_{6} \mathrm{H}_{12} \mathrm{O}_{6}+6 \mathrm{CO}_{2}+\mathrm{I}_{2} \mathrm{H}_{2} \mathrm{O}$.

Takahashi ${ }^{4}$ takes issue with this conception, for he points out that ethyl alcohol is less easily oxidised than sugar; hence changing sugar to alcohol must retard respiration rather than increase it.

Palladin ${ }^{5}$ obtained the following results in his studies of the respiratory metabolism of the single celled alga, Chlorothecium saccharophilum. After not too long an anaerobiosis there follows a marked increase in the production of $\mathrm{CO}_{2}$ by the normal respiration. This observation had been made earlier by Maquenne, ${ }^{6}$ who noted a less marked stimulation. Because

1 Kostytschew, S. und M. Afanassjewa. loc. cil.; Kostytschew, S. Z. f. physiol. Chem. III: 236. 1920. [Cf. Butkewitsch, W. Biochem. Z. 159: 395-4r3. I925 for the basis of opinion that quinic acid is not first changed to sugar.]

2 The fluctuating values of $I / N$ in the case of various plants are likewise to be traced to a more or less serious poisoning of the research material when oxygen is excluded.

? Godlewski and Polzeniusz. Anz. d. Akad. d. Wiss. Krakau. I901, p. 227.

T Takahashi. Bull. coll. agr. Tokyo 5:243. 19a2-03.

${ }^{5}$ Palladin, W. Zentralbl. f. Bakt., Parasitenk. u. Infektionskrankh. (II) II: I 46.1904.

${ }^{6}$ Maquenne. Compt. rend. I19: 100,697. I894. 
the Pflüger theory of the connection of anaerobic with normal respiration presupposed a formation of easily oxidised substances in the absence of oxygen, Palladin followed the theory of connection, at first without more closely defining his views on the subject. Later he gave a detailed theory of respiration which will be discussed in the next section.

Mazé ${ }^{1}$ assumes that alcoholic fermentation is the first stage in oxygen respiration as well as in the assimilation of carbohydrate by plants. This investigator seeks to demonstrate that all the sugar consumed by normal respiration decomposes into $\mathrm{CO}_{2}$ and ethyl alcohol in the process of alcoholic fermentation. The alcohol is assimilated by the absorption of molecular oxygen and is not totally burned. In this way respiration and structural change are represented as two inseparably connected processes and all the carbon dioxide of respiration is formed by the action of zymase. These far-reaching conclusions are not sufficiently supported by Mazé's experimental results. This assumption is to be regarded as too weak to hold in the light of modern discoveries, particularly in regard to the assimilation of carbohydrate by way of the intermediate stage of ethyl alcohol. This question will be more fully explained below.

In his earlier work Kostychev ${ }^{2}$ made the following assumptions in regard to the connection of oxygen respiration with alcoholic fermentation. Alcoholic fermentation of itself is a complicated process which consists of several stages. With aerobic plants alcohol is formed only when oxygen is excludedhence in the absence of biochemical oxidation processes. A complete oxidation of labile intermediate products of alcoholic fermentation occurs with free access to oxygen before alcohol is actually formed. In this way ethyl alcohol, contrary to the assumption of Pfeffer and Wortmann, is not an intermediate product of oxygen respiration but a metabolic product which is spontaneously formed in strongly aerobic plants only when oxidation is checked. Nevertheless an action of zymase is indispensable for oxygen respiration because through the action of enzymes of fermentation the sugar is changed into

'Mazé. Ann. de l'inst. Pasteur 16: 195, 346, 433. I902; 18: 277, 378, 535. I904.

2 Kostytschew, S. Jour. f. exp. Landwirtsch. 2: 580. I90I. Russian: Untersuch. über die anaerobe Atmung d. Pflanzen. 1907. Russian; and others. 
labile, easily oxidised substances which then fall before a vital combustion. In later work Kostycher has sought to confirm this theory experimentally. In the first place he has shown that ethyl alcohol is oxidised by seed-plants with difficulty or not at all. Secondly, he has called particular attention to the surprisingly strong stimulation of oxygen respiration by means of fermented sugar solutions. ${ }^{1}$ These results have already been mentioned. To be sure, they yield no direct evidence that it is particularly the intermediate products of alcoholic fermentation which are burned in normal respiration but they could be interpreted in the sense suggested. On the other hand Kostychev has shown² that fermented solutions contain substances which are completely burned under the influence of the oxidising enzymes of seed-plants. Yet the same oxidising enzymes are unable to form $\mathrm{CO}_{2}$ from grape sugar. All these experiments will be discussed later.

\section{THE LATEST OBJECTIONS TO THE THEORY OF THE CON- NECTION OF ANAEROBIC WITH NORMAL RESPIRATION}

From the above statement it is clear that the following facts can be cited in favor of the theory of connection.

I. The universal dissemination of anaerobic respiration. So far not a single plant has been found which is unable to produce $\mathrm{CO}_{2}$ in the total absence of oxygen $[c f$. editorial note $b$ above]. Most of these plants live under conditions which preclude an actual anaerobic condition. The supposed importance of anaerobic respiration as a "biological adaptation" is therefore most questionable. The assumption is much more probable that it represents a normal vital process.

2. The activity of zymase is unchecked by free access to oxygen. From the subsequent exposition it will be clear that zymase of seed-plants is no exception in this respect. ${ }^{3}$ The absence of a production of alcohol in the normal life of seedplants is therefore not attributable to the inactivity of the

\footnotetext{
${ }_{1}$ Kostytschew, S. lor. cil.; aiso Kostytschew, S. und A. Scheloumow. Jahrb. f. wiss. Bot. 50: 157. 1911 .

2 Kostytschew, S. Z. f. physiol. Chem. 67: i16. I910.

${ }^{2}$ Kostytschew, S. Ber. d. bot. Ges. 22: 207. I904; Zentralbl. f. Bakt., Parasitenk. u. Infektionskrankh. (II). 13: 490. I904; Palladin, W. und S. Kostytschew. Z. f. physiol. Chem. 48: 214. 1907.
} 
enzymes of fermentation in the presence of oxygen. It is much better to assume that the products of fermentation are burned in the respiratory process.

3. This assumption is supported by two kinds of facts. In the first place, sugar solutions fermented by yeast stimulate the normal oxygen respiration of plants. ${ }^{1}$ Secondly, after a temporary deprivation of oxygen there follows a powerful increase in the aerobic production of $\mathrm{CO}_{2}$ if the material is not severely poisoned during the anaerobiosis. ${ }^{2}$

4. It is a consistent fact that the oxidising enzymes of plants are unable to attack sugar directly but are able to burn to $\mathrm{CO}_{2}$ the substances contained in fermented solutions. Hereby the necessity for the anaerobic cleavage of sugar for the normal process of oxygen respiration becomes clear. ${ }^{3}$

5. Various types of external influences on normal and anaerobic respiration do not modify the value of $I / N$. This shows that the aerobic and the anaerobic production of $\mathrm{CO}_{2}$ are influenced in the same way and to the same degree. ${ }^{4}$ For example, it is worthy of note that, according to Amm, the course of the anaerobic respiration in the germination of seeds may be shown by the same curve of the grand period of respiration as the course of oxygen respiration and of growth. Thus it appears that increased respiratory activity requires a corresponding increase in the intensity of the first phase of respiration. None the less convincing are the results of Morkowin and especially those of Smimoff. Morkowin has shown that the value of $I / N$ remains unchanged when respiration is stimulated by the action of poisons. Smirnoff produced the same effect by wound stimulus. In this connection there is the folluwing circumstance which may be regarded as an unequirocal confirmation of the theory of connection. The stimulation of anaerobic respiration by mechanical stimuli is possible

${ }^{3}$ Kostytschew, S. Biochem. Z. I5: 164. I908; 23: 137. I909; Ber. d. bot. Ges. 31 : 422,432 . 1913.

2 Maquenne. Compt. rend. I I9: I00, 697. I894; Palladin, W. Zentralbl. f. Bakt., Parasitenk. u. Infektionskrankh. (I1). I I : I46. I904.

Kostytschew, S. Z. f. physiol. Chem. 67: II6. I9I0.

Amm. Jahrb. f. wiss. Bot. 25: I. 1893; Palladin, W. Rev. gén. de. bot. 6: 20 I. 1894; Chudiakow, N. Landwirtschaftl. Jahrb. 23: 333. I894; Morkowin, N. Ber. d. bot. Ges. 21: 72. I903; Smirnoff. Rev. gén. de bot. 15:32. 1903. 
only if the stimulated objects respire alternately ${ }^{e}$ under aerobic and anaerobic conditions. If the experimental material is left without oxygen, wound stimulation has no effect on the anaerobic respiration.

It must be pointed out at once that the genetic connection of anaerobic with normal respiration is not fully proven by the facts just given. A direct proof could only be supplied if it were possible to demonstrate which products of the anaerobic metabolism are oxidised in the presence of oxygen and how this oxidation takes place. Nevertheless the theory is and remains a fruitful working hypothesis, the full meaning of which will be demonstrated in the next section. On this account it has usually been favorably received, particularly in its modern form (as the oxidation of the intermediate products of fermentation), especially since it has turned out that the "intermediate products of fermentation" actually exist. Alcoholic fermentation has proved to be a complicated process.

Only Maquenne and Boysen-Jensen have recently raised objections to the general validity of the theory of connection. Maquenne and Demoussy ${ }^{1}$ have found that foliage leaves are quickly ruined in an atmosphere entirely free of oxygen. The writers perceive in this a contradiction to the theory of connection which appears to the author of these lines to be hardly correct. If the respiratory processes be considered from the energy standpoint it is evident that the heat released by anaerobic respiration is very insignificant in comparison with that of the oxidative processes, even if the latter take place to only a limited extent. Just on this account plants go to ruin when oxygen is excluded. If the anaerobic respiration be considered as a preparatory act, the importance of which consists in the production of easily oxidised intermediate products of alcoholic fermentation, it appears to be quite natural that this intermediate stage of normal respiration of itself is not allied with a development of energy. Moreover, the modern view

1 Maquenne, L. et E. Demoussy. Compt. rend. 173:373. 1921 .

"By the word "alternately" (abwechselnd) Kostychev apparently" means to emphasize the progressive nature of the whole process of respiration. It refers to the fate of a singie molecule of respiratory material and does not suggest that the tissue must be placed under first anacrobic and then aerobic conclitions. - Ed. 
of the combustion of the intermediate products of fermentation appears to be unknown to Maquenne and Demoussy.

Boysen-Jensen ${ }^{1}$ emphasizes the fact that in his experiments with some plants the value of $\mathrm{I} N$ fell below $1 / 3$. The author assumes that in the case of plants which exhibit a more or less intensive anaerobic respiration this is really connected with the normal respiration and facilitates the complete oxidation of sugar. On the contrary, plants which exhibit a very weak anaerobic respiration present difficulties to the theory of connection, in the opinion of Boysen-Jensen. That is to say, if the total amount of the sugar used in respiration were first handled by enzymes of fermentation the latter must complete the fermentation of the sugar in the absence of oxygen and thereby liberate $1 / 3$ the amount of $\mathrm{CO}_{2}$ which is set free by the total combustion of sugar.

$$
\begin{gathered}
\mathrm{C}_{6} \mathrm{H}_{12} \mathrm{O}_{6}={ }_{2} \mathrm{CO}_{2}+{ }_{2} \mathrm{CH}_{3}-\mathrm{CH}_{2} \mathrm{OH} \text { (Fermentation) } \\
\mathrm{C}_{6} \mathrm{H}_{12} \mathrm{O}_{6}+6 \mathrm{O}_{2}=6 \mathrm{CO}_{2}+6 \mathrm{H}_{2} \mathrm{O} \text { (Combustion). }
\end{gathered}
$$

It has already been pointed out that the determinations of $\mathrm{I} / \mathrm{N}$ are of no great significance because the intensity of the anaerobic respiration is affected by the degree of the poisoning. Boysen-Jensen himself also calls special attention to the fact that especially with plants which gave small values of $\mathrm{I} / \mathrm{N}$ in his experiments the anaerobic production of $\mathrm{CO}_{2}$ decreased from hour to hour. Thus it appears that the author contradicts himself when he writes: "Incleed there is the possibility that the intramolecular respiration is insignificant with plants of this group because the plants are injured during the anaerobiosis. Against this is the fact that the plants recover after a short anaerobiosis" (page 29). However, on page 8 of his interesting paper Boysen-Jensen writes to the effect that "the value of this quotient $(\mathrm{I} / \mathrm{N})$ is very problematical" and later on continues: "As we shall see later the quantity of carbon dioxide formed during anaerobiosis is not constant for various plant material but decreases from hour to hour. The value of the quotient in question changes very rapidly with the duration of the anaerobiosis."

' Boysen-Jensen, P. Biol. Meddel. udgivne af det danske videnskab. selskab. 4: I. I923. 
The author of this book agrees fully with this latter view. Moreover, it must not be forgotten that the recovery of plants after the anaerobiosis does not constitute an objection to the assumption of a toxic effect under such circumstances. Whether the plant recovers or finally dies depends only on the degree of the poisoning. Boysen-Jensen's demonstrations in behalf of a possibility of the direct combustion of sugar in the respiratory process will be further treated below. It appears that this kind of direct combustion is hardly possible in the plant cell.

Let it be noted that the treatise of Boysen-Jensen contains important and interesting experimental results which have already been considered in part but some of which are mentioned on subsequent pages. The theoretical differences of opinion are really of secondary importance. The author of these lines sees, for example, in the various facts communicated by Boysen-Jensen, a confirmation of the theory of the connection of anaerobic with normal respiration. As there is no direct, unambiguous proof of the validity of this theory such adverse views are probably unavoidable. 


\section{THE CHEMICAL PROCESSES IN PLANT RESPIRATION}

\section{THE ANAEROBIC MATERIAL TRANSFORMATIONS AND THE PARTICIPATING ENZYMES}

By virtue of the preceding exposition it is advisable to consider the material transformations of respiration from the standpoint of the theory of the genetic connection of anaerobic with normal respiration. Consequently we assume that the handling of matter in normal respiration may be divided into two groups of reactions-anaerobic cleavage processes and oxidative processes. We wish now to deal with the cleavage processes.

It has already been emphasized that ethyl alcohol is formed regularly by the anaerobic respiration of plants. Kostychev failed to observe a formation of alcohol only in the case of the following: I. fruiting bodies of Psalliota campestris, 2. dormant potato tubers, 3. peptone cultures of Aspergillus niger. Of course all these objects produced considerable quantities of $\mathrm{CO}_{2}$ in the absence of oxygen. It was certainly important to determine whether enzymes of alcoholic fermentation appear in aerobic plants. This question may also be answered in the affirmative. Shortly after the discovery of zymase in yeast Stoklasa ${ }^{1}$ exhibited preparations from seed-plants which fermented sugar to ethyl alcohol and $\mathrm{CO}_{2}$. At first this gave rise to rloubt whether bacteria were not to be regarded as the cause of the fermentation. Later zymase was isolated by Kostycher ${ }^{2}$ from pure cultures of various aerobic molds. Palladin and Kostychev $^{3}$ also established beyond question the action of zymase in various killed seed-plants through the exclusion of

${ }^{1}$ Stoklasa, J. und Cerny. Ber. d. chem. Ges. 36: 622, 1903; Zentralbl. f. Physiol. I6: 652. 1903: Stoklasa, Jelinek, and Vitek. Hofm. Beitr. 3: 460 . 1903; Stoklasa, Cerny, Jelinek, and Vitek. Zentralbl.f. Bakt., Parasitenk, u. Infektionskrankh. (II). 13:86. I904; Stoklasa. Zentralbl. f. Physiol. I $7: 465$. I903; Arch. ges. Physiol. 101: 3 I I. 1904.

${ }^{2}$ Kostytschew, S. Ber. d. bot. Ges. 22: 207. 1904; Zentralbl. f. Bakt., Parasitenk. u. Infektionskrankh. (II). 13: 490. 1904.

${ }_{3}$ Palladin, W. und S. Kostytschew. Z. f. physiol. Chem. 48: 2 I 4. 1906. 
lower organisms. The mode of operation of the zymase isolated from seed-plants and aerobic molds is just like that of zymase from yeast. In both cases oxygen has no effect on the process of formation of alcohol. These results show that the absence of alcohol in living aerobic plants under normal conditions cannot be attributed to a restraint of the enzymes of fermentation but to the further use of the products of fermentation. All theories which dispute the genetic connection between anaerobic and normal respiration must furnish a satisfactory explanation for the absence of the formation of ethyl alcohol when air is admitted, and indeed for the fact that the action of zymase in seed-plants and aerobic fungi is not checked by oxygen.

Carboxylase, an enzyme which separates $\mathrm{CO}_{2}$ from $\alpha$-ketonic acids and is admitted to be a constituent part of the complex of enzymes of fermentation which is included in the term zymase was found in seed-plants by Zaleski. ${ }^{1}$ In like manner hexosephosphatase, an enzyme which esterifies sugar with phosphoric acid and likewise probably participates in alcoholic fermentation, was found to be present. ${ }^{2}$

It is very worthy of note that Meyerhof ${ }^{3}$ found that the alcoholic fermentation of yeast is strongly stimulated by an aqueous extract of animal muscle or of germinating plants. Conversely, yeast extracts increase the normal respiration of plants as Kostychev ${ }^{4}$ has pointed out before.

Meyerhof alludes to the necessity of the same "coenzymes" for the normal respiration of animal tissue as for yeast fermentation. Hexose phosphate particularly is said to be just as indispensable for the enzymatic oxygen respiration as for the enzymatic alcoholic fermentation. Although the idea of coenzymes is very indefinite, ${ }^{5}$ these results of Meyerhof by agreeable interpretation favor the assumption that there is a genetic connection between fermentation and respiration.

1 Zaleski, W. und E. Marx. Biochem. Z. 47: 184. I912; Zaleski, W. Ibii. 48: 175. 1913: Ber. d. bot. Ges. 32: 457. 1914; Bodnar, J. Biochem. Z. 73: 193. 1916.

2 Nemec, A. und F. Duchon. Biochem. Z. 119: 73. I921.

Meyerhof, O. Arch. ges. Physiol. 170: 367, 428. I918; Z. f. physiol. Chem. 101 : i65. 1918; 102: I. 1918.

Kostytschew, S. Biochem. Z. 15: 164. 1908; 23: I37. I909; Kostytschew, S. und A. Scheloumow. Jahrb. f. wiss. Bot. 50: I57. 1911; Ber. d. bot. Ges. 31: 422, 432.1913. ${ }^{3} \mathrm{Cf}$. also Abderhalden, E. und $\mathrm{H}$. Schaumann. Fermentforschung. $2: 120$. I9I $8 ; 3: 44$. I919. 
Moreover, the identity of alcoholic fermentation of seedplants and molds with that of yeast has been successfully shown through the isolation of acetaldehyde, which is undoubtedly to be regarded as an intermediate product of yeast fermentation. In the case of plants which possess stores of loosely bound oxygen and a considerable quantity of oxidising enzymes, the acetaldehyde is not completely reduced to ethyl alcohol even when oxygen is excluded. Thus for example, Kostycher and his coworkers $^{1}$ were able to demonstrate the formation of appreciable amounts of acetaldehyde by the anaerobic respiration of poplar blossoms. Neuberg and his collaborators ${ }^{2}$ have caught acetaldehyde in the form of bisulphite compounds in the case of the alcoholic fermentation of various fungi.

It has already been pointed out that $\mathrm{CO}_{2}$ appears in the anaerobic respiration of plants as the only gaseous product. According to modern investigations the liberation of hydrogen, as presupposed by earlier writers, especially when mannite is used in respiration, is nothing but a result of bacterial infection. ${ }^{3}$ On the other hand it is quite probable that products of anaerobic metabolism other than ethyl alcohol are formed in plants. In the first place, it must be taken into consideration that the value of $\frac{\mathrm{CO}_{2}}{\mathrm{C}_{2} \mathrm{H}_{5} \mathrm{OH}}$ in the case of most aerobic plants does not correspond to the molecular proportion required by the equation for alcoholic fermentation. Particularly, a considerable surplus of $\mathrm{CO}_{2}$ is often formed. This condition can be explained in two ways.

I. Previous to the actual formation of alcohol a part of the products of fermentation become altered in such a way that $\mathrm{CO}_{2}$ but no alcohol is formed from the decomposed sugar molecule.

II. Alcoholic fermentation is not the only source of $\mathrm{CO}_{2}$ in seed-plants which are respiring in the absence of oxygen. Other processes take place by which $\mathrm{CO}_{2}$ is released but no alcohol is formed.

\footnotetext{
${ }^{3}$ Kostytschew, S., Hübbenet, E. und A. Scheloumow. Z. f. physiol. Chem. 83: I05. I9I3.

2 Cohen, C. Biochem. Z. II2: I39. I920; Neuberg. C und C. Cohen. Ibid. I22: 204. I921; also Eliasberg, P. Jour. d. Landw. Inst. in Petrogad I921. P. 74. Russian. (With Mucors.)

${ }^{3}$ Kostytschew, S. Ber. d. bot. Ges. 24: 436. I906; 25: 178. I907.
} 
Both assumptions are not unlikely for the following reasons:

With potato tubers and fruiting bodies of Psalliota campestris not the least formation of alcohol was observed in the absence of oxygen ${ }^{1}$ although the former contain sugar while the mushrooms contain considerable amounts of mannite. It was found by analyses that a considerable part of the mannite in Psalliota is consumed when oxygen is excluded; ${ }^{2}$ there was likewise a consumption of sugar in the potato tubers. On the basis of specific experiments of the author, discussed later, the consumption of mannite by aerobic molds in the absence of oxygen is nothing but the formation and fermentation of sugar (fructose). It is natural to assume that mannite is also worked up in the anaerobic respiration of the mushrooms by way of sugar as an intermediate. This is all the more probable because, with access to oxygen, a formation of sugar from mannite takes place to a large extent in these plants. It is also hardly conceivable that the working up of sugar in potatoes is not effected by the use of zymase, for in all the seed-plants the cleavage of sugar has so far been found to take place only through alcoholic fermentation. On the strength of all these considerations it is natural to assume that, in the above plants as well as in other cases in which there appears a considerable surplus of $\mathrm{CO}_{2}$ with the exclusion of oxygen and the disappearance of sugar, the alcoholic fermentation takes a somewhat abnormal course and an intermediate product of fermentation is converted in part into other substances.

According to the view of the author of these lines, only acetaldehyde can be considered in the cases before us, because ethyl alcohol is formed from acetaldehyde by the absorption of hydrogen after $\mathrm{CO}_{2}$ has been split off. $f$ Important reasons favor the assumption that in alcoholic fermentation there arises, by

${ }_{3}$ Kostytschew, S. Ber. d. bot. Ges. 25: I88. I907; 26a: 167. 1908; 31: I25. I913.

2 Kostytschew, S. Z. f. physiol. Chem. 65:350. 1910.

Stoklasa does not accept this theory of the formation of alcohol (in the anaerobic phase of respiration) but considers that it arises from lactic acid through the removal of a molecule of carbon dioxide. Acetaldehyde, acetic acid and formic acid are formed later by way of the alcohol. Stoklasa's recent paper (Ber. d. bot. Ges $44: 248-262$. 1926) reviews the problem and presents some new experimental evidence.-Ed. 
means of various transformations, pyruvic acid, which is then split by carboxylase into acetaldehyde and carbon dioxide.

$$
\mathrm{CH}_{3}-\mathrm{CO}-\mathrm{COOH}=\mathrm{CH}_{3}-\mathrm{CHO}+\mathrm{CO}_{2}
$$

The acetaldehyde is then reduced to ethyl alcohol. Hence it is clear that in alcoholic fermentation the $\mathrm{CO}_{2}$ and alcohol do not arise simultaneously. This explains how the ratio $\frac{\mathrm{CO}_{2}}{\mathrm{C}_{2} \mathrm{H}_{5} \mathrm{OH}}$ comes to be abnormal in some plants. It can be so because the acetaldehyde either unites with other substances or becomes inaccessible before reduction through the eventual formation of aldol or by similar alterations. These side reactions could also be brought about through the checking of the reducing forces which, in the case of normal fermentation, induce a change of aldehyde to alcohol. This checking could be eroked by means of oxidising agencies and indeed by the oxidation of the hydrogen necessary for the formation of the alcohol. The circumstance is worthy of note that particularly in plants in which there are powerful oxidative processes and in which loosely bound oxygen is contained, the value of $\frac{\mathrm{CO}_{2} \mathrm{H}_{5} \mathrm{OH}}{\mathrm{C}_{2}}$ is found to be abnormal in the absence of oxygen. In actual practice the ratio $\frac{\mathrm{CO}_{2}}{\mathrm{C}_{2} \mathrm{H}_{5} \mathrm{OH}}$ for aerobic molds is always the same as for normal yeast fermentation. On the other hand, a considerable part of the sugar consumed by molds in the absence of oxygen is not made into $\mathrm{CO}_{2}$ and alcohol but into other substances, the nature of which has not been established at the present time.

The abnormal size of $\frac{\mathrm{CO}_{2}}{\mathrm{C}_{2} \mathrm{H}_{5} \mathrm{OH}}$ in the case of the anaerobic working-up of sugar may often be traced to the fact that in some plants acetaldehyde, the intermediate step in the formation of alcohol, is not reduced to alcohol but is consumed in another manner.

Apparently all cases in which neither the working-up of sugar nor the presence of zymase is demonstrable are to be explained otherwise. Thus Kostychev and Afanassjewa ${ }^{1}$ found that

\footnotetext{
${ }_{1}$ Kostytschew, S. und M. Afanassjewa. Jahrb. f. wiss. Bot. 60:628. I92I; $f$. also Kostytschew, S. Z. f. physiol. Chem. II I : 236 . 1920.
} 
peptone cultures of Aspergillus niger give off $\mathrm{CO}_{2}$ in the absence of oxygen but do not produce the smallest amount of alcohol. In this case the lack of formation of alcohol is probably due to the absence of zymase, because peptone cultures of Aspergillus niger do not work up added sugar in the absence of oxygen. After a short stay on sugar solutions with access to oxygen peptone cultures do produce considerable amounts of zymase and so gain the power to ferment energetically sugar to $\mathrm{CO}_{2}$ and alcohol in the absence of oxygen. It can hardly be doubted that in the cases before us the anaerobic respiration took place in the absence of sugar at the expense of the cleavage products of the protein and so presented an entirely different process from alcoholic fermentation. In other plants also there occurs, under certain conditions, such a cleavage of $\mathrm{CO}_{2}$ from nitrogenous products of protein hydroly'sis simultaneously with alcoholic fermentation that the total excretion of $\mathrm{CO}_{2}$ is considerably increased and the ratio $\frac{\mathrm{CO}_{2}}{\mathrm{C}_{2} \mathrm{H}_{5} \mathrm{OH}}$ attains an abnormal value.

\section{THE NATURE OF THE OXIDATION PROCESSES IN PLANT CELLS}

Before we seek to define more closely the connection of the anaerobic clearage processes with the subsequent oxidation of the clearage products, the foundations of biological oxidation in plant cells must be discussed.

It is acknowledged that Lavoisier was the first to prove that oxidations are to be traced to the fixation of oxygen. Later investigations by various workers showed that autoxidations at the expense of molecular oxygen often introduce complicated processes, because the absorption of atmospheric oxygen by autoxidisable substances is not uncommonly accompanied by the oxidation of compounds which of themselves do not fix molecular oxygen at all or only very slowly. Thus phosphine is quickly oxidised by atmospheric oxygen. With it there easily occurs a simultaneous oxidation of indigo white which of itself proceeds slowly and incompletely. Analogous phenom- 
ena were also observed for the autoxidation of aldehydes and other substances.

Thus it is clear that autoxidation does not lead directly to the formation of oxides as seemed to be the case from the classic experiments of Lavoisier. The processes of autoxidation are rather to be regarded as instructive coupled reactions. After their investigation the physiological significance of chemical induction was first correctly understood.

Schönbein ${ }^{1}$ was the first to conceive of the processes of autoxidation as complicated reactions. He made the correct assumption that the first phase of all autoxidative processes consists in the change of inactive, molecular oxygen into an active form. But Schönbein incorrectly pictured the activation of oxygen. For this process he supposed that two bodies were formednegative ozone and positive antozone. At present this theory is considered too weak to hold.

Hoppe-Seyler ${ }^{2}$ expressed his opinion to the effect that the activation of oxygen is nothing but a dissociation process. Van't Hoff ${ }^{3}$ further developed this theory. According to him the molecule of oxygen dissociates into two charged ions, $\mathrm{O}^{+}$ and $\mathrm{O}^{-}$. If an oxidisable substance reacts with one ion, e.g. with $\mathrm{O}^{+}$, an oxidation of other substances can easily follow through the action of the oppositely charged ion, $\mathrm{O}^{-}$. In this way van't Hoff believed he could explain the simultaneous autoxidation of triethyl phosphine and indigo white as well as other analogous processes.,

This theory too met with only little approval. Thus Bodländer ${ }^{4}$ points out that two oppositely charged atoms of oxygen could hardly be separated by measurable distances. If the latter is true a selective oxidation of different substances by $\mathrm{O}^{+}$and $\mathrm{O}^{-}$seems to be quite inconceivable. Engler and Weissberg $^{5}$ showed that the autoxidation of triethyl phosphine and

\footnotetext{
${ }^{1}$ Schönbein, C. F. Verhandl. d. Naturf. Ges. Basel. $3: 5$ I6. I863; Jour. f. prakt. Chem. 105: 198. I868; Zeitsch. f. Biol. 4:367. I868.

${ }^{2}$ Hoppe-Seyler. Z. f. physiol. Chem. 2: 22. I878; Ber. d. chem. Ges. I2: I551. I879.

${ }^{3}$ van't Hoff. Z. f. physikal. Chem. I6: 4 I I. I 895; Verhandl. d. Naturf. Ges. Frankfurt. 2: 107. I897; Ewan. Z. f. physikal. Chem. I6: 321 . I895; Jorissen. Ber. d. chem. Ges. 30: 1951. I897.

' Bodländer. Samml, chem. und chem.-techn. Vorträge von Arens 3: 450. I899.

s Engler, A. und Weissberg. Ber. d. chem. Ges. 31 : 3055. 1898.
} 
benzaldehyde leads to the formation of labile peroxides, in connection with which a whole molecule of oxygen is absorbed and so no dissociation of oxygen occurs. On the strength of these results the dissociation theory is also to be considered too weak to hold.

The theory of peroxide formation developed by Traube, ${ }^{1}$ out of which later grew the modern theories of Bach-Engler and ron Wieland, proved more fruitful. Traube assumed that in all autoxidations hydrogen peroxide is first formed and finally there occurs the fixation of a whole molecule of oxygen and the formation of organic peroxides. Thus Traube ${ }^{2}$ proved that not only slow oxidation of hydrogen but also the combustion of hydrogen in the flame depends on the formation of hydrogen peroxide. ${ }^{3}$ The oxidation of metallic zinc in alkaline solution is also accompanied, according to Traube's statements, ${ }^{4}$ by an intermediate formation of hydrogen peroxide.

(I) $\mathrm{Zn}+{ }_{2} \mathrm{H}_{2} \mathrm{O}=\mathrm{Zn}(\mathrm{OH})_{2}+{ }_{2} \mathrm{H}$

(II) $2 \mathrm{H}+\mathrm{O}_{2}=\mathrm{H}_{2} \mathrm{O}_{2}$

(III) $\mathrm{Zn}+\mathrm{H}_{2} \mathrm{O}_{2}=\mathrm{Zn}(\mathrm{OH})_{2}$.

Traube assumed that all autoxidations are possible only in the presence of water, since hydrogen peroxide can be formed only under this condition. The Traube theory was then remodelled by Bach and Engler. Bach ${ }^{5}$ assumes that in processes of autoxidation the oxygen is active only in the form of unsaturated molecules $-\mathrm{O}-\mathrm{O}-$. Fixation of two atoms of oxygen always occurs by the formation of so-called moloxides which possess the

\footnotetext{
1 Traube, M. Ber. d. chem. Ges. 15: 222,659,2491. I882; 16:123, $463 . \quad 1883 ; 18$ : $1877,1887,1890,1894.1885 ; 19: 1111.1886 ; 26: 1471,1894$.

2 Traube, M. Ber. d. chem. Ges. 18: 1897. 1885; 19: I1 II. 1886; Engler. Ibid. 33: I 109.1900.

${ }^{3}$ In my laboratories this reaction is used as a lecture demonstration. A long rubber tube is attached by one end to a hydrogen generator and the other end is fitted with a finely drawn-out glass tube. The hydrogen is passed through the tube and lighted as it escapes from the capillary opening. In this way there is obtained a slender flame with which a deep. narrow hole is bored in a block of ice. In this the flame is frequently extinguished by melting water and must be relighted with a burner kept nearby. Part of the intermediate products of the hydrogen combustion are retained in the hole in the ice by rapid cooling before they are destroyed, and are collected with the water in a tumbler set beneath the hole. In this water the presence of hydrogen peroxide may then be demonstrated by the release of iodine from potassium iodide or by other specific reactions. Cf. Engler. Ber. d. chem. Ges. 33: I 109 . 1900 .

4Traube, M. Ber. d. chem. Ges. 26:1471. 1894.

5 Bach, A. Compt. rend. I 24: 95 I. 1897; Monit, sci. (1V) I1: 479 . 1897; Arch. sci. phys. et nat. (IV) $35: 240.1913$.
} 
properties of peroxides. Contrary to the opinion of Traube, Bach considers the direct formation of various organic peroxides to be possible. Thus the latter process can take place without an intermediate formation of hydrogen peroxide and even with the complete exclusion of water. A. Engler ${ }^{1}$ also proposed this theory entirely independently of Bach.

According to Bach-Engler, certain substances called autoxidators can fiz at mospheric oxygen directly. This process may be expressed by the following schematic equation:

e.g.

$$
\begin{gathered}
\mathrm{A}+\mathrm{O}_{2}=\mathrm{AO}_{2}, \\
\mathrm{H}+\mathrm{H}+\mathrm{O}_{2}=\mathrm{H}_{2} \mathrm{O}_{2} .
\end{gathered}
$$

This reaction is often made possible by the separation of the autoxidator $\mathrm{A}$ from a molecular complex through the intervention of certain substances (pseudo-autoxidators). Thus e.g.:

$$
\mathrm{Zn}+{ }_{2} \mathrm{H}_{2} \mathrm{O}=\mathrm{Zn}(\mathrm{OH})_{2}+\mathrm{H}+\mathrm{H} \text { (see above) }
$$

The moloxides formed by the autoxidation then decompose while they bind half of the absorbed oxygen to remaining molecules or atoms of the autoxidator as is the case in the combustion of hydrogen.

(I) $\mathrm{H}+\mathrm{H}+\mathrm{O}_{2}=\mathrm{H}_{2} \mathrm{O}_{2}$

(II) $\mathrm{H}+\mathrm{H}+\mathrm{H}_{2} \mathrm{O}_{2}={ }_{2} \mathrm{H}_{2} \mathrm{O}$.

It is evident that one-half of the hydrogen is oxidised to water by atmospheric oxygen but that the other half is oxidised by the oxygen of hydrogen peroxide. The moloxides formed by the autoxidation are always more powerful mediums of oxidation than molecular oxygen of the atmosphere. Consequently not only surplus quantities of the autoxidator but also other substances are oxidised by moloxides. In this the relocities of the respective reactions play a guiding rôle. Thus the oxidation of indigo white along with the autoxidation of triethyl phosphine or benzaldehyde may be represented by the following reactions:

\footnotetext{
Engler, A. und Wild. Ber. d. chem. Ges. 30: 1669. 1897; Engler und Weissberg. Ibid. 31 : 3055. I 898; 33: 1097. 1900; Krit. Studien über die Vorgänge d. Autoxydation. r904; Engler und Herzog. Z. f. physiol. Chem. 59: 327. 1909; Engler. Z.f. Elektrochem. I 8: 945 . I 9 I 2 ; and others.
} 
(I) $\mathrm{P}\left(\mathrm{C}_{2} \mathrm{H}_{5}\right)_{3}+\mathrm{O}_{2}=\mathrm{PO}_{2}\left(\mathrm{C}_{2} \mathrm{H}_{5}\right)_{3}$

(II) $\mathrm{PO}_{2}\left(\mathrm{C}_{2} \mathrm{H}_{5}\right)_{3}+\mathrm{C}_{6} \mathrm{H}$<smiles>O=C1CCCCC1</smiles>
$\mathrm{PO}\left(\mathrm{C}_{2} \mathrm{H}_{5}\right)_{3}+\mathrm{H}_{2} \mathrm{O}+\mathrm{C}_{6} \mathrm{H}_{4}\left\langle{ }_{N \mathrm{H}}^{\mathrm{CO}}>\mathrm{C}=\mathrm{C}\left\langle{ }_{N \mathrm{H}}^{\mathrm{CO}}>\mathrm{C}_{6} \mathrm{H}_{4}\right.\right.$

or

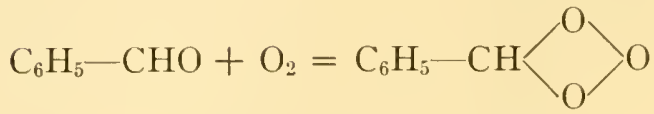

$\mathrm{C}_{6} \mathrm{H}_{5}$<smiles></smiles><smiles>O=C(O)c1ccccc1</smiles><smiles>C=C(CCCCC)NC(=O)CCCCCCCCC</smiles>

Substances which are not oxidised by molecular oxygen but by the oxygen of the moloxides, Engler called acceptors. In the case before us, indigo white plays the rôle of the acceptor and is oxidised to indigo blue by the oxygen of the moloxides. In the absence of indigo white the surplus of triethyl phosphine or of benzaldehyde would act as the acceptor, since the moloxides are unstable and have to give up an atom of oxygen in some way. The autoxidation of pure triethyl phosphine consists of the following stages:

(I) $\mathrm{P}\left(\mathrm{C}_{2} \mathrm{H}_{5}\right)_{3}+\mathrm{O}_{2}=\mathrm{PO}_{2}\left(\mathrm{C}_{2} \mathrm{H}_{5}\right)_{3}$

(II) $\mathrm{PO}_{2}\left(\mathrm{C}_{2} \mathrm{H}_{5}\right)_{3}+\mathrm{P}\left(\mathrm{C}_{2} \mathrm{H}_{5}\right)_{3}={ }_{2} \mathrm{PO}\left(\mathrm{C}_{2} \mathrm{H}_{5}\right)_{3}$;

and combined,

$$
{ }_{2} \mathrm{P}\left(\mathrm{C}_{2} \mathrm{H}_{5}\right)_{3}+\mathrm{O}_{2}={ }_{2} \mathrm{PO}\left(\mathrm{C}_{2} \mathrm{H}_{5}\right)_{3} .
$$

The autoxidation of benzaldehyde is accomplished in a similar way:

$$
\mathrm{C}_{6} \mathrm{H}_{5}-\mathrm{CHO}+\mathrm{O}_{2}=\mathrm{C}_{6} \mathrm{H}_{5}-\mathrm{CH}>\mathrm{O}
$$


(II)

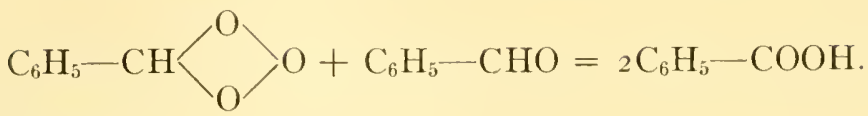

Or, briefly stated:

$$
{ }_{2} \mathrm{C}_{6} \mathrm{H}_{5}-\mathrm{CHO}+\mathrm{O}_{2}={ }_{2} \mathrm{C}_{6} \mathrm{H}_{5}-\mathrm{COOH} .
$$

It is to be emphasized expressly that the formation of moloxides is experimentally established for the processes of autoxidation. Engler and Weissberg ${ }^{1}$ isolated a peroxide of triethyl phosphine with the formula of triethyl phosphine and thereby proved that the mechanism of triethyl phosphine oxidation assumed by van't Hoff does not exist. The same investigators have shown that, contrary to Traube's view, the autoxidation of triethyl phosphine proceeds smoothly with the complete exclusion of water. A formation of peroxide in the autoxidation of aldehydes was also established by various investigators. ${ }^{2}$ Of the structural formulae which have been proposed for the moloxide of benzaldehyde that of Bach $^{3}$ proved to be the most reliable:<smiles>c1ccc(C2OOO2)cc1</smiles>

This very unstable compound with an enormously high oxidation potential changes spontaneously into a stable hydrate form which always has a considerable oxidation potential and which Bodländer thought to be a primary product of oxidation:<smiles>O=C(OO)c1ccccc1</smiles>

Moloxides very often change to peroxide hydrates whereby a fixation of water takes place under certain conditions:<smiles>O[14CH2]O[V]O</smiles>

${ }_{1}^{1}$ Engler, A. und Weissberg. Ber. d, chem. Ges. 31:3055. 1898.

2 Erlenmeyer. Ber. d. chem. Ges. 27: 1959. I894; Engler und Wild. 1bid. 30: 16691897; Bach. Monit. scient. (IV) II: 479. I897; Bodländer. Samm], chem. u. chem.. techn. Vorträge von Arens. $3:+70 . \quad$ I 899.

${ }^{3}$ Bach, A. loc, cit,; Engler und Wild. Krit. Studien über die Vorgänge der Autoxydation. 190.4. P. 90; Luther und Schilow. Z. f. physikal. Chem. 46: 8II. I903. 
The simultaneous oxidation of autoxidators and acceptors by molecular oxygen from the atmosphere is a very clear example of coupled reactions. If we represent the autoxidator by $\mathrm{A}$ and the acceptor by $\mathrm{B}$, the general nature of the coupled oxidation may be represented as follows:

(I) $\mathrm{A}+\mathrm{O}_{2}=\mathrm{AO}_{2}$

(II) $\mathrm{AO}_{2}+\mathrm{B}=\mathrm{AO}+\mathrm{BO}$.

This is a simple case of chemical induction. The reaction of the oxidation of $\mathrm{B}$ by atmospheric oxygen, which cannot take place of itself, is set in action by the simultaneous oxidation of A. Sometimes all the oxygen passes over to $B$ as follows:

(I) $\mathrm{A}+\mathrm{O}_{2}=\mathrm{AO}_{2}$

(II) $\mathrm{AO}_{2}+\mathrm{B}=\mathrm{AO}+\mathrm{BO}$

(III) $\mathrm{AO}+\mathrm{B}=\mathrm{A}+\mathrm{BO}$.

It is evident that only the specific reaction velocities of the single stages determine whether the whole process exhibits chemical induction or catalysis. That is to say, if the velocity of reaction $\mathrm{II}$ is greater than that of reaction III, AO as well as $\mathrm{BO}$ is formed by the process as a whole. If the ratio of the reaction velocities is reversed only $\mathrm{BO}$ is formed as the end product of the oxidation, since in this case the total process is expressed by the equation:

$$
\mathrm{A}+{ }_{2} \mathrm{~B}+\mathrm{O}_{2}=\mathrm{A}+{ }_{2} \mathrm{BO} \text {. }
$$

This is a typical case of the so-called "catalysis by means of intermediate products." It is evident that this kind of catalysis is nothing but a special case of chemical induction.

It must be made clear that, to all appearances, oxidation catalyses appear in living cells but very seldom or not at all. A chemical induction consisting of a greater number of stages often takes place in the living protoplasm. Very often the activation of oxygen effected by the formation of moloxide proves to be insufficient. A further increase in the oxidation potential is necessary for the oxidation of certain acceptors. This raising of the potential ${ }^{1}$ is evoked, among other ways, by means of the formation of secondary peroxides. Typical cases

\footnotetext{
${ }^{1}$ It is practically immaterial whether we have to do here with a real increase in potential or with a reduction of the passive resistance. The latter supposition is theoretically more probable.
} 
of this type of coupling are oxidations in the presence of ferrous ions as $c$.g. the oxidation of tartaric acid by hydrogen peroxide in the presence of ferrous salts, as described by Fenton. ${ }^{1}$ Tartaric acid is attacked only very slowly by hydrogen peroxide. After the addition of a trace of ferrous sulphate there follows a rapid oxidation of tartaric acid to di-hydroxy-malic acid. Manchot and Wilhelms ${ }^{2}$ have found that in the case of such processes there occurs a reduction of hydrogen peroxide by the formation of secondary iron peroxide, $\mathrm{Fe}_{2} \mathrm{O}_{5} \cdot{ }^{3}$ The iron peroxide then oxidises various acceptors which are unaffected by hydrogen peroxide because the oxidation potential of iron peroxide is much higher than that of hydrogen peroxide. If we picture the oxidation of tartaric acid by atmospheric oxygen by means of coupled reactions, an increase of the potential must take place twice; the first time from molecular oxygen to hydrogen peroxide, then from hydrogen peroxide to iron peroxide. Tartaric acid is finally attacked by means of the last union of oxygen:

$$
\mathrm{H}+\mathrm{H}+\mathrm{O}_{2}=\mathrm{H}_{2} \mathrm{O}_{2}
$$

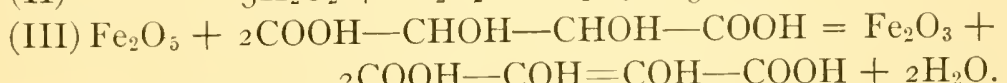

It is evident that iron peroxide contains two atoms of activated oxygen and that it is reduced to ferric oxide after this oxygen is split off. It is worthy of note that ferric oxide is only very slowly oxidised by hydrogen peroxide. The iron peroxide does not regenerate itself with a sufficient velocity and so does not represent a catalyst but an inductor.

According to Bach and Chodat ${ }^{4}$ physiological oxidation in plant cells is accomplished according to the same scheme which

1 Fenton. Jour. chem. soc. (London) 65: 899. 1895. LOr the experiments by Ray (J. Gen. Physiol. 5: 469, 6r r, 623. 1922-23) with unsaturated organic acids or plant tissues.]

2 Manchot und Wilhelms. Ber. d. chem. Ges. 34:2479. I90I.

3 According to Engler and Weissberg (Krit. Studien uber die Vorgänge der Autoxydation. $\left.\mathrm{P} . \mathrm{IO}_{4}\right)$ the structural formula of this peroxide is hydrate $\mathrm{Fe}(\mathrm{OH})_{2}-\mathrm{O}-\mathrm{OH}$ which contains I atom of activated oxygen.

Bach. Compt. rend. 124: 954. 1897; Ber. d. chem. Ges. 41: 216 . I908; Bach und Chodat. Ibid. 35: 2466,3943. 1902; 36:601. 1903; 37:36. I904; Arch. des sci. physiques et nat. de Genève I $7: 47$. I904; and others. 
had been drawn up by Bach, Engler and their collaborators for the processes of slow oxidation in vitro. From the preceding exposition it is evident that, according to the theory of BachEngler, the atmospheric oxygen is bound only by means of autoxidators (i.e. substances which transform the saturated oxygen molecule $\mathrm{O}=\mathrm{O}$ into unsaturated $-\mathrm{O}-\mathrm{O}-$ ). and of course by the formation of peroxide-like moloxides. In living plant cells there have been found peroxide-like substances ${ }^{1}$ which were termed oxygenases by Chodat and Bach. Whether the question here is one of organic peroxides or simply hydrogen peroxide does not appear to be of particular importance, since the most essential oxidations in the plant cell only come to pass after secondary activation of oxygenases. Substances which activate oxygenases Bach and Chodat call peroxidases and thereby assume that peroxidase is to be included in the

${ }^{1}$ Bach, A. und Chodat. loc. cit.; also Kastle and Loewenhardt. Amer. Jour. of Chem. 26: 539. I90I; Engler und Wöhler. Z. f. anorg. Chem. 29: I. I902. [For a complete account of oxidases as understood in 1909 see Kastle, J. H. The Oxidases and other Oxygencatalysts Concerned in Biological Oxidations. U. S. Treas. Dept. Hygienic Lab. Bull. 59. which also contains a valuable bibliography of 467 entries.]

g The best-known substance of this type, found in both plant and animal cells, was discovered by Hopkins (Biochem. Jour. 15:286-305. I92 r) and called glutathione. Its composition is so well-known as to have been proven by synthesis (Stewart and Tunnicliffe. Biochem. Jour. 19:207. I925). It represents the union of $\alpha$-amino glutaric acid and $\alpha$-amino, $\beta$-thiopropionic acid (hence gluta-thione) with the elimination of a molecule of water. Possibly by the aid of the catalytic action of traces of iron, it is found to act as a carrier of oxygen to the oxidisable constituents of cells, and even to fats and proteins (Hopkins, F. G. Biochem. Jour. 19: 787-819. 1925).

If $\mathrm{GSH}$ be taken as the symbol for the reduced form and $\mathrm{G}_{2} \mathrm{~S}_{2}$ for the oxidised form, the action may be represented by the equation

$$
{ }_{4} \mathrm{GSH}+\mathrm{O}_{2} \rightleftarrows{ }_{2} \mathrm{G}_{2} \mathrm{~S}_{2}+{ }_{2} \mathrm{H}_{2} \mathrm{O} \text {. }
$$

The energy of the oxidised form is available for oxidation and that of the reduced form for reduction. The recent work of Kendall and Nord (J. Biol. Chem. $69: 295-337$. I 926) has added to our knowledge of the conditions which govern the equilibrium between the oxidised and reduced forms, and of the intermediate "oxygen addition product" which Kendall and Nord believe to be the active component of the system. The oxygen in this compound is thought to be in the unsaturated form, - $\mathrm{O}-\mathrm{O}-$.

These workers deny the catalytic rôle of iron in relation to glutathione but the existence of such a relationship would qualify the older view of autoxidation. The demonstration of glutathione and the production of evidence in favor of its dependence on iron have done much to call into question the enzymatic nature of the "oxidases" as a whole.-Ed. 
category of enzymes. let Bach himself ${ }^{1}$ proved that the active oxygen passes over to the peroxidase in the case of the activation of oxygenases. After Kostychev ${ }^{2}$ found that peroxidase preparations, like ferrous salts in the scheme of Manchot. rapidly become exhausted and obviously function not as catalysts but as inductors. it was natural to assume that the effect of peroxidase is entirely analogous to that of the ferrous ion. This hypothesis is further confirmed by the fact ${ }^{3}$ that organic peroxides isolated from various plants as well as hydrogen peroxicle are activated by one and the same preparation of peroxidase. Such a general effect of peroxidase differs markedly from the effect of ordinary enzymes but is easily explained in the sense of coupling by means of an intermediate stage of the inductor. The oxygen passes over to the peroxidase from all activated peroxides and in all cases there is formed the same substance, peroxidase peroxide. Only the chemical nature of this peroxide is important for the subsequent oxidation of plant materials while the intermediate stages of the oxygen activation could be very varied. The investigations of $\mathrm{W}^{\prime}$ olff ${ }^{4}$ have also brought to light a striking similarity between peroxidase and ferrous ion action. However, one may hardly assume more than an analogy, for the latest investigations of Willstätter and his collaborators ${ }^{5}$ as to the performance of preparations of pure enzymes have already led to a very active preparation of peroxidase, entirely free from iron. ${ }^{h}$

1 Bach, A. Ber. d. chem. Ges. 37:3787. I904; 38: 1878. 1905; 40:3185. 1907.

2 Kostytschew, S. Z. f. physiol. Chem. 67: I16. I910.

3 Chodat und Bach. Ber. d. chem. Ges. 35: 3943. 1902; 36: 1758. 1903; Engler, A und Herzog. Z. f. physiol. Chem. 59: 359. 1909.

4 Wolff, J. Contrib. à la connaisance de divers phénomènes oxydasiques. I9Io.

5 Willstätter, R. und A. Stoll. Ann. d. Chem. 4I6:2I. I9I8; Willstätter, R. und F. Racke. Ibid. 425: I. 192I; 427: III. 1922; Willstätter, R., T. Oppenheimer und W. Steibelt. Z. f. physiol. Chem. I I0: 232. I920; Willstätter, R. und W. Steibelt. Ibid. I I I : I57. I920; Willstätter, R. und R. Kuhn. Ibid. II6:53. I92 I; Willstätter, R. und W. Csanyi. Ibid. 117: I72. I92I; Willstätter, R., J. Graser und M. Kuhn. Ibid. 123: I. I922; Willstätter, R. und E. Waldschmidt-Leitz. Ber. d. chem. Ges. 54: 2988 . I92I; Willstätter, R. Ibid.55:360I. 1922 (A comprehensive review*). According to Willstātter the effect of purified peroxidase preparations is purely catalytic.

${ }^{h}$ In a more recent study by Willstätter and Pollinger (Ann. d. Chem. 430: 269-319. I923) it was found that all active preparations of peroxidase do contain a trace of iron. This almost simultaneous demonstration of iron in both oxidase and glutathione preparations goes far toward the establishment of some theory of vital oxidation which shall include iron as an essential factor.- $E d$. 
Thus the oxidising agencies of the protoplasm, previously termed "oxidases," according to the investigations of Bach, Chodat and their adherents, are nothing but systems of oxygenases and peroxidases. ${ }^{i}$ At present it is not known whether the increase of the potential of the oxygenase in the living cell occurs but once or repeatedly. In any case the latter assumption is not precluded. Thus Bodländer ${ }^{1}$ expresses his opinion on the subject as follows: "By means of the active oxygen of superoxide, substances which are oxidised with difficulty are not entirely oxidised to carbon dioxide and water. Hence substances which are easily oxidised and which thereby effect a further activation of oxygen could arise from them. Of this we have an example in the alcohols which of themselves are only slowly oxidised by free oxygen but which, by means of activated oxygen, pass over into aldehydes which by their autoxidation bring about the oxidation of other inactive substances."

Another conclusion which can be drawn from recent investigations of biochemical processes is that these processes are apparently not to be traced to enzyme action but to chemical induction (coupled reactions). Engler and Herzog ${ }^{2}$ express their opinion that the importance of enzymes in biological oxidations is strongly overrated: "In any case it would be entirely precipitous to include the autoxidisable substances among the enzymes; at least the subordination of the agencies called oxidases under the true enzymes in the sense of catalysts is perhaps to be refused. Apparently on the contrary, the further. study of physiological oxidation already shows that the dominant significance to be ascribed to them to-day as a result of biochemical study, is not that of an enzymatic process, but that the coupled reactions are to be sought as new motives to which the organism also owes its peculiar character of the chemical regulatory mechanism."

1 Bodländer. $l o c$, cil.

2 Engler, A. und Herzog. Z. f. physiol. Chem. 59: 375. 1909.

${ }^{i}$ The most important objections to this view are those stated by Moore and Whitley (Biochem. Jour. 4: I36. I909), who doubt the presence of an oxygenase, and by Mrs. Onslow (Biochem. Jour. I3: I-9. I9I9; 14:535-547. I920) who differs in certain details. On the other hand, new support to the theory is to be found in the work of Gallaghar (Biochem. Jour. I7: 515-529. I923 and later numbers).-Ed. 
The following substances were described as oxidising enzymes or the so-called oxidases by older writers:

Laccase, obtained from the Japanese lacquer tree by Ioshida and G. Bertrand, ${ }^{1}$ was the first known oxidase. Then it was discovered in various rubber trees ${ }^{2}$ and to-day is admitted to be a widespread enzyme. Yet in some cases laccase proves to be a mixture of peroxidase and organic peroxides. In other cases it can be identified only by means of various color reactions as e.g. by the blue coloration of guaiacum, etc. From the preceding statement it is evident that all these color reactions are hardly reliable because the presence of autoxidators can be proven only by gasometric determinations of the absorption of oxygen from the surrounding air. The color reactions are in many cases due to the transfer of atomic oxygen and so have nothing to do with the activation of molecular oxygen.

Tyrosinase, which oxidises tyrosin to brown pigments, was discovered by Bourquelot and Bertrand ${ }^{3}$ and seems to represent a specific activator of oxygen. According to Bach and Chodat ${ }^{4}$ tyrosinase always consists of the usual components-oxygenase and peroxidase.

Oenoxidase was discovered in fleshy fruits ${ }^{5}$ and likewise appears to represent a non-uniform substance. Hence we are well entitled to conclude that the existence of specific oxidising enzymes in the sense of catalysts is by no means proven, as Engler and Herzog also point out.

O. Warburg $^{6}$ has proposed a noteworthy physical-chemical theory of cell respiration which is provisionally supported only by experiments with animal cells and inorganic models, and

1 Yoshida. Jour. Amer. Chem. Soc. 43: 472. I883; Bertrand, G. Compt. rend. I I8: I215. I894: I20: 266. I895; I21: I66. I895; I22: I132. I896; I45: 340 . 1907; Bull. de la soc. de chim.-biol. (IV) I : I 120.1907.

2 Spence, D. Biochem. Jour. 3: 165, 35i. I908; Cayla, V. Bull. de la soc. de chim.biol. 65: 128. 1908; and others.

${ }^{3}$ Bourquelot, E. et G. Bertrand. Jour. de pharm. et de chim. (VI) $3: 177$. I896; Bull. de la soc. mycol. 1896: 18, 27; 1897:65; Gessard. Compt. rend. des séances de la soc. de biol. (X) 5: 1033. r898; Bertrand, G. Compt. rend. I22: 1215. I896; 123: 463. I896; Bertrand, G. et Mutermilch. Ibid. I44: 1285. 1907; Ann. de l'inst. Pasteur. 21: 833. 1907; Zerban, F. W. Jour. ind. eng. chem, I0: 814. 1918.

4 Bach, A. Ber. d. chem. Ges. 39:2126. ro06; Chodat et Staub. Arch. de sci. physiques et nat. Genèvé (IV) 23 : 265. 1907; and others.

${ }^{5}$ Laborde. Compt. rend. 126: 536. I898; Cazeneuve. Ibid. 124: 406, 751. 1907; Bouffard. Ibid. 124:706. 1907.

6 Warburg, O. Biochem. Z. I19: 134. I92I; 136:266. I923:142:518. 1923:Zeitschr. f. Elektrochem., p. 70. I922; [Science 61 : $575^{-582 . ~ 1925] . ~}$ 
yet it might be applicable to plant respiration when completed. From a series of experiments on the cells of the blood of birds and on sea urchin eggs on the one hand, as well as on various charcoal powders on the other, Warburg concludes that "cell respiration is a capillary-chemical process which takes place at the iron-containing surfaces of the fixed cell constituents." That is, it appeared that various amino acids are burned to $\mathrm{NH}_{3}, \mathrm{CO}_{2}$ and $\mathrm{H}_{2} \mathrm{O}$ when adsorbed to charcoal and that the velocities and accelerations of the oxidation processes are thereby exactly the same as in the case of true cell respiration. The experiments on the effect of various narcotics are especially convincing. For equally strong checking of respiration this effect can be expressed by the following equation:

$$
x \cdot \mathrm{F}=\mathrm{K} \text {, }
$$

where $x$ represents the number of adsorbed molecules of the narcotic and $\mathrm{F}$ is the area occupied by each molecule on the surface of the adsorbent. In this way it appears that the chemical nature of the various narcotics is of no importance and the checking of the oxidation can only be traced to the fact that the substances to be oxidised, e.g. the amino acids, are displaced from the surface by the more strongly adsorbed narcotics and are not oxidised in the solution. The following table of Warburg shows that $x \cdot \mathrm{F}$ actually varies but a little for equally strong checking and is therefore almost a constant. ${ }^{1}$

\begin{tabular}{lc}
\multicolumn{1}{c}{ SubSTANCE } & $\mathrm{K}^{\prime}$ \\
Dimethylurea & 9.0 \\
Diethylurea & 6.9 \\
Phenylurea & 8.7 \\
Acetamide & 7.3 \\
Valeramide & 6.9 \\
Acetone & 8.3 \\
Methylphenylketone & 8.0 \\
Amyl alcohol & 7.9 \\
Acetonitrile & 7.7
\end{tabular}

Since oxidation is checked by such small amounts of hydrocyanic acid, it alone occupies a special position inasmuch as practically no noticeable displacement of the substance to be oxidised could be effected. However, it is evident that

1 A constant which is proportional to the magnitude of $x \cdot F$. 
hydrocyanic acid unites with ferric ions and consequently this causes a displacement of respiratory material from the regions of oxidation, since ferric ions are said to be indispensable for the oxidation.

It is certainly very welcome to have physiological-chemical theories of respiration finally arrive. Without doubt a thorough explanation of various processes which are physiologically important can be obtained only by drawing on the capillary phenomena. Warburg himself ${ }^{1}$ expresses the opinion "that the conception of respiration as a surface reaction will indicate the way followed by the transformation of energy in the living cell," since the forces of surface tension perform work. Moreover, the assumption is not precluded that various supposed "enzyme effects" might often be traced to the fact that the particular process represents a boundary surface phenomenon by which the concentration of the substances concerned in the reaction is uncommonly high. ${ }^{2}$ However, in the field of plant respiration some facts have not yet been harmonized with various points of the Warburg theory as it now stands. Thus ferric ions for the most part are not detectable in plant cells because the iron exists in rather stable organic combination. On the other hand, it would be premature to deny the participation of peroxidases in the respiratory processes. According to Willstätter, these enzymes are found to be entirely free from iron. ${ }^{3}$ It is to be emphasized especially that sugars serve as the respiratory material of plants. A repetition of the Warburg model experiment by Meyerhof ${ }^{4}$ shows that various amino acids but no sugars are burned under these conditions. It would certainly be most interesting to test fermented sugar solutions on the Warburg model. Meyerhof declares that hexose phosphate is hereby attacked. From the standpoint of the theory of genetic connection of the anaerobic with normal respiration, the results obtained by Meyerhof certainly do not contradict Warburg's

\footnotetext{
1 Warburg, O. loc. cil.

2 In this case the specific nature of the adsorbent is of secondary importance. Hence an assumption of specific catalysts seems to be superfluous in many cases.

${ }^{3}$ Hence it is apparent that a biological activation of oxygen can also occur without the assistance of ferric ions. [Note that the results of the later work of Willstatter and Pollinger (loc. cit.) contradict this statement.]

${ }_{4}$ Meyerhof, O. und H. Weber. Biochem. Z. I35: 558 . 1923.
} 
theory of respiration. They could rather be used in favor of the assumption that a primary anaerobic cleavage of sugar is necessary for sugar respiration. ${ }^{1}$

An entirely different theory of the oxidation processes has been developed by Wieland. ${ }^{2}$ According to his view. the oxygen of water is utilised for all biological oxidations. The atmospheric oxygen only serves to bind the hydrogen of the water. In general Wieland supposes that oxidations are always accompanied by simultaneous reductions, for always the hydrogen and not the molecular oxygen is said to be activated. The latter is said to remain entirely passive and to form no unsaturated molecules. According to Wieland oxidation is to be traced solely to the formation of active atomic hydrogen. If the active hydrogen of the water is tied up by a hydrogen acceptor the residual unsaturated oxygen of the water can unite with various substances. Either atmospheric oxygen or various other substances could serve as hydrogen acceptors. In the latter case it is possible to carry out various oxidations and reductions with air excluded: Thus Wieland has shown that acetic acid fermentation of ethyl alcohol by atmospheric oxygen, commonly thought to be an oxidation, proceeds smoothly in the presence of methylene blue or m-dinitrobenzol with oxygen entirely excluded. According to Wieland a state of equilibrium is therefore precluded under these conditions because the active hydrogen is permanently bound up. As for the manner of action of peroxidases, Wieland assumes that - these enzymes only activate the hydrogen of the polyphenols

1 The latest discovery of Warburg and Yabusoe, according to which fructose undergoes oxidation in the presence of phosphates, is interesting. Cf. Warburg, O. und M. Yabusoe. Biochem. Z. 146: 380. 1924; Spoehr, H. A. Jour. Amer. Chem. Soc, 46: 149.4. 1924. However, this oxidation is so feeble that it can not serve as the basis of normal respiration. On this point of. Meyerhof, O. und K. Matsuoka. Biochem. Z. I50: I. I924. [The latter have confirmed and augmented the work of Warburg and Yabusoe. The presence of traces of iron in a certain form is said to be responsible for the slow but regular oxidation of fructose (but not glucose) al $37^{\circ}$ and in pure oxygen. These experimental conditions and the absence of any effect on glucose-the more common source of respiratory energy-weakens the argument for the general application of Warburg's suggestion. It is also true that a careful demonstration of the catalytic action of ron for the oxidation of fructose has been made only with alkaline solutions, whereas fructose is oxidised in neutral solutionsof phosphate in Warburg's experiments ( $c f$. Wind, F. Biochem. Z. 159: 58-67. 1925). It would seem that too little consideration was given to the possible catalytic effect of the phosphate. $C f$. editorial note $k$, page 126.1

2 Wieland, H. Ber. d. chem. Ges, 45: 2606. 1912; 46:3327. 1913; 47:2085. 1914; 55: 3639.1922 . 
and make possible their oxidation by means of atmospheric oxygen. In fact it must be pointed out that the peroxidase preparations so far exhibited from plants, only oxidise the hydrogen of phenols and are unable to break carbon chains and in general to unite the oxygen of peroxide with carbon. Wieland's theory may be successfully applied to cases in which the oxidation is wholly or partly due to the splitting-off of hydrogen. Then it serves well and provides the explanation of processes which present difficulties for the Bach-Engler theory. An example of these is the following oxidation described by Thunberg. ${ }^{1}$ Succinic acid is easily changed to fumaric acid in the presence of muscle extract and methylene blue (M) as the hydrogen acceptor:

$\mathrm{COOH}-\mathrm{CH}_{2}-\mathrm{CH}_{2}-\mathrm{COOH}+\mathrm{M}=\mathrm{COOH}-\mathrm{CH}=$

$$
\mathrm{CH}-\mathrm{COOH}+\mathrm{MH}_{2} \text {. }
$$

Furthermore, fumaric acid can change to malic by the fixation of water.

\section{$\mathrm{COOH}-\mathrm{CH}=\mathrm{CH}-\mathrm{COOH}+\mathrm{H}_{2} \mathrm{O}=\mathrm{COOH}-\mathrm{CH}_{2}-$ \\ $\mathrm{CHOH}-\mathrm{COOH}$.}

In this way it is possible to explain a whole series of biochemical reactions which involve a transfer of hydrogen or oxygen. It must be borne in mind, however, that there are objections to Wieland's theory as an explanation of all the processes of oxidation in plant cells. Wieland ${ }^{2}$ himself expresses the opinion that his theory possesses a general validity and that the Bach-Engler theory should be abandoned as too weak to hold. ${ }^{j}$

1 Thurberg. Skand. Arch. f. Physiol. 30: 285. I9I3.

2 Wieland, H. Ber. d. chem. Ges. 55:3639. 1922.

$j$ A criticism of Wieland's theory is to be found in a paper by Batelli and Stern (Compt. rend. soc. physiques et hist. nat. Genève. 37:65. 1920) while an entirely new idea was recently advanced by Quastel (Biochem. Jour. 20 : r66-I94. 1926). This new theory was evolved primarily to explain the results of Quastel's studies of dehydrogenations produced by resting bacteria but it offers interesting suggestions for other oxidations and reductions. Space does not permit a full summary but the basic idea is that of an activation of the substance to be oxidised by reason of the action of an electrical field of force and the consequent shifts in certain chemical bonds within the molecule. This theory is said to 
It must be taken into consideration that two experimentally established important facts favor the Bach-Engler theory: I. Formation of moloxides by the autoxidation of some organic substances and, II. The activation of hydrogen peroxide and various other peroxides by means of peroxidases. The Wieland theory can explain some cases of oxygen fixation only questionably. For example, Wieland seeks to explain the autoxidation of aldehyde to carboxylic acid at the expense of the oxygen of water by means of the intermediate formation of aldehyde hydrate:

$$
\begin{gathered}
\mathrm{CH}_{3}-\mathrm{CHO}+\mathrm{H}_{2} \mathrm{O}=\mathrm{CH}_{3}-\mathrm{CH}(\mathrm{OH})_{2} \\
\mathrm{CH}_{3}-\mathrm{CH}(\mathrm{OH})_{2}=\mathrm{CH}_{3}-\mathrm{COOH}+{ }_{2} \mathrm{H} \\
2 \mathrm{H}+\mathrm{O}=\mathrm{H}_{2} \mathrm{O} .
\end{gathered}
$$

Wieland bases this explanation on the fact that acetic acid bacteria oxidise ethyl alcohol to acetic acid in the absence of oxygen by way of the intermediate stage of acetaldehyde if the active hydrogen which is split off is taken up by methylene blue. The first stage (oxidation of ethyl alcohol to acetaldehyde), in the absence of oxygen, can be made intelligible only through an activation of hydrogen:

$$
\mathrm{CH}_{3}-\mathrm{CH}_{2} \mathrm{OH}=\mathrm{CH}_{3}-\mathrm{CHO}+\mathrm{H}+\mathrm{H} \text {. }
$$

The second stage (oxidation of acetaldehyde to acetic acid) is also, according to Wieland, to be traced to the fact that there is first formed aldehyde hydrate which then, owing to the activation of hydrogen, splits off atomic hydrogen and changes to acetic acid. Since no atmospheric oxygen was available under his experimental conditions, Wieland claims that his explanation of the formation of acetic acid is the only one possible. Not only possible but more probable than the details of the reaction

account for all the well-known oxidations in vivo, even to such reactions as $\beta$-oxidation. It places the emphasis on the material used rather than on an illdefined system of enzymes and enzyme action, and promises at least a partial reconciliation between the views of Wieland and those of the opponents of his theory. The catalytic or promoter action of iron or similar components of the "oxidase" system is not precluded because some such an agent provides the field of force which is thought to activate the substrate.-Ed. 
as assumed by Wieland is the transformation of acetaldehyde according to the Cannizzaro reaction:

$$
\begin{gathered}
{ }_{2} \mathrm{CH}_{3}-\mathrm{CHO}=\mathrm{CH}_{3}-\mathrm{CO}-\mathrm{O}-\mathrm{CH}_{2}-\mathrm{CH}_{3} \\
\mathrm{CH}_{3}-\mathrm{CO}-\mathrm{O}-\mathrm{CH}_{2}-\mathrm{CH}_{3}+\mathrm{H}_{2} \mathrm{O}=\mathrm{CH}_{3}-\mathrm{COOH} \\
\quad+\mathrm{CH}_{3}-\mathrm{CH}_{2} \mathrm{OH} .
\end{gathered}
$$

The ethyl alcohol again changes to acetaldehyde and finally all the alcohol may change to acetic acid.

From the preceding exposition it is evident that the removal of hydrogen from the aldehyde hydrates is unlikely, so much the more so because demonstrable aldehyde peroxides are formed as intermediate products with access to oxygen. To all appearances entirely different processes take place with the exclusion of oxygen than with access to oxygen: aldehydes change to alcohols and acids according to Cannizzaro.

These objections do not have the effect of setting aside the Wieland theory. They only go to show that in some cases the Bach-Engler theory deserves the preference. In the case of biological oxidation processes there is probably hydrogen activation as well as oxygen activation. In some cases the oxidation proceeds according to the Bach-Engler scheme, but in other cases according to that of Wieland.

\section{THE RESPIRATORY MATERIAL}

The fermentable sugars serve as the respiratory material of plants. This fact has been proven for seed-plants by means of a large number of unequivocal experimental results. Boussingault ${ }^{1}$ has shown by means of numerous analyses of the elements that carbohydrates in particular disappear during the respiration of germinating plants. Borodin" showed that leafy shoots respire more energetically after an exposure to light, a condition which is doubtless due to the formation in the light of respiratory material in the form of carbohydrates. Palladin ${ }^{3}$ proved that etiolated bean leaves, which contain very small amounts of soluble carbohydrates, respire much more energeti-

\footnotetext{
1 Boussingault, J. B. Agronomie, chimie agrtcole et physiol. 4:245. 1868.

${ }^{2}$ Borodin, J. Physiol. Untersuch, über die Atmung der Laubsprosse. 1876. Russian.

${ }^{3}$ Palladin, W. Rev. gén. de bot. 5: 449. I893; 6: 201 . 1894; 13: I8. I 90 I; and others.
} 
cally after a temporary immersion in sugar solutions, where they absorb considerable quantities of the dissolved sugar. An increase in the oxygen respiration after a dose of sugar was also observed by Kostychev ${ }^{1}$ in the case of wheat seedlings. An enormous consumption of sugar may be observed in some very energetically respiring plant organs. For example, this is the case in the respiration of the spadix of Arum which develops a large amount of heat. ${ }^{2}$ The number of cases which exhibit an energetic oxidation of sugar could be further augmented but it is sufficient to refer to the literature just cited.

Nevertheless Detmer ${ }^{3}$ years ago proposed a theory which supposes that the "living" protein substance of the protoplasm functions as the immediate material for respiration. According to Detmer, the sugars are said to be used only to regenerate the proteins which are used in respiration. This assumption contradicts an abundance of facts recently established beyond question. At present it offers only historical interest and an illustration of the over-emphasis of the rôle of proteins in physiological metabolism, which was very general at the end of the igth century. It was generally assumed (without reasons founded on fact) that proteins constitute the most important component of the protoplasm and therefore take part in all material transformations. Life was regarded as a continuous breaking down and rebuilding of the protoplasmic framework and especially of the "living" protein material." On this point Pfeffer ${ }^{5}$ writes very decisively in his text book of plant physiology: "It is of course essential that the specific structures of the protoplasm to which it owes its hereditary character must not be irreparably disorganized by respiration. In all these considerations it is unjustifiable to content oneself with the hypothetical notion that the destruction of protein and the protoplasmic elements is essential for the operating metabolism."

\footnotetext{
${ }_{1}^{1}$ Kostytschew, S. Biochem. Z. 15: I64. 1908; Physiol.nchem. Untersuch, über Pflanzenatmung. 1910. Russian.

2 Kraus, G. Ann. jard. bot. Buitenzorg. 13:217. 1896; and others.

setmer. Jahrb. f. wiss. Bot. I2: 287. I879; Ber. d. bot. Ges, Io: 201, 442. 1892; Lehrb. d. Pflanzenphysiol. 1883. P. 153.

4 Pflüger. Arch. ges. Physiol, Io: 251,641. 1875; and others.

- Pfeffer, W. Pflanzenphysiol. 2nd. ed. Vol. I, p. 553. I\$97.
} 
The later biochemical studies showed that in reality sugars are considerably easier to oxidise than proteins. The modern theories of biological oxidation processes make it possible to furnish a satisfactory explanation for the respiration of sugar by means of the theory of the participation of enzymes of fermentation in the normal respiratory process. The theory of the connection of the anaerobic with normal respiration of course directly contradicts Detmer's views. The latter are not based on a single experimentally established fact and are incompatible with many experimental results. This is an example of the way in which purely speculative theories have been able to appear even in more recent times as well as at the beginning of the igth century.

In the seed-plants almost all living cells are provided with a supply of sugars or other carbohydrates. All the polysaccharides such as starch, hemi-celluloses, and inulin, as well as the glucosides, break down easily in the protoplasm through the action of specific enzymes, to form simple sugars, particularly glucose and fructose, which as direct respiratory material undergo an oxidative cleavage.

Sugars and polysaccharides are also contained in large amounts in various lower plants. The starch of the higher plants is often replaced by glycogen while among the disaccharides trehalose is especially common in fungi. There is never lacking in these plants a supply of respiratory material which furnishes fermentable hexoses by means of hydrolytic cleavage.

In the plants containing chlorophyll, as well as in those without chlorophyll, the respiratory material is often deposited in the form of fat. The conversion of fat to sugar is a process which has not yet been done artificially but it proceeds easily in living plant cells. ${ }^{1}$ The respiration of fat is associated with a comparatively low value of $\frac{\mathrm{CO}_{2}{ }^{2}}{\mathrm{O}_{2}}$ and undoubtedly is effected by way of the intermediate stage of sugar.

${ }^{1}$ Leclere du Sablon. Compt. rend. 117:524. 1893; I19:610. 1894; Maquenne. Ibid. 127:625. 1908. For the respiration of fat in the lower fungi see Flieg, O. Jahrb. f. wiss. Bot. 6r: 24. 1922.

${ }^{2}$ Godlewski, E. Jahrb. f. wiss. Bot. 13: 524. 1882. 
Many saprophytic fungi and bacteria thrive on solutions of various organic substances and use up these substances in the respiratory process. The question here arises whether all these substances are worked up by way of the intermediate stage of sugar, or whether, on the given nutrient solutions, certain "trimmings" (Garnituren) of enzymes are formed in microörganisms and consequently each nutrient substance is resolved and oxidised by the temporary enzyme in a specific way. The latest investigations of Kostychev and Afanassjewa ${ }^{1}$ furnished a solution of this question. If, in the case of the mold Aspergillus niger, the oxidation processes are checked by lack of oxygen or even by the exclusion of oxygen, sugar appears in the nutrient solution in the case of feeding with mannite. glycerine, quinic acid, tartaric acid and lactic acid. Part of the sugar formed from these substances is fermented to ethyl alcohol and carbon dioxide when there is a deficiency of oxygen. This is a new proof that the respiration of various nitrogen free organic substances is effected not only by way of sugar as the intermediate stage but also by the same coupled reactions which take place in sugar nutrition. ${ }^{2}$ These results agree with the older statements of Czapek $^{3}$ and other investigators as to the relative value of various sources of carbon for the nutrition of fungi. It is known that polyvalent alcohols, particularly the hexavalent ones such as mannite and sorbite, represent excellent sources of carbon; likewise the hydroxy acids. Substances with unoxidised carbon atoms are less suitable material for respiration. For example, propionic acid is harder to use than lactic acid but the latter is more difficult than tartaric acid. Substances with a long, unbranched carbon chain are more easily assimilated and used in respiration than substances with a short or branched chain. Aromatic compounds are distinguished by an especially low nutritive value. On the contrary, hydro-aromatic alcohols such as inositol and quercitol are very easily assimilated. All these regularities are easily

\footnotetext{
${ }^{1}$ Kostytschew, S. Z. f. physiol. Chem. III: 236. I920; Kostytschew, S. und M. Afanassjewa. Jahrb. f. wiss, Bot. 60:628. I92I.

2 The older theory of Diakonow is hereby completely refuted. There is not the slightest difference to be noted between the products of anacrobie respiration with sugar on the one hand and with nitrogen free non-sugars on the other.

${ }^{3}$ Czapek, F. Hofmeisters Beitr. I: 538. I902; $2: 584$. I902; 3:62. I902.
} 
understood through the fact that the relative value of various sources of carbon depends on the ease of conversion into fermentable sugars. Kostychev ${ }^{1}$ has identified as glucose the sugar formed from tartaric acid, glycerine, quinic acid and lactic acid. Fructose appears to accumulate on mannite solutions.

In this way fermentable sugars represent the usual material for respiration. However, there seems to be another kind of plant respiration-that at the expense of the protein of the protoplasm, a type found in starving cells. At the same time it must be emphasized that this has nothing to do with that assumed in Detmer's theory. Detmer assumes a dissociation and oxidation of protoplasmic protein even under conditions in which a direct analysis shows only the consumption of sugar. A destruction of the protein material in the presence of sugar is purely hypothetical, whereas Detmer attempts to explain the normal type of plant respiration by this theory. Actually a noticeable respiration of protein only occurs with a deficiency of sugar, as in etiolated bean leaves. ${ }^{2}$ Respiration is thereby considerably weaker than under normal circumstances.

Kostychev and Afanassjewa ${ }^{3}$ have found that Aspergillus niger, fed with peptone as a source of carbon, behaves peculiarly. In the absence of oxygen neither sugar nor alcohol is formed in peptone cultures. Afterwards these cultures are to all appearances generally free from zymase, since they do not ferment added sugar. It has already been pointed out that zymase is formed in these cultures only after a brief exposure to air in the presence of sugar.

Since peptone cultures of Aspergillus niger liberate $\mathrm{CO}_{2}$ in the absence of oxygen but form neither sugar nor alcohol, we may suppose that the oxygen respiration of these cultures is peculiar and differs in principle from the normal sugar respiration. On the strength of these results Kostychev assumes that there are two kinds of plant respiration- "sugar respiration" and "protein respiration." The former is the usual type and proceeds by means of the participation of enzymes of alcoholic

\footnotetext{
${ }^{1}$ Kostytschew, S. loc, cit.

${ }^{2}$ Palladin, W. Rev. gén. de bot. 5: 449. I893; 6: 201. 1894; 13: r8. r9or.

${ }^{3}$ Loc, cil.
} 
fermentation. The latter is only started after stoppage of the supply of carbohydrates, and takes place without manifestation of the enzymes of fermentation. The chemical side of the material transformations which proceed thereby is at present wholly unknown. Peptone cultures of molds are a favorable research material to use in the study of protein respiration, since they are entirely free from sugar yet are not studied in the starving condition.

\section{THE NATURE OF THE CONNECTION BETWEEN THE AN- AEROBIC CLEAVAGE PROCESSES AND THE SUBSEQUENT OXIDATION OF THE CLEAVAGE PRODUCTS}

This question can only be discussed in relation to the "sugar respiration" since the chemical side of "protein respiration" is still entirely unknown.

It is hardly to be doubted that in the case of plants which respire at the expense of sugar, anaerobic respiration is essentially an alcoholic fermentation. It has been pointed out already that the value of $\frac{\mathrm{CO}_{2}}{\mathrm{C}_{2} \overline{\mathrm{H}_{5}} \mathrm{OH}}$ often does not correspond to that of alcoholic fermentation by yeast. In all these cases there is a surplus of $\mathrm{CO}_{2}$. In extreme cases the formation of alcohol is entirely suppressed. These conditions may be explained as follows:

I. Protein respiration takes place simultaneously with sugar respiration. In peptone cultures of Aspergillus niger all the $\mathrm{CO}_{2}$ produced in the absence of oxygen is due to protein respiration. With some other plants probably part of the $\mathrm{CO}_{2}$ is formed from cleavage products of proteins in the absence of oxygen.

II. The abnormal value of $\mathrm{C}_{2} \mathrm{H}_{5} \mathrm{OH}$ depends on the fact that either part of the alcohol formed disappears as a result of ester formation and similar processes, or the preliminary stage of alcohol formation is somewhat irregular and consequently products other than ethyl alcohol appear.

It is thus evident that the first phase of sugar respiration is usually nothing but alcoholic fermentation. Now Kostychev ${ }^{1}$

\footnotetext{
I Kostytschew, S. Biochem. Z. 15: 164. I908; Jour. d. russ. bot. Ges, I: IS2. I9I6.
} 
showed that ethyl alcohol can be oxidised by various seedplants either not at all or only incompletely, and in any case is not to be regarded as an intermediate product of oxygen respiration. The same result was indicated by the older work of Mazé and Perrier, ${ }^{1}$ who undertook to test the assimilation of ethyl alcohol by seed-plants. It appeared that ethyl alcohol is partly esterified by leafy twigs, partly thrown off by transpiration, but is neither oxidised nor assimilated.

Further studies by Kostychev and his coworkers ${ }^{2}$ showed that fermented sugar solutions induce an enormous increase in the rate of respiration of different seed-plants, but particularly that of wheat seedlings. This indicates that there are easily oxidised intermediates of alcoholic fermentation in fermented sugar solutions. Hexose phosphate cannot be an intermediate of oxygen respiration, for pure preparations of this substance effect no increase in such respiration, according to Kostychev.

Of course the results just described could also be interpreted in another way as they were by Meyerhof, ${ }^{3}$ among others, who has observed an increase in the respiration of animal tissues through the influence of products of fermentation and that of yeast extracts. The stimulative effect of fermented solutions could be attributed to a content of coenzyme or vitamine which exerts an effect on the enzymes of the seed-plants. Kostychev, ${ }^{4}$ however, demonstrated a modification of the action of peroxidase by means of fermented sugar solutions. It has long been known that peroxidase preparations from various seed-plants exhibit a weakened, specific oxidising effect. They are only able to oxidise phenol groups. For example, hydroquinone is oxidised to quinone by $\mathrm{H}_{2} \mathrm{O}_{2}$ and peroxidase, with the formation of water but not of $\mathrm{CO}_{2}$. The possibility of oxidising

1 Mazé, P. et Perrier. Ann. de l'inst. Pasteur 18: 740. I904.

${ }^{2}$ Kostytschew, S. Biochem. Z. 15: 164. I908; 23: 137. I909; Ber. d. bot. Ges. 31: 422, 432. 19 I3; Kostytschew, S. und A. Scheloumow. Jahrb. f. wiss. Bot. 50: I57. I911. [The interpretation of these experimental results is questioned by L. Iwanow (Ber. d. bot. Ges. 32: 19I-I96. I914) who considers that components of the fermented sugar solutions other than intermediates of alcoholic fermentation might have induced the increased production of $\mathrm{CO}_{2}$ by the plants to which they were applied. The experiments play such an important part in Kostytschew's argument that they are well worth repeating for confirma. tion and further analysis of the components of such solutions.]

${ }^{3}$ Meyerhof, O. Z. f. physiol. Chem. I0I: I65. I918; 102: I. I918. [Naturwissenschaften $7: 253-259$. 1919.]

1 Kostytschew, S. Z. f. physiol. Chem. 67: i16. I910. 
to $\mathrm{CO}_{2}$ a single plant substance with the aid of oxidising enzymes of plants furnished great difficuities to each theory that stood for a participation of peroxidase in the respiratory process. Bertrand, Portier and Porodko ${ }^{1}$ each claimed that the oxidising enzymes of plants have nothing to do with respiration because they are entirely unable to attack the respiratory material. Several other investigators have followed this suggestion. Kostychev's experiments showed that $\mathrm{CO}_{2}$ is liberated in abundance when the system, peroxidase $+\mathrm{H}_{2} \mathrm{O}_{2}$, acts on fermented sugar solutions. The same system-peroxidase + $\mathrm{H}_{2} \mathrm{O}_{2}$-is entirely unable to decompose dissolved sugar to form $\mathrm{CO}_{2}$. In this way for the first time plant substances (the chemical nature of which is by no means established) have been successfully oxidised to $\mathrm{CO}_{2}$ with the aid of peroxidase outside the living cell. ${ }^{k}$ and the participation of peroxidase in the respiratory process been made plausible. It is very evident that this result favors the theory of connection of alcoholic fermentation with oxygen respiration. Whether one traces, with Meyerhof, the

\begin{abstract}
' Bertrand, G. Compt. rend. 122: 1132. 1896; Portier. Les oxydases dans la série animale. 1897; Porodko. Beih. z. Bot. Centralbl. 16: 1. I904.

${ }^{k}$ By the use of a mixture of neutral sodium.(or potassium) phosphate solution and an aqueous extract of oxidase from potato tubers, Lyon (Harrard thesis. 1926; Amer. Jour. Bot. 14: $274^{-28} 3$, I927) was able to effect a slow oxidation of glucose or fructose with the liberation of $\mathrm{CO}_{2}$. 'Together with a demonstration of the increased rate of production of $\mathrm{CO}_{2}$ when such phosphate solutions were applied to Elodea, wheat seedlings or Spirogyra (J. Gen. Physiol. 6:299-306. 1923-24), these experiments constitute the basis of a claim that the phosphate ion exerts a promoter action on the oxidases. I more exact analysis of the relationship showed that for the $\mathrm{CO}_{2}$-production by Elodea the effect could be expressed by the equation
\end{abstract}

$$
\left(\mathrm{CO}_{2}-62.475\right)\left(\mathrm{pPO}_{4}-2 . \mathrm{I}_{3}\right)=\text { I I } 4.43 \text {, }
$$

which was described in a footnote on page $2 \mathrm{I}$. A similar analysis of the published data of other workers indicated that the phosphate ion exerts the same effect on other enzymes including peroxidase (Smirnow, A. J. Biochem. Z. 155: I-33. 1925) and pancreatic lipase (Platt and Dawson. Biochem. Jour. 19: 860-874. 1925; and other workers). The same hyperbolic relationship to phosphate ion concentration, expressed by the equation

$$
\text { (Activity of Enzyme) }\left(\mathrm{pPO}_{4}\right)^{n}=K
$$

where $n$ and $K$ are constants and $n$ varies from one to six under different conditions, appears to hold.

This relationship of phosphate to respiration may be related to the problem of the connection between lipoids and respiration which is discussed by Palladin (Plant Physiology. Trans. by Livingston. 3rd. ed. pp. IS6-ISS).-Ed. 
effect of yeast extracts and fermented solutions to an increase in the activity of respiratory enzymes by means of specific coenzymes, or assumes, with Kostychev, the presence of easily oxidised substances in fermented sugar solutions is not different in principle. In both cases there is a connection between fermentation and respiration. The following result could also. be used in favor of the latter interpretation. It was shown ${ }^{1}$ that fermented solutions liberate considerable amounts of $\mathrm{CO}_{2}$ in the presence of a ferrous salt and $\mathrm{H}_{2} \mathrm{O}_{2}$, whereas the system, ferrous salt plus $\mathrm{H}_{2} \mathrm{O}_{2}$, is unable to oxidise plant protein as far as the formation of $\mathrm{CO}_{2}$. The assumption is certainly not precluded that the coenzymes existing in fermented solutions raise not only the oxidation potential of peroxidase but also that of the ferrous ion.

From the preceding exposition it is evident that various experimental results support the theory of connection of alcoholic fermentation with sugar respiration. This connection may be schematically represented as follows, after Kostycher. ${ }^{1}$

Fermentable Sugars

Intermediates of Alcoholic Fermentation

Fermentation Products $\left(\mathrm{CO}_{2}\right.$ and $\left.\mathrm{CH}_{3}-\mathrm{CH}_{2} \mathrm{OH}\right)$
Respiration Products

$\left(\mathrm{CO}_{2}\right.$ and $\left.\mathrm{H}_{2} \mathrm{O}\right)$

Palladin ${ }^{2}$ has proposed an interesting theory to explain the oxidation of the intermediates of fermentation. This theory represents a combination of those of Bach-Engler and Wieland. According to Palladin, the so-called respiratory chromogens play a very important rôle in the respiratory process. Palladin

\footnotetext{
1 Kostytschew, S. loc. cit.

${ }_{2}$ Palladin, W. Ber. d. bot. Ges. 26a: 125, 378, 389. 1908; 27: 101. I909; 29: 472. I91 ; 30: 104. 1912; Z. f. phys1ol. Chem. 55:207. I908; Rev. gén. de bot. 23:225. I911; Z. f. Garrungsphysiol. I: 91. I912; Palladia, W. und S. Lwow. Ibid. 2: 326. I913; Palladin, W. und Z. Tolstoi. Mitt. d. Akad. d. W1ss. Petersburg 1913: 93.
} 
applied the term chromogen to various substances which by autoxidation split off hydrogen and change to the corresponding pigment. For example, hydroquinone is oxidised to red quinone by peroxidase, indigo white to blue indigo. All such oxidations are due to a splitting off of two atoms of hydrogen with the formation of water:

$$
\mathrm{RH}_{2}+\mathrm{O}=\mathrm{R}+\mathrm{H}_{2} \mathrm{O} \text {. }
$$

According to Palladin, reserve respiratory chromogens are stored in the form of prochromogens. Under this term Palladin included many tannins, glucosides and similar compounds which liberate oxidisable chromogens after hydrolysis.

The respiratory pigments $\mathrm{R}$ which are formed from chromogens by oxidation are effective as hydrogen acceptors according to Palladin, while the oxidation of carbon is said by Wieland to take place by means of the oxygen of water. In living tissues the respiratory process, according to Palladin, is initiated by the catalytic dissociation of water. The oxygen of the water oxidises the carbon of the intermediate products of fermentation. The hydrogen of the water and of the respiratory material is thereby temporarily bound to respiratory pigments, i.e. oxidised chromogens. The first phase of respiration may be expressed by the following equation (since the chemical nature of the intermediate products of fermentation is unknown, the respiratory material is represented here by the empirical formula for sugar):

$$
\mathrm{C}_{6} \mathrm{H}_{12} \mathrm{O}_{6}+6 \mathrm{H}_{2} \mathrm{O}+\mathrm{I}_{2} \mathrm{R}=6 \mathrm{CO}_{2}+\mathrm{I}_{2} \mathrm{RH}_{2} \text {. }
$$

From this it is evident that all the $\mathrm{CO}_{2}$ of oxygen respiration is of anaerobic origin, in Palladin's opinion. The carbon of the respiratory material is oxidised by the oxygen of water and of the respiratory material. The second phase of the oxidation processes of respiration consists in the oxidation of the respiratory chromogens by peroxidase at the expense of atmospheric oxygen (naturally through the intermediate stage of peroxide formation), whereby all the hydrogen taken from the respiratory material goes into water:

$$
\mathrm{I}_{2} \mathrm{RH}_{2}+6 \mathrm{O}_{2}=\mathrm{I}_{2} \mathrm{H}_{2} \mathrm{O}+\mathrm{I} 2 \mathrm{R} \text {. }
$$


The hydrogen acceptors (chromogens) are thus completely regenerated and could be used in the oxidation of new portions of respiratory material. Thus according to Palladin, the atmospheric oxygen oxidises only the labile hydrogen of the respiratory pigments. This process, taking place through the action of peroxidase, has nothing to do with the formation of $\mathrm{CO}_{2}$, a view which corresponds entirely with the current idea of the nature of the action of peroxidase. It has already been pointed out that peroxidase preparations oxidise only phenol groups.

The assumption is certainly not precluded that the results of the above mentioned experiments of Kostychev, in which fermented sugar solutions develop $\mathrm{CO}_{2}$ after the addition of peroxidase and hydrogen peroxide, are due to the presence in fermented sugar solutions of not only the respiratory material but also peculiar hydrogen acceptors. These results could be explained by Palladin's scheme.

Palladin has proven experimentally that the conversion of respiratory chromogens into pigments involves the absorption of oxygen from the surrounding air. ${ }^{1}$ The above mentioned investigations of Wieland on acetic acid fermentation also favor Palladin's theory. The following interesting discovery of Oparin ${ }^{2}$ can serve as a particularly clear illustration of Palladin's theory. From sunflower seeds Oparin isolated a substance which appears to be identical with chlorogenic acid and which brings about the oxidative deaminization of amino acids entirely in the sense of Palladin's scheme. The substance in question is changed to a green pigment as a result of the oxidation of its hydrogen. Chlorogenic acid $\mathrm{C}_{16} \mathrm{H}_{18} \mathrm{O}_{9}$ is a Depsid and a constituent part of the tannin known as caffetannic acid. ${ }^{3}$ Caffetannic acid would thus be called a prochromogen.

Palladin's theory is an important working hypothesis which should be tested further."

${ }^{1}$ Palladin, W. und Z. Tolstoí. loc. cit.

2 Oparin, A. Biochem. Z. 124:90. 1921.

${ }^{3}$ Freudenberg, K. Ber. d. chem. Ges. 53:232. I920; Freudenberg und E. Vollbrecht. Z. f. physiol. Chem. 116:277. 1921.

4 On this point of. Thunberg. Skand. Arch. f. Physiol. 30: 285. I913; Meyerhof. Arch. ges. Physiol. 170: 367, 428. I918; 175: I919; Z. f. physiol. Chem. 101: I65. I9I8; 102 : 1. 1918. 


\section{HYPOTHESES AS TO THE NATURE OF THE OXIDISABLE PRODUCTS OF FERMENTATION}

It has already been demonstrated that ethyl alcohol, the end product of fermentation, is hardly to be considered an intermediate product of respiration. Apparently, substances which are formed as intermediates of alcoholic fermentation are oxidised by the respiratory process and their oxidative cleavage proceeds more easily than that of unchanged sugar.

The chemical side of alcoholic fermentation is not yet fully known and unmistakable advances in this field must first be made, for one does not begin with the first but rather with the last phases of fermentation. Kostychev ${ }^{1}$ has discovered in fermenting sugar solution under the influence of zinc and cadmium salts, an aggregation of acetaldehyde which severely checks the reducing power of the enzymes of yeast. At the same time he has proven that yeast can reduce considerable amounts of acetaldehyde to ethyl alcohol. ${ }^{2}$ From this condition Kostychev has concluded that the formation of acetaldehyde represents the next to the last phase in alcoholic fermentation. An important confirmation of this view was furnished by the sulphite method of preparing glycerine by yeast, which was worked out by Connstein and Lüdecke ${ }^{3}$ and patented in I9I5. In the presence of a considerable amount of sodium sulphite (which in acid reaction changes in part to the bisulphite) sugar is split by yeast not only into $\mathrm{CO}_{2}$ and alcohol but also in part into $\mathrm{CO}_{2}$, acetaldehyde, and glycerine. The equation for the sulphite fermentation was established by Neuberg and Hirsch: ${ }^{4}$

$$
\mathrm{C}_{6} \mathrm{H}_{12} \mathrm{O}_{6}=\mathrm{CH}_{2} \mathrm{OH}-\mathrm{CHOH}-\mathrm{CH}_{2} \mathrm{OH}+\mathrm{CH}_{3}-\mathrm{CHO}+\mathrm{CO}_{2} \text {. }
$$

\footnotetext{
${ }^{1}$ Kostytschew, S. Ber, d. chem. Ges, 45: I 289. I912; Z. f. physiol. Chem. 79: 130. I912; 83:93. 1913; 85:493. I913; III: 126, 132. 1920.

${ }^{2}$ Kostytschew, S. und E. Hübbenet. Z. f. physiol. Chem. 79:359. I91 2; Kostytschew, S. Ibid. 85:408. 1913; $f$. also Kostytschew, S. Ibid. 89:367. I914;92:402. I9I \&; the brief paper of Neuberg and Kerb (Z. f. Gärungsphysiol. I: 114. 1912), which was published before the communication of Kostytschew and Hubbenet, gave only negative results, yet aldehyde ammoniac and not free acetaldehyde was used for the reduction experiments.

${ }^{3}$ On this point (f. W. Connstein und $\mathrm{K}$. Ludecke. Ber, d. chem, Ges, 52: 1385. 1919; Zerner, E. Ibid. 53:325. 1920.

'Neuberg, C. und J. Hirsch. Biochem. Z. 100: 304. 1919; Neuberg, C., J. Hirsch und E. Reinfurth. Ibid. 105:307. 1920.
} 
The formation of such important amounts of aldehyde is really due to the fact that the acetaldehyde is removed from the system of coupled reactions in the form of the bisulphite compound. Consequently the active hydrogen does not reduce the acetaldehyde but reduces an unidentified substance to glycerine. Neuberg and his coworkers ${ }^{1}$ have shown that all aldehydes studied by them could be reduced by yeast.

An accumulation of acetaldehyde also results from the random choice of active hydrogen by suitable acceptors, ${ }^{2}$ whereat the greater part or even all of the acetaldehyde is changed to acetic acid and alcohol or to ethyl acetate by the Cannizzaro reaction. The same process takes place if alcoholic fermentation proceeds in a weakly alkaline medium. ${ }^{3}$ The more recent discovery of Abderhalden, ${ }^{4}$ that a fermentation of sugar to acetaldehyde and glycerine by yeast takes place in the presence of animal charcoal, is very interesting.

Such varied proofs of the formation of acetaldehyde by alcoholic fermentation, and its liability of reduction to ethyl alcohol by yeast hardly leaves room for any doubt but that acetaldehyde is an intermediate of alcoholic fermentation. Kostychev ${ }^{5}$ has already assumed that acetaldehyde comes from pyruvic acid. Grab ${ }^{6}$ showed that pyruvic acid is probably formed as follows in alcoholic fermentation: he proved that the addition of $\beta$-naphthylamine to fermenting yeast juice effects the formation of methyl naphtho-cinchoninic acid. The process cannot be explained except by the reaction of naphthylamine, pyruvic acid and acetaldehyde, for the following reaction is characteristic of pyruvic acid: ${ }^{7}$

1 Neuberg, C. und Steenbock. Biochem. Z. 52: 494. I9I3; 59: I88. I914; Neuberg, C. und F. Nord. Ibid. 67:24. I9I4; Neuberg, C. und Schwenk. Ibid.71: II4. I9I5; Mayer, P. und C. Neuberg. Ibid. 71: 174. I9I5; and others.

2 Kostytschew, S. Z. f. physiol. Chem. 83: 93. I9r3.

${ }^{3}$ Wilenko, G. Z. f. physiol. Chem. 98: 255. I917; 100: 225. 1917; Oelsner, A. und A. Koch. Ibid. 104: I75. I919: Neuberg, C. und J. Hirsch. Biochem. Z. I00: 304. I9r9; Neuberg, C., J. Hirsch und E. Reinfurth. Ibid. I05:307. 1920.

${ }^{4}$ Abderbalden, E. Fermentforschung. 5: 89, 255. 1921-22; 6: 162. 1922; Abderhalden, E. und Fodor. Ibid. 5: I38. I9r9; Abderhalden, E. und S. Glaubach. 1bid. 6: 143. 1922; [however see Warburg. loc. cit. for consideration of the possible effect of inpur1ties in the charcoal].

${ }^{5}$ Kostytschew, S. Ber. d. chem. Ges. 45: I289. I9I2; Z. f. physiol. Chem. 79: I30. 191 2. [Cf. F. F. Nord. Chem. Rev. 3: 4 I-79. I926 for an English résumé of the chemistry of fermentation in which acetaldehyde is given a prominent place.]

${ }^{6}$ Grab, M. v. Biochem, Z. 123:69. 1921 .

7 Döbner. Ann. d. Chem. 242:291. 1887;281: I. IS94. 


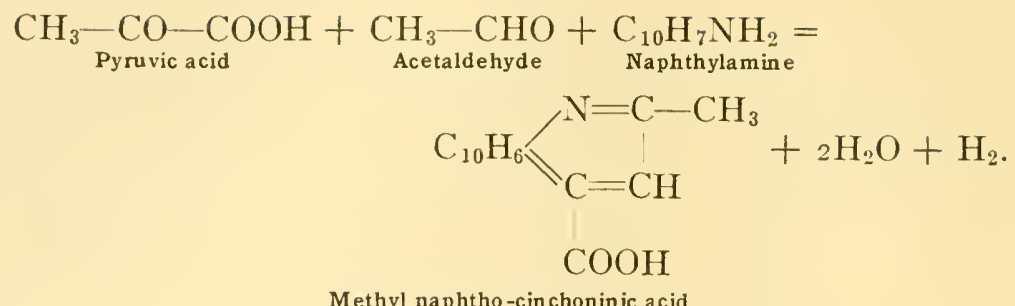

Methyl naphtho-cinchoninic acid

It is very evident that acetaldehyde as well as pyruvic acid is more easily oxidised than ethyl alcohol. Acetaldehyde can probably be burned to $\mathrm{CO}_{2} \cdot{ }^{m}$ Still we know that by the action of nitric acid on acetaldehyde not acetic acid but chiefly glyoxal, $\mathrm{CHO}-\mathrm{CHO}$, is formed. A combustion of glyoxal to $\mathrm{CO}_{2}$ and $\mathrm{H}_{2} \mathrm{O}$ by way of glyoxylic or oxalic acid is very practicable. Nevertheless the hypothesis seems to be more probable that other substances are to be considered as normal intermediates of oxygen respiration, substances which are formed in the first stages of alcoholic fermentation. These first phases of fermentation are not yet studied and we have only purely theoretical conceptions of them. We shall here disregard the older theories of alcoholic fermentation, which do not take into consideration the intermediate formation of acetaldehyde, and consider biiefly only the modern theories.

Kostychev's scheme is really not a theory but a compilation of experimentally grounded facts which clarify only the last phases of the process. By means of a series of unknown coupled reactions, fermentable sugars change to two molecules of pyruvic acid and atomic hydrogen which is loosely joined to acceptors. Then follow both end reactions. First, by the action of carboxylase, pyruvic acid decomposes into acetaldehyde and carbon dioxide. ${ }^{n}$ Then the acetaldehyde is reduced to ethyl alcohol by active hydrogen.

${ }^{m}$ For a recent study of the mechanism of oxidation of aldehyde by dehydroxydation see Müller, E. Ann. d. Chem. 420:24I-263. I920.-Ed.

${ }^{n}$ No release of energy is involved in this reaction. This is evidenced by a comparison of the heats of combustion per mol of pyruvic acid and acetaldehyde. For the details of this comparison see H. Blaschko. Biochem. Z. $158: 4^{28-434}$. r925.-Ed. 
(I) $\mathrm{C}_{6} \mathrm{H}_{12} \mathrm{O}_{6}={ }_{2} \mathrm{CH}_{3}-\mathrm{CO}-\mathrm{COOH}+{ }_{4} \mathrm{H}$ (summarized

reaction)

$$
\begin{aligned}
& { }_{2} \mathrm{CH}_{3}-\mathrm{CO}-\mathrm{COOH}={ }_{2} \mathrm{CH}_{3}-\mathrm{CHO}+{ }_{2} \mathrm{CO}_{2} \\
& { }_{2} \mathrm{CH}_{3}-\mathrm{CHO}+{ }_{4} \mathrm{H}={ }_{2} \mathrm{CH}_{3}-\mathrm{CH}_{2} \mathrm{OH} .
\end{aligned}
$$

The very marked reducing property of yeast was taken into consideration in this scheme for the first time. Moreover, it is evident from these equations that the formation of $\mathrm{CO}_{2}$ and alcohol represent two separate processes. If part of the acetaldehyde is not reduced but is worked up in another way it results in an abnormally small yield of alcohol, as is actually the case in the anaerobic respiration of various plants. On the other hand, an excessive formation of alcohol is precluded according to the equations as given and it has never been experimentally found.

The phases of alcoholic fermentation which precede the formation of pyruvic acid are hypothetically dealt with in the theories of v. Lebedew ${ }^{1}$ and Neuberg. ${ }^{2}$ According to v. Lebedew, the sugar decomposes in to glyceric aldehyde and di-hydroxyacetone. Furthermore, glyceric aldehyde is split according to Kostychev's scheme into one molecule of $\mathrm{CO}_{2}$ and one of ethyl alcohol but di-hydroxy-acetone forms the triose-monophosphate which condenses to hexose phosphate. From the latter the fermentable sugars are reformed, and the whole process is repeated until all the sugar is changed to $\mathrm{CO}_{2}$ and alcohol:
(I) $\mathrm{CH}_{2} \mathrm{OH}-(\mathrm{CHOH})_{4}-\mathrm{CHO}=\mathrm{CH}_{2} \mathrm{OH}-\mathrm{CHOH}-\mathrm{CHO}+$ $\mathrm{CH}_{2} \mathrm{OH}-\mathrm{CO}-\mathrm{CH}_{2} \mathrm{OH}$
(II) $\mathrm{CH}_{2} \mathrm{OH}-\mathrm{CHOH}-\mathrm{CHO}=\mathrm{CH}_{3}-\mathrm{CO}-\mathrm{COOH}+{ }_{2} \mathrm{H}$
(III) $\mathrm{CH}_{3}-\mathrm{CO}-\mathrm{COOH}=\mathrm{CH}_{3}-\mathrm{CHO}+\mathrm{CO}_{2}$
(IV) $\mathrm{CH}_{3}-\mathrm{CHO}+{ }_{2} \mathrm{H}=\mathrm{CH}_{3}-\mathrm{CH}_{2} \mathrm{OH}$
(V) $\mathrm{CH}_{2} \mathrm{OH}-\mathrm{CO}-\mathrm{CH}_{2} \mathrm{OH}+\mathrm{RH}_{2} \mathrm{PO}_{4}=\mathrm{CH}_{2} \mathrm{OH}-\mathrm{CO}-$

$$
\mathrm{CH}_{2}-\mathrm{O}-\mathrm{RHPO}_{3}+\mathrm{H}_{2} \mathrm{O}
$$
(VI) ${ }_{2} \mathrm{C}_{3} \mathrm{H}_{5} \mathrm{O}_{2}-\mathrm{O}-\mathrm{RHPO}_{3}=\mathrm{C}_{6} \mathrm{H}_{10} \mathrm{O}_{4}\left(\mathrm{O}-\mathrm{RHPO}_{3}\right)_{2}$
(VII) $\mathrm{C}_{6} \mathrm{H}_{10} \mathrm{O}_{4}\left(\mathrm{O}-\mathrm{RHPO}_{3}\right)_{2}+{ }_{2} \mathrm{H}_{2} \mathrm{O}=\mathrm{C}_{6} \mathrm{H}_{12} \mathrm{O}_{6}+{ }_{2} \mathrm{RHPO}_{4}$.

In this theory the biochemical meaning of the formation of hexose phosphate was more nearly explained for the first time.

${ }^{1}$ Lebedew, A. $\mathbf{7}$. Compt, rend. 153: I36. I911; Ber. d. chem. Ges. 45: 3240. I012.

${ }^{2}$ Neuberg, C. und J. Kerb. Biochem, Z. 53: 406. I9I3; 58: I58. I9I3. 
Lebedew thought that he had found experimentally that di-hydroxy-acetone forms with phosphates the triose-monophosphate which readily condenses to hexose phosphate. This finding is refuted, however, by more recent studies by Neuberg and his coworkers ${ }^{1}$ and the Lebedew theory is thereby deprived of its experimental foundation.

Lebedew ${ }^{2}$ has recently proposed another theory. He supposes that the fermentation of sugar beyond the intermediate stages of glyceric aldehyde, glyceric acid and pyruvic acid proceeds of itself. According to v. Lebedew's experiments glyceric acid as well as glyceric aldehyde is fermentable by yeast. Proof of this by no means improbable theory has not yet been worked out.

Neuberg himself attempts to explain the formation of methyl groups (which will really be the key to the puzzle of alcoholic fermentation) by means of the intermediate formation of methyl glyoxal, and represents the whole process by the following equations in which the Cannizzaro reaction, first proven for yeast by Kostycher, ${ }^{3}$ plays an important rôle.

(I) $\mathrm{C}_{6} \mathrm{H}_{12} \mathrm{O}_{6}=\mathrm{C}_{6} \mathrm{H}_{8} \mathrm{O}_{4}$ (methyl glyoxal aldol) $+{ }_{2} \mathrm{H}_{2} \mathrm{O}$

(II) $\mathrm{C}_{6} \mathrm{H}_{8} \mathrm{O}_{4}={ }_{2} \mathrm{CH}_{2}=\mathrm{COH}-\mathrm{CHO}$ or ${ }_{2} \mathrm{CH}_{3}-\mathrm{CO}-\mathrm{CHO}$

Methyl glyoxal

(III) ${ }_{2} \mathrm{CH}_{2}=\mathrm{COH}-\mathrm{CHO}+{ }_{2} \mathrm{H}_{2} \mathrm{O}=$ $\mathrm{CH}_{2} \mathrm{OH}-\mathrm{CHOH}-\mathrm{CH}_{2} \mathrm{OH}+\mathrm{CH}_{3}-\mathrm{CO}-\mathrm{COOH}$ Glycerine

(IV) $\mathrm{CH}_{3}-\mathrm{CO}-\mathrm{COOH}=\mathrm{CH}_{3}-\mathrm{CHO}+\mathrm{CO}_{2}$

(V) $\mathrm{CH}_{3}-\mathrm{CO}-\mathrm{CHO}+\mathrm{CH}_{3}-\mathrm{CHO}=\mathrm{CH}_{3}-\mathrm{CO}-\mathrm{COOH}+$ $\mathrm{CH}_{3}-\mathrm{CH}_{2} \mathrm{OH}$.

It is evident that such hypothetical equations are noc easily reconciled with the modern conception of the nature of the Cannizzaro reaction. Nor are they very probable on other grounds. For example, the progress of the "mixed" Cannizzaro reaction ( $\mathrm{V}$ and III together) and similar problematical

I Neuberg, C., E. Farber, A. Levite, und E. Schwenk. Biochem. Z. 83:244. I917.

${ }^{2}$ Lebedew, A. v. Z. f. physiol. Chem. 132:275. 1924.

${ }^{8}$ Kostytschew, S. Z. f. physiol. Chem. 89: 367. I914; 92: 402. IoIf. Neuberg's claim (in his latest communication) that he previously succeeded in demonstrating the Cannizzaro reaction wath yeast (with reference to Neuberg und Kerb. Biochem. Z. 58: 158. I913) is incorrect. No experimental studies of the Cannizzaro reaction are contained in this communication of Neuberg and Kerb. 
processes requires the existence of a regulatory principle, even if the fermentation of sugar outside the living cells were not actually conceivable. Such a regulation is hardly possible without the coöperation of the protoplasm.

Hence we find that at present it has not yet been possible to represent alcoholic fermentation by a series of obvious coupled reactions; our present knowledge is still insufficient. Perhaps the solution of the question of the formation of the methyl groups in alcoholic fermentation could furnish the key to the solution of the problem of fermentation. Even now it is very probable that in the first stages of the process of fermentation there occurs a cleavage of the chain of six carbon atoms into two molecules of three carbon atoms each. The author of this book believes that he can assume that oxidising enzymes of normal oxygen respiration are sympathetically affected by these steps, and therefore before the origin of the methyl groups. Disregarding the fact that in general compounds with only oxidised carbon atoms are more susceptible to biological oxidation, it is pertinent to consider the processes in animal respiration. In the case of the higher animals, the anaerobic cleavage of sugar appears to be essentially identical with lactic acid fermentation. Yet we may suppose that this process forms the preparatory step to oxygen respiration. Thus there is consumed by oxidising enzymes a substance which is formed in the course of anaerobic glycolysis previous to the formation of lactic acid, and so before the separation of the process of fermentation into alcoholic and lactic acid fermentation. A connection of the respiration of animal tissues with yeast fermentation is shown by the fact that in the former the coenzymes of alcoholic fermentation play an important rôle ${ }^{1}$ and the well-known hexose phosphate is formed in the first phases of the respiratory process. ${ }^{2}$

\section{THE SUPPOSED FORMATION OF ORGANIC ACIDS IN THE RESPIRATORY PROCESS}

From the above exposition it is evident that at present it is undecided which intermediate products of fermentation func-

1 Meyerhof, O. loe. cit.

${ }_{2}$ Embden und Laqueur. Z. f. physiol. Chem, 98: I8r. I9r6-17. 
tion at the same time as respiratory products. In the oxidation of these substances very unstable carboxylic acids could be formed, since it is most probable that $\mathrm{CO}_{2}$ is split off from carboxyl groups. In this respect the following observation of Euler and Bolin ${ }^{1}$ is worthy of note. It was found that laccase preparations from Medicago sativa contain a considerable quantity of glycolic acid, $\mathrm{CH}_{2} \mathrm{OH}-\mathrm{COOH}$, glyoxylic acid, $\mathrm{CHO}-$ $\mathrm{COOH}$, and particularly mesoxalic acid, $\mathrm{COOH}-\mathrm{CO}-\mathrm{COOH}$. It is not unlikely that glycolic and glyoxylic acids are to be regarded as products of the oxidation of acetaldehyde. Mesoxalic acid may represent the oxidation product of the "threecarbon substance," the formation of which precedes that of pyruvic acid, and which would be considered as the normal intermediate of alcoholic fermentation as well as of oxygen respiration. Mesoxalic acid can be easily oxidised to $\mathrm{CO}_{2}$ and $\mathrm{H}_{2} \mathrm{O}$ and is therefore even more probably a normal intermediate of oxygen respiration.

It is evident that such direct products of the oxidation of the substances arising from the anaerobic cleavage of sugar appear only in small quantities, since they are continually consumed and could never accumulate in large amounts. Quite different is the physiological rôle of those plant acids which are formed in large quantities in fleshy fruits and succulent parts and which are also found in other plants. Of these acids we shall consider only the most common-oxalic, malic, citric and tartaric acid. The latter appears in plants of southern regions while the rest, especially malic acid, are contained in most plants and sometimes in high concentration.

These acids have also been regarded by various authors as intermediates of oxygen respiration at a time when the nature of oxidation processes in plant cells was still unintelligible and the connection of alcoholic fermentation with oxygen respiration was not yet a subject of experimental investigation. From the present viewpoints, such theories are neither theoretically nor experimentally justified. Years ago they found much favor and are still admitted to modern texts. For example, there is a consideration of the physiological transformations of plant

1 Euler, H. und J. Bolin. 2. f. physiol. Chem. 6r: r. 1909. 
acids in the new edition of the basic handbook "Biochemie der Pflanzen" by F. Czapek ${ }^{1}$ under the section on plant respiration. From what follows it is clear that this statement can scarcely be regarded as free from objections.

A. Mayer ${ }^{2}$ declared long ago that in plant respiration under some conditions malic and oxalic acids could be formed in place of carbon dioxide. That the views of $\mathrm{A}$. Mayer depend on observations too weak to hold is evident from the fact that he also assumed the reverse process, i.c. a direct synthesis of sugars from plant acids by light, whereby carbon dioxide was not even temporarily formed. Mayer's theory was then perfected and extended by Warburg $^{3}$ and by Puriewitsch. ${ }^{4}$ These authors assumed that sugar is generally oxidised by means of the formation of plant acids containing more oxygen. Finally oxalic acid is said to be formed as the preliminary to complete combustion. Oxalic acid was then erroneously taken to be the plant acid which accumulates in excess. In reality, malic acid is the most important acid product of the metabolism of fleshy fruits and succulents, as is shown by the following table: ${ }^{5}$

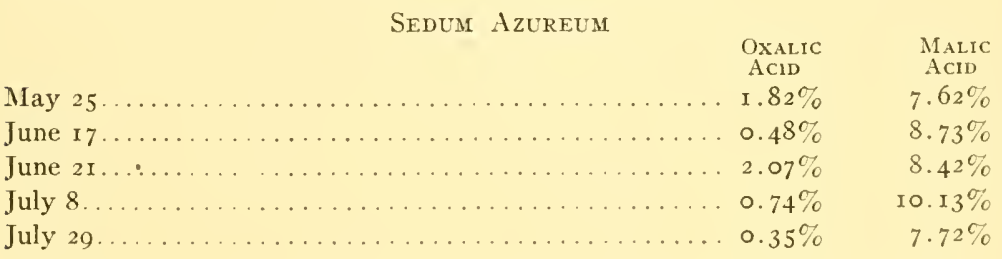

The malic acid content of succulents is subject to great variations. It accumulates at night but during the day a decrease in the amount of acid is to be noted. ${ }^{6}$ This depends on the oxidation of malic acid to $\mathrm{CO}_{2}$ in the light. In darkness this process ceases. This explains the accumulation of acid at night.

1 Czapek, F. Biochemie der Pflanzen. 2nd. ed. 3:65-1 ro. I921.

2 Mayer, A. Landwirtschaft1. Versuchs-Stationen. 34: 127. I887.

3 Warburg, O. Untersuch, aus d. bot. Inst. Tübingen. 2: 53. I 886.

4 Puriewitsch, K. Aufbau und Abbau von organischen Säuren in Samenpflanzen. I89.3.

- Andre, G. Compt. rend. I40: 1708. 1905; $c f$. also Branhofer und Zellner. Z. f. physiol. Chem. I09: 12. 1920.

6 Kraus, G. Abh. d. Naturf. Halle. Vol. I6. I88.4; Lange, P. Inaug. Diss. Halle. I886; Puriewitsch. loc. cit. [For a discussion of the acids in the cacti see Spoehr, H. A. The carbohydrate economy of cact. Carn. Inst. Wash. Publ. 287. I9I9.] 
It is thus evident that malic acid in plant cells can be oxidised to $\mathrm{CO}_{2}$. The combustion of oxalic acid is even more easily accomplished. Zaleski and Reinhard ${ }^{1}$ found in plants a specific enzyme which oxidises oxalic acid. Then Staehelin ${ }^{2}$ showed that this enzyme is very widely distributed in the plant kingdom. Although the plant acids could doubtless be burned to $\mathrm{CO}_{2}$ and $\mathrm{H}_{2} \mathrm{O}$ it would be hasty to conclude that this process of oxidation represents the final phase of normal oxygen respiration. Above all it is to be observed that the common plant acids could be formed from amino acids as well as from sugar.

Since deaminization has been recognized as a widespread process we know that the cleavage products of proteins may be regarded as parent substances of various nitrogen free plant materials. The author of this book considers that he can assume that the common plant acids represent either transformation products of amino acids, or either normal or by-products of incomplete change of sugar to amino acids in the case of the synthesis of proteins.

Such a strongly oxidised substance as oxalic acid can of course be derived from protein as well as from sugar. It is known, for one thing, that a considerable amount of oxalic acid is formed in the treatment of proteins with nitric acid. Wehmer ${ }^{3}$ showed that some molds produce enormous quantities of oxalic acid at the expense of sugar, yet this investigator refers expressly to the fact that part of the oxalic acid is formed not from sugar but from protein substances. It also appears that oxalic acid is formed in fungus cultures with peptone as the sole nutrient. ${ }^{4}$ From single amino acids as the sources of carbon the same product was observed. According to some unpublished experiments, Aspergillus niger produces oxalic acid in the synthesis of protein from sugar and nitrates. Also the copious formation of oxalic acid in the case of the regeneration of protein from asparagine in seed-plants is nothing but a result of

\footnotetext{
${ }^{3}$ Zaleski, W. und Reinhard. Biochem. Z. 33: 449. I9II; Palladin, W. und Lowtschinowsky. Mitt. d. Akad. d. Wiss. Petersburg. 1916:937.

2 Staehelin, M. Biochem. Z. 96: I-49. 1919.

${ }^{3}$ Wehmer, C. Bot. Zeitschr. 49:233. I89r; Ber. d. bot. Ges. 24:38r. I 906; Zentralbl. f. Bakt., Parasitenk. u. Infektionskrankh. (II). 3: 102. I897.

- Butkewitsch, W. Biochem. Z. 129: $4+4$. I922.
} 
an oxidation of the carbon framework of asparagine, according to Petrow. ${ }^{1}$

If it is conceivable that oxalic acid may be formed from protein as well as from sugar the possibility of the formation of other organic acids from the cleavage products of the proteins appears to be still greater. Yet the formation of succinic acid from sugar has not been recorded though its formation from glutamic acid is established beyond question." This process is effected by yeast as follows: ${ }^{3}$

(I) $\mathrm{COOH}-\mathrm{CH}_{2}-\mathrm{CH}_{2}-\mathrm{CH}\left(\mathrm{NH}_{2}\right)-\mathrm{COOH}+\mathrm{O}=$ $\mathrm{COOH}-\mathrm{CH}_{2}-\mathrm{CH}_{2}-\mathrm{CO}-\mathrm{COOH}+\mathrm{NH}_{3}$.

(II) $\mathrm{COOH}-\mathrm{CH}_{2}-\mathrm{CH}_{2}-\mathrm{CO}-\mathrm{COOH}=\mathrm{COOH}-$

$\mathrm{CH}_{2}-\mathrm{CH}_{2}-\mathrm{CHO}+\mathrm{CO}_{2}$.

(III) $\mathrm{COOH}-\mathrm{CH}_{2}-\mathrm{CH}_{2}-\mathrm{CHO}+\mathrm{O}=\mathrm{COOH}-$

$\mathrm{CH}_{2}-\mathrm{CH}_{2}-\mathrm{COOH}$.

The circumstance is noteworthy that no nitrogen free acid is furnished when aspartic acid is used by yeast. The process of deaminization of aspartic acid also takes place in seed-plants to an enormous extent when protein is regenerated at the expense of asparagine and soluble carbohydrates. Butkewitsch $^{4}$ has established beyond doubt that asparagine only serves as a source of $\mathrm{N}$ in that ammonia is split off and used to build up the amino acids; but the carbon framework of every amino acid consists of sugar. Hence, one should expect that when protein is regenerated in the growing parts of plants large amounts of the unused residue of asparagine would remain as malic acid or similar compounds. This is not the case, for just as in the deaminization of aspartic acid by yeast, in the utilization of asparagine in germinating plants no nitrogen free residues were found. Kostychev explains this relationship as follows. Malonic acid should come from aspartic acid in the same way that succinic acid is formed from glutamic acid.

\footnotetext{
${ }_{1}^{1}$ Petrow, G. G. Stickstoffassimilation durch Samenpflanzen im Lichte und in Dunkelheit. 1917. Russian.

2Ehrlich, F. Biochem. Z. 18:391, 1909.

${ }^{3}$ Neubauer, O. und Fromherz. Z. f. physiol. Chem. 70: 326. I9ri; Neuberg, C. Biochem. 2. 91: 131. 1918.

- Butkewitsch, W. Biochem. Z. 16: fII. I909; 4I: 431. I9I2.
} 
(I) $\mathrm{COOH}-\mathrm{CH}_{2}-\mathrm{CH}\left(\mathrm{NH}_{2}\right)-\mathrm{COOH}+\mathrm{O}=\mathrm{COOH}-\mathrm{CH}_{2}-$ $\mathrm{CO}-\mathrm{COOH}+\mathrm{NH}_{3}$

(II) $\mathrm{COOH}-\mathrm{CH}_{2}-\mathrm{CO}-\mathrm{COOH}=\mathrm{COOH}-\mathrm{CH}_{2}-\mathrm{CHO}+$

(III) $\mathrm{COOH}-\mathrm{CH}_{2}-\mathrm{CHO}+\mathrm{O}=\mathrm{COOH}-\mathrm{CH}_{2}-\mathrm{COOH}$.

However, this process cannot take place because the oxalacetic acid $\mathrm{COOH}-\mathrm{CH}_{2}-\mathrm{CO}-\mathrm{COOH}$ is not split by carboxylase in the same way as is $\alpha$-keto-glutaric $\mathrm{COOH}-\mathrm{CH}_{2}-\mathrm{CH}_{2}-$ $\mathrm{CO}-\mathrm{COOH}$. It has been shown experimentally that oxalacetic acid splits off two rather than one molecule of $\mathrm{CO}_{2}$, whereby it is changed to acetaldehyde. ${ }^{1}$

Acetaldehyde is probably oxidised higher than acetic acid or glyoxal to oxalic acid, which either remains as the end-product of the cleavage of asparagine or most of it passes over into $\mathrm{CO}_{2}$ and $\mathrm{H}_{2} \mathrm{O}$. In some unpublished experiments Kostychev has been able to form malic acid by the action of yeast since $\mathrm{CO}_{2}$ is not split off because the carbonyl group is reduced to the hydroxyl group before the carboxylase takes hold:

$$
\mathrm{COOH}-\mathrm{CH}_{2}-\mathrm{CO}-\mathrm{COOH}+{ }_{2} \mathrm{H}=\mathrm{COOH}-\mathrm{CH}_{2}-\mathrm{CHOH}
$$

The same reduction appears to be effected in the case of some molds and possibly is not precluded in seed-plants under certain conditions. In this way we are justified in assuming that malic as well as oxalic acid can be formed from aspartic acid. If malic acid is formed from sugar it is really not a stage of the normal respiratory process but an intermediate phase of the formation of asparagine. Actually an increased formation of malic acid or malic acid monamide was demonstrated by Schulow and Petrow ${ }^{2}$ for germinating seed-plants. Prianischnikow and his students ${ }^{3}$ have also observed a considerable increase in the amount of asparagine in seedlings after artificial feeding of salts of malic acid. Still more interesting in this connection are the pioneer studies in animal physiology by Embden and

${ }_{1}$ Neuberg, C. und L. Karczag. Biochem. Z. 36:68. I9I I.

${ }^{2}$ Schulow, Iw. Untersuch, im Bereich der Physiol. der Ernähr, höherer Pflanzen. I9I3. Russian; Petrow, G. G. loc. cit.

Prianischnikow, D. Tagebuch d. I. Kongr. d. russ. Bot. I921:65: Smirnow, A. Biochem. Z. I37: I. 1923. 
his coworkers ${ }^{1}$ who have effected a regular transformation of the ammonium salts of $\alpha$-keto- or $\alpha$-hydroxy-acids into amino acids of the corresponding constitution by experiments in which blood is passed through isolated liver. This work indicates the course of the biological synthesis of amino acids.

On the basis of these investigations it is most probable that the greater part of the malic acid of seed-plants is formed in the process of formation or deaminization of asparagine. Frequently, perhaps because of a deficiency of nitrogen, all the malic acid cannot be worked into asparagine. The excess of malic acid is then destroyed by oxidation processes leading to the formation of $\mathrm{CO}_{2}$, but this is not a direct or normal respiratory process. The oxidation of plant acids is much more like the "protein respiration" already mentioned [see page I23]. The following curious phenomenon, observed by Warburg and Negelein, ${ }^{2}$ may be noted in this connection. It was found that an excess of $\mathrm{CO}_{2}$ is given off during the assimilation of nitrates by the single-celled alga Chlorella vulgaris. The formation of $\mathrm{CO}_{2}$ is not a real respiratory process. It can be sharply separated from the respiratory release of $\mathrm{CO}_{2}$ by means of certain toxic effects. The assumption is not precluded that in this case there is an oxidation of plant acids in connection with the formation of protein.

The studies of Ruhland and Wetzel, ${ }^{3}$ Ullrich ${ }^{4}$ and A. Smirnoff ${ }^{5}$ are decidedly in favor of a connection of the formation of organic acids with the transformation of plant proteins.

In the case of the lower plants, at the most only traces of malic acid can be formed. It is also to be noted that asparagine is never formed in the fungi and bacteria.

As for citric acid with its branched carbon chain, a direct transformation of sugar into this acid during the respiratory process is not very probable. It is worthy of note that in the formation of amino acids, branched chains are synthesized from

\footnotetext{
${ }^{1}$ Embden, G. und E. Schmitz. Biochem. Z. 29: 423. I910; 38:393. 1912; Kondo, K. Ibid. 38:407. 1912; Fellner. Ibid. 38:414. I9I2.

2 Warburg, O. und Negelein. Biochem. Z. 110:66. I9zo.

${ }^{3}$ Ruhland, W. und K. Wetzel. Planta. I : 558. 1926.

- Ullrich, H. Ibid. I: 565. 1926.

5 Smirnoff, A. Zur Frage des Stoff wechsels im Tabakeblatt $1 \mathrm{~m}$ Laufe senner Entwickelung. 1926. Russian.
} 
sugar. For example the carbon framework of citric acid is identical with that of isoleucin:

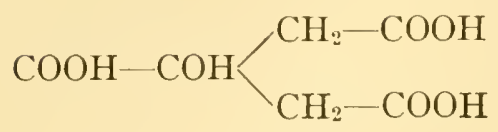

Citric acid

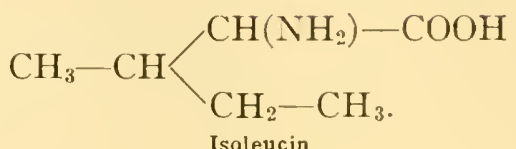

Isoleucin

It is evident that citric acid might be formed from isoleucin and some other cleavage products of protein substances without the participation of synthetic processes. However, the greater part of the citric acid is formed from sugar, not as a result of respiratory processes but as a by-product of the formation of amino acids and purine derivatives.

The so-called forms of Citromyces produce considerable quantities of citric acid according to Wehmer. ${ }^{1}$ According to recent studies the capacity to form citric acid is peculiar to various molds under anomalous conditions of nutrition, ${ }^{2}$ so the genus Citromyces should perhaps be dropped. The detailed studies by Mazé and Perrier ${ }^{3}$ have established beyond doubt that the formation of citric acid by molds represents an extremely complicated process. In addition to this Buchner and $W$ üstenfeld ${ }^{4}$ have sought in vain to isolate an enzyme of citric acid fermentation ${ }^{5}$ from Citromyces. Moreover, Butkewitsch ${ }^{6}$ has shown that molds form citric acid only in the presence of considerable amounts of sugar.

The general conclusion may therefore be drawn that the plant acids, such as malic, tartaric, citric, etc., which are formed in large quantities are not at all normal intermediate products of oxygen respiration. These acids arise either from amino

\footnotetext{
1 Wehmer, C. Ber. d. bot. Ges. II: 3.33. 1893; Zentralbl. f. Bakt., Parasitenk. u. Infektionskrankh. (11) 15: 427. I906.

${ }^{2}$ Currie, N. Jour. Biol. Chem. 31: 15. 1917; Elfving, F. Öfvers. af Fin. VetenskapsSoc. Förh. A. Mathem. o. Naturw. 61: 1. 1920; Molliard. Compt. rend. 168: 360. I919; 174: 88I. 1922; 178: 4I. I9 24; Butkewitsch. Biochem. Z. 129: 445, 455, 464. 1922.

${ }^{8}$ Mazé et Perrier. Ann. de l'inst. Pasteur 18: 553. 1905; 23: 830. I909; $c f$. also Elfving. loc, cit.

- Buchner, H, und Wüstenfeld. Biochen. Z. r7: 395. 1909.

5 It is scarcely valid to designate the processes of acid formation as "oxalic acid fermentation," "citric acid fermentation," etc. According to the modern conception, true fermentations are independent systcms of coupled reactions which may be scparated from the living protoplasm and which serve as sources of energy.

${ }^{6}$ Butkewitsch, W. loc. cit.
} 
acids or from intermediate products of the synthesis of protein, ${ }^{1}$ and the oxidation of the common plant acids represents a process which is more like "protein respiration" than "sugar respiration."

\section{THE COÖRDINATION OF THE VARIOUS PROCESSES IN PLANT RESPIRATION}

From the previous statements it is evident that the normal oxygen respiration of plants consists of various stages and so represents a complicated process. The smooth course of processes as complicated as are those of alcoholic fermentation or oxygen respiration is really to be traced to a remarkable coördination of the reaction velocities of the several stages. This is demonstrated by various known cases of disturbance of the coördination in the case of plant respiration. According to the ratio of the reaction velocities of the two most essential processes, the primary anaerobic cleavage and the subsequent oxidation, the following types of plant respiration are possible:

First Case.-The amount of zymase in the plant cells is extremely large in comparison with the quantity of the oxidising enzymes. For that reason the velocity of the primary cleavage of sugar is greater than the velocity of the subsequent oxidation. Consequently, part of the sugar attacked by the enzymes of fermentation cannot be entirely consumed, even with free access to oxygen. The labile, intermediate products of the alcoholic fermentation become changed, under aerobic conditions, into the stable form of alcohol and $\mathrm{CO}_{2}$, since the activity of the oxidising enzymes does not suffice to effect a complete oxidation of all the products of fermentation.

This is a solution of the problem of the effect of oxygen on fermentation by yeast. Nägeli ${ }^{2}$ and Brown, ${ }^{3}$ on the basis of calculations not entirely free from objections, assumed a stimulatory effect of oxygen on alcoholic fermentation but other investigators such as Hoppe-Seyler, Pedersen, Hansen, and

\footnotetext{
1 For the formation of acids during the germination of plants $c f$. Windisch und Dietrich. Wochenschr. f. Brauerei. 35: I59. I9I8; Lüers, H. Biochem. Z. I04:30. I920.

2 Nägeli, C. v. Theorie der Gärung. I879. P. I8.

${ }^{3}$ Brown, A. Jour. Chem. Soc. (London) I : $369 . \quad 1892$.
} 
Chudiakow $^{1}$ claim the contrary while A. Mayer, ${ }^{2}$ D. Iwanowski, ${ }^{3}$ and $\mathrm{H}$. Buchner and Rapp ${ }^{4}$ have shown that in either the presence or absence of oxygen, equal amounts of sugar are destroyed by the fermentation process and almost equal quantities of $\mathrm{CO}_{2}$ escape. On the strength of these results Iwanowski and $H$. Buchner claim that yeast obtains the energy necessary for its life only from the process of alcoholic fermentation, in the presence of oxygen just as in its absence.

However, Iwanowski has already shown that living yeast cells absorb small amounts of oxygen. This shows that they are able to bring about oxidation processes. Kostychev and Eliasberg ${ }^{5}$ have recently pointed out that in the presence of oxygen, yeast develops a strong, normal respiration which produces for it considerably more energy than the whole process of fermentation, the impetuous course of which is so striking. That is to say, it is to be taken into consideration that the use of one molecule of sugar in respiration furnishes just as much energy as the fermentation of twenty-five molecules. The amount of sugar consumed by respiration may be ascertained in the following manner. First Giltay and Aberson ${ }^{6}$ and then H. Buchner and Rapp ${ }^{7}$ showed by direct analyses that in the presence of oxygen the ratio $\mathrm{CO}_{2}: \mathrm{C}_{2} \mathrm{H}_{5} \mathrm{OH}$ of yeast fermentation is larger than in the absence of oxygen. Only in the latter case do the quantities of $\mathrm{CO}_{2}$ and alcohol correspond to the theoretical equation for alcoholic fermentation. Hence we are justified in assuming that, with an unrestricted entry of oxygen, the amount of $\mathrm{CO}_{2}$ equivalent to the alcohol is to be regarded as the carbon dioxide of fermentation, while the surplus $\mathrm{CO}_{2}$ is to be considered as the $\mathrm{CO}_{2}$ of respiration. On this basis it is possible to calculate the amounts of sugar fermented and respired. The calculations of Kostychev and Eliasberg showed that about

1 Hoppe-Seyler. Über Einwirkung des Sauerstoffs auf Gärungen. I881; Pedersen. Medd. fră Carlsberg lab. 1: 78. 1878; Hansen. Ibid. 2: 133. 1879; Chudiakow, N. Landwirtschaftl. Jahrb. 23: 391. 1894.

2 Mayer, A. Ber. d. chem. Ges. I3: I163. 1880; Landwirtschaftl. Versuchs-Stationen 25: 30 T. 1880.

3 Iwanowski, D. Untersuch. über alkoholische Gärung. 1894. Russian.

"Buchner, H. und R. Rapp. Z. f. Biol. 37: 82. I899; "Zymasegärung." 1903.

${ }^{5}$ Kostytschew, S. und P. Eliasberg. Z. f. physiol. Chetn. XII: I4I. I920.

6 Giltay und Aberson. Jahrb. f. wiss. Bot. $26: 543$. I 894.

7 Buchner, H. und Rapp. loc. cil. 
one-third of all the $\mathrm{CO}_{2}$ may be traced to oxygen respiration when air is admitted; hence the amount of sugar used in respiration is one-ninth of that used in fermentation, and the energy derived from the oxygen respiration is about two and a half times as great as that furnished by alcoholic fermentation when oxygen is excluded. The previously unexplained meaning of oxygen for the propagation of yeast has now become easily understood. When oxygen is excluded the energy production of the yeast is so low that the multiplication of cells proceeds but slowly.

So with free access to oxygen, alcoholic fermentation is a wholly unessential process for yeast. For that reason it continues only because the yeast cells contain a large quantity of the enzymes of fermentation which are essential to the anaerobic life of the yeast. But in the presence of oxygen a complete combustion of such enormous quantities of sugar would be wholly superfluous. So with good aeration the unoxidised, intermediate products of fermentation are changed into alcohol and $\mathrm{CO}_{2}$, since the atmospheric oxygen does not attack these intermediate products. Kostychev and Eliasberg have shown by means of direct determinations of sugar, alcohol and $\mathrm{CO}_{2}$, that some mucors such as $M$. racemosus, $M$. mucedo and Rhizopus nigricans behave like yeast and in the presence of oxygen maintain oxygen respiration and alcoholic fermentation simultaneously. The explanation given for yeast is strengthened in many respects by studies of the Mucoraceae. For example, the alcoholic fermentation of Rhizopus nigricans is so weak in the presence of oxygen that it often does not suffice for the requirements of the life of the fungus. Yet it continues during unrestricted aeration because the ratio of the oxidising enzymes to those of fermentation prevents a complete combustion of sugar.

Second Case.-The quantities of oxidising and fermentation enzymes are so coördinated in the plant cells that the velocity of the primary sugar cleavage is always less than the velocity of the subsequent oxidation. Consequently alcohol is never formed when air is admitted, since all the intermediate products pass over into the end-products of oxygen respiration. This 
is the usual respiration of the seed-plants and the strongly aerobic microörganisms in which there is a complete combustion of sugar even with low oxygen tension. ${ }^{1}$ The following observation, already described, can serve as an illustration of the unequal behavior of strongly aerobic fungi, such as $A$ spergillus niger, on one hand, and the aerobic, fermenting fungi which are rich in zymase, such as yeasts and mucors, on the other hand, in the case of a somewhat restricted access to oxygen. ${ }^{2}$ If Aspergillus niger is immersed in a sugar solution it does not produce a trace of alcohol if the surface of the solution is left in equilibrium with the air. The oxidising capacity of this fungus is so strong that even the small amount of oxygen dissolved in the solution effects a complete oxidation of the respiratory material. The fermenting yeasts and mucors behave quite differently. Under the same experimental conditions they give rise to a vigorous alcoholic fermentation and the combustion of sugar is discontinued.

Third Case.-The plant cells contain an insufficient amount of enzymes of fermentation. Hence the oxidising enzymes are not only able to oxidise completely all the intermediate products of fermentation but they also attack the unchanged sugar, ${ }^{\circ}$ since their working capacity is not spent on the insignificant quantities of the fermentation products. An incompletely proven example of this case is that of the formation of gluconic acid by Aspergillus niger. M. Molliard ${ }^{3}$ has found that with a deficiency of mineral nutrients, Aspergillus niger oxidises grape sugar to gluconic acid:

${ }_{2} \mathrm{CH}_{2} \mathrm{OH}-(\mathrm{CHOH})_{4}-\mathrm{CHO}+\mathrm{O}_{2}={ }_{2} \mathrm{CH}_{2} \mathrm{OH}-(\mathrm{CHOH})_{4}-$

$\mathrm{COOH}$

It is characteristic of oxidising enzymes of plants that they are able neither to break carbon chains nor to unite carbon

${ }^{1}$ Stich. Flora. 74: 1. r89r; Amm. Jahrb. f. wiss, Bot. 25: r. r893; Johannsen. Untersuch. aus d. Bot. Inst. Tübingen $1: 716 . \quad 1885$.

2 Kostytschew, S. und M. Afanassjewa. Jour, d. russ, bot. Gres, $2: 77$, r917.

S Molliard, M. Compt. rend. 174:881. 1922; 178: 4 r. 1924.

- There seems to be no proof that the sugar is "unchanged" (unzersetzten) under these conditions. A number of points previously mentioned by the author favor the view that the sugar must be changed to some isomer or derivative before it can be attacked by the oxidising enzymes.-Ed. 
atoms and oxygen. This has been discussed in previous statements. For that reason Boysen-Jensen ${ }^{1}$ is mistaken in saying that the capacity of plants to ferment sugar directly (i.e. without the use of enzymes of fermentation) is demonstrated by such processes as the oxidation of sorbitol to sorbose, glycerine to di-hydroxy-acetone, glucose to gluconic acid, etc. On the contrary, all such reactions furnish striking proofs that, in the direct oxidations in the protoplasm of plant cells, there is only an oxidation of hydrogen and never a disruption of carbon chains.

The established limitations, previously stated, were first based on the fact that the mixtures of respiratory enzymes taken from various plants ${ }^{2}$ exhibit very unlike compositions. Kostychev $^{3}$ proved this soon after the discovery of zymase. He was able to exhibit from molds capable of fermentation, dry preparations which were in all respects similar to killed yeast (zymin and "Hefanol"). Strongly aerobic molds furnished preparations of enzymes which, outside of living celis, effected a metabolism wholly analogous to respiration and which may be traced to a corresponding quantitative ratio between the enzymes of cleavage and of oxidation. Strongly aerobic fungi contain a large quantity of oxidising inductors. By means of these experiments it was first shown that oxygen respiration represents a fermentative process. Preparations of lasting yeast (Dauerhefe), which consist of killed yeast cells, exert no oxidising effect. As long as only such preparations were known it appeared as if the capacity to use molecular oxygen in an oxidation of organic substances which involved a release of $\mathrm{CO}_{2}$ were peculiar to living protoplasm. Accordingly respiration appeared to be not a chemical process but a resultant of heterogeneous material transformations carried out in the protoplasm, so much the more since it had been known in the meantime that oxidising enzymes could link oxygen to hydrogen but not to the carbon of organic compounds. As soon as it

\footnotetext{
${ }^{1}$ Boysen-Jensen, P. loc. cit., p. 29.

2 This characteristic was first demonstrated by Kostytschew, S. Ber. d. bot. Ges. 22: 207. I904.

${ }^{3}$ Kostytschew, S. loc. cit.; Zentralbl. f. Bakt., Parasitenk. u. Infektionskrankh. (II). 13: 490. I904; $c f$. also Maximow, N. Ber. d. bot. Ges. 22: 225. I904.
} 
was found that the respiratory metabolism could also be effected by means of killed cells the question of a mechanism of the combustion of sugar could arise.

If we survey the known facts in the field of the chemical processes which take place in oxygen respiration, we come to the conclusion that the experimental investigation is seeking absolutely new goals in recent years. Previously the principal object of research was merely the external side of respiration (influence of various effects of poisons, the stages of development, etc.). At present there is developing the real biochemistry of respiration which provisionally records only the isolated results, yet the results already won allow the advancement of a connected theory of respiration which can serve as a working hypothesis for further studies. It is also evident now that the further development of the chemistry of plant respiration is closely bound with the chemical investigations of alcoholic fermentation. In the first place, it would be of the greatest importance to identify the compound which serves simultaneously as the intermediate product of oxygen respiration and of alcoholic fermentation, which is therefore formed from sugar through the participation of the enzymes of fermentation, and is then burned to the end-products of respiration by means of oxidising agents. The supposition is not precluded that the oxidising enzymes attack different products of fermentation although the most oxidisable substance really constitutes the normal intermediate product of oxygen respiration. It has already been pointed out that this substance probably contains no methyl groups.

In conclusion we shall further raise the question whether there are any organisms of fermentation which do not respire even with unrestricted aeration. That yeast with free access to oxygen owes its working energy chiefly to the process of oxygen respiration appears to be scarcely questionable according to the studies of Kostychev and Eliasberg (loc. cit.). On the whole, the conclusion would perhaps not be sustained that organisms which produce alcoholic fermentation when oxygen is excluded respire normally when oxygen is admitted. This is not true for all fermentations. Unpublished studies by $\mathrm{S}$. 
Kostychev and M. Afanassjewa show that the agents of lactic acid fermentation, Bac. caucasicus and Bacterium lactis acidi Leichmann, which ferment sugar to lactic acid without forming by-products, do not form the slightest trace of carbon dioxide with unrestricted aeration. Hence they are wholly incapable of respiration. It is to be observed that these bacteria, which belong in the category of facultative anaerobes, cause the fermentation of much larger amounts of sugar per unit of dry substance than does yeast, which is only a temporarily anaerobic fungus and which cannot exist for an indefinite period without access to the air. 


\section{RESPIRATION AT THE EXPENSE OF MINERAL SUBSTANCES}

\section{NITRIFYING BACTERIA}

Through the pioneer researches of S. Winogradski there were discovered bacteria which grow well in purely mineral media and which effect peculiar transformations of materials. Of all these forms the nitrifying bacteria are especially striking because they can be cultivated in pure cultures only in the absence of organic compounds. According to Winogradski and Omelianski ${ }^{1}$ the growth of nitrifying bacteria is checked or prevented by the following quantities of various organic substances:

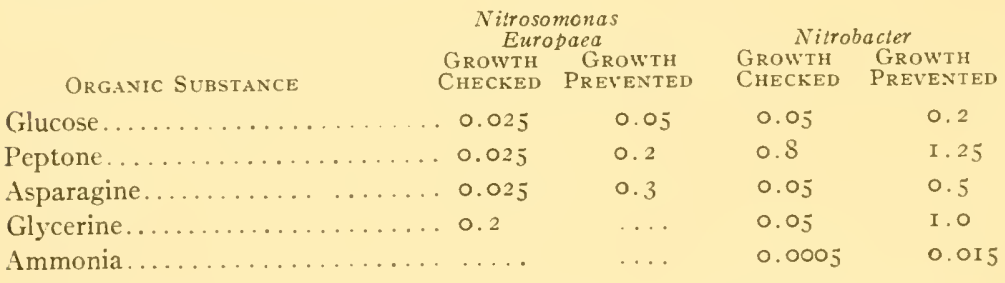

The isolation of pure cultures of the nitrifying bacteria can be done only by the use of silicic acid jelly or strong paper plates, for neither gelatine nor agar permits a growth of these most peculiar organisms.

The nitrifying bacteria effect a vigorous formation of nitrate from ammonium salts and Vitrosomonas or Vitrosococcus oxidises ammonia to nitric acid, although Nitrobacter completes the process in that it oxidises $\mathrm{HNO}_{2}$ to $\mathrm{HNO}_{3}$. Both reactions are exothermic:

(I) $2 \mathrm{NH}_{3}+{ }_{3} \mathrm{O}_{2}={ }_{2} \mathrm{HNO}_{2}+{ }_{2} \mathrm{H}_{2} \mathrm{O}+\mathrm{I}_{5} \mathrm{~S}$ Cal.

(II) ${ }_{2} \mathrm{HNO}_{2}+\mathrm{O}_{2}={ }_{2} \mathrm{HNO}_{3}+43.2 \mathrm{Cal}$.

\footnotetext{
' Winogradski, S. und W. Omelianski. Zentralbl. f. Bakt., Parasitenk. u. Infektionskrankh. (II). 5: 338, 377, 429. I899; cf. also Meyerhof, O. Arch. ges. Physiol, I65: 229. 1916; 166:240. 1917 .
} 
We are entirely justified in calling this process respiration, especially since no simultaneous combustion of organic substance takes place in these forms. According to the work of Meyerhof, ${ }^{1}$ the amount of atmospheric oxygen absorbed by Vitrobacter corresponds exactly to the amount of nitrite oxidised: hence an oxidation of organic substance is precluded. This is apparent from the following table:
$\mathrm{O}_{2}$ Absorbed
$0.270 \mathrm{cc}$.
$0.392 \mathrm{cc}$.
c. $277 \mathrm{cc}$.
$0.293 \mathrm{cc}$.
o. $244 \mathrm{cc}$.

$\mathrm{O}_{2}$ USED TO OXIDISE

$$
\begin{aligned}
& \text { THE NITRITE } \\
& 0.273 \mathrm{cc} \text {. } \\
& 0.396 \mathrm{cc} \text {. } \\
& 0.290 \mathrm{cc} \text {. } \\
& 0.295 \mathrm{cc} \text {. } \\
& 0.240 \mathrm{cc} \text {. }
\end{aligned}
$$

From this we understand how Nitrobacter obtains the energy for its vital processes in the absence of organic substances. The oxidation of $\mathrm{NH}_{3}$ or $\mathrm{HNO}_{2}$ is so vigorous that, as is wellknown, the free energy suffices to assimilate the atmospheric carbon dioxide without the intervention of radiant energy. For Nitrosomonas Winogradski found that one atom of carbon is assimilated for each $33 \cdot 3-36.6$ molecules of oxidised ammonia. According to Meyerhof, Nitrobacter assimilates one atom of carbon for each $13 \mathrm{I}^{-1} 46$ molecules of oxidised nitrite. The figures correspond exactly to the heat release from the oxidation of ammonia and nitrite.

\section{SULPHUR BACTERIA, IRON BACTERIA, HYDROGEN BAC- TERIA, ETC.}

The peculiar behavior of the sulphur bacteria, first described by Winogradski, ${ }^{2}$ means that here there is likewise a respiration at the expense of mineral substances. It was shown by the studies of Dangeard and Keil ${ }^{3}$ that Beggiatoa can be grown in pure cultures on purely mineral solutions. Under these conditions Beggiatoa assimilates the carbon dioxide of the air and so its behavior is entirely analogous to that of the nitrifying

1 Meyerhof, O. Arch. ges. Physiol. 164: 353. 1916.

2 Winogradski, S. Bot. Zeitschr. 45: 489. I887; Ann. de l'inst. Pasteur. 3: $49 . \quad$ I 889. [Baas-Beckıng (Ann. of Bot. 39:613-650. 1925) has recently given a complete statement of the physiology of this group of bacteria.]

${ }^{3}$ Dangeard. Compt. rend. 153:963. I91 I; Keil. Cohns Beitr. II: 335. I9I3. 
bacteria. $^{p}$ The respiration of Beggiatoa consists in the oxidation of hydrogen sulphide, first to molecular sulphur and then to sulphuric acid:

(I) $\mathrm{H}_{2} \mathrm{~S}+\mathrm{O}=\mathrm{H}_{2} \mathrm{O}+\mathrm{S}$

(II) $\mathrm{S}+{ }_{3} \mathrm{O}=\mathrm{SO}_{3}$

The oxidation of one molecule of $\mathrm{H}_{2} \mathrm{~S}$ to $\mathrm{H}_{2} \mathrm{SO}_{4}$ releases I I $_{5}$ Calories of heat.

The thiosulphate bacteria discovered by Nathansohn ${ }^{1}$ also grow without any organic nutrient. As respiration they make use of the following reaction: ${ }^{q}$

$$
6 \mathrm{Na}_{2} \mathrm{~S}_{2} \mathrm{O}_{3}+{ }_{5} \mathrm{O}_{2}={ }_{4} \mathrm{Na}_{2} \mathrm{SO}_{4}+2 \mathrm{Na}_{2} \mathrm{~S}_{4} \mathrm{O}_{6} .
$$

This oxidation releases considerable energy. The iron bacteria oxidise ferrous salts to ferric salts. This exothermic process serves as respiration for them, ${ }^{2}$ for they can be grown on purely mineral solutions. The hydrogen bacteria ${ }^{3}$ also respire on the basis of the combustion of hydrogen:

$$
{ }_{2} \mathrm{H}_{2}+\mathrm{O}_{2}={ }_{2} \mathrm{H}_{2} \mathrm{O},
$$

and are able to utilize the resultant free energy for the assimilation of the atmospheric carbon dioxide. As for the methane bacteria, ${ }^{4}$ they oxidise methane to $\mathrm{CO}_{2}$ and water, so it is uncertain whether this process is to be thought of as a direct oxidation or as an ordinary sugar respiration. That is to say, methane could serve as material for the synthesis of sugar. Still we

1 Nathansohn. Mitt. d. Zool. Stat. Neapel. 15: 655. I902; Beijerinck. Zentralbl. f. Bakt., Parasitenk. u. Infektionskrankh. (II). I I : 593.1904.

${ }_{2}$ Winogradski, S. Bot. Zeitschr. 46: 26I. I888; Lieske, R. Jahrb. f. wiss. Bot. 49: 91. I9I ; 50:328. I9I 2; ZentralbI. f. Bakt., Parasitenk. u. Infektionskrankh. (II). 49: 413. Igr9. [See also Cholodny, N. Die Eisenbacterien, Beitrage zu einer Monograplie. Jena. 1926.]

${ }^{3}$ Söhngen. Zentralbl. f. Bakt., Parasitenk. u. Infektıonskrankh. (II). I5: 5 I3. I906; Kaserer. Ibid. 15:575. 1900; 16:681, 769. I906; Lebedew, A. v. Biochem. Z. 7: I. ı 908; Niklewski. Jahrb. f. wiss. Bot. 48: i 13. ig10; Zentralbl. f. Bakt., Parasitenk. u. Infektionskrankh. (I1). 20: 469. I908.

- Söhngen. loc. cit.; Kaserer. loc. cr:.

${ }^{p}$ An exceptional case is that of Thiobacillus thiöxidans which does use small amounts of glucose but only in the presence of sulphur. Its nitrogen is obtained only from ammonium salts. $C f$. R. L. Starkey. Jour. Bact. Io: 135-195. $1925 .-E d$.

2 A facultative carbon autotropic form was found by Trautwein (Centralbl. Bakt. (II). 53: 513-560. 192I) which gives as the product of oxidation either a sulphate, a dithionate or a tetrathionate.- $E d$. 
know that some bacteria are able to use coal, peat, paraffin oil and other substances which are very hard to assimilate. Without doubt in these cases there is a synthesis of sugar which then serves as respiratory material. The products of the oxidation of methane are not different from the normal products of respiration in the case of sugar nutrition.

Oxidations of other mineral substances might perhaps be utilized for respiration by some bacteria and new discoreries in this field are not precluded. It is worthy of note that bacteria which effect chemical synthesis respire at the expense of mineral substances. The simple oxidations of mineral substances, which do not form the basis of complicated processes of many stages and which proceed as ionic reactions with a velocity too great for measurement, appear to be especially peculiar in furnishing the extraordinarily large amounts of energy which are necessary for the accomplishment of chemical synthesis. 



\section{INDEX}

This index includes the names of authors cited in notes or mentioned in the text, plant names, and important subject entries. All authors' names are given in bold-face type and the pages on which they are followed by full citations are printed in the same type. The scientific names of plants are given in italics. All other entries are in ordinary type.

\section{Abderhalden, E., I3I; A. and Foder, I3I; A. and Glaubach, I3I; A. and $\mathrm{H}$. Schaumann, 98}

Aberson. (See Giltay and A.)

Abies excelsa, 55

Absorption apparatus, 26-33

Acceptors, 106, 108, I09. (See also Hydrogen acceptors.)

Acer platanoides, 60

Acetaldehyde, 6r, 62, 74, 75, 78, 99IOI, I I 8 , I I9, I 30-I 34 , I 36, I 40

Acid, acetic, 76, Iо0, I 6 , II8, II9, I 29, I3I, I32, I40; amino, II4, I $29, \mathrm{I}_{3} 8-\mathrm{I} 42$; aspartic, I39, I40; chlorogenic, I 29; citric, I36, I4I, I42; fumaric, I 7 ; gluconic, I 46 , I 47; glutamic, I39; glyceric, I34; glycolic, I36; glyoxylic, I32, I36; lactic, $80,88,89$, 100, I22, I 23 , I35, I 49; malic, I36-I42; malonic, 139; mesoxalic, 136; oxalic, ro, I32, I36-I40; pyruvic, IOI, I3II 34, I 36 ; quinic, $88-90$, I 22, г 23; succinic, II7, I39; tartaric, Io, 88,89 , 109, г 22, г 23, г 36 ; organic acids, 8, IO, I 7, I $35^{-1} 43$

Acidity, effect of, 24,89

Aerobic fungi, 53, 59, 87, 89, I 46, I 47

Aerobic respiration, 8. (See also Oxygen respiration.)

af Ugglas. (See Euler and af Ugglas.) Afanassjewa. (See Kostychev and A.) Agaricus, I3; A. campestris, 27. (See also Psalliota campestris.)

Alcohol, oxidation of, 9; qualitative tests for, $72-75$; quantitative tests for, $75^{-78}$
Alcoholic fermentation, abnormal, 100, IOI, r24; effect of oxygen on, 98, I $43^{-I} 45$; energy from, 52,56 , $I_{44}$; in fruits, $54,62,64$; in germinating seeds, $8,54,60,64$; in seedplants, 52-54, 99; intermediate products of, 82,99, I 25, I 27, I $30-$ I 35 ; theories of, 52 , I $32-135$

\section{Amm, 57, 87, 93, I46}

Anaerobic respiration, $52-78$; a biological adaptation, $64,65,84$; as abnormal, 80, 8I ; connection of, with normal respiration, 57, 7996, I 2.4-129; energy from, $56,5^{8}$, 65 ; in seed-plants, $54-56,60$; measurement of, $65-78$; occurrence of, $54,63-65$; products of, $53,59-63,99$, 128; rate of, 54-59; theories of, (See Theory of); without alcoholic fermentation, 60-62, 97, 99-102

Anaerobiosis, 22, 24, 57, 82, 84, 86, 90, 95

Analytical methods, $25-5 \mathrm{I}, 65-78$

André, G., I37

Antagonism and respiration, 20, 2I

Apparatus of Barcroft, 34, 5I ; Bardeleben, 66-68; Bolas, 49-50; Bonnier and Mangin, 43-45; Chudiakow, 27; Godlewski, 45; Osterhout, 50-5I; PolowzowRichter, $3 t^{-4}+3$

Appleman and Arthur, 7

Apples, 60

Arrhenius, I 6 
Arthur. (See Appleman and A.)

Arum, I3, I $20 ; A$. italicum, I $2 ; A$. maculatum, 55

Asparagine, $138-14 \mathrm{I}, \mathrm{I}_{5} \mathrm{O}$

Aspergillus niger, 5, 6, I I, 22, 59-6I, $\mathrm{S}_{3}, 88,89,97$, 102, I 22-1 24, 1 38 , I 46

Aspirators, 32

Atkinson, 13

Aubert, E., I7, 43

A uricularia, I3

Autoxidation, I02-II I

A zotobacter chroococcum, 5

\section{Baas-Becking, I5 I}

Bach, A., I04, 105, 107, 109, I I I-II3; B. and Chodat, I09, I Iо. (See also Chodat, R. and B.)

Bacillus Botulinus, 7I; B. caucasicus, I 49; B. mesentericus, $5 ;$ B. tctani, 7I ; B. Welchii, 7 I

Bacteria, hydrogen, $15_{2}$; iron, $15^{2}$; lactic acid, I49; methane, I52, $_{52}$ I 53 ; nitrifying, I 50, I 5 I ; sulphur, I 5 I, 152

Bactcritum lactis acidi, $\mathbf{1} 49$

Barcroft, 34, 5I ; B. apparatus, 34, 5I Bardeleben apparatus, 66-68

Barendrecht, H. P., 77

Barley, i 8

Baryta water, 26, 30-32

Batelli and Stern, II 7

Becquerel, P., 6

Beggiatoa, ${ }_{5}$ I, ${ }^{5} 2$

Beijerinck, $13,5^{2}$

Bellamy. (See Lechartier and B.)

Bérard, 53

Bernard, $\mathrm{Cl}$., 19

Berthelot, M., 34, 74

Berthelot's test for alcohol, 74

Bertrand, G., II3, I26; B. and Mutermilch, 113. (See also Bourquelot and B.)

Blackman, F. F. and Matthaei, r6

Blaschko, H., I32

Bode, H. R., 24

Bodländer, $\mathrm{IO}_{3}, \mathrm{IO} 7, \mathrm{II} 2$

Bodnar, J., 98

Böhm, 2I, 53
Bolas, B. D., 49 ; B. apparatus, $49-50$

Bolin. (See Euler and B.)

Bonnier, G., I2, I5; B. and Mangin, 8, I7, 43; B. and M., apparatus of, $43-45$

Bornträger, H., 7 I

Borodin, J., I7, I9, 20, 82, 86, I I9

Bouffard, I I 3

Bourquelot, E. and G. Bertrand, I I 3

Boussingault, J. B., 2, II9

Boyle, I 3

Boysen-Jensen, P., 55, 6r, 64, 95, 96, 147

Branhofer and Zellner, 137

Brassica Napus, 55 ; B. rapa, 60

Brefeld, 54, 80

Briggs. (See Kidd, West and B.)

Brilliant. (See Kostychev, B. and Scheloumow.)

Brooks, M. M., 2 I

Brown, A., I43

Buchner, E., 87; Buchner, E., H. Buchner and M. Hahn, 9, 87; B. and J. Meisenheimer, 75

Buchner, H. and R. Rapp, 144; B. and Wüstenfeld, 142. (See also Buchner, E., B. and M. Hahn.)

Bunsen, R., 34, 37, 38, 4 I

Burlakoff, 4,7

Burri, R., I 3

Butkewitsch, W., 90, I38, I39, I42

Cacti, 137

Cahours, 7

Caltha palustris, 5

Cannabis sativa, 55

Cannizzaro reaction, I I9, I3I, I34

Cantharellus cibarius, 55

Carbon dioxide as a measure of respiration, 4 ; effect of, on respiration, 19, 20, $7 \mathrm{I}$; preparation of, 71,72

Carbon monoxide, 4I, 66

Carboxylase, 98 , IoI, I32, I 40

Catalysis, ros

Cayla, V., I 13

Cazeneuve, II 3

Celakowski, I9

Ceratozamia, 13 
Corcus, I 2

Cerny. (See Stoklasa and C.; Stoklasa, C., Jelinek and Vitek.)

Chemical induction, Io8, I I 2 ; stimulation, $2 \mathrm{I}-24,58$

Chlorella vulgaris, I4 I

Chlorothecium saccharophilum, 90

Chodat, R. and Bach, III; C. and de Coulon, I3; C. and Staub, II3. (See also Bach, A. and C.)

Cholodny, N., 152

Chromogens, respiratory, I $27^{-1} 29$

Chudiakow, N., 27, 57, 58, 86, 87, 93, I44; C. apparatus, 27

Citromyces, 142

Clark, W. M., I

Clausen, H., 3 I

Coenzymes, 98, I 25, 127,135

Cohen, C., 99. (See also Neuberg and C.)

Connstein, W. and K. Lüdecke, I 30

Constamm, 8

Cook, S. F., 20

Coupled reactions, 103ff.

Crié, L., I3

Crozier, W. J., 7, 16, 24, 57

Csanyi. (See Willstätter and C.)

Cucurbita Pepo, 55

Currie, N., I42

Czapek, F., I 22, I37

\section{Dangeard, I5 I}

Daucus carota, 56, 6o-62

Dawson. (See Platt and D.)

Daynes, H. A., 5 I

de Coulon. (See Chodat and de C.)

de Luca. (See Luca, de.)

de Saussure. (See Saussure, Th. de.)

Teaminization, ${ }_{3}$ S-I4I

Déhérain and Landrin, I9; D. and Maquenne, 20

Deleano. (See Mayer, A. and D.)

Demoussy. (See Maquenne and D.)

Denigès, G., 74, 75

Detmer, I 20, I 2 I, I 23

Devaux, I9, 64

Diakonow, N., I I, 83-9o, I 22

Dietrich. (See Windisch and D.)

Di-hydroxy-acetone, I 33, I 34, I 47
Döbereiner, 53

Döbner, I3 I

Dorofeieff, 2 I

Doyer, L. C., I5

Doyère, 34

Dubois, R., I4

Duchon. (See Nemec and D.)

Dude, 87

Dumont, 53

Dutrochet, 12

Ehrlich, F., I 39

Elfving, F., I7, 22, I42

Eliasberg, P., 99. (See also Kostychev and E.)

Elodea canadensis, $2 \mathrm{I}, 65, \mathrm{I} 26$

Embden, G., and Laqueur, I35; E. and E. Schmitz, I4 I

Energy from anaerobic respiration, 56, 58, 65; radiant, 3, I 2-1 5 ; solar, 3

Engler, A., 104, I05; E. and Herzog, I05, I I I-I I3; E. and Weissberg, I03, 105, 107, I09; E. and Wild, I05, 107; E. and Wöhler, I IO

Enzyme poisons, 23

Eriksson, 57

Erienmeyer, 107

Emest. (See Stoklasa and E.)

Eudiometer, 49, 72

Euler, H. and J. Bolin, I36; E. and af Ugglas, 23

Ewan, I03

External factors, influence of, $15^{-25}$, 57

Farber. (See Neuberg, F., Levite and Schwenk.)

Fats, 10, 1 I, I 2 I

Fellner, I4 I

Fenton, 109

Fermentation, I, 52, I42. (See also Alcoholic fermentation.)

Fermented sugar solutions, 24, 25, 92, I $25^{-1} 27$

Flieg, O., I 2 I

Foder. (See Abderhalden and F.)

Freudenberg, K., I29; F. and E. Vollbrecht, I 29 
Freyberg, 5

Fromherz. (See Neubauer and $\mathrm{F}$.)

Gailey. (See Langdon and G.)

Gallaghar, I I2

Garreau, 5

Gas analysis, 33-49; exchange, 3-1 2; pipette, 46-49, 70

Gaunt, R., 75

Gerber, I9, 64

Gessard, II3

Giltay and Aberson, I44

Gladiolus, 23

Glaubach, S. (See Abderhalden and G.)

Glutathione, I Io

Glyceric aldehyde, I 33, I 34

Glycerine, S9, I 22, I 23, I30, I3I, I 34, I 47,150

Glyoxal, I32, I 40

Godlewski, E., Io, I I, 45, 83, I 2 I ; G. and Polzeniusz, 60, 90 ; G. apparatus, $4 \vec{s}$

Gorini, C., I3

Gottschalk. (See Neuberg and G.)

Grab, M. v., I3I

Grand curve of growth, 6, 7; of respiration, 6,7

Grapes, 56, 64

Graser. (See Willstätter, G. and Kuhn.)

Gustafson, F. G., 2I, 24. (See also Hover and G.)

Haas, 22

Hahn. (See Buchner, E., H. Buchner and $\mathrm{H}$.)

Haldane, J. S., 34

Hansen, A., 73, 144

Harvey, E. N., 14

Hay, heating of, I3

Heat production, $10^{-1} 5,56,57, I_{50-}$ 152

Hefanol, I47

Helianthus annuus, 6, 55

Hempel, 34, 42

II racleum giganteum, 55

Herzog. (See Engler and H.)

Hettlinger, A., 4
Hexose phosphate, 9S, II 5, I25, I33I 35

Hirsch. (See Neuberg and H.; Neuberg, H. and Reinfurth.)

Hoff, van't, 16, 103, 107

Hopkins, F. G., I I0

Hoppe-Seyler, I03, 144

Hover and Gustafson, 6

Hübbenet. (See Kostychev and H.; Kostychev, H. and Scheloumow.)

Humboldt, 63

Hydnum repand $u m, 55$

Hydrogen acceptors, II6-I I8, I 28, I 29, I 31 ; bacteria, I 52 ; cyanide, 22, II4; generation of, 66-68; peroxide, I04, 105, I09, I10, II 8 , I $25-127$

Hypnum cupressiforme, 5 ; $H$. triquetrum, I6

Indicator methods, 26, 50-5I

Inman, O. L., 20

Intermediate products of alcoholic fermentation, $82,99, \quad 125$, I 27 , I $30^{-1} 35$

Iodoform test, 73

Iraklionoff, I7

Iron bacteria, I 52 ; catalysis, 24, I10, I I I, I I 5 , I I 6 , I I 8

Irritation effects, I 7

Irving, A., 22

Isatschenko, B., I4

Iwanow, L., I 25

Iwanowski, D., 144

Jacobi, B., 22

Jelinek. (See Stoklasa, J. and Vitek; Stoklasa, Cerny, J. and Vitek.)

Johannsen, W., I8, 22, 59, I46

Jönsson, B., 5

Jorissen, I03

Karczag. (See Neuberg and K.)

Karlsen, A., 57

Kaserer, I52

Kastle, J. H., IIo; K. and Loewenhardt, I IO

Katharometer, I S, 5 I

Keil, I5 I 
Kendall and Nord, I Io

Kerb. (See Neuberg and K.)

Kidd, F., 20; K., West and Briggs, 6

Kipp generator, 66, 7I

Knoch, E., I2

Koch. (See Oelsner and $\mathrm{K}$.)

Kolkwitz, R., 6

Komleff. (See Palladin and K.)

Kondo, K., I4I

Kosinski, 20

Kostychev, S., v, 3, 5, 9-II, I9, 22, 24, $25,27,42,46,54,57,59-63,71$, 78, 87-93, 97-10I, I I I, I 20, I22I 25, I 26, I 27, I 29, I30, I 3 I, I 34, I 39, I 40, I47 ; K. and M. Afanassjewa, 59 6r, 89, 90, I0 I, I22, I23, I46, I49; K., Brilliant and A. Scheloumow, $24 ; \mathrm{K}$. and P. Eliasberg, $9,59,60,73, \mathrm{I} 44, \mathrm{I} 45, \mathrm{I} 48$; K. and E. Hübbenet, $130 ; \mathrm{K}$., Hübbenet and Scheloumow, 78, $99 ; \mathrm{K}$. and A. Scheloumow, 24, 25 , 92, 98,'125. (See also Palladin and K.)

Kostycher's flask, 45-49, 69, 70; gas pipette, 46-49, 70; theories, 9I, $92, I_{2} 7, I_{32}, I_{33}, I_{3} 8-I_{43}$

Kostytschew. (See Kostychev.)

Krasnoselsky, T., 2 I

Kraus, G., I3, I20, I37

Kreusler, U., 16

Krzemieniewski, 20

Kuhn. (See Willstätter and K.; Willstätter, Graser and K.)

Kuijper, I6

Kutscher, F., I3

Laborde, I I3

Lascase, II $3, I_{3} 6$

Lactarius piperatus, 55

Lactuca sativa, 5

Lamium album, 5

Landrin. (See Déhérain and L.)

Langdon, I9; L. and Gailey, I9

Lange, P., I 37

Laqueur. (See Embden and L.)

Lavoisier, I, 3, 80, 102, 103

Lebedew, A. v., I33, I34, I52

Lechartier and Bellamy, 52
Leclere du Sablon, I 2 I

Leick, E., I2

Lepidium satium, 60

Levite. (See Neuberg, Farber, L. and Schwenk.)

Liaskowski, I0, II

Lieske, R., I52

Light, effect of, on respiration, $I 7$, I 8 ; formed in respiration, I3, I4

Ligustrum vulgare, 55

Lipoids, I 26

Loeb, J. and H. Wasteneys, 24

Loewenhardt. (See Kastle and L.)

Lolium italicum, 5

Lopriore, 20

Löwschin, A., I7

Lowtschinowsky. (See Palladin and L.)

Luca, de, 54,63

Lüdecke. (See Connstein and L.)

Lüers, H., I43

Lupinus, 22; L. luteus, 55

Luther and Schilow, 107

Lwow. (See Palladin and L.)

Lyon, 21, 57, 65, 126

Maige, A., 7; M. and G. Nicolas, 20

Maige, G., 7

Manchot and Wilhelms, Iog

Mangin. (See Bonnier and M.)

Mannite, 63,89 , гоo, I 22, I 23

Maquenne, L., 86, 90, 93, I2 I ; M. and

E. Demoussy, 94. (See also Déhérain and M.)

\section{Marcet, 63}

Marx. (See Zaleski and M.)

Material loss in respiration, 2

Matruchot and Molliard, 54

Matsuoka. (See Meyerhof and M.)

Matthaei, G. L. C., I6. (See also Blackman and M.)

Maximow, N., v, I6, I7, 147

Mayer, A., 6, 137, 144; M. and Deleano, r8; M. and L. Plantefol, 9, 16

Mayer, P. and C. Neuberg, I3 I

Mazé, P., 9I; M. and Perrier, I25, I 42

Mcdicago sativa, I36 
Meisenheimer. (See Buchner, E. and M.)

Wentha aquatica, 5

Methane bacteria, $\mathrm{I}_{52}, \mathrm{I}_{53}$

Methyl glyoxal, I34

Meyerhof, O., 9, 98, I25, I 26, I29, I35, I50, I5I; M. and K. Matsuoka, 24, I16; M. and H. Weber, II5

Middleton, I8

Miehe, H., 13

Moeller, 55, 70, 82

Molisch, H., 13

Molliard, M., I5, I42, 146. (See also Matruchot and M.)

Moloxides, ro5-iro, in 8

Moore and Whitley, II 2

Morkowin, N., 22, 25, 58, 87, 93

I ucor muccdo, 145; M. racemosus, 6o, $\mathrm{I} 45$

Mucoraccac, 9, 59, 145. (See also INucor, Rhizopus, etc.)

Müller, E., I32

Muntz, 6, 54, 63, 73, 8I

Mutermilch. (See Bertrand and MI.)

Nabokich, A., 72

Nägeli, C., 80, 143

Narcosis, 21, 22, II 4

Nathansohn, I52

Negelein. (See Warburg and N.)

Nemec, A. and F. Duchon, 98

Nereocystis Luetkcana, 9

Neubauer, O. and Fromherz, I 39

Neuberg, C., I39; N. and C. Cohen, 99; N., Farber, Levite and Schwenk, I34; N. and Gottschalk, $62 ; N$. and J. Hirsch, I30, I3I; N., Hirsch and Reinfurth, I30, I3I; N. and Karczag, I40; N. and J. Kerb, I30, I33, I34; N. and F. Nord, I3I; N. and Schwenk, I3I;N. and Steenboch, I3I. (See also Mayer, P. and N.)

Nicloux, M., 76

Nicolas, G., 7. (See also Maige, G. and $\mathrm{N}$.)

Niklewski, I52

Nishi, 3 I

Nitrifying bacteria, 150,151
Nitrobacter, 150,151

Nitrogen, preparation and use of, 6870

Nitrosococcus, $\mathrm{I}_{50}$

Vitrosomonas europea, $150,15 \mathrm{I}$

Nord, F. F., 53, I3 I. (See also Kendall and N.; Neuberg and N.)

Novy, Roehm and Soule, 26

Noyons, 51

Oelsner, A. and A. Koch, I3I

Oenoxidase, I 3

Omelianski. (See Winogradski and O.,

Onslow, I 12

Oparin, A., 129

Oppenheimer. (See Willstätter, O. and Steibelt.)

Oranges, 60

Orobanche ramosa, 55

Osmotic effect, 20

Osterhout, W. J. V., 33, 50; O. apparatus, $50^{-} 5^{\mathrm{I}}$

Oxidases, I IO-II3, I26, I $46-I_{4} 8$

Oxidation of alcohol, 9; fructose, II 6 , I 26; oxalic acid, ro; tartaric acid, ro

Oxidation processes in plant cells, IC $2-$ II $9,146,147$

Oxygen, activation of, 102-III; deficiency in plants, 19, 63, 64; effect of concentration of, 18,19 ; effect of, on alcoholic fermentation, 95, I $43-145$; measurement of, $37 \mathrm{ff}$; removal of, 66; respiration, v., I5 I, $79-96$

Oxygenase, I Io-I I 3

Palladin, W., 2, 4, 8, II, I 7, 20, 23, 27, $53,57,58,84-87,90,9$ I, 93, II 9 , I23, 126, I27, I 28,$129 ; P$. and Komleff, 20 ; P. and Kostychev, 92,$97 ;$ P. and Lowtschinowsky, I38; P. and S. Lwow, 127; P. and

Z. Tolstoi, I27, I 29

P'alladin's mercury regulator, 32

Papaver somniferum, 5

Parker, 5 I

Pasteur, L., 52, 53, 60, 73, 79-8I 
Pea seeds, 9, 56, 60, 6r, 63, 64. (See also $P$ isum.)

\section{Pedersen, 144}

Pclargonium zonale, I 8

Penicillium glaucum, 53, $8_{3}, 87,89$

Peroxidase, I Io-I 33, I I 5 , I I 7 , I I $S$, I 25-I 29

Perrier. (See Mazé and P.)

Petrow, G. G., I39, I 10

Pettenkoffer, M., 30

Pettenkoffer tubes, 30-33

Pfeffer, W., I9, 30, 54, 8I-83, 85, I 20

Pflüger, 79, 80, I20

Phleum pratense, 5

Phosphate, effect of, 57, I I6, 126

Phosphorescent plants, I3, I4

Photobacterium, I3

Photosynthesis, 2

Phragmites communis, 5

Pisum sativum, 58, $\mathrm{S}_{4}$. (See also Pea seeds.)

Plantefol. (See Mayer, A. and P.)

Platt and Dawson, I $26_{6}$

Pollinger. (See Willstätter and P.)

Polowzow, V., 9, го, 34, 63, 86; Polowzow-Richter apparatus, $34^{-}$ 43

Polyporus, I3

Polzeniusz. (See Godlewski and P.)

Porodko, 126

Portier, 126

Potato, 56, 6o-62, I 26

Prianischnikow, I40

Prochromogens, I 28 , I 29

Protein respiration, I 23, I 24, I 43

Protoplasmic poisons, 23

Prunus Padus, 60

Psalliota campestris, 27,60, 61, 97, 100

Primpkin, I 9

Puriewitsch, K., I I, I7, 26, I37

Quastel, II7

Racke. (See Willstätter and R.)

Rapp. (See Buchner, H. and R.)

Ray, G. B., 2I, I09

Reinfurth. (See Neuberg, Hirsch and R.)

Reinhard. (See Zaleski and R.)
Reinke, J., 83

Respiration, anaerobic (See Anaerobic respiration); and growth, 6, I5; and water content, $6,7,9,16,24$; as criterion of life, 3 ; as slow combustion, I, 3; coördination of, I43-I 49 ; early history of, I, 2; equations for, 2, 8, 1 28; function of, 3 ; grand curve of, 6,7 ; intramolecular, 54, 79; measurement of, $25-51,65-78$; of bacteria, 5 , 13, I 22, I 49-1 53; of flowers, 7, I 2 ; of seeds, 2, 5-7; of yeast, 9, 52, 55 , 144-146; oxygen (See Oxygen respiration); rate of, $3^{-7}, \mathrm{I}_{4}^{-25}$; rate of, as affected by ions, 18,20 ; rate of, as affected by $\mathrm{pH}, 24$; rate of, as affected by temperature, I6, I7, 57, 58 ; theories of (See Theory of.)

Respiratory chromogens, I 27-129; enzymes (See Oxidases); index, 6; material, 2, 12, 13, I19-I 24; pigments, I 28, I29; quotient, 8-I 2, I 7 , IS, 2I, 66; quotient, calculation of, $47-48$; quotient, fluctuation of, 8-I I, 95

Rhizopus nigricans, $8_{3}, 88, \mathrm{I} 45$

Ribes nigrum, 5

Rice, 5

Richards, 2 I

Richter, A., 34, 43

Ricinus communis, 84

Rischawi, 6

Rockwell, G. E., 7 I

Rodewald, I4

Roehm. (See Novy, R. and Soule.)

Roll cultures, $27^{-2} \mathrm{~S}$

Rollo, 53

Ruhland, W. and $\mathrm{K}$. Wetzel, I4I

Sachs, J., 80, 8 I

Sanders, C. B., I3

Saussure, Th. de, I, 6, 7, I2, I8, I9, 53

Schaumann, H. (See Abderhalden and S.)

Scheloumow. (See Kostycher, Brilliant and S.; Kostycher, Hübbenet and S.; Ko-tycher and S.) 
Schilow. (See Luther and S.)

Schmitz. (See Embden and S.)

Schönbein, C. F.,' '103

Schroeder, H., 22

Schulow, I., I40

Schwenk. (See Neuberg and S.; Neuberg, Farber, Levite and S.)

Sedum azurcum, I 37

Sinapis alba, 55 ; nigra, 5 ; sp., 56, 62

Smirnoff, A., 21, 93, I 26, I40, I4I

Smith, A. M., 16

Smith, W. G., 13

Söhngen, 152

Soule. (See Novy, Roehm and S.)

Spence, D., II3

Sphagnum cuspidatum, 5

Spirogyra, 24, I 26

Spoehr, H. A., І8, '1 16,137

Staehelin, M., I38

Starkey, R. L., I52

Staub. (See Chodat and S.)

Steenboch. (See Neuberg and S.)

Steibelt. (See Willstätter and S.; Willstätter, Oppenheimer and S.)

Stern. (See Batelli and S.)

Stewart and Tunnicliffe, I ro

Stich, C., I8, 21, 59, I46

Stohmann, F., I2

Stoklasa, J., 5, 62, 97, 100; S. and Cerny, 97 ; S., Cerny, Jelinek and Vitek, 97; S. and A. Ernest, 19; S., Jelinek and Vitek, 97

Stoll. (See Willstätter and S.)

Straub, $5^{\dot{I}}$

Sugar as respiratory material, 2, 10, 20, II9-I27; measurement of, I 44

Sulphur bacteria, I 5 I, I 52

Syringa vulgaris, 5,60

\section{Takahashi, 90}

Temperature, effect of, I6, I 7, 57, 58 ; regulation of, $\mathrm{I} 2$

Theory of Bach-Engler, IO4-II3, I I I 9; Bach and Chodat, r Io-ris; connection, viii, 79-97, I26, I27; Detmer, 120, I2 I, I 23; Diakonow, $83-90$, I22; Godlewski, 83,90 ; Kostychev, 9I, 92, I27, I32-133, I38-143; lebedew, I33, I34;
Mlazé, 91; Neuberg, I34; Palladin, 4,23, I 27 -I 29; Pfeffer, $8 \mathbf{I}, 82$; I'flüger, 79, 80; Quastel, Ir 7-I I8; Schönbein, I03; Traube, I04, I05; van't Hoff, I03, I04; Warburg, 23, II3-II6; Wieland, II6-II9; Wortmann, 82

Thiobacillus thioöxidans, I52

Thoday, D., 22, 43

Thomas, H. S., 2 I

Thunberg, 117,129

Tilia europea, 5

Tolstoi. (See Palladin and T.)

Toxicity, explanation of, 23 ; from lack of oxygen, 22

Traube, M., 104, 107

Trautwein, 152

Triticum vulgare, 55. (See also Wheat.)

Tropacolum majus, 56, 62

Tscherniaeff, 2 I

Tunnicliffe. (See Stewart and T.)

Tyrosinase, I I 3

Ullrich, H., I4I

Van Slyke, $5^{I}$

van't Hoff. (See Hoff, van't.)

Veronica Beccabunga, 5

Vicia Faba, 22, 55, 58, 82, $S_{4}$

Victoria rcgia, I2

Vignol, M., 5

Viscum, I6

Vitek. (See Stoklasa, Cerny, Jelinek and $\mathrm{V}$.; Stoklasa, Jelinek and V.)

Vollbrecht. (See Freudenberg and V.)

Waldschmidt-Leitz. (See Willstätter and $\mathrm{WT}$.)

Waller, J. C., I 8, $5^{1}$

Warburg, O., 22-24, 5I, II3, II 4 -I I5, 131, 137; W. and Negelein, 14 I; W. and M. Yabusoe, I 16

Warden, C. C., 53

Wasteneys. (See Loeb" and IV.)

Water, formation in respiration, 2, I I, I2; relation of, to respiratory quotient, 9

Weaver, E. R., 5 I

Weber. (See Meyerhof and $\mathbb{W}$.) 
Wehmer, C., I38, 142

Weissberg. (See Engler and W.)

West. (See Kidd, W. and Briggs.)

Wetzel. (See Ruhland and $\mathrm{W}$.)

Wheat embryos, 25; roots, 5 ; seedlings, I 5, I 20, I25, I 26. (See also Triticum.)

\section{Whimster, 18}

Whitley. (See Moore and $\mathrm{T}$.)

Wieland, H., II6, II7, II 8 , II9, I $27^{-}$ I 29

Wild. (See Engler and IV.)

Wilenko, G., I3 I

Wilhelms. (See Manchot and W.)

Willstätter, R., III, II5; W. and W. Csanyi, III; W., Graser and Kuhn, III; W. and R. Kuhn, III; W., Oppenheimer and Steibelt, III; W. and Pollinger, III, II5; W. and F. Racke, III; W. and W. Steibelt, III; W. and A. Stoll, 3, III; W. and Waldschmidt-Leitz, II I

Wilson, $18,54,59,82$

Wind, F., I 16
Windisch and Dietrich, I43

Winogradski, S., 151, 152; W. and W. Omelianski, 150

Wöhler. (See Engler and IF.)

Wolff, J., II I

Wood parenchyma, r9, 63, 64

Wortmann, J., 82, 83, 90

Wound stimulus, I3, 2I, 62, 94

Wüstenfeld. (See Buchner, H. and IV.)

Yabusoe. (See Warburg and Y.)

Yeast, extracts, 24, 25, 125, I 27; respiration of, $9,52,55,144^{-1} 46$

Yoshida, I 13

Zaleski, W., 2I-23, 98; Z. and E Marx, 98; Z. and Reinhard, 20, 138

Zellner. (See Branhofer and Z.)

Zerban, F. W., II 3

Zerner, E., r 30

Zymase, 61, 87, 92, 97, 98, 100-102, $I_{43}, 146, I_{47}$

Zymin, I 47 




$8 x-8$

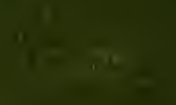

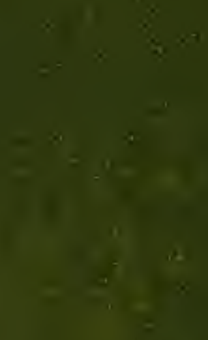

$+$

3.87

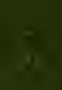

